Stereoselective Polymerization of Lactones.

Properties of Stereocomplexed PLA Building Blocks 


\title{
STEREOSELECTIVE POLYMERIZATION OF LACTONES. \\ PROPERTIES OF STEREOCOMPLEXED PLA BUILDING BLOCKS
}

\author{
PROEFSCHRIFT \\ ter verkrijging van \\ de graad van doctor aan de Universiteit Twente, \\ op gezag van de rector magnificus, \\ prof. dr. H. Brinksma, \\ volgens besluit van het College voor Promoties \\ in het openbaar te verdedigen \\ op donderdag 10 juni 2010 om 16:45 uur \\ door \\ Mark Randolf ten Breteler \\ geboren op 15 september 1979 \\ te Haaksbergen
}


Dit proefschrift is goedgekeurd door:

Promotor: Prof. dr. J. Feijen

Assistant promotor: Dr. P.J. Dijkstra 


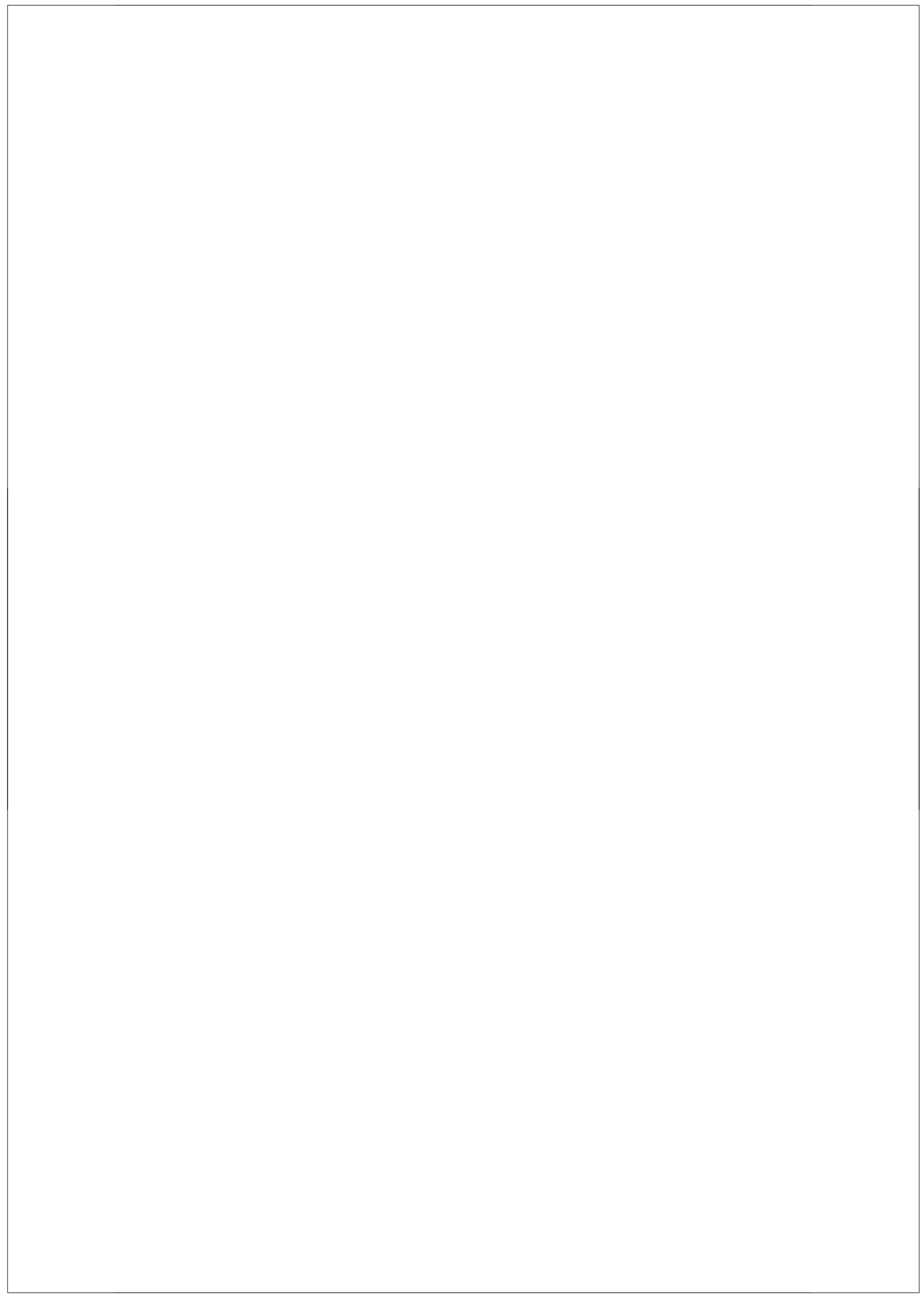


Committee

Promotor: prof. dr. J. Feijen

University of Twente

Assistant Promotor:

dr. P.J. Dijkstra

University of Twente

Members:

prof. dr. J.J.L.M. Cornelissen

University of Twente

prof. dr. D.W. Grijpma

University of Twente

prof. dr. W.E. Hennink

University of Utrecht

prof. dr. ir. J.C.M. van Hest

Radboud University

prof. dr. Ch. Jérôme

University of Liège

prof. dr. G. van Koten

University of Utrecht

prof. dr. A.-J. Schouten

University of Groningen

The research described in this thesis was financially supported by Technologiestichting STW.

Stereoselective Polymerization of Lactones. Properties of Stereocomplexed PLA

Building Blocks

Ph.D.Thesis with references; summary in English and Dutch

University of Twente, the Netherlands

ISBN: 978-90-365-3045-3.

Copyright (C) 2010 by M.R. ten Breteler

All rights reserved.

Printed by Ipskamp Drukkers B.V., Enschede, the Netherlands, 2010. 


\section{$\mathbf{P}$ \\ Preface}

In all these years in which I've been working towards finishing this thesis, I've always had in mind to write a limited preface, without elaborations on how I've spend my daybreaks, enjoyed all kinds of parties, or dragged myself trough 'desperate' moments. And thus, a short preface it will be, in which I'd nevertheless would like to thank a number of people, whose help was invaluable in creating this thesis..

I'd like to thank my promotor, Jan Feijen, and assistant promotor, Piet Dijkstra, for the opportunity of doing my promotion within their group, for their endless time and help in corrections (especially Piet) and their supervision throughout the years. A great part of the 'tutoring' was in the capable hands of Zhiyuan, for which I'd like to thank him.

During my promotion I've had the pleasure of working with collegues from other universities, and some results are mentioned in this thesis. I'd like to express my thanks to prof. Gerard van Koten, Johann Jastrzebski, Henk Kleijn and Rainer Wechselberger for their contributions to chapter 3 and 4, Anja Palmans and Joris Peeters for their contribution to chapter 5 and Linda Havermans-van Beek for her contribution to chapter 8. I enjoyed working with Rainer Kränzle and Mark Leemhuis, and was fortunate to walk along the 'educational highway' with a number of students. Dimitri, Erwin, Roel, Martha, Marloes, Kicki and Lucas: thanks for your contributions.

Much obliged to the 'labmates' - in particular Priscilla (who 'lured' me into the group), Ingrid and Christine, who were essential discussion partners, and Marc, for his assistance in numerous experiments. A special thanks is in place for Zlata and Karin, who have helped out in many ways. And of course many thanks to all my PBM and other collegues at the university; I will not mentioned names here, because I'm bound to forget some. Last but not least, I'd like to thank my friends, family - especially my parents, Bart and Phoebe, for all their love and support. My greatest thanks go to my wife Kim, whose endless patience and gentle encouragements turned out to be the most important as well as most successful ingredient in finishing this thesis.

Mark 


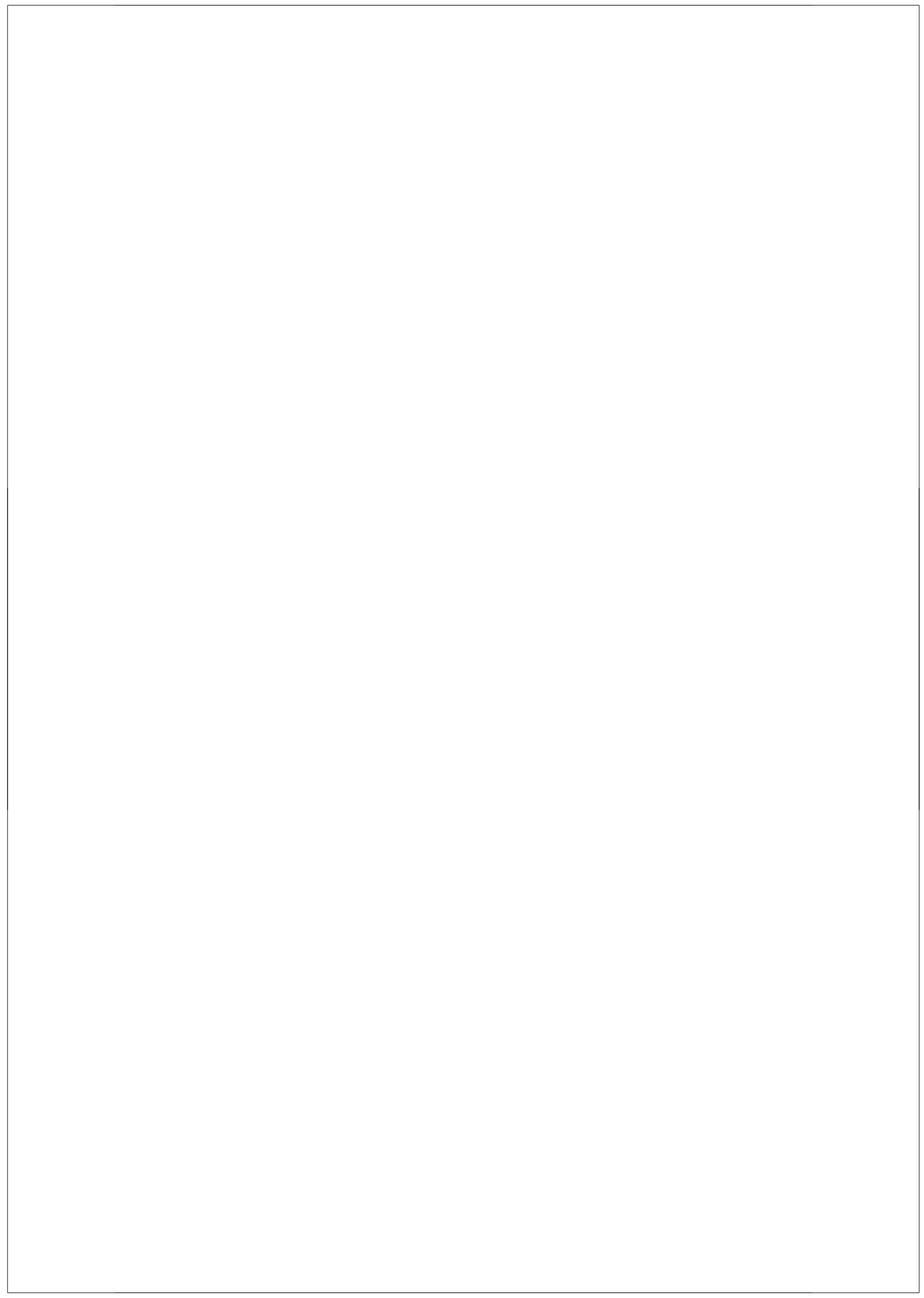




\section{Contents}

Chapter 1 General Introduction

Chapter 2 The Synthesis of Polyesters by Controlled Ring-Opening

Polymerization and Their Use in Biomedical Applications

9

Chapter 3 NO-Bidentate and NON-Tridentate Zinc Alkoxides for the Controlled Ring-Opening Polymerization of Lactides

Chapter 4 Controlled Ring-Opening Polymerization of Lactides by Thiophenolate-Based Zinc Catalysts

Chapter 5 Ring-Opening Polymerization of Substituted $\varepsilon$-Caprolactones Using a Chiral (Salen) AlO $i$ Pr-Complex

Chapter 6 Synthesis and Ring-Opening of $\gamma$-Boc-Amino- $\varepsilon$-Caprolactone

Chapter 7 Synthesis and Thermal Properties of Heterobifunctional PLA Oligomers and Their Stereocomplexes

Chapter 8 Stereocomplexed Hydrogels from Dextrans Grafted with PLA Amines

Summary 


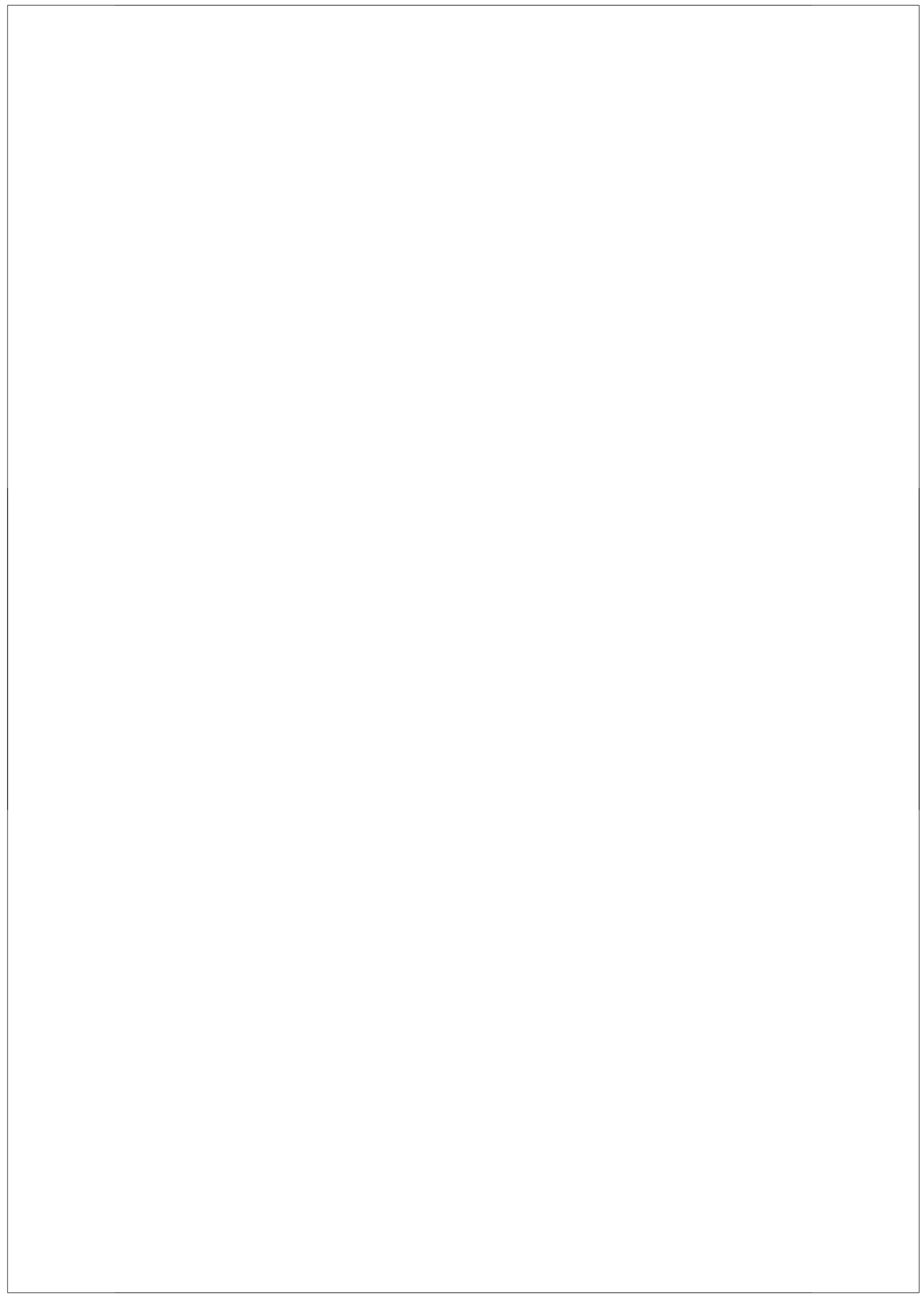




\section{1| \\ General Introduction}

Hydrogels have found numerous applications in biomedical technology such as tissue engineering and drug delivery systems. ${ }^{1-5}$ Hydrogels resemble natural living soft tissues and in general their high water content renders them highly biocompatible. When used as implant materials hydrogels have to be preferably biodegradable, thus allowing the replacement of the material in time by a new extracellular matrix produced by surrounding or in the hydrogel incorporated cells. Hydrogels that are biofunctional, e.g. by the incorporation of growth factors to guide cellular behavior, receive a lot of attention in current research.

In biomedical technology either preformed or in situ generated hydrogels may be used. Injectable, in situ-forming hydrogels offer the advantage of ease of cell seeding or incorporating drugs and the ability to readily fill irregularly shaped defects. ${ }^{6-8}$ Moreover, this method, which involves a simple injection of hydrogel precursor solutions that crosslink into a hydrogel, makes invasive surgery unnecessary.

Hydrogel networks are insoluble in water, due to the presence of chemical crosslinks or physical crosslinks, such as hydrogen bonds, hydrophobic interactions, or ionic interactions. ${ }^{9}$ Physical crosslinking generally proceeds under mild conditions, which allows an easy immobilization of e.g. therapeutic proteins and cells. However, in general physically crosslinked hydrogels are mechanically weak and degrade faster than chemically crosslinked hydrogels.

Well known biodegradable hydrogels are amphiphilic block copolymers of hydrophobic aliphatic polyesters and hydrophilic polymers like poly(ethylene oxide) or polysaccharides. ${ }^{10-12}$ Aliphatic polyesters like poly(lactide)s (PLA) and lactide copolymers are nontoxic to the human body and widely applied as biomedical materials. In recent years stereocomplexation or stereocomplex formation between enantiomeric PLAs (poly $(L$-lactide) and poly $(D$-lactide)) in amphiphilic block or graft copolymers has been developed as a method to prepare physically crosslinked injectable hydrogels. ${ }^{8,11-14}$ 


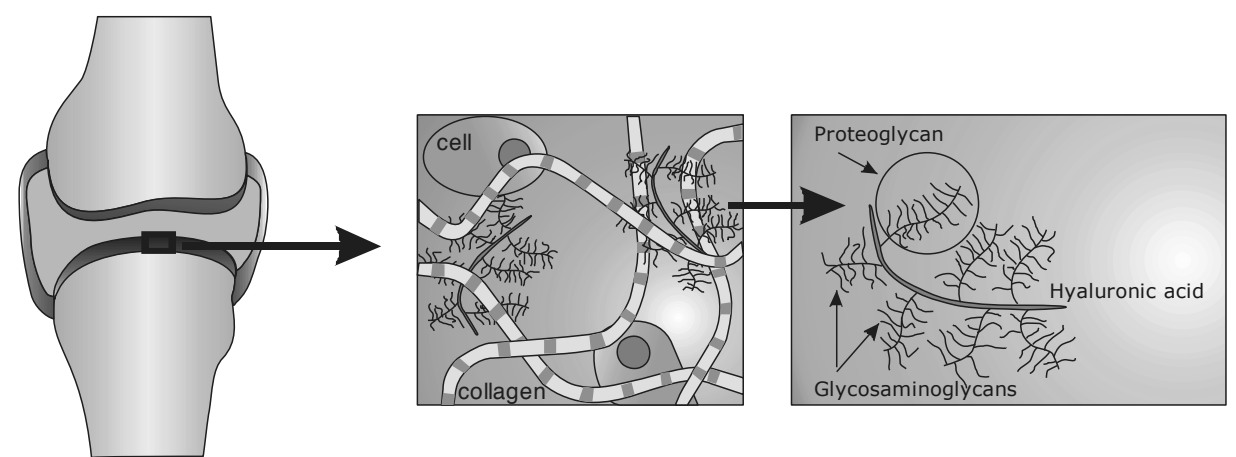

Figure 1. Schematic representation of the extracellular matrix in articular cartilage (middle), containing the typical 'brushed brush' structure of proteoglycans attached to a hyaluronic acid backbone.

Tissue regeneration is a promising methodology for the repair of tissues like cartilage. ${ }^{15}$ The ECM of natural cartilage contains approximately $25 \%$ of proteoglycans. ${ }^{16}$ These proteoglycans are brush-like structures, composed of several different glycosaminoglycans (GAGs) (polysaccharides), and covalently attached to a single polypeptide chain. In the presence of hyaluronic acid, higher aggregates of aggrecans can be formed, resulting in 'brushed brushes' (Figure 1). In general, the GAGs are highly negatively charged, and therefore able to bind large amounts of water. In combination with collagen, which provides mechanical strength, these extracellular matrix (ECM) components provide the characteristic viscoelastic properties of cartilage tissue. In designing hydrogels for tissue engineering, the structure and properties of the natural ECM can be used as guidance.

\section{Aim of the Study and Hydrogel Design}

In this study, we have focused on different aspects of biodegradable polymers that may be used in the development of hydrogels for tissue engineering. Building blocks with a predetermined structure, that could be combined to give temporal in situ-forming hydrogels, were designed and finally applied in graft copolymers. We based our design on the structure of the aggrecans as found in the natural ECM of cartilage. 
The brush-like structures should form upon self-assembly after mixing of the individual components, and gelation times should be tunable. By applying biodegradable and water soluble components that can be removed from the body by natural pathways biocompatible hydrogels are expected.

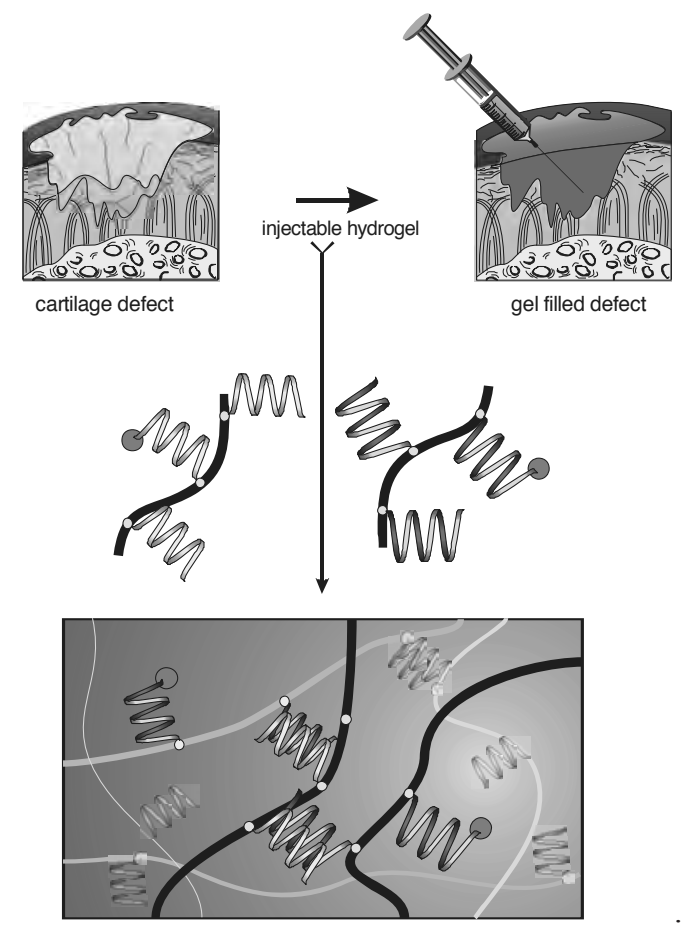

Figure 2. Schematic representation of the filling of cavities by injectable, in-situ forming hydrogels, based on complex formation between complementary segments attached to a polymer backbone.

The aims of the research described in this thesis are to study (1) potential biocompatible catalyst systems that can induce stereoselective polymerization of lactides and substituted caprolactones and (2) to apply these systems in the preparation of new polyesters bearing functional groups. Such polyesters can be studied in the preparation of self-assembling moieties, for application in tissue engineering. The self-assembly of the individual components into hydrogels is based on the concept of stereocomplex formation between 
poly(lactic acid) (PLA) segments of opposing chirality (Figure 2). Thus, applying biodegradable and water soluble components that can be removed from the body by natural pathways, biocompatible hydrogels are expected. The mild crosslinking method allows simultaneous incorporation of cells, cell receptors or growth factors, or combinations thereof. In full-thickness defects progenitor cells from the bone marrow should eventually lead to regeneration of the tissue. ${ }^{17}$

\section{Outline of the Thesis}

The synthesis of stereoregular PLAs and stereocomplexation of PLA oligomeric segments ${ }^{18}$ plays a central role in the research described in this thesis. The ring-opening polymerization (ROP) of racemic lactide to PLAs with stereoregular sequences, the effect of end groups of oligomeric, enantiomeric PLA segments on stereocomplexation, and the modification of dextrans with the oligomeric PLAs has been investigated. First steps were also performed in the stereoregular polymerization of substituted caprolactones, either by enzymes or by a single-site chiral aluminum-salen complex. In an attempt to prepare amine functionalized poly(caprolactone)s, a rearranged monomer rather than polymers was obtained.

In Chapter 2 a literature overview is presented on the use of stereoselective catalysts in ROP of lactides and lactones. New zinc phenolate catalysts were explored in the ROP of lactides, with emphasis on catalyst activities and stereoselectivities (Chapter 3). It was shown that all catalysts gave a well-controlled lactide polymerization. The stereoselective behavior of one of these catalysts, which ligand could potentially coordinate to the metal species via three donor atoms ('tridentate'), showed an interesting dependence on the polymerization medium used. In the ROP of rac-lactide, a shift from atactic polymers upon using $\mathrm{CH}_{2} \mathrm{Cl}_{2}$ as the polymerization medium to isotactic enriched polymers upon using THF as a solvent was observed. Isotactic enrichment upon using zinc catalysts is hitherto not reported. In Chapter 4, the use of three zinc thiophenolate catalysts in the ROP of lactides is described. Similar to the phenolate analogues, well-controlled polymerizations were found, with a mild enrichment in syndiotactic sequences in the resulting polymers. 
General Introduction

In recent literature on stereoselective polymerization the ROP of chiral lactones other than lactide is rarely described. An initial detailed study on the use of $R, R^{\prime}$-(salen) (Jacobsen ligand) aluminum isopropoxide as a stereoselective catalyst in the ROP of 4methyl- and 6-methyl substituted $\varepsilon$-caprolactone is described in Chapter 5. Stereoselective ring-opening of 6-methyl- $\varepsilon$-caprolactone was observed, although in this case the stereoselectivity and activity of this catalyst were much lower in comparison with rac-lactide polymerizations. The 4-methyl substituted caprolactone was polymerized faster than the 6-methyl substituted analogue, but not in a stereoselective manner. In contrast, the enzyme lipase Candida Antarctica $B$ gave stereoselective polymerization of 4-methyl- $\varepsilon$-caprolactone, but no polymerization of 6-methyl- $\varepsilon$-caprolactone.

The design and synthesis of a temporarily protected amine-functionalized monomer that may be used in the synthesis of polyesters carrying pendant amine functional groups is described in Chapter 6. The synthesis of a substituted $\varepsilon$-caprolactone, having a tertbutoxycarbonyl-protected amine group at its $\gamma$-position was carried out successfully, using procedures analogous to the general preparation of substituted caprolactones. The monomer could be ring-opened, but ring rearrangement rather than polymerization occurred.

In Chapter 7 the synthesis of various homo- and heterotelechelic PLA oligomers is described. It was demonstrated that the modification of the oligomeric chain ends has a suppressive effect on crystallization, which is more eminent when both ends are modified.

Grafting of dextran or oxidized dextran with amine end group functionalized short lactic acid oligomers (as described in Chapter 7) was applied to prepare hydrogel precursors. These graft copolymers contain hydrolytically stable carbamate or secondary amine linkages (Chapter 8) and do degrade slowly. Hydrogels were formed upon mixing of dextran-PLA copolymers with PLA segments of opposite chirality, but the hydrogels formed slowly and had a low mechanical strength. 


\section{References}

1. K. Y. Lee and D. J. Mooney, Hydrogels for tissue engineering. Chem. Rev., 2001, 101(7), 1869-1879.

2. A. S. Hoffman in Advanced Drug Delivery Reviews; Elsevier Science B.V., 2002, 3-12.

3. N. A. Peppas, J. Z. Hilt, A. Khademhosseini and R. Langer, Hydrogels in biology and medicine: From molecular principles to bionanotechnology. Adv. Mater., 2006, 18(11), 1345-1360.

4. R. V. Ulijn, N. Bibi, V. Jayawarna, P. D. Thornton, S. J. Todd, R. J. Mart, A. M. Smith and J. E. Gough, Bioresponsive hydrogels. Mater. Today, 2007, 10(4), 4048.

5. L. Klouda and A. G. Mikos, Thermoresponsive hydrogels in biomedical applications. Eur. J. Pharm. Biopharm., 2008, 68(1), 34-45.

6. S. L. Riley, S. Dutt, R. de la Torre, A. C. Chen, R. L. Sah and A. Ratcliffe, Formulation of PEG-based hydrogels affects tissue-engineered cartilage construct characteristics. J. Mater. Sci.-Mater. Med., 2001, 12(10-12), 983-990.

7. R. Jin, C. Hiemstra, Z. Y. Zhong and J. Feijen, Enzyme-mediated fast in situ formation of hydrogels from dextran-tyramine conjugates. Biomaterials, 2007, 28(18), 2791-2800.

8. S. R. Van Tomme, G. Storm and W. E. Hennink, In situ gelling hydrogels for pharmaceutical and biomedical applications. Int. J. Pharm., 2008, 355(1-2), 1-18.

9. W. E. Hennink and C. F. van Nostrum, Novel crosslinking methods to design hydrogels. Adv. Drug Deliv. Rev., 2002, 54(1), 13-36.

10. F. Li, S. M. Li and M. Vert, Synthesis and rheological properties of polylactide/poly(ethylene glycol) multiblock copolymers. Macromol. Biosci., 2005, 5(11), 1125-1131.

11. C. Hiemstra, Z. Y. Zhong, X. Jiang, W. E. Hennink, P. J. Dijkstra and J. Feijen, PEG-PLLA and PEG-PDLA multiblock copolymers: Synthesis and in situ hydrogel formation by stereocomplexation. J. Controlled Release, 2006, 116(2), e17-e19.

12. Y. J. Jun, K. M. Park, Y. K. Joung and K. D. Park, In situ Gel Forming Stereocomplex Composed of Four-Arm PEG-PDLA and PEG-PLLA Block Copolymers. Macromol. Res., 2008, 16(8), 704-710.

13. C. Hiemstra, Z. Y. Zhong, L. Li, P. J. Dijkstra and J. Feijen, In-Situ Formation of Biodegradable Hydrogels by Stereocomplexation of PEG-(PLLA) 8 and PEG-(PDLA) 8 Star Block Copolymers. Biomacromolecules, 2006, 7(10), 27902795.

14. H. Y. Chung, Y. Lee and T. G. Park, Thermo-sensitive and biodegradable hydrogels based on stereocomplexed Pluronic multi-block copolymers for controlled protein delivery. J. Controlled Release, 2008, 127(1), 22-30.

15. E. B. Hunziker, Articular cartilage repair: basic science and clinical progress. A review of the current status and prospects. Osteoarthritis Cartilage, 2002, 10(6), 432-463.

16. M. A. Randolph, K. Anseth and M. J. Yaremchuk, Tissue engineering of cartilage. Clin. Plast. Surg., 2003, 30(4), 519-537. 
17. C. Erggelet, M. Endres, K. Neumann, L. Morawietz, J. Ringe, K. Haberstroh, M. Sittinger and C. Kaps, Formation of Cartilage Repair Tissue in Articular Cartilage Defects Pretreated with Microfracture and Covered with Cell-Free Polymer-Based Implants. J. Orthop. Res., 2009, 27(10), 1353-1360.

18. D. Brizzolara, H. J. Cantow, K. Diederichs, E. Keller and A. J. Domb, Mechanism of the stereocomplex formation between enantiomeric poly(lactide)s. Macromolecules, 1996, 29(1), 191-197 


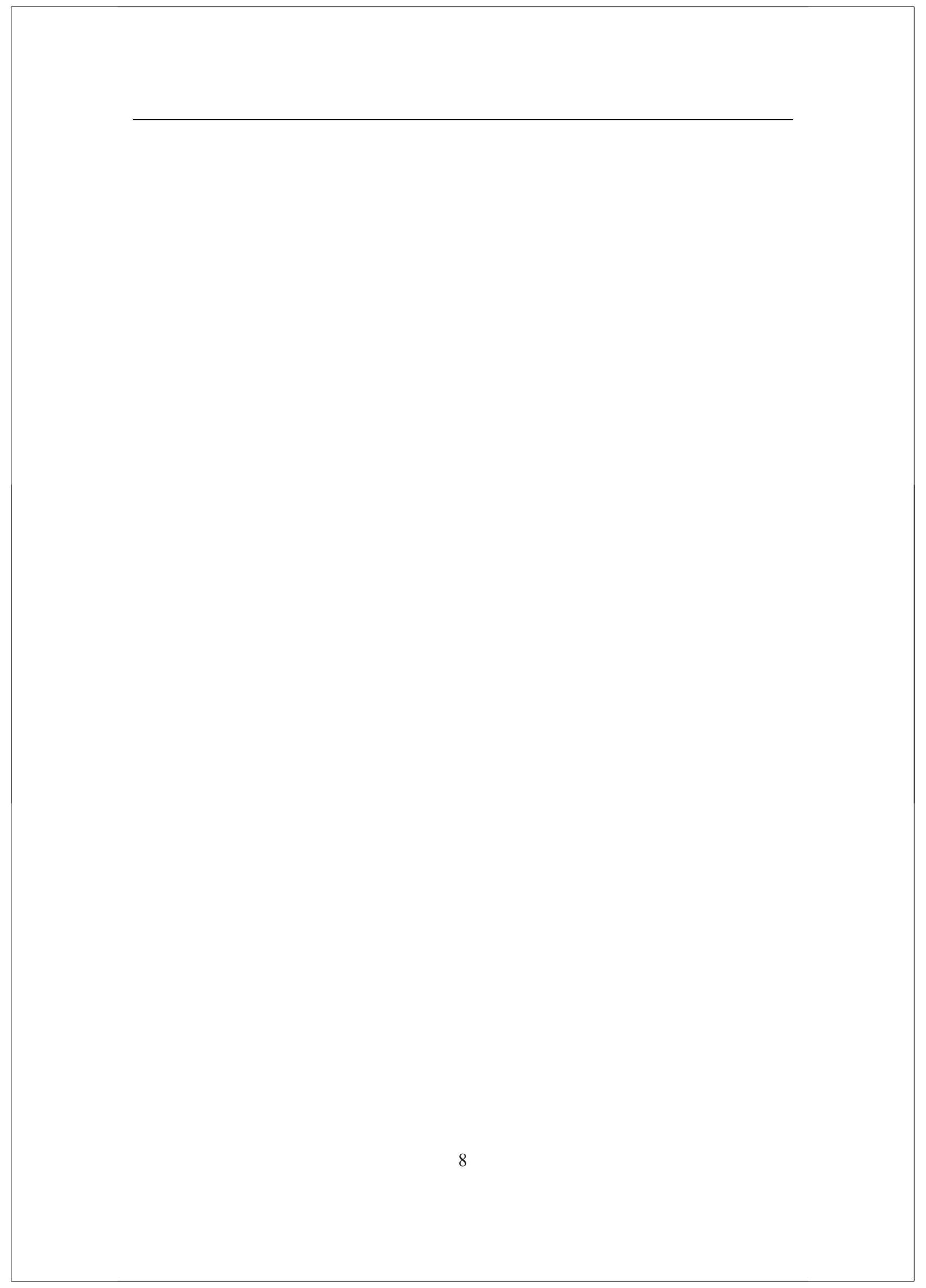




\section{The Synthesis of Polyesters by Controlled Ring-Opening \\ Polymerization and Their Use in Biomedical Applications}

\section{Introduction}

Historically there has been an ongoing effort to improve the quality of life and find solutions to overcome health problems caused by disease, injury or old age. The development of effective treatments is not restricted to the medical field. Nowadays many scientific disciplines act in conjunction, amongst which the field of biomedical technology. The continuous request for design and improvement of medical devices, implants, drug delivery systems and artificial organs has led to the development and application of a large variety of so-called 'biomaterials'. ${ }^{1,2}$ Biomaterials science, the study of the characteristics and performance of materials (metals, polymers and ceramics) used for medical applications evolved mainly during the past decades. Especially the mechanisms of the interactions between materials and tissues have been a major subject of study.

Examples of polymeric materials are Ultra High Molecular Weight Polyethylene (UHMWPE) in orthopedic devices, polyurethanes in artificial heart and heart assist devices and vascular grafts made of polyethylene terephthalate or polytetrafluorethylene. Besides for medical devices, biomaterials were also developed for applications in pharmaceutical devices (drug and gene delivery), and regenerative medicine and tissue engineering. Implant materials should not cause inflammatory, immunological or toxicological responses in the human body, and biocompatibility of implant materials has become a major issue in the development and design of new biomedical devices. ${ }^{3-5}$

Biodegradable polymers, a special class of biomaterials, have received a lot of interest in the past decades. Aliphatic polyesters, ${ }^{6,7}$ in particular poly(lactic acid) (PLA), ${ }^{8-11}$ poly(glycolic acid) (PGA), poly( $\varepsilon$-caprolactone) (PCL), 11, 12 and copolymers thereof were studied extensively. These materials degrade through hydrolysis of the ester bonds and the most well known application of some of these polymers is that of degradable sutures. Nowadays these types of materials are widely investigated for applications in regenerative medicine, constructs for the growth of new tissue, and the challenge in this respect is to gear the materials' degradation process to the body's regeneration process. 


\section{Synthesis of Polyesters by Ring-Opening Polymerization}

Polymers such as PLA and PCL are preferably prepared by ring-opening polymerization ${ }^{9}$ ${ }^{13,14}$ (ROP) of the corresponding cyclic monomers, i.e. lactide and $\varepsilon$-caprolactone ( $\varepsilon$-CL) (Scheme 1). Compared to polycondensation of hydroxyacids, ROP of lactides and lactones offers several advantages, such as control over the polymerization reaction and access to advanced architectures. ${ }^{14}$ The ring-opening reaction is generally initiated by an alcohol in the presence of a catalyst, resulting in polymer chains with an ester and an alkoxy end group to which the catalyst is coordinated (Scheme 1). ${ }^{15}, 16$ The term 'controlled' or 'living' polymerization refers to ROP with good control over molecular weight, low polydispersities and in principal 'infinite' chain growth as long as monomer is provided and no terminating agent has been added.

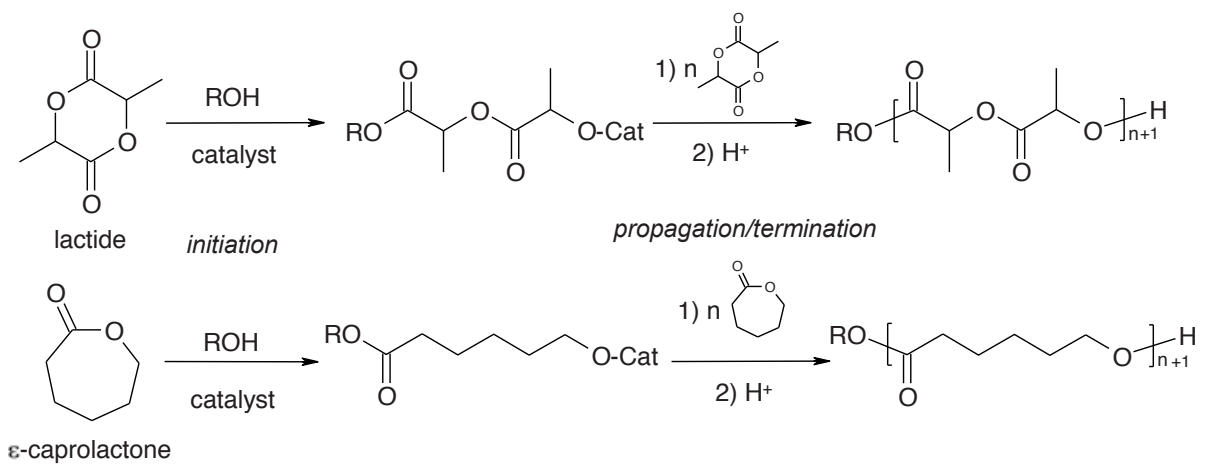

Scheme 1. Ring-opening of lactide (upper) and lactones (lower): alcohol initiation and polymer propagation, followed by termination by acid.

Numerous catalysts have been explored for the ring-opening of lactides and lactones, ${ }^{7,10}$, ${ }^{13,17-19}$ and they can be subdivided in metal-free catalysts ${ }^{20}$ and metal-based ${ }^{21-25}$ catalysts. Examples of metal-free catalysts are 4-(dimethylamino)pyridine (DMAP), ${ }^{26,}{ }^{27} \mathrm{~N}$ propylsulfonic acid, ${ }^{28}$ trifluoromethanesulfonic acid, ${ }^{29} \mathrm{HCl} \cdot \mathrm{Et}_{2} \mathrm{O},{ }^{30} \mathrm{~N}$-heterocyclic carbenes, ${ }^{31-33}$ guanidines and amidines ${ }^{34,35}$ and phosphazene bases. ${ }^{36}$ The majority of catalysts studied, however, are metal based. With respect to biomaterial applications, the biocompatibility of the metal is of importance, as complete catalyst removal from the polymer material is generally not performed. ${ }^{18,21}$ 
Many of the catalysts investigated induce ROP by a pseudo-anionic ${ }^{37}$ mechanism. A well-explored, pseudo-anionic mechanism, referred to as a coordination-insertion mechanism, is depicted in Scheme 2. The metal alkoxide catalytic species coordinates to the carbonyl oxygen and a nucleophilic acyl substitution reaction takes place to give the ring opened product $\mathbf{C}$. The newly formed metal alkoxide will subsequently open a new monomer and these steps are repeated many times to yield a polymeric chain. By following this approach, many of the side-reactions observed in anionic polymerizations that interfere with the control over molecular weight, polydispersity and stereochemistry (epimerization, chain termination, trans-esterification) may be suppressed.

R

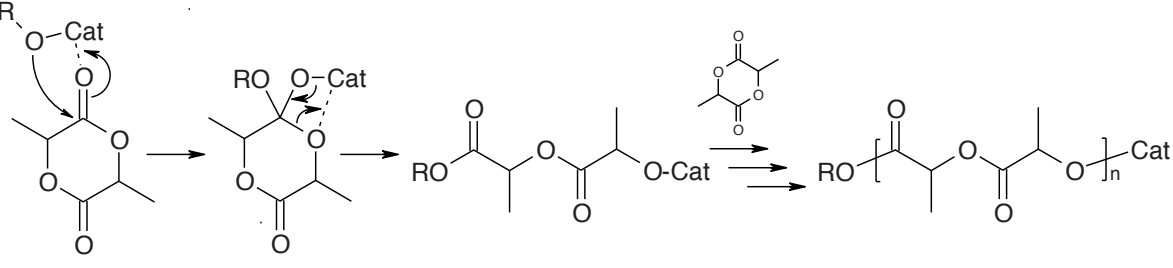

A

B

C

D

Scheme 2. Ring-opening polymerization of lactide via a coordination-insertion mechanism.

\section{Multivalent metal alkoxides}

Well-known and intensively studied organometallic compounds, used as catalyst/initiators in coordination-insertion polymerization, are metal alkoxides. Multivalent metal alkoxides enable the growth of more than one polymeric chain from a metallic center. Examples are aluminum isopropoxide ${ }^{38}$ and binolate complexes of zinc and aluminum. ${ }^{39}$ Other systems consist of sterically protected catalysts. This protection prevents formation of higher aggregates, and the metal species are rather inactive or 'dormant', resulting in negligible polymerization. A far more active complex of the metal species and the alkoxide initiator is formed upon in situ alcoholysis of the protected catalyst, and prevention of aggregation is no longer required due to fast propagation. Examples are the highly active yttrium ${ }^{40}$ alkoxides developed in our laboratories and the widely applied stannous alkoxides, generated in situ from stannous octoate $\left(\mathrm{Sn}(\mathrm{Oct})_{2}\right){ }^{41}$ 


\section{Single-Site Catalysts}

In a single-site catalyst, the metal is coordinated by a ligand in such a way that only one initiating moiety is present and thus only one polymeric chain will grow from the metal center. These catalysts (or catalyst/initiator complexes) have the general formula $L_{n}-M-R$, where $\mathrm{L}$ represents a ligand, $\mathrm{M}$ the metal and $\mathrm{R}$ the initiating species, which is generally an alkoxide. Alternatively, exchange of an $\mathrm{R}$ group by an alkoxide group upon in situ alcoholysis is possible, e.g. when $\mathrm{R}$ is an alkyl or bis(trimethylsilyl)amide group. The inert ligand $\mathrm{L}$ is permanently coordinated to the metal center, and is important in controlling parameters such as polymerization rate and polymer stereochemistry. Over the years, a large variety of metal-ligand combinations have been explored for the ROP of lactides and lactones. ${ }^{14,21-25,42}$ Besides catalytic activity, the stereoselective behavior of the catalysts in the ROP of especially racemic mixtures of lactides has received great interest.

\section{Stereoselective Ring-Opening Polymerization}

In 1987 Ikada was the first to show stereocomplex formation between poly $(L$-lactide) and poly $(D$-lactide), leading to materials with significanltly increased melting points. This has triggered many researchers to study the stereoselective ring opening polymerization of (racemic) mixtures of $D$ - and $L$-lactide and of meso-lactide and the influence of chain stereochemistry on the properties of the resulting polyesters. When a stereogenic environment around the metal center in an $L_{n}-M-R$ catalyst/initiator is present, in many cases addition of one of the lactide enantiomers in racemic lactide (rac-LA) to the growing chain is favored. Two possible mechanisms have been proposed to explain the preferred addition. In the 'chain-end control' mechanism, the stereogenic center of the ultimate monomeric unit of the polymer chain attached to the metal center is decisive for the insertion of the next type of enantiomer. ${ }^{43}$ In contrast, in the 'enantiomorphic site control' mechanism the selectivity is only governed by the stereogenic environment of the coordinating ligand. In certain cases the mechanisms may act cooperatively. Moreover, enantiomorphic site control has also been reported for apparent non-chiral catalyst/initiator complexes, which provide a chiral environment upon the formation of aggregates. $^{44}$ 


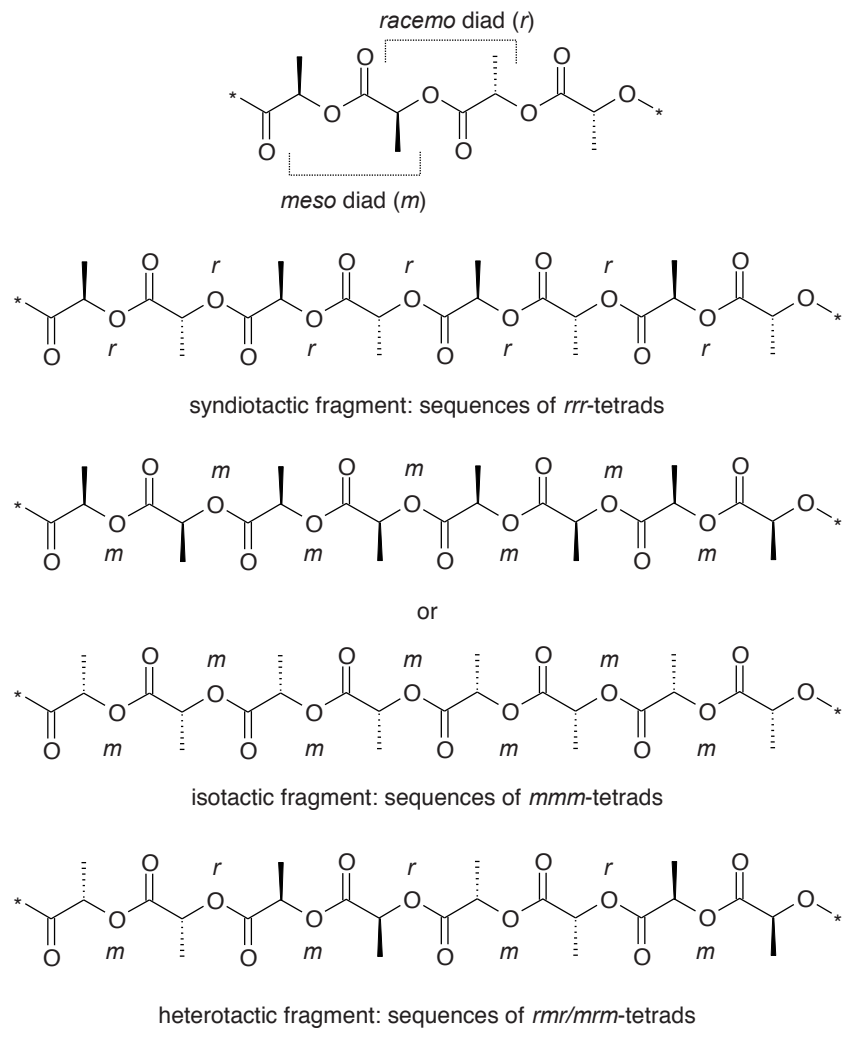

Figure 1. Stereoregular domains and their nomenclature, using polylactide as a specific example.

In stereoselective polymerization, the chirality of each newly inserted monomer may be identical or opposite to that of the previously inserted monomer, resulting in isotactic or syndiotactic sequences, respectively. This is also often referred to as meso $(\mathrm{m})$ or racemic (r) enchainment, respectively (Figure 1). ${ }^{45}$ Two adjacent structural units in a polymer molecule constitute a diad. If the diad consists of two units with identical configuration, it is called a meso diad, abbreviated with ' $m$ '. If the diad consists of units with opposite configuration, it is called a racemo or racemic diad, abbreviated with ' $r$ '. In a similar way, triads and tetrads can be assigned to three and four consecutive repeating units, respectively. The term 'isotactic' refers to a non-changing configuration or tacticity when 


\section{Chapter 2}

moving along the repeating units in a polymer backbone, i.e. -RRRR- or -SSSS- or, in terms of tetrads, ' $m m m$ '. When the configuration is alternating (i.e. -RSRS- or ' $r r r$ '), the sequence is referred to as 'syndiotactic'. ${ }^{46}$ Inherent to the monomer structure, a purely syndiotactic polymer cannot be obtained upon polymerization of rac-lactide, and the alternating sequence of $D$ - and $L$-monomer (i.e. $-R R$-SS- or ' $m r m$ '/'rmr') is referred to as 'heterotactic'. ${ }^{47}$ When no stereoregular enrichments are present, the polymer is called 'atactic'.

-RRRRRR-S-RRRR-S-RRRR-S-RRR-S-RRR-SS-RR-S-RR-SS-R-SSSS-R-SSSS-R-SSSSSisotactic enrichment atactic segment isotactic enrichment

Figure 2. Schematic structure of a tapered isotactic chain.

However, as catalysts known nowadays are never 100\% selective, a purely isotactic polymer will not be formed. During polymerization of rac-lactide depletion of the preferred enantiomer upon higher conversions leads to more frequent built-in of the other enantiomer over time, giving tapered structures with isotactic segments on the chain ends and an atactic center (Figure 2). For enantiomorphic site-controlled polymerizations, tapering might be suppressed by using a racemic catalyst mixture.

Despite many studies in the past decade, the exact mechanism of a catalyst's stereoselective behavior is still relatively poorly understood. ${ }^{48}$ Stereoselectivity is influenced by factors associated with the type of metal species, the polymerization medium, polymerization temperature as well as the size and chirality of the ligand. The coordination to and the geometry around the metal center are factors that influence the stereoselectivity. In the following sections different parameters that have been investigated so far will be reviewed.

\section{Metal species}

The activity of a metal alkoxide catalyst initiator in ROP reactions is related to the strength of the metal-alkoxide bond, with higher activities upon weaker bonds. ${ }^{49}$ In this 
respect, magnesium/ligand, calcium/ligand and lanthanide/ligand complexes generally are more active than zinc/ligand or aluminum/ligand complexes. ${ }^{50,51}$ Considering selectivity, however, a complex of a ligand with a certain metal may result in enrichment in stereoregular sequences of lactides, whereas the same ligand in combination with another metal might not. A few examples can be found in literature.

Upon using a binolate ligand (Figure 3A), Chisholm et al. obtained complexes with two aluminum or titanium metal species, whereas combination with zinc and lithium resulted in complexes with three and four metallic species, respectively. ${ }^{39}$ The zinc catalysts gave PLAs with heterotactic enrichments, whereas the lithium and aluminum analogues afforded atactic PLAs. The latter was explained by extensive transesterification reactions associated with these complexes.

Using $\beta$-diiminate ligands, heterotactic enrichments were obtained for both zinc ${ }^{52}$ and $\operatorname{tin}^{53}$ complexes (Figure 3B), but in the latter case, selectivity was lower. In contrast, the calcium $^{54}$ and magnesium analogues, ${ }^{52,} 55$ though more active, gave polymers with no enrichment in stereoregular sequences.

Applying a calcium $\beta$-diiminate complex with trispyrazolylborate ligands resulted in very fast polymerizations of rac-lactide ${ }^{54}$ with high levels of heterotactic enrichment (over $90 \%$ ), whereas the magnesium and zinc analogues were less active and apparently showed no stereoselectivity in lactide polymerization.<smiles>[R]c1cc([2H])c(O)c(-c2c([R])c([R])cc([2H])c2O)c1[R]</smiles><smiles>[R]c1cccc([R])c1N=C(C)CC(C)=Nc1c([R])cccc1P</smiles>

$\left(P_{r}\right.$ not specified)

$\left(P_{r}=0.90\right.$ upon combination with $\left.\mathrm{Zn}\right)$

A

B

Figure 3. Schematic representation of a binolate $\left(\mathrm{R}_{1}=\mathrm{R}_{2}=\mathrm{Me}, \mathrm{R}_{3}=t \mathrm{Bu}\right)^{39}(\mathbf{A})$ and $\beta$ diiminate ligand $\left(\mathrm{R}_{1}=i \operatorname{Pr}\right)(\mathbf{B})$ as used by Chisholm et al. ${ }^{53}$ The $P_{r}$ value given in parentheses is the highest value reported for these types of structures. 
Whereas the use of N-heterocyclic carbenes in combination with zinc (Figure 4B) ${ }^{32,56}$ resulted in slight heterotactic enrichment $\left(P_{r}=0.60\right)$, cyclic carbenes (Figure 4A) also are able to stereoselectively polymerize lactides in the absence of a metal. At room temperature a slight isotactic enrichment $\left(P_{m}=0.55-0.59\right){ }^{57}$ was observed. At lower temperatures this selectivity increases.<smiles>[R]c1ncn([R7])c1[R]</smiles>

A

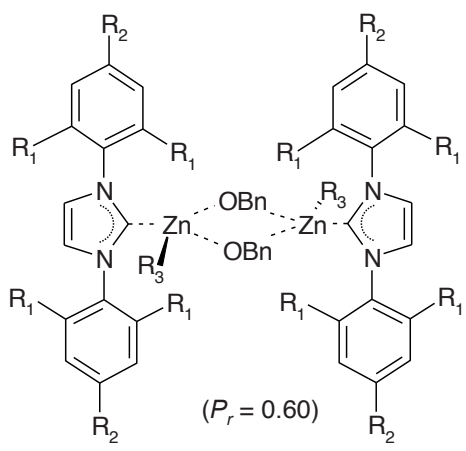

B

Figure 4. $N$-heterocyclic carbenes $\left(\mathrm{R}_{1}=2,4,6-\mathrm{Me}_{3}-\mathrm{Ph}, 2,6-i \mathrm{Pr}_{2}-\mathrm{Ph}\right.$ or $\left.t \mathrm{Bu}, \mathrm{R}_{2}=\mathrm{H}\right)(\mathbf{A})$ and their complex with zinc $\left(\mathrm{R}_{1}=\mathrm{R}_{2}=\mathrm{Me}, \mathrm{R}_{3}=\mathrm{OBn}\right.$ or $\left.\mathrm{R}_{1}=i \operatorname{Pr}, \mathrm{R}_{2}=\mathrm{H}, \mathrm{R}_{3}=\mathrm{Cl}\right)(\mathbf{B})$. The $P_{r}$ and $P_{m}$ values given in parentheses are the highest values reported for these types of structures.

\section{Polymerization medium and temperature}

In various cases, stereoselectivity was shown to be influenced by the polymerization medium as well as the polymerization temperature. In general, stereoselective behavior is shown to be amplified by polymerization at lower temperatures, ${ }^{32,46,49-51,56-58}$ which has been explained by the less rapid interchange of conformations. The $\beta$-diiminate zinc complex as presented in Figure $3 \mathrm{~B}$ gave polymers with high levels of heterotactic enrichment $\left(P_{r}=0.90\right)$ in THF, $\mathrm{CH}_{2} \mathrm{Cl}_{2}$ and benzene. ${ }^{59}$ In contrast, the more active magnesium analogue gave heterotactic enriched polymers in THF as the polymerization medium, but atactic polymers in benzene. Similar results have been obtained for other $\beta$ diiminate complexes. ${ }^{60}$ 
$\mathrm{Wu}$ et al. reported on the use of a mono-methylether Salen-type ligand in combination with magnesium and zinc (Figure 5). ${ }^{50,51}$ The magnesium complex afforded a moderate isotactic enrichment in rac-lactide polymerization in $\mathrm{CH}_{2} \mathrm{Cl}_{2}\left(P_{m}=0.58, \mathrm{~T}_{\mathrm{r}}=0{ }^{\circ} \mathrm{C}\right)$, which could be significantly increased upon lowering the polymerization temperature $\left(P_{m}\right.$ $=0.67, \mathrm{~T}_{\mathrm{r}}=-30^{\circ} \mathrm{C}$ ). Applying $\mathrm{CH}_{2} \mathrm{Cl}_{2}$ as the polymerization medium, the zinc complex gave polymers with a significant heterotactic enrichment $\left(P_{r}=0.75, \mathrm{~T}_{\mathrm{r}}=25^{\circ} \mathrm{C}\right)$.

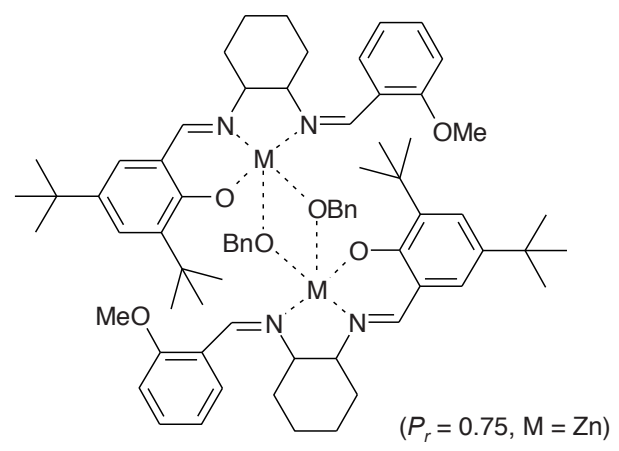

Figure 5. General formula of a mono-methylether Salen-complex. ${ }^{50}$ The $P_{r}$ value given in parentheses is the highest value reported for these types of structures.

Huang et al. investigated a number of zinc and magnesium NNO-tridentate ketiminate complexes for the ROP of rac-lactide (Figure 6). ${ }^{61}$ In THF as the polymerization medium the magnesium complex (Figure 6A) as a catalyst/initiator afforded poly(lactide)s with high levels of heterotactic enrichment $\left(P_{r, 50^{\circ} \mathrm{C}}=0.79, P_{r, 0^{\circ} \mathrm{C}}=0.85\right)$. These $\operatorname{Pr}$ values were lower when $\mathrm{CH}_{2} \mathrm{Cl}_{2}$ was used as a solvent $\left(P_{r, 30^{\circ} \mathrm{C}}=0.64\right)$. In contrast, for the zinc analogue (Figure 6B), the stereoselectivity appeared higher when the polymerization was performed in $\mathrm{CH}_{2} \mathrm{Cl}_{2}\left(P_{r, 0^{\circ} \mathrm{C}},=0.71\right)$ compared to $\mathrm{THF}\left(P_{r, 0^{\circ} \mathrm{C},}=0.61\right)$. 


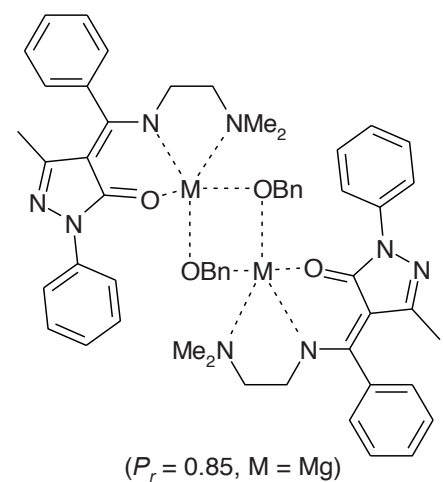

A

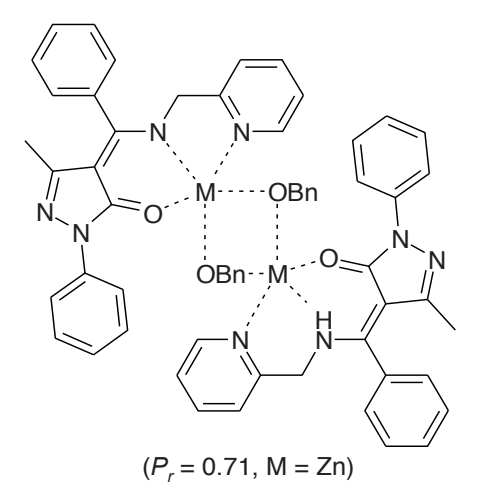

B

Figure 6. NNO-tridentate ketiminate metal complexes. ${ }^{61}$ The $P_{r}$ values given in parentheses are the highest values reported for these types of structures.

The different stereoselective behavior upon using THF as the polymerization medium has been ascribed to the ability of THF to coordinate to the metal species. This is well known for organo-magnesium complexes, $50,51,59,61$ and may result in a change in the stereogenic environment of the catalytic site.

\section{Ligand (substituent) size and electronegavity}

In single-site catalysts, ligands are applied that have multiple, relatively stable, coordination sites to the active metal center, leaving a single active site available for polymerization. Increasing the ligand size generally decreases the catalysts' activity as a result of steric crowding around the reactive center. It has to be noted here that in cases where the bulkier ligands prevent complex association (as reported for certain $\beta$ diiminate ligands), ${ }^{46}, 62$ the catalyst activity will be higher. With respect to stereoselectivity, bulky ligands generally result in higher levels of enrichment in stereoregular sequences in the resulting polymers. 
Both Chisholm et al. and Coates and coworkers reported on $\beta$-diiminate zinc complexes (Figure 7A) that gave polymers with high levels $\left(P_{r}\right.$ up to 0.90) of heterotactic enrichment by chain-end control. ${ }^{52}$ Replacing the isopropyl substituents on the ligand phenoxide groups by less bulky ethyl or propyl groups resulted in lower levels of heterotactic enrichment $\left(P_{r}=0.79\right.$ and 0.76 , respectively). ${ }^{46}$

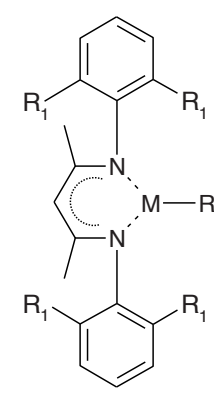

$\left(P_{r}=0.90\right)$<smiles></smiles>

(no selectivity)

B

Figure 7. Schematic representations of a $\beta$-diiminate metal complex $\left(\mathbf{A}: \mathrm{R}_{1}=\mathrm{Et},{ }^{46} \mathrm{Pr},{ }^{46}\right.$ or $\left.i \mathrm{Pr}^{52,55,58}\right)$ and a Schiff base zinc complex $\left(\mathbf{B}: \mathrm{R}=\mathrm{N}\left(\mathrm{SiMe}_{3}\right)_{2}\right.$ or $\left.\mathrm{R}=\mathrm{OPh}(2,6-t \mathrm{Bu})^{63}\right)$. The $P_{r}$ values given in parentheses are the highest values reported for these types of structures.

The Schiff base ligand (Figure 7B) as studied by Chisholm et al. did not display stereoselective behavior. The reduced steric hindrance around the metal center ${ }^{63}$ is given as a reason. Chen et al. reported on a series of zinc alkoxides with Schiff base-type NNOtridentate ligands with moderate levels of heterotactic enrichment $\left(P_{r}=0.59-0.65\right)$ (Figure 8). ${ }^{49}$ Increasing the ligand bulkiness on the ortho position $\left(\mathrm{R}_{2}\right)$ resulted in higher levels of heterotactic enrichments $\left(P_{r}=0.74\right)$, whereas lower polymerization temperatures enhanced this effect $\left(P_{r,-55^{\circ} \mathrm{C}}=0.91\right)$. 


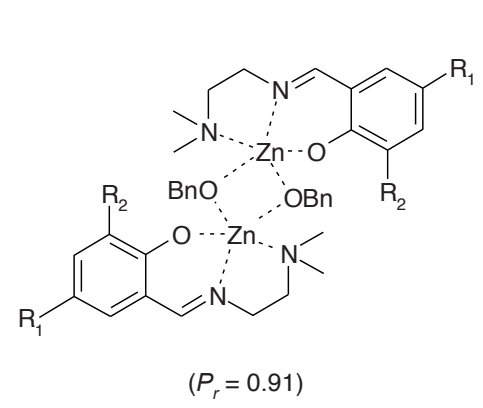

A

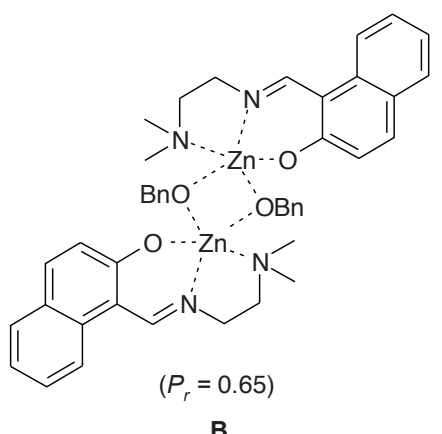

B

Figure 8. Zinc alkoxides bases on NNO-tridentate ligands. ${ }^{49}$ The $P_{r}$ values given in parentheses are the highest values reported for these types of structures.

Salen-aluminum complexes have been intensively studied for the stereoselective polymerization of lactides. The general structure of these complexes is presented in Figure 9. Moderate to high levels of isotactic enrichments upon using Schiff base ligands with non-substituted phenoxide groups were reported by Le Borgne et al. ${ }^{64}$ and BhawLuximon et al. ${ }^{65}$ In later years Nomura et al. also investigated a series of analogous aluminum/achiral Schiff base ligand complexes. ${ }^{66,67}$ The complexes with a propylene spacer $\left(\mathrm{R}_{1}=\mathrm{C}_{3} \mathrm{H}_{6}\right)$ gave much higher activities than analogous ligands having an ethylene spacer $\left(\mathrm{R}_{1}=\mathrm{C}_{2} \mathrm{H}_{4}\right)$, which was ascribed to a higher flexibility imparted to the metal coordination sphere.

Stereoselectivities in rac-lactide polymerization of the aforementioned Al-complexes were comparable, and improved with alkyl substituent size (0.69-0.91). Stereoselectivity was enhanced even more by using bulkier substituents on the ortho position of the phenolic rings, e.g. $\mathrm{SiEt}_{3}\left(P_{m}=0.95\right)$ or $t \mathrm{BuMe}_{2} \mathrm{Si}\left(P_{m}=0.97\right),{ }^{66,67}$ whereas bulky substituents on the para positions had no additional effect. Using a dimethyl-substituted spacer $\left(\mathrm{R}_{1}=\mathrm{CH}_{2} \mathrm{C}\left(\mathrm{CH}_{3}\right)_{2} \mathrm{CH}_{2}\right)$ resulted in a small increase in isotactic enrichment in the resulting polymers, but replacing the spacers' side groups by larger ethyl or phenyl groups had a suppressive effect on the stereoselectivity. ${ }^{66,67}$ 


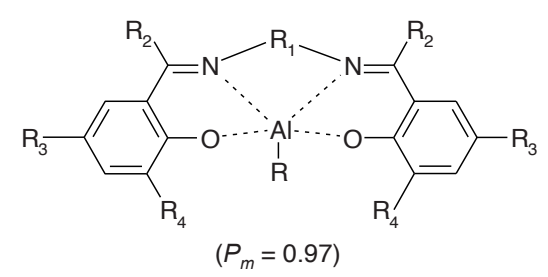

Figure 9. General structure of the aluminum salen-type complexes as used by Le Borgne et al. $\left(\mathrm{R}_{1}=\mathrm{C}_{2} \mathrm{H}_{4}, \mathrm{R}_{2}=\mathrm{R}_{3}=\mathrm{R}_{4}=\mathrm{H}\right)$, Bhaw-Luximon et al. $\left(\mathrm{R}_{1}=\mathrm{C}_{2} \mathrm{H}_{4}, \mathrm{R}_{2}=\mathrm{Me}, \mathrm{R}_{3}=\mathrm{R}_{4}\right.$ $=\mathrm{H})$ and Nomura et al. $\left(\mathrm{R}_{1}=\mathrm{C}_{2} \mathrm{H}_{4}, \mathrm{C}_{3} \mathrm{H}_{6}\right.$ or $\left.\mathrm{CH}_{2} \mathrm{C}\left(\mathrm{CH}_{3}\right)_{2} \mathrm{CH}_{2}\right)$ The $P_{m}$ value given in parentheses is the highest value reported for these types of structures.

Similar findings were reported by Hormnirun et al. ${ }^{48}$ and $\mathrm{Du}$ et al. ${ }^{68,}{ }^{69}$ In general, catalyst activity is decreased upon using bulkier substituents on the ortho position $\left(\mathrm{R}_{4}\right)$, which is explained by hindering of the approach of monomer to the reactive center or a key transition state in the ROP.

Closely related types of catalyst/initiators are the Al-Salan complexes depicted in Figure 10. Hormnirun et al. reported a moderate isotactic enrichment $\left(P_{m}=0.68\right)$ for polymers prepared with an unsubstituted salan-type catalyst, whereas heterotactic enriched polymers were found upon using analogous catalysts with ortho-substituted phenolic rings $\left(P_{r}=0.80-0.88\right){ }^{70}$

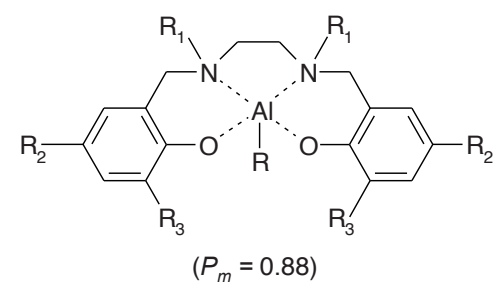

Figure 10. Salan-type complexes as used by $\mathrm{Du}$ et al. and Hormnirun et at. $\left(\mathrm{R}_{1}=\mathrm{R}_{2}=\mathrm{R}_{3}\right.$ $=\mathrm{Me} ; \mathrm{R}_{1}=\mathrm{Me}, \mathrm{R}_{2}=\mathrm{R}_{3}=\mathrm{Cl}$ ). The $P_{m}$ value given in parentheses is the highest value reported for these types of structures. 


\section{Chapter 2}

This effect was enhanced by increasing the size of the substituents on the $\mathrm{N}$ donor atoms from methyl to benzyl groups. Both higher levels of isotactic enrichment with the nonphenyl-substituted catalyst $\left(P_{m}=0.79\right)$ and heterotactic enrichment for catalyst having ortho-substituted phenyl rings $\left(P_{r}=0.83-0.96\right)$ were found. Increasing the ligand substituent size does not infinitely improve the catalysts' stereoselectivity. The complex with tert-butyl groups on both the ortho and para positions of the phenyl rings $\left(P_{r}=\right.$ $0.61)$ has a lower selectivity than the complex with methyl groups on those positions $\left(P_{r}\right.$ $=0.83)$.

The 'spacer effect', the length of the diimine bridge in these complexes, on the stereoselectivity was also described for a number of enolic Schiff base aluminum complexes (Figure 11A). ${ }^{71}$ The selectivity was relatively high in case of a disubstituted propylene spacer and was low when $\mathrm{R}_{1}$ was a 1,2-dimethylene benzene spacer. Decreased ligand flexibility in the latter case, and consequently a decreased steric hindrance upon monomer coordination, is given as a reason for the lower selectivity in this lactide polymerization by a chain-end controlled mechanism.

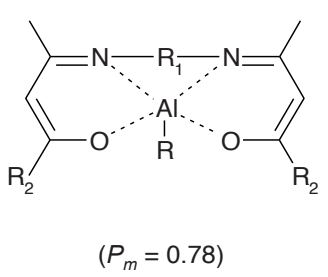

A

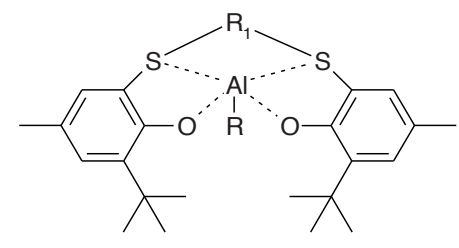

$\left(P_{m}=0.65\right)$

Figure 11. Gereral structure of salen-type aluminum complexes as used by Pang et al. (A) and aluminum sulfanediyl bis(phenolate) complexes as used by Ma et al. (B). The $P_{m}$ values given in parentheses are the highest values reported for these types of structures.

Ma et al. described the use of a number of aluminum sulfanediyl bis(phenolate) complexes in the ROP of rac-lactide (Figure 11B). ${ }^{72}$. Activities were moderate when $\mathrm{R}_{1}$ is an ethylene spacer, but resulting polymers showed no enrichment in stereoregular sequences. In contrast, when $\mathrm{R}_{1}$ was an ortho-xylylene spacer, polymers with moderate 
heterotactic enrichments $\left(P_{r}=0.65\right)$ were obtained, but activities were $\sim 10$ times lower. The weak coordination between the aluminum and sulfur causes rapid interconversion between conformations and no stereoselectivity is induced in this chain-end controlled polymerization when $R_{1}$ is an ethylene bridge. The bulky ligand environment in the xylylene analogue was presented as the main reason for the selectivity in this chain-end controlled polymerization.

Catalyst activities and stereoselectivities are also influenced by the electronegativity of the ligand substituents. Catalysts carrying electron-withdrawing groups such as chlorine ${ }^{48,73}$ and bromine, ${ }^{48}$ show enhanced activities, resulting from increased metal electrophilicities. Apparently, electronic effects may overpower the steric effects with respect to catalyst activity. However, when compared to the unsubstituted analogues, the halogen-bearing catalysts may give heterotactic instead of isotactic enrichment, ${ }^{71}$ with comparable $^{68}$ or lower levels ${ }^{48}$ or even the absence ${ }^{74,75}$ of stereoregularity in the resulting polymers.

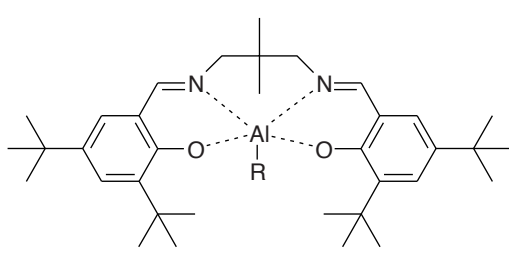

$\left(P_{m}=0.90\right)$

A

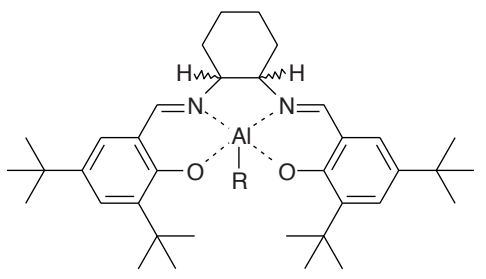

$\left(P_{m}=0.92\right)$

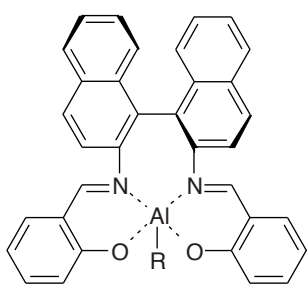

$\left(P_{m}=0.88\right)$

B

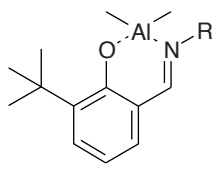

(no selectivity)

Figure 12. Aluminum Schiff base complexes with various salen-type ligands as used by Tang et al. (A),${ }^{77-79}$ Spassky et al. (B) ${ }^{80}$ Feijen et al. (C) ${ }^{81}$ and Iwasa et al. (D) ${ }^{76}$ 


\section{Multiple donor atoms}

A sufficiently strong interaction between ligand and metal species is required to preserve the structure of a single-site catalyst. Ligand chirality and/or chirality induced by the growing polylactide chain makes a stereoselective polymerization more likely to occur. Also the shielding of the metal in the complex appears to be important. As an example, the non-bridged, 'half-salen' ligand aluminum complexes as used by Iwasa et al. ${ }^{76}$ (Figure 12D) did not give any stereoselective polymerizations. In this catalyst the shielding of the monomer and ligating sites is not sufficient to give stereoselectivity in the insertion of a new monomer.

Table 1. Stereoselectivities (expressed by $P_{m}$ ) of various salen-type aluminum complexes in the ROP of $r a c$-lactide at $70{ }^{\circ} \mathrm{C}$ in toluene; selected examples. ${ }^{67}$

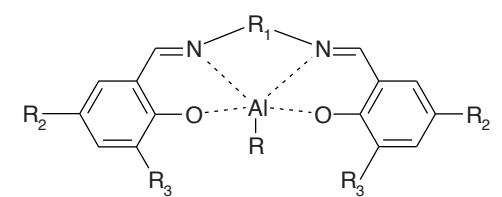

\begin{tabular}{|c|c|c|c|c|}
\hline Entry & $\mathbf{R}_{1}$ & $\mathbf{R}_{2}$ & $\mathbf{R}_{\mathbf{3}}$ & $\boldsymbol{P}_{m}$ \\
\hline 1 & & $t \mathrm{Bu}$ & $t \mathrm{Bu}$ & 0.92 \\
\hline 2 & & $\mathrm{Cl}$ & $t \mathrm{Bu}$ & 0.90 \\
\hline 3 & * & $\mathrm{H}$ & $\mathrm{SiMe}_{3}$ & 0.90 \\
\hline 4 & & $\mathrm{Ph}$ & $\mathrm{SiMe}_{3}$ & 0.92 \\
\hline 5 & & $t \mathrm{Bu}$ & $t \mathrm{Bu}$ & 0.93 \\
\hline 6 & & $\mathrm{H}$ & $\mathrm{SiMe}_{3}$ & 0.92 \\
\hline 7 & & $\mathrm{Ph}$ & $\mathrm{SiMe}_{3}$ & 0.92 \\
\hline 8 & & $\mathrm{H}$ & $\mathrm{SiEt}_{3}$ & 0.95 \\
\hline 9 & & $\mathrm{CF}_{3}$ & $\mathrm{SiEt}_{3}$ & 0.95 \\
\hline 10 & & $\mathrm{H}$ & $t \mathrm{BuMe}_{2} \mathrm{Si}$ & 0.97 \\
\hline
\end{tabular}

Symmetric tetradentate salen aluminum complexes on the other hand are highly efficient in stereoselective polymerization of lactides, and isotactic enrichments over $90 \%$ have 
been reported for various salen-type complexes (Figure $12^{77-81}$ and Table $1^{66,67}$ : selected examples), some of which have been proven to also give stereoselective polymerization in the melt. ${ }^{82}$ It appears that the better shielding of the metal ion by the ligand, ligand chirality and flexibility are most important. The flexibility of the ligand can be changed through the spacer connecting the two symmetric ligand halves. Shorter spacers (e.g. $\mathrm{C}_{2} \mathrm{H}_{4}$ ) generally led to lower $P_{m}$ values. ${ }^{48,66-68}$ Large substituents on the phenoxide rings appear to be necessary to limit conformational changes of the complex during polymerization. Although speculative, this structural feature may well be a reason for the high selectivities of the complexes listed in Table 1.

\section{Zinc catalyst/initiators}

Organozinc compounds and their derivatives have been explored as reagents and catalysts in numerous organometallic and organic reactions. Recently, zinc complexes have received attention as catalysts for the ring opening polymerization of lactide. Early examples of active zinc catalysts for enantioselective lactide ROP, such as $\beta$-diiminate complexes reported by Coates et al., utilize bulky, achiral ancillary ligands to obtain highly heterotactic PLA via a chain-end control mechanism. This strategy has been used successfully by a number of groups. ${ }^{39,51}$

Examples of highly selective catalysts that promote enantiomorphic site control of raclactide polymerization are limited to trivalent metals supported by chiral ligands. In the following section we will summarize the current literature on zinc catalyst/initiators investigated for the stereoselective polymerization of lactides. Complexes mentioned earlier in this chapter may be repeated and also some of the structures are presented again with others. Most catalyst structures are presented in Figure 14.

The multiple-donor atom strategy to exert control over stereoselective polymerization has been investigated for $\mathrm{Zn}$ complexes. Increasing the number of donor atoms within a ligand (creating tridentate and tetradentate structures) to the zinc has so far not resulted in catalysts that can compete in stereoselectivity with the salen-type aluminum complexes. Only the zinc $\beta$-diiminate catalysts as reported by Coates and coworkers have a high stereoselectivity, affording heterotactic polylactides from rac-lactide. ${ }^{46,52}$ A number of 
NNO-tridendate zinc complexes as described by Chen et al. showed stereoselective behavior. ${ }^{49}$ A high level of heterotacticity was obtained $\left(P_{r}=0.91\right)$ at low temperatures. Similarly the tridendate ketiminate complexes as described by Huang et al. give heterotactic polylactides with a $P_{r}$ value of $0.85 .{ }^{61}$

Dove et al. and Chisholm et al. investigated a potentially tridentate $\beta$-diiminate ligand ${ }^{60,83}$ in combination with magnesium and zinc, resulting in catalysts with higher activity, but less controlled and less stereoselective polymerizations than the previously mentioned $\beta$ diiminate complexes by Coates and coworkers. This was explained by the fact that the extra O-donor with respect to the symmetric diisopropyl analogue was dissociated from the metal center. Similar results were found with tetradentate ligands, ${ }^{60}$ whereas introducing $\mathrm{P}$ donor atoms led to uncontrolled and non-stereoselective polymerizations (Figure 14). ${ }^{43}$

Using phenolate-based ligands has up to now resulted in similar findings. Williams et al. reported on zinc phenolate complexes (Figure 14) (4, 85 that were highly efficient, but gave atactic polylactides. This was also found for the analogous complex with a cyclohexane diamine side group, as used by Labourdette et al. (Figure 14). ${ }^{86}$

Alonso-Moreno et al. ${ }^{87}$ investigated various heteroscorpionate ligands in combination with zinc and lithium (Figure 13). In combination with rac-lactide, a number of zinc catalysts $\left(\mathrm{M}=\mathrm{Zn}, \mathrm{R}_{1}=t \mathrm{Bu}, \mathrm{R}_{2}=\mathrm{Et}, \mathrm{R}_{3}=t \mathrm{Bu}, \mathrm{R}=\mathrm{Me}\right.$ or Et $)$ showed relatively low activities, and resulting polymers displayed a moderate heterotactic enrichment $\left(P_{r}=\right.$ $0.60)$.

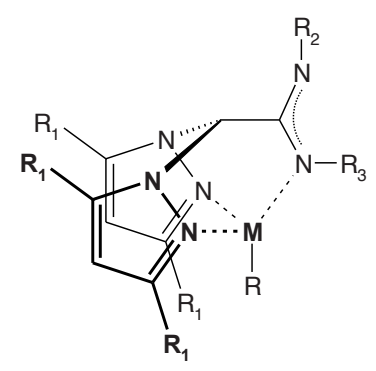

Figure 13. General formula of metal-heteroscorpionate complexes. ${ }^{87}$ 


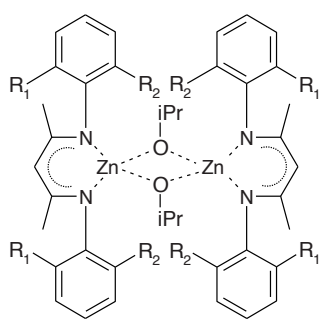

$\left(P_{r}=0.94\right)$

Chamberlain et al. ${ }^{46}$

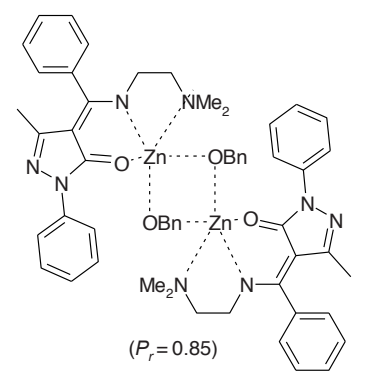

Huang et al. ${ }^{6}$

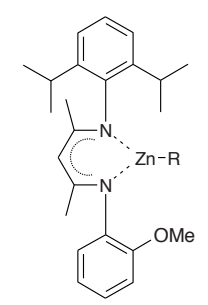

(no selectivity)

Dove et al. ${ }^{81}$

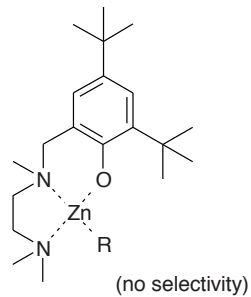

Williams et al. 82,83

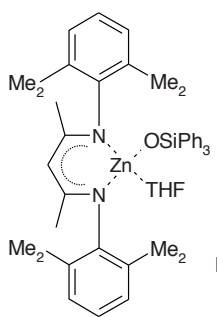

$\left(P_{r}=0.90\right)$

Chisholm et al. 52

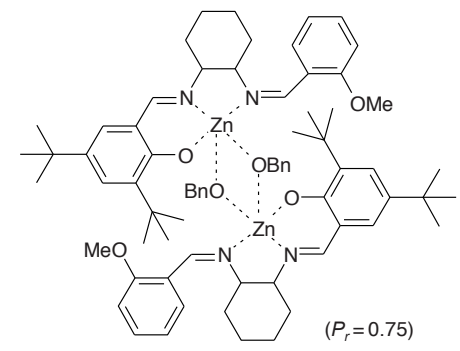

Wu et al. 50

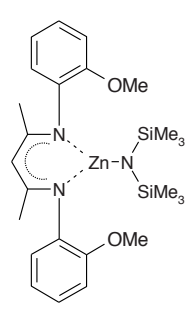

(no selectivity)

Chisholm et al. ${ }^{60}$

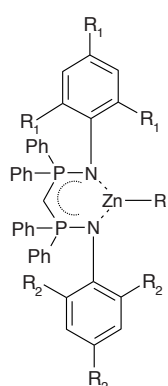

(no selectivity)

Hill et al. ${ }^{43}$

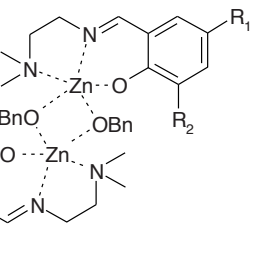

$\left(P_{r}=0.74\right)$

Chen et al. ${ }^{49}$
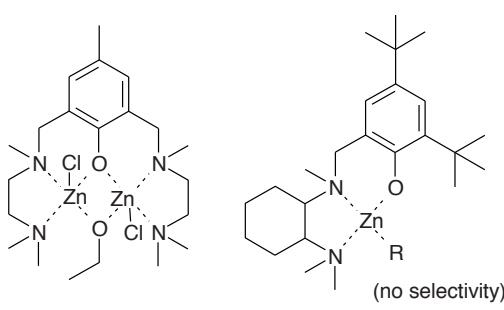

Labourdette et al. 84

Figure 14. Zinc complexes with various ligands, as used in the ROP of rac-lactide. The $P_{r}$ values given in parentheses are the highest values reported for these types of structures. 


\section{Chapter 2}

\section{Rare earth metals}

Although most studies have focused on the use of aluminum, stereoselective polymerizations have also been reported for other metal catalysts. Cai et al. reported on yttrium- and lanthane-based complexes with an alkoxy-amino-bis(phenolate) ligand, giving heterotactic enrichments $\left(\mathrm{M}=\mathrm{Y}: P_{r}=0.80 ; \mathrm{M}=\mathrm{La}: P_{r}=0.64\right)($ Figure $15 \mathrm{~A}){ }^{88}$<smiles>[R]Oc1ccc(C(C)(C)C)cc1CN(Cc1cc(C(C)(C)C)cc(C(C)(C)C)c1O)Cc1cc(C(C)(C)C)cc(C(C)(C)C)c1OC</smiles>

A

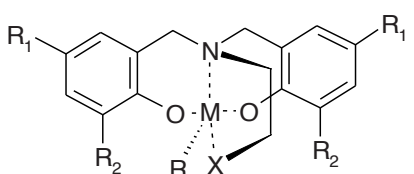

B

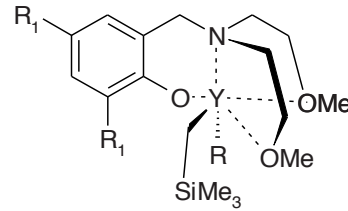

C

Figure 15. Group 3 metal complexes with alkoxy-amino-bis(phenolate) tetradentate (A, B) or NOOO-tetradentate ligands $(\mathbf{C})$.

Most interestingly, whereas most ROPs with single-site catalysts proceed according to the coordination-insertion mechanism, hence require an initiating metal alkoxide (or amine), the yttrium catalyst/alkyl complex initiated lactide polymerization in absence of such an alkoxide. A large series of comparable amino-bis(phenolato) Group 3 metal complexes $(\mathrm{M}=\mathrm{Y}, \mathrm{Nd}, \mathrm{La})$ was studied by the group of Carpentier, affording mainly heterotactic enriched PLA's upon ROP of rac-lactide. Best results were obtained with the bulky ligand as presented in Figure $15 \mathrm{~B}\left(P_{r}=0.90\right) .{ }^{89,} 90$ The use of yttrium NOOOtetradentate complexes (Figure $15 \mathrm{C}$ ) by Miao et al. gave isotactic enriched polymers. ${ }^{91}$ In contrast, combining this type of ligands with aluminum, only moderate levels of enrichment were obtained (Figure 15B: $\mathrm{M}=\mathrm{Al} ; \mathrm{R}_{1}=\mathrm{Me}: P_{m}=0.73 ; \mathrm{R}_{1}=i \operatorname{Pr}, P_{m}=0.65$; $\left.\mathrm{R}_{1}=t \mathrm{Bu}: P_{r}=0.57\right)^{74,75}$ 
Ma et al. investigated a series of rare earth metal sulfanediyl bis(phenolato) complexes for the ROP of rac-lactide (Figure 16: M $=\mathrm{Sc}, \mathrm{Y}, \mathrm{Lu}$ ). ${ }^{92,93}$ For all catalysts, moderate to high levels of heterotactic enrichment were obtained (0.67-0.96), but some polymers had rather broad molecular weight distributions. Best results with respect to stereoselectivity were obtained with the catalyst/initiator complex depicted in Figure $16\left(P_{r}=0.96\right)$.

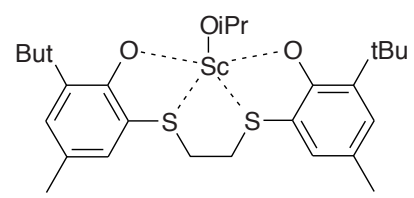

Figure 16. A sulfanediyl bis(phenolato) scandium complex as used by Ma et al. ${ }^{92}$

Chmura et al. reported on extremely active, well-controlled, single-site zirconium and hafnium amine tris(phenolate) alkoxides, which under solvent-free conditions (at $130{ }^{\circ} \mathrm{C}$ ) gave highly heterotactic PLA's upon the ROP of rac-lactide $\left(P_{r}=0.96\right) .{ }^{94-96}$ Wang et al. reported on the use of two NNO-binuclear (NOBIN) ligands (Figure 17) $)^{97}$ in combination with yttrium and samarium for the ROP of rac-lactide, resulting in polymers with isotactic enrichtments.<smiles>Oc1ccc2ccccc2c1-c1c(NCc2ccccn2)ccc2ccccc12</smiles><smiles>Oc1ccc2ccccc2c1-c1c(NCc2ccc[nH]2)ccc2ccccc12</smiles>

Figure 17. NOBIN-type ligands. ${ }^{97}$ 


\section{Stereoselective ROP of chiral lactones}

In order to invoke stereoselective polymerization, a lactone monomer has to possess at least one chiral center in its ring. Various substituted, chiral $\beta$-propiolactones ( $\beta$-PL), $\gamma$ butyrolactones $\left(\gamma\right.$-BL), $\delta$-valerolactones $(\delta \text {-VL) })^{62,98-104}$ and $\varepsilon$-caprolactones $(\varepsilon-\mathrm{CL}),{ }^{105}$ as well as higher-membered lactones ${ }^{106}$ and glycolide-like cyclic diesters ${ }^{107-109}$ have been described in literature (Figure 18: selected examples). Whereas numerous publications have appeared on the stereoselective ROP of rac-and meso-lactide, relatively few are dedicated to chiral lactones. ${ }^{110}$
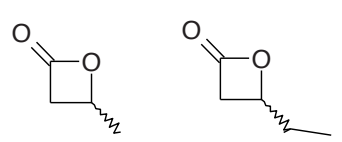

rac- $\beta-B L$<smiles>CC(C)(C)[C@H]1CCCCOC1=O</smiles>

rac- $\beta-\mathrm{VL}$<smiles>CC(=O)O[C@H]1CCOC(=O)CC1</smiles>

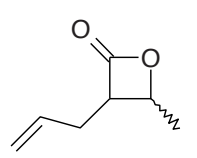

allyl-rac- $\beta-B L$<smiles>O=C1CC[C](Cl)CCO1</smiles>

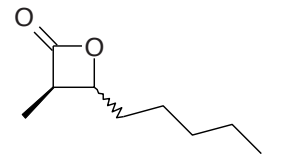

2-methyl-3-pentyl-rac- $\beta$-PL<smiles>C[C@H]1CCOC(=O)CC1</smiles>

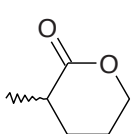

rac-2-Me- $\delta-\mathrm{VL}$

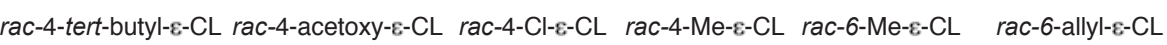

Figure 18. Various substituted lactones.

To the best of our knowledge, stereoselective polymerizations by chemical catalysis up to know have only been reported for substituted $\beta$-PLs and $\beta$-BLs. Carpentier and coworkers reported on the controlled, stereoselective ROP of rac- $\beta$-butyrolactone (rac$\mathrm{BL})^{111,112}$ and $\mathrm{rac}$-allyl- $\beta-\mathrm{BL}^{113}$ by a tetradentate aminoalkoxybis(phenolate) yttrium complex (Figure 19A), ${ }^{112}$ which has previously been reported as stereoselective in the ROP of rac-lactide $\left(P_{r}=0.80\right) .{ }^{88}$ Poly $(\beta$-hydroxybutyrate)s with high levels of syndiotactic enrichment $\left(P_{r}\right.$ up to 0.94$)$ were obtained, whereas in the copolymerization with $r a c$-allyl- $\beta$-BL, syndiotactic enrichments were lower $\left(P_{r}=0.80-0.84\right)$. The systems' stereoselectivity is believed to originate from chain-end control. Likewise, the use of lanthanide guanidines (Figure 19B: $\mathrm{M}=\mathrm{Y}, \mathrm{Nd}, \mathrm{Sm}, \mathrm{Lu})^{114}$ gave polymers with syndiotactic enrichment. Interestingly, the same complexes did not show stereoselective 
behavior when used in the ROP of rac-lactide. Syndiotactic enrichments in poly( $\beta$ hydroxybutyrate) $\left(P_{r}\right.$ up to 0.79$)$ were also obtained with several tin alkoxides, ${ }^{115-119}$ such as 2,2-dibutyl-1,3,2-dioxastannolane (Figure 19C) ) $^{120}$ as well as 18-crown-6 complexes of a potassium alkoxide ${ }^{121}$ and $\mathrm{Al}(\mathrm{O} i \mathrm{Pr})_{3} .{ }^{122}$ Zintl et al. used chromium (III) salophen complexes (Figure 19D: $\mathrm{X}=\mathrm{H}, \mathrm{Cl}, \mathrm{Br}$ or $\mathrm{F}$ ) for the ROP of rac- $\beta$-BL, giving isotactically enriched poly $\left(\beta\right.$-butyrolactone $\left(P_{m}=0.6-0.7\right) .{ }^{123}$ Isotactic enrichment had previously been reported upon using tetrabutylammonium salts of carboxylic acids ${ }^{124}$ as well as aluminoxanes. ${ }^{125-127}$ Kramer and Coates investigated the ROP of fluorinated $\beta$ PLs using a $\beta$-diiminate zinc complex (Figure 19E: $\mathrm{R}_{1}=i \operatorname{Pr}, \mathrm{R}_{2}=\mathrm{H}$ ). ${ }^{99}$ Although no comments on stereoselectivity were made, the steric constraint of the catalyst was notable in copolymerization of the fluorinated $\beta$-PLs and $\beta$-BL, as tapered block-co-polymers rather than the expected random copolymers were obtained. ${ }^{99}$

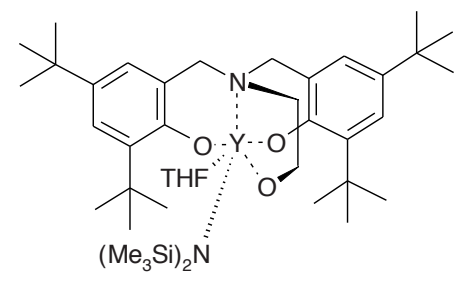

A

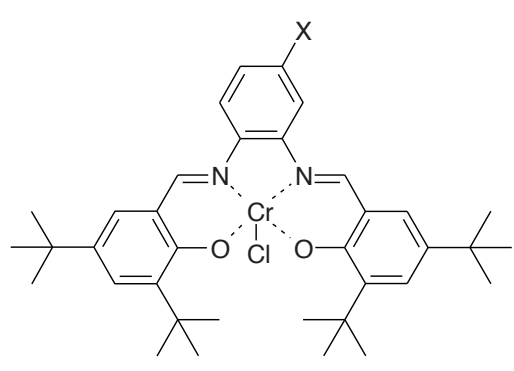

D<smiles>CN(C)C(=NC(=N[Si](C)(C)C)[Si](C)(C)C)N(C)C</smiles>
$=\mathrm{L}$ in $\mathrm{L}_{2} \mathrm{MOR}$<smiles>[R]C1=C(C)N(c2c([R])cccc2[R])[Z20](OC(C)C)N(c2c([R])cccc2[R])C1=C</smiles>

E<smiles>OCCO[Sn][Sn](Br)(Br)Br</smiles>

C<smiles>CC[Z20]1(CC)[C@H]2Oc3c(cc(C(C)(C)C)cc3C(C)(C)C)C[N+]2(C)CCN1C</smiles>

F

Figure 19. Catalysts used in the ROP of substituted $\beta$-butyrolactone as used by Cai et al. and Carpentier and coworkers (A, B), Wei et al. (C), Zintl et al. (D), Hillmyer and coworkers and Coates and coworkers $(\mathbf{E})$. 
Many enzymes are highly stereoselective and active catalysts. Hence, various enzymes (in particular lipases) have been explored for the ROP of lactides and lactones. ${ }^{128-130}$ Lipase Candida antarctica $B$ is known to polymerize various lactones, and stereoselective behavior has been reported for the ROP of methyl substituted $\varepsilon$-CL monomers $^{131-133}$ and $4-E t-\varepsilon-C L{ }^{133}$ In all polymerizations, a preference for the ringopening of the $S$-enantiomer was observed, except for 5-Me- $\varepsilon$-CL. In the latter case, the $R$-enantiomer is preferably ring-opened, which has also been reported for 4-Pr- $\varepsilon-\mathrm{CL}$ (though selectivity is rather low) ${ }^{134}$ and higher ring-size $(\geq 8)$ lactones. For the larger rings, this is explained by the transoid conformational preference of the ester bond in larger rings. ${ }^{135}$ The lipase Pseudomonas fluorescens has been reported to preferably ringopen the $S$-enantiomer in the ROP of 3-methyl- $\beta$-propiolactone, ${ }^{136}$ giving optically active polymers. Lipases have been applied for the ROP of fluorinated macrolides (ring-sizes 10-12 and 14), which led to optically active polymers. ${ }^{137}$ Lactides can be ring-opened by lipase Candida antarctica B, but despite fast 'initiation', polymer propagation fails, which is explained by the fact that the lactate secondary alcohol cannot be accommodated in the 'stereospecific pocket' of the enzyme. ${ }^{138,139}$

Though many chemical catalysts have proven to stereoselectively ring-open the lactide ring, relatively few reports have been published on the ROP of chiral lactones, applying the same catalysts. It would therefore be interesting to investigate whether the observed stereoselectivity in lactide polymerization is also observed upon polymerizing substituted, chiral lactones.

\section{Perspectives}

Poly(caprolactone) (PCL), poly(lactic acid) (PLA) and related polyesters are of significant importance in various (bio)medical fields. The controlled polymerizations of these monomers allow the preparation of advanced structures and thereby adjust the polymer properties. Recent developments on the stereoselective polymerization of lactides have shown that new properties can be added. In this respect, biocompatible catalysts systems are of interest because removal of the catalyst after polymerization is generally not performed. As the mechanism for most catalyst systems in stereoselective 
polymerization is still relatively poorly understood, more fundamental research is needed. The design of new catalysts, their structure elucidation in the solid state and in solution will help to understand the mechanism involved in stereoselective polymerization.

\section{References}

1. M. Martina and D. W. Hutmacher, Biodegradable polymers applied in tissue engineering research: a review. Polym. Int., 2007, 56(2), 145-157.

2. H. Y. Cheung, K. T. Lau, T. P. Lu and D. Hui, A critical review on polymerbased bio-engineered materials for scaffold development. Compos. Part B: Eng., 2007, 38(3), 291-300.

3. Z. W. Ma, C. Y. Gao, Y. H. Gong, J. Ji and J. C. Shen, Immobilization of natural macromolecules on poly-L-lactic acid membrane surface in order to improve its cytocompatibility. J. Biomed. Mater. Res., 2002, 63(6), 838-847.

4. H. Shin, S. Jo an d A. G. Mikos, Biomimetic materials for tissue engineering. Biomaterials, 2003, 24(24), 4353-4364.

5. U. Hersel, C. Dahmen and H. Kessler, RGD modified polymers: biomaterials for stimulated cell adhesion and beyond. Biomaterials, 2003, 24(24), 4385-4415.

6. Y. Ikada and H. Tsuji, Biodegradable polyesters for medical and ecological applications. Macromol. Rapid Commun., 2000, 21(3), 117-132.

7. A. C. Albertsson and I. K. Varma, Aliphatic polyesters: Synthesis, properties and applications. Adv. Polym. Sci., 2002, 157(-), 1-40.

8. D. Garlotta, A literature review of poly(lactic acid). J. Polym. Environ., 2001, 9(2), 63-84.

9. O. Dechy-Cabaret, B. Martin-Vaca and D. Bourissou, Controlled ring-opening polymerization of lactide and glycolide. Chem. Rev., 2004, 104(12), 6147-6176.

10. A. P. Gupta and V. Kumar, New emerging trends in synthetic biodegradable polymers - Polylactide: A critique. Eur. Polym. J., 2007, 43(10), 4053-4074.

11. E. S. Place, J. H. George, C. K. Williams and M. M. Stevens, Synthetic polymer scaffolds for tissue engineering. Chem. Soc. Rev., 2009, 38(4), 1139 - 1151.

12. D. Goldberg, A review of the biodegradability and utility of poly(caprolactone). $J$. Polym. Environ., 1995, 3(2), 61-67.

13. C. Jérôme and P. Lecomte, Recent advances in the synthesis of aliphatic polyesters by ring-opening polymerization. Adv. Drug Delivery Rev., 2008, 60(9), 1056-1076.

14. O. Dechy-Cabaret, B. Martin-Vaca and D. Bourissou in Handbook of RingOpening Polymerization; P. Dubois, O. Coulembier and J.-M. Raquez; WileyVCH Verlag GmbH \& Co. KGaA, Weinheim, 2009, 255-286.

15. A. Kowalski, J. Libiszowski, T. Biela, M. Cypryk, A. Duda and S. Penczek, Kinetics and mechanism of cyclic esters polymerization initiated with tin(II) octoate. Polymerization of epsilon-caprolactone and L,L-lactide co-initiated with primary amines. Macromolecules, 2005, 38(20), 8170-8176.

16. M. Sobczak, E. Oledzka and W. L. Kolodziejski, NOTE: Polymerization of cyclic esters using aminoacid initiators. J. Macromol. Sci. Pure Appl. Chem., 2008, 45(10), 872-877. 
17. A. C. Albertsson and I. K. Varma, Recent developments in ring opening polymerization of lactones for biomedical applications. Biomacromolecules, 2003, 4(6), 1466-1486.

18. R. H. Platel, L. M. Hodgson and C. K. Williams, Biocompatible Initiators for Lactide Polymerization. Polymer Reviews, 2008, 48(1), 11-63.

19. M. J. Stanford and A. P. Dove, Stereocontrolled ring-opening polymerisation of lactide. Chem. Soc. Rev., 2010, 39(2), 486-494.

20. N. E. Kamber, W. Jeong and R. M. Waymouth, Organocatalytic Ring-Opening Polymerization. Chem. Rev., 2007, 107(12), 5813-5840.

21. B. J. O'Keefe, M. A. Hillmyer and W. B. Tolman, Polymerization of lactide and related cyclic esters by discrete metal complexes. J. Chem. Soc.-Dalton Trans., 2001, 2001(15), 2215 - 2224.

22. G. W. Coates, Polymerization catalysis at the millennium: frontiers in stereoselective, metal-catalyzed polymerization. J. Chem. Soc., Dalton Trans., 2002, 2002(4), 467 - 475.

23. M. H. Chisholm and Z. Zhou, New generation polymers: the role of metal alkoxides as catalysts in the production of polyoxygenates. J. Mater. Chem., 2004, 14(21), 3081-3092.

24. J. C. Wu, T. L. Yu, C. T. Chen and C. C. Lin, Recent developments in main group metal complexes catalyzed/initiated polymerization of lactides and related cyclic esters. Coord. Chem. Rev., 2006, 250(5-6), 602-626.

25. C. A. Wheaton, P. G. Hayes and B. J. Ireland, Complexes of $\mathrm{Mg}, \mathrm{Ca}$ and $\mathrm{Zn}$ as homogeneous catalysts for lactide polymerization. Dalton Trans., 2009, 2009(25), 4832-4846.

26. F. Nederberg, E. F. Connor, M. Moller, T. Glauser and J. L. Hedrick, New paradigms for organic catalysts: The first organocatalytic living polymerization. Angew. Chem.-Int. Edit., 2001, 40(14), 2712-2715.

27. T. Satoh, M. Tamaki, Y. Kitajyo, T. Maeda, H. Ishihara, T. Imai, H. Kaga and T. Kakuchi, Synthesis of unimolecular reversed micelle consisting of a poly(Llactide) shell and hyperbranched D-mannan core. J. Polym. Sci., Part A: Polym. Chem., 2006, 44(1), 406-413.

28. B. C. Wilson and C. W. Jones, A Recoverable, Metal-Free Catalyst for the Green Polymerization of $\varepsilon$-Caprolactone. Macromolecules, 2004, 37(26), 9709-9714.

29. D. Bourissou, B. Martin-Vaca, A. Dumitrescu, M. Graullier and F. Lacombe, Controlled Cationic Polymerization of Lactide. Macromolecules, 2005, 38(24), 3599-3608.

30. M. S. Kim, K. S. Seo, G. Khang and H. B. Lee, Ring-Opening Polymerization of $\varepsilon$-Caprolactone by Poly(ethylene glycol) by an Activated Monomer Mechanism. Macromol. Rapid Commun., 2005, 26(8), 643 - 648.

31. E. F. Connor, G. W. Nyce, M. Myers, A. Möck and J. L. Hedrick, First Example of N-Heterocyclic Carbenes as Catalysts for Living Polymerization: Organocatalytic Ring-Opening Polymerization of Cyclic Esters. J. Am. Chem. Soc., 2002, 124(6), 914-915.

32. T. R. Jensen, L. E. Breyfogle, M. A. Hillmyer and W. B. Tolman, Stereoselective polymerization of D,L-lactide using N-heterocyclic carbene based compounds. Chem. Commun., 2004, 21), 2504-2505. 
33. N. Marion, S. Díez-González and S. P. Nolan, N-Heterocyclic Carbenes as Organocatalysts. Angew. Chem. Int. Ed., 2007, 46(17), 2988 - 3000.

34. B. G. G. Lohmeijer, R. C. Pratt, F. Leibfarth, J. W. Logan, D. A. Long, A. P. Dove, F. Nederberg, J. Choi, C. G. Wade, R. M. Waymouth and J. L. Hedrick, Guanidine and Amidine Organocatalysts for Ring-Opening Polymerization of Cyclic Esters. Macromolecules, 2006, 39(25), 8574-8583.

35. A. Chuma, H. W. Horn, W. C. Swope, R. C. Pratt, L. Zhang, B. G. G. Lohmeijer, C. G. Wade, R. M. Waymouth, J. L. Hedrick and J. E. Rice, The Reaction Mechanism for the Organocatalytic Ring-Opening Polymerization of 1-Lactide Using a Guanidine-Based Catalyst: Hydrogen-Bonded or Covalently Bound? JACS, 2008, 130(21), 6749-6754.

36. L. Zhang, F. Nederberg, R. C. Pratt, R. M. Waymouth, J. L. Hedrick and C. G. Wade, Phosphazene Bases: A New Category of Organocatalysts for the Living Ring-Opening Polymerization of Cyclic Esters. Macromolecules, 2007, 40(12), 4154-4158.

37. A. Bhaw-Luximon, D. Jhurry, N. Spassky, S. Pensec and J. Belleney, Anionic polymerization of D,L-lactide initiated by lithium diisopropylamide. Polymer, 2001, 42(24), 9651-9656.

38. A. Duda and S. Penczek, Polymerization of Epsilon-Caprolactone Initiated By Aluminum Isopropoxide Trimer and/or Tetramer. Macromolecules, 1995, 28(18), 5981-5992.

39. M. H. Chisholm, C. C. Lin, J. C. Gallucci and B. T. Ko, Binolate complexes of lithium, zinc, aluminium, and titanium; preparations, structures, and studies of lactide polymerization. Dalton Trans., 2003, 2003(3), 406 - 412.

40. W. M. Stevels, M. J. K. Ankoné, P. J. Dijkstra and J. Feijen, Kinetics and Mechanism of L-Lactide Polymerization Using Two Different Yttrium Alkoxide as Initiators. Macromolecules, 1996, 29(19), 6132-6138.

41. R. F. Storey and J. W. Sherman, Kinetics and mechanism of the stannous octoatecatalyzed bulk polymerization of epsilon-caprolactone. Macromolecules, 2002, 35(5), 1504-1512.

42. M. H. Chisholm, D. Navarro-Llobet and W. J. Simonsick, A comparative study in the ring-opening polymerization of lactides and propylene oxide. Macromolecules, 2001, 34(26), 8851-8857.

43. M. S. Hill and P. B. Hitchcock, Synthesis of C-2 and C-s symmetric zinc complexes supported by bis(phosphinimino)methyl ligands and their use in ring opening polymerisation catalysis. J. Chem. Soc.-Dalton Trans., 2002, 24), 46944702 .

44. N. Spassky in Ring-Opening Polymerization; Rapra Technologies Ltd., Shropshire, 1995.

45. T. M. Ovitt and G. W. Coates, Stereoselective ring-opening polymerization of rac-lactide with a single-site, racemic aluminum alkoxide catalyst: Synthesis of stereoblock poly(lactic acid). J. Polym. Sci., Part A: Polym. Chem., 2000, 38(S1), 4686 - 4692.

46. B. M. Chamberlain, M. Cheng, D. R. Moore, T. M. Ovitt, E. B. Lobkovsky and G. W. Coates, Polymerization of lactide with zinc and magnesium beta-diiminate 
complexes: Stereocontrol and mechanism. J. Am. Chem. Soc., 2001, 123(14), 3229-3238.

47. J. Coudane, C. Ustariz-Peyret, G. Schwach and M. Vert, More about the stereodependence of DD and LL pair linkages during the ring-opening polymerization of racemic lactide. J. Polym. Sci., Part A: Polym. Chem., 1997, 35(9), 1651-1658.

48. P. Hormnirun, E. L. Marshall, V. C. Gibson, R. I. Pugh and A. J. P. White, Study of ligand substituent effects on the rate and stereoselectivity of lactide polymerization using aluminum salen-type initiators. Proc. Natl. Acad. Sci. U. S. A., 2006, 103(42), 15343-15348.

49. H. Y. Chen, H. Y. Tang and C. C. Lin, Ring-opening polymerization of lactides initiated by zinc alkoxides derived from NNO-tridentate ligands. Macromolecules, 2006, 39(11), 3745-3752.

50. J. C. Wu, B. H. Huang, M. L. Hsueh, S. L. Lai and C. C. Lin, Ring-opening polymerization of lactide initiated by magnesium and zinc alkoxides. Polymer, 2005, 46(23), 9784-9792.

51. J. Wu, X. Pan, N. Tang and C. C. Lin, Synthesis, characterization of aluminum complexes and the application in ring-opening polymerization of 1-lactide. Eur. Polym. J., 2007, 43(12), 5040-5046.

52. M. H. Chisholm, J. Gallucci and K. Phomphrai, Coordination chemistry and reactivity of monomeric alkoxides and amides of magnesium and zinc supported by the diiminato ligand $\mathrm{CH}\left(\mathrm{CMeNC}_{6} \mathrm{H}_{3}-2,6-{ }^{\mathrm{i}} \mathrm{Pr}_{2}\right)_{2}$. A comparative study. Inorg. Chem., 2002, 41(10), 2785-2794.

53. A. P. Dove, V. C. Gibson, E. L. Marshall, A. J. P. White and D. J. Williams, A well defined tin(II) initiator for the living polymerisation of lactide. Chem. Commun., 2001, 03), 283.

54. M. H. Chisholm, J. Gallucci and K. Phomphrai, Lactide polymerization by welldefined calcium coordination complexes: comparisons with related magnesium and zinc chemistry. Chem. Commun., 2003, 2003(1), 48-49.

55. M. H. Chisholm, J. C. Huffman and K. Phomphrai, Monomeric metal alkoxides and trialkyl siloxides: (BDI) $\mathrm{Mg}((\mathrm{OBu})-\mathrm{Bu}-\mathrm{t})(\mathrm{THF})$ and $(\mathrm{BDI}) \mathrm{Zn}\left(\mathrm{OSiPh}_{3}\right)(\mathrm{THF})$. Comments on single site catalysts for ring-opening polymerization of lactides. $J$. Chem. Soc., Dalton Trans., 2001, 2001(3), 222-224.

56. T. R. Jensen, C. P. Schaller, M. A. Hillmyer and W. B. Tolman, Zinc Nheterocyclic carbene complexes and their polymerization of D,L-lactide. $J$. Organomet. Chem., 2005, 690(24-25), 5881-5891.

57. A. P. Dove, H. B. Li, R. C. Pratt, B. G. G. Lohmeijer, D. A. Culkin, R. M. Waymouth and J. L. Hedrick, Stereoselective polymerization of rac- and mesolactide catalyzed by sterically encumbered N-heterocyclic carbenes. Chem. Commun., 2006, 2006(27), 2881-2883.

58. M. Cheng, A. B. Attygalle, E. B. Lobkovsky and G. W. Coates, Single-site catalysts for ring-opening polymerization: Synthesis of heterotactic poly(lactic acid) from rac-lactide. J. Am. Chem. Soc., 1999, 121(49), 11583-11584.

59. M. H. Chisholm and K. Phomphrai, Conformational effects in beta-diiminate ligated magnesium and zinc amides. Solution dynamics and lactide polymerization. Inorg. Chim. Acta, 2003, 350(-), 121-125. 
60. M. H. Chisholm, J. C. Gallucci and K. Phomphrai, Comparative study of the coordination chemistry and lactide polymerization of alkoxide and amide complexes of zinc and magnesium with a 6-diiminato ligand bearing ether substituents. Inorg. Chem., 2005, 44(22), 8004-8010.

61. Y. Huang, W. C. Hung, M. Y. Liao, T. E. Tsai, Y. L. Peng and C. C. Lin, Ringopening polymerization of lactides initiated by magnesium and zinc complexes based on NNO-tridentate ketiminate ligands: Activity and stereoselectivity studies. J. Polym. Sci., Part A: Polym. Chem., 2009, 47(9), 2318-2329.

62. L. R. Rieth, D. R. Moore, E. B. Lobkovsky and G. W. Coates, Single-site $\beta$ diiminate zinc catalysts for the ring-opening polymerization of $\beta$-butyrolactone and $\beta$-valerolactone to poly(3-hydroxyalkanoates). J. Am. Chem. Soc., 2002, 124(51), 15239-15248.

63. M. H. Chisholm, J. C. Gallucci, H. H. Zhen and J. C. Huffman, Three-coordinate zinc amide and phenoxide complexes supported by a bulky Schiff base ligand. Inorg. Chem., 2001, 40(19), 5051-5054.

64. A. Le Borgne, M. Wisniewski and N. Spassky, Towards The Controlled Synthesis Of Polylactide With New Organoaluminum Initiators. Abstr. Pap. Am. Chem. Soc., 1995, 210(-), 217-218.

65. A. Bhaw-Luximon, D. Jhurry and N. Spassky, Controlled polymerization of DLlactide using a Schiff's base al-alkoxide initiator derived from 2hydroxyacetophenone. Polym. Bull., 2000, 44(1), 31-38.

66. N. Nomura, R. Ishii, M. Akakura and K. Aoi, Stereoselective ring-opening polymerization of racemic lactide using aluminum-achiral ligand complexes: Exploration of a chain-end control mechanism. J. Am. Chem. Soc., 2002, 124(21), 5938-5939.

67. N. Nomura, R. Ishii, Y. Yamamoto and T. Kondo, Stereoselective ring-opening polymerization of a racemic lactide by using achiral salen- and homosalenaluminum complexes. Chem.-Eur. J., 2007, 13(16), 4433-4451.

68. H. Z. Du, X. Pang, H. Y. Yu, X. L. Zhuang, X. S. Chen, D. M. Cui, X. H. Wang and X. B. Jing, Polymerization of rac-lactide using schiff base aluminum catalysts: Structure, activity, and stereoselectivity. Macromolecules, 2007, 40(6), 1904-1913.

69. H. Z. Du, A. H. Velders, P. J. Dijkstra, J. R. Sun, Z. Y. Zhong, X. S. Chen and J. Feijen, Chiral Salan Aluminium Ethyl Complexes and Their Application in Lactide Polymerization. Chem. Eur. J., 2009, 15(38), 9836-9845.

70. P. Hormnirun, E. L. Marshall, V. C. Gibson, A. J. P. White and D. J. Williams, Remarkable stereocontrol in the polymerization of racemic lactide using aluminum initiators supported by tetradentate aminophenoxide ligands. J. Am. Chem. Soc., 2004, 126(9), 2688-2689.

71. X. Pang, D. Du, X. Chen, X. Wang and X. Jing, Enolic Schiff Base Aluminum Complexes and Their Catalytic Stereoselective Polymerization of Racemic Lactide. Chem. Eur. J., 2008, 14(10), 3126-3136.

72. H. Y. Ma, G. Melillo, L. Oliva, T. P. Spaniol, U. Englert and J. Okuda, Aluminium alkyl complexes supported by [OSSO] type bisphenolato ligands: synthesis, characterization and living polymerization of rac-lactide. Dalton Trans., 2005, 2005(4), 721-727. 
73. P. A. Cameron, D. Jhurry, V. C. Gibson, A. J. P. White, D. J. Williams and S. Williams, Controlled polymerization of lactides at ambient temperature using [5Cl-salen]AlOMe. Macromol. Rapid Commun., 1999, 20(12), 616-618.

74. Z. H. Tang and V. C. Gibson, rac-Lactide polymerization using aluminum complexes bearing tetradentate phenoxy-amine ligands. Eur. Polym. J., 2007, 43(1), 150-155.

75. Z. Tang and V. C. Gibson, rac-Lactide polymerization using aluminum complexes bearing tetradentate phenoxy-amine ligands. Eur. Polym. J., 2007, 43(1), 150-155.

76. N. Iwasa, M. Fujiki and K. Nomura, Ring-opening polymerization of various cyclic esters by Al complex catalysts containing a series of phenoxy-imine ligands: Effect of the imino substituents for the catalytic activity. J. Mol. Catal. A: Chem., 2008, 292(1-2), 67-75.

77. Z. H. Tang, X. S. Chen, X. Pang, Y. K. Yang, X. F. Zhang and X. B. Jing, Stereoselective polymerization of rac-lactide using a monoethylaluminum Schiff base complex. Biomacromolecules, 2004, 5(3), 965-970.

78. Z. H. Tang, X. S. Chen, Y. K. Yang, X. Pang, J. R. Sun, X. F. Zhang and X. B. Jing, Stereoselective polymerization of rac-lactide with a bulky aluminum/Schiff base complex. J. Polym. Sci., Part A: Polym. Chem., 2004, 42(23), 5974-5982.

79. Z. H. Tang, X. Pang, J. R. Sun, H. Z. Du and X. S. Chen, Five-coordinated active species in the stereoselective polymerization of rac-lactide using N,N '-(2,2dimethyl-1,3-propylene)bis(3,5-di-tert-butyl-salicylideneimine) aluminum complexes. J. Polym. Sci., Part A: Polym. Chem., 2006, 44(16), 4932-4938.

80. N. Spassky, M. Wisniewski, C. Pluta and A. LeBorgne, Highly stereoelective polymerization of rac-(D,L)-lactide with a chiral Schiff's base/aluminium alkoxide initiator. Macromol. Chem. Phys., 1996, 197(9), 2627-2637.

81. Z. Y. Zhong, P. J. Dijkstra and J. Feijen, Controlled and stereoselective polymerization of lactide: Kinetics, selectivity, and microstructures. J. Am. Chem. Soc., 2003, 125(37), 11291-11298.

82. Z. Y. Zhong, P. J. Dijkstra and J. Feijen, [(salen)Al]-mediated, controlled and stereoselective ring- opening polymerization of lactide in solution and without solvent: Synthesis of highly isotactic polylactide stereocopolymers from racemic D,L-lactide. Angew. Chem.-Int. Edit., 2002, 41(23), 4510-4513.

83. A. P. Dove, V. C. Gibson, E. L. Marshall, A. J. P. White and D. J. Williams, Magnesium and zinc complexes of a potentially tridentate beta-diketiminate ligand. Dalton Trans., 2004, 2004(4), 570 - 578.

84. C. K. Williams, L. E. Breyfogle, S. K. Choi, W. Nam, V. G. Young, M. A. Hillmyer and W. B. Tolman, A highly active zinc catalyst for the controlled polymerization of lactide. J. Am. Chem. Soc., 2003, 125(37), 11350-11359.

85. C. K. Williams, N. R. Brooks, M. A. Hillmyer and W. B. Tolman, Metalloenzyme inspired dizinc catalyst for the polymerization of lactide. Chem. Commun., 2002, 18), 2132.

86. G. Labourdette, D. J. Lee, B. O. Patrick, M. B. Ezhova and P. Mehrkhodavandi, Unusually Stable Chiral Ethyl Zinc Complexes: Reactivity and Polymerization of Lactide. Organometallics, 2009, 28(5), 1309-1319. 
87. C. Alonso-Moreno, A. Garcés, L. F. Sánchez-Barba, M. Fajardo, J. FernándezBaeza, A. Otero, A. Lara-Sánchez, A. Antiñolo, L. Broomfield, M. L. LópezSolera and A. M. Rodríguez, Discrete Heteroscorpionate Lithium and Zinc Alkyl Complexes. Synthesis, Structural Studies, and ROP of Cyclic Esters. Organometallics, 2008, 27(6), 1310-1321.

88. C. X. Cai, A. Amgoune, C. W. Lehmann and J. F. Carpentier, Stereoselective ring-opening polymerization of racemic lactide using alkoxy-aminobis(phenolate) group 3 metal complexes. Chem. Commun., 2004, 2004(3), 330331.

89. A. Amgoune, C. M. Thomas, T. Roisnel and J.-F. Carpentier, Ring-Opening Polymerization of Lactide with Group 3 Metal Complexes Supported by Dianionic Alkoxy-Amino-Bisphenolate Ligands: Combining High Activity, Productivity, and Selectivity. Chem. Eur. J., 2005, 12(1), 169-179.

90. A. Amgoune, C. M. Thomas and J.-F. Carpentier, Controlled ring-opening polymerization of lactide by group 3 metal complexes. Pure Appl. Chem., 2007, 79(11), 2013-2030.

91. W. Miao, S. Lia, H. Zhang, D. Cui, Y. Wang and B. Huang, Mixed ligands supported yttrium alkyl complexes: Synthesis, characterization and catalysis toward lactide polymerization. J. Organomet. Chem., 2007, 692(22), 4828-4834.

92. H. Y. Ma, T. P. Spaniol and J. Okuda, Highly heteroselective ring-opening polymerization of rac-lactide initiated by bis(phenolato)scandium complexes. Angew. Chem.-Int. Edit., 2006, 45(46), 7818-7821.

93. H. Ma, T. P. Spaniol and J. Okuda, Rare-Earth Metal Complexes Supported by 1, $\omega$-Dithiaalkanediyl-Bridged Bis(phenolato) Ligands: Synthesis, Structure, and Heteroselective Ring-Opening Polymerization of rac-Lactide. Inorg. Chem., 2008, 47(8), 3328-3339.

94. A. J. Chmura, M. G. Davidson, M. D. Jones, M. D. Lunn, M. F. Mahon, A. F. Johnsons, P. Khunkamchoo, S. L. Roberts and S. S. F. Wong, Group 4 Complexes with Aminebisphenolate Ligands and Their Application for the Ring Opening Polymerization of Cyclic Esters. Macromolecules, 2006, 39(21), 7250-7257.

95. A. J. Chmura, M. G. Davidson, C. J. Frankis, M. D. Jones and M. D. Lunn, Highly active and stereoselective zirconium and hafnium alkoxide initiators for solvent-free ring-opening polymerization of rac-lactide. Dalton Trans., 2008, 2008(11), 1293 - 1295.

96. A. J. Chmura, D. M. Cousins, M. G. Davidson, M. D. Jones, M. D. Lunn and M. F. Mahon, Robust chiral zirconium alkoxide initiators for the room-temperature stereoselective ring-opening polymerisation of rac-lactide. Dalton Trans., 2008, 2008(11), 1437 - 1443.

97. Q. Wang, L. Xiang, H. Song and G. Zi, Synthesis, structure, and catalytic activity of binuclear lanthanide complexes with chiral NOBIN-based NNO ligands. $J$. Organomet. Chem., 2009, 694(5), Pages 691-696.

98. G. Adamus and M. Kowalczuk, Anionic Ring-Opening Polymerization of $\beta$ Alkoxymethyl-Substituted $\beta$-Lactones. Biomacromolecules, 2008, 9(2), 696-703.

99. J. W. Kramer and G. W. Coates, Fluorinated $\beta$-lactones and poly $(\beta$ hydroxyalkanoate)s: synthesis via epoxide carbonylation and ring-opening polymerization. Tetrahedron, 2008, 64(29), 6973-6978. 
100. J. A. Marco, M. Carda, S. Rodriguez, E. Castillo and M. N. Kneeteman, Synthesis of conjugated gamma- and delta-lactones from aldehydes and ketones via a vinylation(allylation)-ring closing metathesis-oxidation sequence. Tetrahedron, 2003, 59(23), 4085-4101.

101. C. Aprile, M. Gruttadauria, M. E. Amato, F. D'Anna, P. Lo Meo, S. Riela and R. Noto, Studies on the stereoselective selenolactonization, hydroxy and methoxy selenenylation of alpha- and beta-hydroxy acids and esters. Synthesis of delta- and gamma-lactones. Tetrahedron, 2003, 59(13), 2241-2251.

102. J. Cossy, F. Bargiggia and S. BouzBouz, Tandem crossmetathesis/hydrogenation/cyclization reactions by using compatible catalysts. Org. Lett., 2003, 5(4), 459-462.

103. G. S. Liu and X. Y. Lu, Palladium(II)-catalyzed coupling of allenoic acids and alpha,beta-unsaturated carbonyl compounds through tandem intramolecular oxypalladation and conjugate addition reactions. Tetrahedron Lett., 2003, 44(1), 127-130.

104. B. Parrish, R. B. Breitenkamp and T. Emrick, PEG- and peptide-grafted aliphatic polyesters by click chemistry. J. Am. Chem. Soc., 2005, 127(20), 7404-7410.

105. M. R. Ten Breteler, P. J. Dijkstra and J. Feijen, Synthesis and Ring-Opening of $\gamma$ Boc-Amino- $\varepsilon$-Caprolactone. Chapter 6, this thesis, 2009.

106. M. A. Hatcher, K. Borstnik and G. H. Posner, New silicon-mediated ring expansion of $n$-sized conjugated cycloalkenones into homoallylic $n+3$ lactones. Tetrahedron Lett., 2003, 44(29), 5407-5409.

107. M. Leemhuis, J. H. van Steenis, M. J. van Uxem, C. F. van Nostrum and W. E. Hennink, A versatile route to functionalized dilactones as monomers for the synthesis of poly(alpha-hydroxy) acids. Eur. J. Org. Chem., 2003, 17), 33443349.

108. T. Trimaille, M. Möller and R. Gurny, Synthesis and ring-opening polymerization of new monoalkyl-substituted lactides. J. Polym. Sci., Part A: Polym. Chem., 2004, 42(17), 4379 - 4391.

109. B. Saulnier, S. Ponsart, J. Coudane, H. Garreau and M. Vert, Lactic acid-based functionalized polymers via copolymerization and chemical modification. Macromol. Biosci., 2004, 4(3), 232-237.

110. C. K. Williams, Synthesis of functionalized biodegradable polyesters. Chem. Soc. Rev., 2007, 36(10), $1573-1580$.

111. A. Amgoune, C. M. Thomas, S. Ilinca, T. Roisnel and J.-F. Carpentier, Highly Active, Productive, and Syndiospecific Yttrium Initiators for the Polymerization of Racemic -Butyrolactone. Angew. Chem. Int. Ed., 2006, 45(17), 2782 - 2784.

112. N. Ajellal, M. Bouyahyi, A. Amgoune, C. M. Thomas, A. Bondon, I. Pillin, Y. Grohens and J.-F. Carpentier, Syndiotactic-Enriched Poly(3-hydroxybutyrate)s via Stereoselective Ring-Opening Polymerization of Racemic $\beta$-Butyrolactone with Discrete Yttrium Catalysts. Macromolecules, 2009, 42(4),

113. N. Ajellal, C. M. Thomas and J.-F. Carpentier, Functional syndiotactic poly( $\beta$ hydroxyalkanoate)s via stereoselective ring-opening copolymerization of rac- $\beta$ butyrolactone and rac-allyl- $\beta$-butyrolactone. J. Polym. Sci., Part A: Polym. Chem., 2009, 47(12), 3177-3189. 
114. N. Ajellal, D. M. Lyubov, M. A. Sinenkov, G. K. Fukin, A. V. Cherkasov, C. M. Thomas, J.-F. Carpentier and A. A. Trifonov, Bis(guanidinate) Alkoxide Complexes of Lanthanides: Synthesis, Structures and Use in Immortal and Stereoselective Ring-Opening Polymerization of Cyclic Esters. Chem. Eur. J., 2008, 14(18), 5440-5448.

115. J. E. Kemnitzer, S. P. McCarthy and R. A. Gross, Syndiospecific Ring-Opening Polymerization of $\beta$-Butyrolactone To Form Predominantly Syndiotactic Poly $(\beta$ hydroxybutyrate) Using Tin(IV) Catalysts. Macromolecules, 1993, 26(23), 61436150 .

116. H. R. Kricheldorf and S. R. Lee, Polylactones. XXXV: Macrocyclic and stereoselective polymerization of $\beta$-D,L-butyrolactone with cyclic dibutyltin initiators. Macromolecules, 1995, 28(20), 6718-6725.

117. H. R. Kricheldorf and S. Eggerstedt, Polylactones. 41. Polymerizations of $\beta$-d,1Butyrolactone with Dialkyltinoxides as Initiators. Macromolecules, 1997, 30(19), 5693-5697.

118. Y. Hori and T. Hagiwara, Ring-opening polymerisation of $\beta$-butyrolactone catalysed by distannoxane complexes: study of the mechanism. Int. J. Biol. Macromol., 1999, 25(1-3), 237-245.

119. H. R. Kricheldorf and S. Eggerstedt, Polylactones. LXI. Polymerization of $\beta$-D,LButyrolactone Initiated with 1,3-Diacetoxy-1,1,3,3-tetrabutyldistannoxane and with 1,3-Dichloro-1,1,3,3-tetrabutyldistannoxane. J. Macromol. Sci. Part A Pure Appl. Chem., 2003, 40(10), 1009-1018.

120. Z. Wei, L. Liu and M. Qi, Synthesis and characterization of homo- and copolymers of $(\mathrm{R}, \mathrm{S})-\beta$-butyrolactone and $\gamma$-butyrolactone or $\beta$-valerolactone initiated with cyclic tin alkoxide. React. Func. Polym., 2006, 66(12), 1411-1419.

121. Z. Jedliński, M. Kowalczuk, P. Kurcok, G. Adamus, A. Matuszowicz and W. Sikorska, Stereochemical Control in the Anionic Polymerization of $\beta$ Butyrolactone Initiated with Alkali-Metal Alkoxides. Macromolecules, 1996, 29(11), 3773-3777.

122. P. Kurcok, P. Dubois and R. Jèrôme, Polymerization of $\beta$-butyrolactone initiated with $\mathrm{Al}(\mathrm{O} i \mathrm{Pr})_{3}$. Polym. J., 1999, 41(4), 479-485.

123. M. Zintl, F. Molnar, T. Urban, V. Bernhart, P. Preishuber-Pflügl and B. Rieger, Variably Isotactic Poly(hydroxybutyrate) from Racemic $\beta$-Butyrolactone: Microstructure Control by Achiral Chromium(III) Salophen Complexes. Angew. Chem. Int. Ed., 2008, 47(18), 3458-3460.

124. P. Kurcok, M. Śmiga and Z. Jedliński, $\beta$-Butyrolactone polymerization initiated with tetrabutylammonium carboxylates: A novel approach to biomimetic polyester synthesis. J. Polym. Sci., Part A: Polym. Chem., 2002, 40(13), 2184 2189.

125. M. Benvenuti and R. W. Lenz, Polymerization and copolymerization of $\beta$ butyrolactone and benzyl- $\beta$-malolactonate by aluminoxane catalysts. J. Polym. Sci., Part A: Polym. Chem., 1991, 29(6), 793-805.

126. B. Wu and R. W. Lenz, Stereoregular Polymerization of [R,S]-3-Butyrolactone Catalyzed by Alumoxane-Monomer Adducts. Macromolecules, 1998, 31(11), 3473-3477. 
127. C. Jaimes, M. Arcana, A. Brethon, A. Mathieu, F. Schue and J. M. DeSimone, Structure and morphology of poly([R, S ]- $\beta$-butyrolactone) synthesized from aluminoxane catalyst. Eur. Polym. J., 1998, 34(2), 175-185.

128. R. A. Gross, A. Kumar and B. Kalra, Polymer synthesis by in vitro enzyme catalysis. Chem. Rev., 2001, 101(7), 2097-2124.

129. I. K. Varma, A.-C. Albertsson, R. Rajkhowa and R. Srivastavab, Enzyme catalyzed synthesis of polyesters. Prog. Polym. Sci., 2005, 30(10), 949-981.

130. A.-C. Albertsson and R. K. Srivastavab, Recent developments in enzymecatalyzed ring-opening polymerization. Adv. Drug Delivery Rev., 2008, 60(9), 1077-1093.

131. H. Kikuchi, H. Uyama and S. Kobayashi, Lipase-catalyzed enantioselective copolymerization of substituted lactones to optically active polyesters. Macromolecules, 2000, 33(24), 8971-8975.

132. K. Shioji, A. Matsuo, K. Okuma, K. Nakamura and A. Ohno, Lipase-catalyzed kinetic resolution of racemic seven-membered substituted lactones. Tetrahedron Lett., 2000, 41(45), 8799-8802.

133. T. F. Al-Azemi, L. Kondaveti and K. S. Bisht, Solventless enantioelective ringopening polymerization of substituted epsilon-caprolactones by enzymatic catalysis. Macromolecules, 2002, 35(9), 3380-3386.

134. J. W. Peeters, O. van Leeuwen, A. R. A. Palmans and E. W. Meijer, Lipasecatalyzed ring-opening polymerizations of 4-substituted epsilon-caprolactones: Mechanistic considerations. Macromolecules, 2005, 38(13), 5587-5592.

135. J. Van Buijtenen, B. A. C. Van As, M. Verbruggen, L. Roumen, J. A. J. M. Vekemans, K. Pieterse, P. A. J. Hilbers, L. A. Hulshof, A. R. A. Palmans and E. W. Meijer, Switching from S- to R-Selectivity in the Candida antarctica Lipase BCatalyzed Ring-Opening of $\omega$-Methylated Lactones: Tuning Polymerizations by Ring Size. J. Am. Chem. Soc., 2007, 129(33), 7393-7398.

136. Y. Y. Svirkin, J. Xu, R. A. Gross, D. L. Kaplan and G. Swift, Enzyme-catalyzed stereoelective ring-opening polymerization of alpha-methyl-beta-propiolactone. Macromolecules, 1996, 29(13), 4591-4597.

137. M. Runge, D. O'Hagan and G. Haufe, Lipase-catalyzed polymerization of fluorinated lactones and fluorinated hydroxycarboxylic acids. J. Polym. Sci., Part A: Polym. Chem., 2000, 38(11), 2004 - 2012.

138. S. Matsumura, K. Mabuchi and K. Toshima, Novel ring-opening polymerization of lactide by lipase. Macromol. Symp., 1998, 130(-), 285-304.

139. J. Wahlberg, P. V. Persson, T. Olsson, E. Hedenstrom and T. Iversen, Structural characterization of a lipase-catalyzed copolymerization of epsilon-caprolactone and D,L-lactide. Biomacromolecules, 2003, 4(4), 1068-1071. 


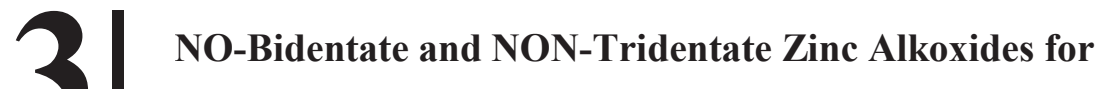 the Controlled Ring-Opening Polymerization of Lactides
}

\begin{abstract}
Three novel ligated zinc-based catalysts of the type $\left[\mathrm{L}_{n} \mathrm{ZnEt}\right]_{2}$ with $\mathrm{L}_{1}=2$ [(dimethylamino)methyl]-4-methylphenol, $\quad \mathrm{L}_{2}=2-[($ dimethylamino $)$ methyl $]-4,6-$ dimethylphenol and $\mathrm{L}_{3}=2$,6-bis[(dimethylamino)methyl]-4-methylphenol were synthesized and applied in the ring-opening polymerization of (racemic) lactides. Polymerizations were fast and controlled, giving $M_{n}$ values close to the theoretical values and low polydispersities. Kinetic studies showed that the polymerizations were first-order in monomer, with rate constants $\mathrm{k}_{\text {app }}=3.09 \mathrm{~h}^{-1}, 1.71 \mathrm{~h}^{-1}$ and $0.48 \mathrm{~h}^{-1}$ for catalysts $\mathbf{1}, \mathbf{2}$ and $\mathbf{3}$, respectively. The stereoselective behavior of the zinc catalysts $\mathbf{1}$ and $\mathbf{3}$ was tested in the ring-opening polymerization of rac-LA in different solvents. $\mathrm{In} \mathrm{CH}_{2} \mathrm{Cl}_{2}$ both 1 and 3 yielded atactic polymers. For 3, a remarkable shift in selectivity was seen upon the use of toluene or THF as polymerization medium. Moderate enrichment in isotactic sequences was found, which has not been previously reported for Zn-based catalysts.
\end{abstract}




\section{Introduction}

The synthesis of poly(lactic acid)s (PLAs) ${ }^{1}$ has been a subject of extensive studies over the past decades. The polymers have been used in a wide range of applications, like packaging materials, ${ }^{2}$ biomedical devices such as sutures and tissue engineering scaffolds and drug delivery systems. ${ }^{3-5}$ A well-developed and convenient method for PLA synthesis is ring-opening polymerization (ROP) of lactides, generally applying metalbased catalysis. A large number of metal complexes, in particular metal alkoxides in combination with a variety of coordinating ligands $\left(\mathrm{L}_{\mathrm{n}}\right)$, has been explored for these purposes. ${ }^{6-8}$ Ideally, these metal alkoxides induce 'living' polymerizations, resulting in polymers with controlled molecular weights and low molecular weight distributions. The type of ligands applied can have a large influence on the ROP of lactones. The use of bulkier ligands effectively suppresses non-desired backbiting and transesterification reactions, which broaden the molecular weight distribution. In addition, coordinating ligands provide a means to design single-site catalysts that facilitate the use of multifunctional initiators in solution polymerization. In nonselective lactide polymerizations, using either a single enantiomer ( $L$-lactide, $L$-LA, or $D$-lactide, $D$-LA) or a racemic mixture, results in a semi-crystalline and an amorphous PLA, respectively. As mechanical and physical properties are closely related to the microstructures of the polymers, these widely vary accordingly. More advanced polymer architectures include (block) copolymers, comprising stereoregular domains of sufficient length and opposing chirality, which are capable of forming stereocomplexes. An interesting approach is the synthesis of such polymers from racemic lactide ( $r a c$-LA) mixtures, which may be achieved by choosing the appropriate ligands in the applied catalysts. In recent years, increasing effort has been put in the design of stereoselective catalysts for the ROP of lactides. $^{7,}$ 9-37 Up to now, most notable results have been obtained with single-site catalysts based on aluminum ${ }^{10-14,}$ 16-28 and zinc. ${ }^{29-41}$ The aluminum alkoxide-based catalysts generally consist of salen-type Schiff base ligands, and high degrees of both isotactic and heterotactic enrichments have been reported (Scheme 1). 


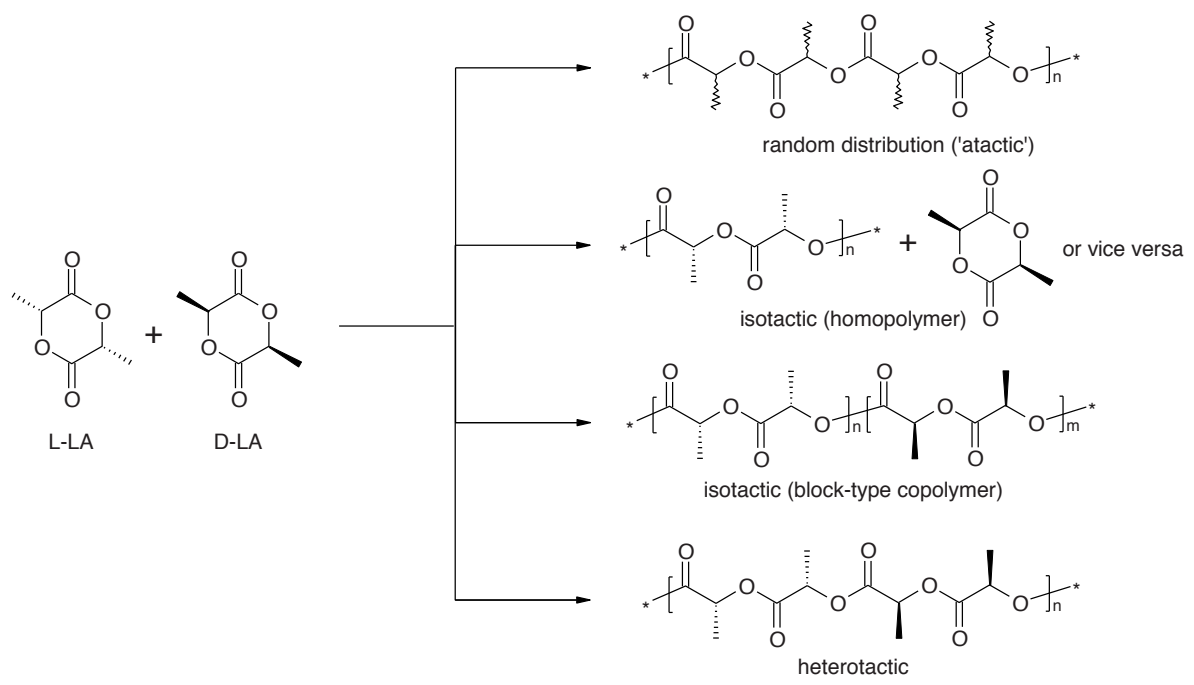

Scheme 1. Various polymer microstructures that may result from ROP of rac-LA.

In isotactic sequences, the configuration of the consecutive repeating units is equal. The term 'heterotactic' refers to a change in configuration every two repeating lactyl units, which - in the case of $D$ - or $L$-lactide - is inherent to the structure of the monomer. The term 'syndiotactic' refers to sequences where the configuration changes every repeating unit, which in the case of lactide can only be achieved using meso-lactide.

Although showing high levels of enantiomeric enrichment, the aluminum-based catalysts generally show moderate to low activity. In contrast, zinc-based catalysts generally give fast and controlled polymerizations at ambient temperatures. Moreover, these zinc catalysts are attractive because of the absence of metal-induced product discoloration and their low toxicity, ${ }^{8}$ making them applicable for the preparation of biomedical grade PLAs. So far, only heterotactic enrichment has been reported in rac-LA polymerization using $\beta$-diiminate zinc-catalysts, ${ }^{30-33}$ catalysts based on Schiff base ligands, ${ }^{34,}{ }^{39}$ NNOtridentate ketiminate ligands, ${ }^{41}$ heteroscorpionate ligands ${ }^{40}$ and $N$-heterocyclic carbenes. ${ }^{35}$ The subtle balance between the bulkiness of the ligand, which improves stereoselectivity, and sterical hindrance, which hampers the catalyst activity has to be regarded in the development of new catalysts. ${ }^{23}, 31$ Changing the electron-donating or electronwithdrawing capacity of the ligands also plays an important role in catalyst activity 
towards ROP of lactides, as pointed out by Chen et al. in their work on zinc alkoxides derived from NNO-tridentate ligands ${ }^{34}$ as well as by Hormnirun et al. in their work on Schiff base aluminum catalysts. ${ }^{23}$

In this study three zinc-based catalysts (1-3; Scheme 2) comprising a NO-bidentate or NON-tridentate coordination pattern were studied for their catalytic activity in the ROP of $L$-LA and $r a c$-LA and stereoselectivity in the ROP of $r a c$-LA using different solvents.

2

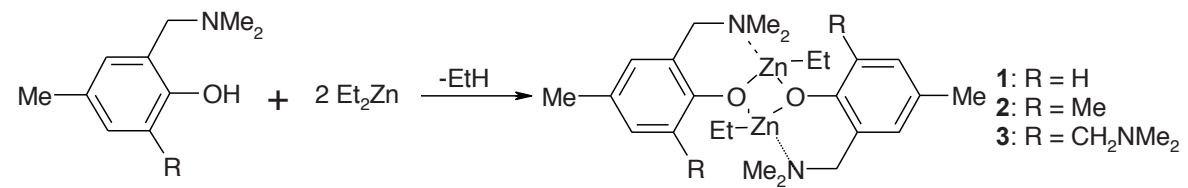

Scheme 2. Synthesis of catalysts 1-3.

\section{Experimental}

\section{Materials}

L-LA and rac-LA (Purac) were recrystallized from dry toluene. Solvents (Biosolye) were dried by distillation over sodium wire (toluene), calcium hydride (dichloromethane and THF) or sodium sand (pentane and hexane) prior to use. Diethyl ether and methanol were used without further purification. Diethyl zinc, $1 \mathrm{M}$ in hexane, was purchased from Aldrich. 2-[(Dimethylamino)methyl]-4-methylphenol, 2-[(dimethylamino)methyl]-4,6dimethylphenol and 2,6-bis[(dimethylamino)methyl]-4-methylphenol were prepared according to published methods ${ }^{42,43}$ Glacial acetic acid (Merck) was used as received.

\section{Synthesis:}

Catalysts: Equimolar amounts of the corresponding phenol and $\mathrm{Et}_{2} \mathrm{Zn}(13 \mathrm{mmol})$ were mixed in pentane. The resulting reaction mixtures were stirred for an additional $4 \mathrm{~h}$ after which the solvent was removed in vacuo affording the phenoxy zinc derivatives 1-3 in quantitative yield. The compounds were recrystallized from hot toluene to give colorless crystals in $\sim 85 \%$ yield.

2-[(Dimethylamino)methyl]-4-methylphenoxy ethylzine (1): ${ }^{1} \mathrm{H}$ NMR $\left(\mathrm{C}_{6} \mathrm{D}_{6}\right): \delta=7.12$ $(\mathrm{d}, J=1.9 \mathrm{~Hz}, 1 \mathrm{H}$, aromatic $H), 6.99(\mathrm{~d}, J=1.9 \mathrm{~Hz}, 1 \mathrm{H}$, aromatic $H), 6.73(\mathrm{~s}, 1 \mathrm{H}$, 
Zn Alkoxides for the Controlled ROP of Lactides

aromatic $H), 4.44\left(\mathrm{~d}, J=12 \mathrm{~Hz}, 1 \mathrm{H}, \mathrm{Ar}-\mathrm{CH}_{2}-\mathrm{N}\right), 2.64\left(\mathrm{~d}, J=12 \mathrm{~Hz}, 1 \mathrm{H}, \mathrm{Ar}-\mathrm{CH}_{2}-\mathrm{N}\right)$, $2.36\left(\mathrm{~s}, 3 \mathrm{H}, \mathrm{N}-\mathrm{CH}_{3}\right), 2.26\left(\mathrm{~s}, 3 \mathrm{H}, \mathrm{Ar}-\mathrm{CH}_{3}\right), 1.79\left(\mathrm{~s}, 3 \mathrm{H}, \mathrm{N}-\mathrm{CH}_{3}\right), 1.35(\mathrm{t}, J=8 \mathrm{fz}, 3 \mathrm{H}$, $\left.\mathrm{Zn}-\mathrm{C}-\mathrm{CH}_{3}\right), 0.35\left(\mathrm{q}, J=8 \mathrm{~Hz}, 2 \mathrm{H}, \mathrm{Zn}-\mathrm{CH}_{2}\right) .{ }^{13} \mathrm{C}$ NMR $\left(\mathrm{C}_{6} \mathrm{D}_{6}\right): \delta=161.3,131.7,130.9$, 126.6, 125.1 and 120.4 (aromatic $C), 63.2\left(\mathrm{Ar}-\mathrm{CH}_{2}-\mathrm{N}\right), 46.7$ and $44.4\left(\mathrm{~N}-\mathrm{CH}_{3}\right), 20.8(\mathrm{Ar}-$ $\left.\mathrm{CH}_{3}\right), 13.6\left(\mathrm{Zn}-\mathrm{C}-\mathrm{CH}_{3}\right),-3.8\left(\mathrm{Zn}-\mathrm{CH}_{2}\right)$. Elemental analysis (calc.) for $\mathrm{C}_{12} \mathrm{H}_{19} \mathrm{NOZn}$ : $\mathrm{C}$ : 55.77 (55.72), H: $7.43(7.40), \mathrm{N}: 5.34$ (5.41), $\mathrm{Zn:} 25.18(25.28)$

Mp $158-160^{\circ} \mathrm{C}$. Mol, weight as determined by cryoscopy (conc. $0.56 \mathrm{wt} \%$ ): calculated: 258.68 (monomer); found: 522.53 .

2-[(Dimethylamino)methyl]-4,6-dimethylphenoxy ethylzinc (2): ${ }^{1} \mathrm{H}$ NMR $\left(\mathrm{C}_{6} \mathrm{D}_{6}\right)$ : $\delta=7.00(\mathrm{~s}, 1 \mathrm{H}$, aromatic $H), 6.60(\mathrm{~s}, 1 \mathrm{H}$, aromatic $H), 4.60\left(\mathrm{~d}, J=12 \mathrm{~Hz}, 1 \mathrm{H}, \mathrm{Ar}-\mathrm{CH}_{2}-\right.$ $\mathrm{N}), 2.60\left(\mathrm{~d}, J=12 \mathrm{~Hz}, 1 \mathrm{H}, \mathrm{Ar}-\mathrm{CH}_{2}-\mathrm{N}\right), 2.36\left(\mathrm{~s}, 3 \mathrm{H}_{4} o \mathrm{Ar}-\mathrm{CH}_{3}\right), 2.32\left(\mathrm{~s}, 3 \mathrm{H}, \mathrm{N}-\mathrm{CH}_{3}\right), 2.25$ (s, $\left.3 \mathrm{H}, p \mathrm{Ar}-\mathrm{CH}_{3}\right), 1.69\left(\mathrm{~s}, 3 \mathrm{H}, \mathrm{N}-\mathrm{CH}_{3}\right), 1.31$ (t, $\left.J=8 \mathrm{~Hz}, 3 \mathrm{H}, \mathrm{Zn}-\mathrm{C}-\mathrm{CH} H_{3}\right), 0.28$ (q, $J=8$ $\left.\mathrm{Hz}, 2 \mathrm{H}, \mathrm{ZnCH}_{2}\right) .{ }^{13} \mathrm{C}$ NMR $\left(\mathrm{C}_{6} \mathrm{D}_{6}\right): \delta=159.1,132.6,129.8,126.2$ and 124.6 (aromatic C), $63.5\left(\mathrm{Ar}-\mathrm{CH}_{2}-\mathrm{N}\right), 47.6$ and $44.4\left(\mathrm{~N}-\mathrm{CH}_{3}\right), 20.6\left(p \mathrm{Ar}-\mathrm{CH}_{3}\right), 18.7\left(\mathrm{o} \mathrm{Ar}-\mathrm{CH}_{3}\right), 14.5$ ( $\left.\mathrm{Zn}-\mathrm{C}-\mathrm{CH}_{3}\right)$, $-3.7\left(\mathrm{Zn}-\mathrm{CH}_{2}\right)$. Elemental analysis (calc.) for $\mathrm{C}_{13} \mathrm{H}_{21} \mathrm{NOZn}: \mathrm{C}: 57.22$ (57.26), H: 7.71 (7.76), N: 5.08 (5.14), Zn; 23.84 (23.98). Mp 199-200 ${ }^{\circ} \mathrm{C}$. Mol. weight as determined by cryoscopy (conc. $0.19 \mathrm{wt} \%$ ): calc. 272.70 (monomer); found: 587.86 .

2,6-Bis[(dimethylamino)methyf]-4-methylphenoxy ethylzinc (3): ${ }^{1} \mathrm{H}$ NMR $\left(\mathrm{C}_{6} \mathrm{D}_{6}\right)$ : $\delta=6.88\left(\mathrm{~s}, 2 \mathrm{H}_{\text {, aromatic } H}\right), 4.00-3.00\left(\mathrm{~s}, 4 \mathrm{H}, \mathrm{Ar}-\mathrm{CH}_{2}-\mathrm{N}\right), 2.60(\mathrm{~d}, J=12 \mathrm{~Hz}, 1 \mathrm{H}, \mathrm{Ar}-$ $\left.\mathrm{CH}_{2}-\mathrm{N}\right), 2.36\left(\mathrm{~s}, 3 \mathrm{H}_{1} o \mathrm{Ar}-\mathrm{CH}_{3}\right), 2.24\left(\mathrm{~s}, 3 \mathrm{H}, \mathrm{p} \mathrm{Ar}-\mathrm{CH}_{3}\right) ; 2.18\left(\mathrm{~s}, 12 \mathrm{H}, \mathrm{N}-\mathrm{CH}_{3}\right) ; 1.31$ (t. $\mathrm{J}$ $\left.=8 \mathrm{~Hz}, 3 \mathrm{H}, \mathrm{Zn}-\mathrm{C}-\mathrm{CH}_{3}\right) ; 0.27\left(\mathrm{q}, J=8 \mathrm{~Hz}, 2 \mathrm{H}, \mathrm{ZnCH}_{2}\right) .{ }^{13} \mathrm{C}$ NMR $\left(\mathrm{C}_{6} \mathrm{D}_{6}\right): \delta=159.0$. 131.2, 127.1, and 126.4 (aromatic C), $61.4\left(\mathrm{Ar}-\mathrm{CH}_{2}-\mathrm{N}\right), 46.0\left(\mathrm{~N}-\mathrm{CH}_{3}\right), 20.8\left(p \mathrm{Ar}-\mathrm{CH}_{3}\right)$; $13.6\left(\mathrm{Zn}-\mathrm{C}-\mathrm{CH}_{3}\right):-4.4\left(\mathrm{Zn}-\mathrm{CH}_{2}\right)$. Elemental analysis (calc.) for $\mathrm{C}_{15} \mathrm{H}_{26} \mathrm{~N}_{2} \mathrm{OZn}$ : C: 56.95 (57.06), H: 8.24 (8.30), N: 8.71 (8.87), Zn: 20.65 (20.71). Mp 167-168 ${ }^{\circ} \mathrm{C}$. Mol.weight as determined by cryoscopy (conc. 0.29 wt \%); calc. 315.77 (monomer); found: 587.33 .

Lactide Polymerizations: All experiments were carried out under nitrogen in a glovebox or under argon using Schlenk techniques. In a typical polymerization lactide $(2.0 \mathrm{~g}, 13.9$ $\mathrm{mmol}$ ), isopropanol (4.2 $\mathrm{mg}, 0.069 \mathrm{mmol}$, added as $2 \mathrm{wt} \%$ solution in dichloromethane) and $7.5 \mathrm{ml}$ of dichloromethane were introduced into a dried reaction vessel equipped with a magnetic stirring bar. The vessel was placed in an oil bath thermostated at $25^{\circ} \mathrm{C}$. To the vigorously stirred solution, a solution of 2,6-bis[(dimethylamino)methyl]-4- 
methylphenoxy ethylzinc (3) $(0.022 \mathrm{~g}, 0.069 \mathrm{mmol})$ in $2 \mathrm{ml}$ of dichloromethane was added, giving $[\mathrm{M}]:[\mathrm{HOi} \mathrm{Pr}]:[\mathrm{Zn}]=200: 1: 1$ and $[\mathrm{M}]_{0} \approx 1.2 \mathrm{M}$. At selected time intervals. about $0.8-1.0 \mathrm{ml}$-aliquots were removed and the reaction was terminated by adding glacial acetic acid. The solvent was evaporated and the conversion was determined using ${ }^{1} \mathrm{H}-\mathrm{NMR}$. The remaining residues were redissolved in chloroform and polymers were precipitated in cold diethyl ether or cold methanol. After centrifugation, the supernatant was decanted and the polymers were dried in vacuo.

\section{Characterization}

NMR: ${ }^{1} \mathrm{H}-\mathrm{NMR}(300 \mathrm{MHz})$ spectra were recorded on a Varian Inova Spectrometer using $\mathrm{CDCl}_{3}$ solutions, and were referenced to shifts of residual $\mathrm{CHCl}_{3}(\delta=7.26)$. The homonuclear decoupled ${ }^{1} \mathrm{H}-\mathrm{NMR}$ were recorded on a Bruker Avance $750 \mathrm{MHz}$ spectrometer with triple axis gradient.

GPC: GPC measurements were conducted with a Waters 6000A GPC apparatus equipped with a series of standard Waters Styragel HR columns and a H502 viscometer detector (Viscotek Corp.). Polystyrene standards were used and the molecular weights were determined using universal calibration. Polymers were dissolved in chloroform $(-5$ $\mathrm{mg} / \mathrm{ml}$ ) and eluted with chloroform at $25^{\circ} \mathrm{C}$ at a flow rate of $1.5 \mathrm{ml} / \mathrm{min}$.

Cryoscopy: Cryoscopic measurements were performed on an Automatic Systems Laboratories F25 precision thermometer using benzene as the solvent.

\section{Results and Discussion}

\section{Catalyst Synthesis and Solid-State Structure}

The selective formation of monoorganozinc alkoxides from a dialkylzinc compound and an alcohol via a protonolysis reaction is well known. ${ }^{44}$ When one of the alkyl groups is protolyzed, the reactivity of the remaining zinc-carbon bond is highly reduced. This selective removal of one alkyl group ${ }^{45}$ allowed an easy preparation of the substituted ethylzinc phenoxides 1-3 by the reaction of $E_{1} \mathrm{Zn}_{2}$ with one equivalent of the corresponding substituted phenol in pentane (Scheme 2). The ethylzinc phenoxides were obtained in quantitative yield and recrystallized from toluene, giving the corresponding compounds as colorless crystals. 


\section{Zn Alkoxides for the Controlled ROP of Lactides}

The solid state structures were determined by X-ray crystallography. In the solid state, 2 exists as a dimer as a result of bridging phenolate oxygen atoms between the two zinc atoms ( $\mathrm{Zn}(1)-\mathrm{O}(1) 2.0674(11), \mathrm{Zn}(2)-\mathrm{O}(1) 2.0228(12)$, all $\AA$ ). The two halves of the dimer are symmetry related via a crystallographic inversion center (Figure 1).
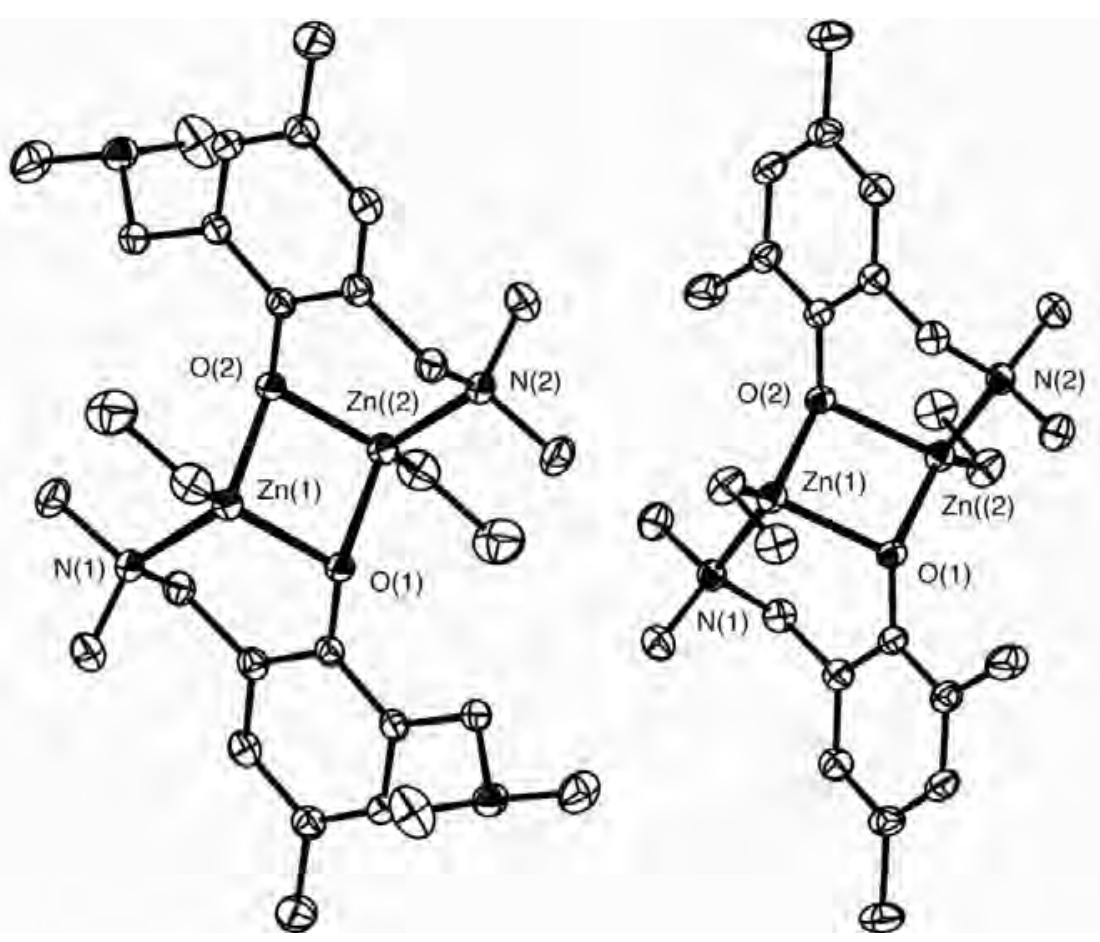

Figure 1. ORTEP drawings of the 2,6-bis[(dimethylamino)methyl]-4-methylphenoxy ethylzine (3) dimer (left) and the 2-[(dimethylamino)methyl]-4,6-dimethylphenoxy ethylzinc (2) dimer (right). Hydrogen atoms have been omitted for clarity. Selected bond distances $(A)$ and bond angles (deg): catalyst 2: $\mathrm{Zn}(1)-\mathrm{O}(1)$ 2.0674(11), $\mathrm{Zn}(1)-\mathrm{O}(\mathrm{la})$ 2.0228(12), Zn(1)-C(12) 1.978(2), Zn(1)-N(1) 2.1271(13), Zn(1)-O(1)-C(1) 117.07(9), $\mathrm{Zn}(1)-\mathrm{O}(1)-\mathrm{Zn}(1 \mathrm{a})$ 95.34(4), O(1)-Zn(1)-O(1a) 88.66(4). O(1)-Zn(1)-C(12) 119.27(6), $\mathrm{O}(1)-\mathrm{Zn}(1)-\mathrm{N}(1)$ 93.12(5); catalyst 3: $\mathrm{Zn}(1)-\mathrm{O}(1) 2.0215(14), \mathrm{Zn}(1)-\mathrm{O}(1 \mathrm{a}) 2.0698(13)$, $\mathrm{Zn}(1)-\mathrm{C}(14)$ 1.977(2), Zn(1)-N(1) 2.1147(17), Zn(1)-O(1)-C(1) 121.06(11), Zn(1)-O(1)$\mathrm{Zn}(1 \mathrm{a})$ 95.86(6), O(1)-Zn(1)-O(1a) 84.14(6), O(1)-Zn(1)-C(14) 133.49(8), O(1)-Zn(1)$\mathrm{N}(1) 92.98(6), \mathrm{N}(1)-\mathrm{Zn}(1)-\mathrm{O}(1 \mathrm{a}) 101.32(6)$ 
The overall structural geometry of $\mathbf{2}$ and relevant bond distances and angles are given in the experimental section. The core structural motif of $\mathbf{2}$ consists of an almost planar central O-Zn-O-Zn ring (O(1)-Zn-O(2) 84.66(4), $\mathrm{Zn}(1)-\mathrm{O}-\mathrm{Zn}(2) 95.34(4)$, all $\left.{ }^{\circ}\right)$. To each of the zinc atoms an ethyl group is bound ( $\mathrm{Zn}-\mathrm{C} 1.9778(23) \AA)$ and a distorted tetrahedral coordination at zinc is reached by the additional coordination ( $\mathrm{Zn}-\mathrm{N} 2.1271(13) \AA$ ) of the nitrogen atom of the $\mathrm{CH}_{2} \mathrm{NMe}_{2}$ substituent. The two ligands are oriented in such a way that one of the coordinating nitrogen atoms is located below the central central O-Zn-O$\mathrm{Zn}$ ring while the other nitrogen atom is located above that plane (anti orientation).

The X-Ray crystal structure of $\mathbf{3}$ shows that this compound, like $\mathbf{2}$, exists in the solid state as a centro symmetric dimer (Figure 1). Only one of the two $\mathrm{CH}_{2} \mathrm{NMc}_{2}$ substituents present on each aryl group is involved in coordination to zinc ( $\mathrm{Zn}(1)-\mathrm{N}(1) 2.1147(17) \AA$ ). The overall structural features of $\mathbf{3}$ are very closely related to those of $\mathbf{2}$ (Figure 1). Like in 2 , the dimer is formed via the bridging of two phenolate oxygen atoms between two zinc atoms $(\mathrm{Zn}(1)-\mathrm{O}(1) 2.0215(14), \mathrm{Zn}(2)-\mathrm{O}(1) 2.0698(13)$, all $\AA$ ). The coordinating nitrogen atoms, and likewise the two ethyl groups bonded to zinc ( $\mathrm{Zn}-\mathrm{C} 1.9765(22) \AA$ ) are in anti position with respect to the planar central $\mathrm{Zn}-\mathrm{O}-\mathrm{Zn}-\mathrm{O}$ four-membered ring $(\mathrm{O}$ $\mathrm{Zn}-\mathrm{O} 84.14(6), \mathrm{Zn}-\mathrm{O}-\mathrm{Zn}$ 95.86(6), all $\left.{ }^{\circ}\right)$.

Usually, alkylzinc alkoxides and aryloxides are aggregated species, and only dimethylamino-pyrrolidin ethylzinc complexes ${ }^{46} 1 H$-pyrazol phenoxy zinc halides ${ }^{47}$ and 2,4-di-tert-butyl-6-\{[(2-dimethylaminoethyl)methylamino]methyl\} phenoxy ethylzinc ${ }^{48}$ are known to exist as discrete monomers. Aggregated species may adopt a variety of structural motifs ${ }^{49}$ of which dimeric ones, like $\mathbf{1}$ and $\mathbf{2}$ and tetrameric ones, having a hetero cubane structure, like e.g. $[\mathrm{MeZnOMe}]_{4}{ }^{50}$ and $[\mathrm{MeZnOBu}-\mathrm{t}]_{4}{ }^{51,52}$ are the most common ones. Cryoscopic measurements using benzene have pointed out that catalysts 1$\mathbf{3}$ are forming dimers in solution as well (degree of association: 2.02, 2.16 and 1.86 for 1, $\mathbf{2}$ and $\mathbf{3}$, respectively, at concentrations of 0.02 and $0.04 \mathrm{~mol} . \mathrm{L}^{-1}$ )

\section{Lactide polymerizations}

The solution ring-opening polymerizations of $L$-LA and $r a c$-LA using the zinc complexes 1-3 were performed in the presence of equimolar amounts of isopropanol with respect to the zinc. The amounts of solvent and catalyst were chosen such that the monomer 
Zn Alkoxides for the Controlled ROP of Lactides

concentration $[\mathrm{M}] \approx 1.2 \mathrm{M}$, and that the monomer to initiator to catalyst ratio $[\mathrm{M}]:[\mathrm{I}]:[\mathrm{Zn}]$ $=200: 1: 1$. All catalysts displayed high activity and promoted fast lactide polymerization to high conversion at room temperature. Independent of the catalyst used, ${ }^{1} \mathrm{H}-\mathrm{NMR}$ end group analysis revealed that all polymer chains were end-capped with an isopropyl ester and a hydroxyl group. These structural data show that the zinc isopropoxides, formed upon the reaction of isopropanol and the zinc complexes 1-3, were the actual initiating species, and that the polymerizations proceed via a coordination-insertion mechanism.

Table 1. Lactide ring-opening polymerization using in situ generated zinc isopropoxides from 1-3 and isopropanol $([\mathrm{Zn}]:[[]=1: 1)$ under various conditions.

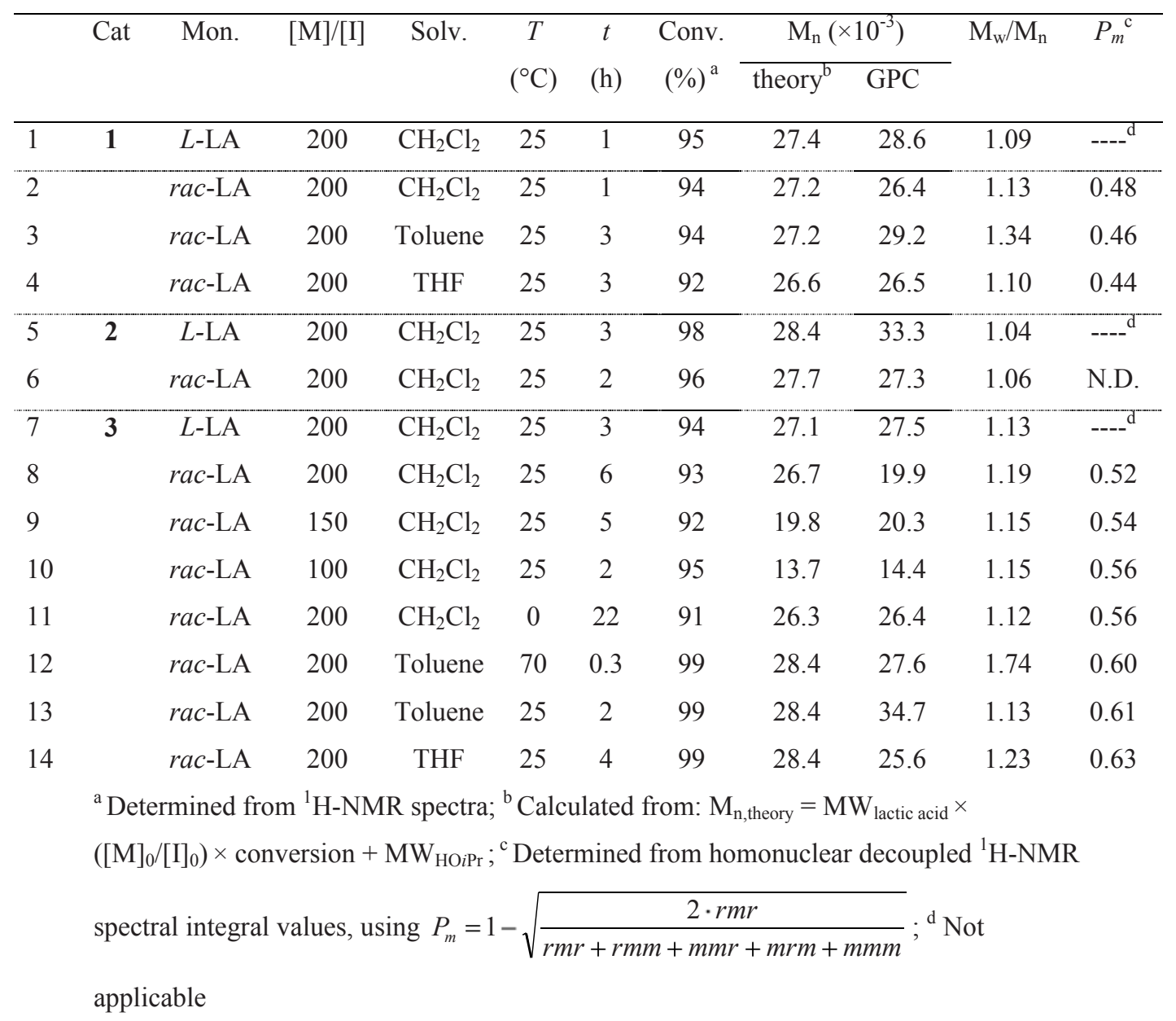




\section{Polymer Molecular Weights}

GPC results showed that all $L$-LA and rac-LA polymerization reactions in $\mathrm{CH}_{2} \mathrm{Cl}_{2}$ were well controlled and afforded polymers with molecular weights $\left(M_{n}\right)$ close to the theoretical values and low polydisperties $\left(\mathrm{M}_{\mathrm{w}} / \mathrm{M}_{\mathrm{n}}\right)(1.12-1.19)$. The molecular weight buildup (Figure 2) was determined as a function of monomer conversion for $\mathbf{1}$ and $\mathbf{3}$ in the polymerization of $L$-LA (Table 1 , entries 1 and 7). For both catalysts, the experimental $\mathrm{M}_{\mathrm{n}}$ values closely matched the theoretical values up to high conversion. Polydispersities of all polymer samples were low in line with the key features of a 'living' polymerization.

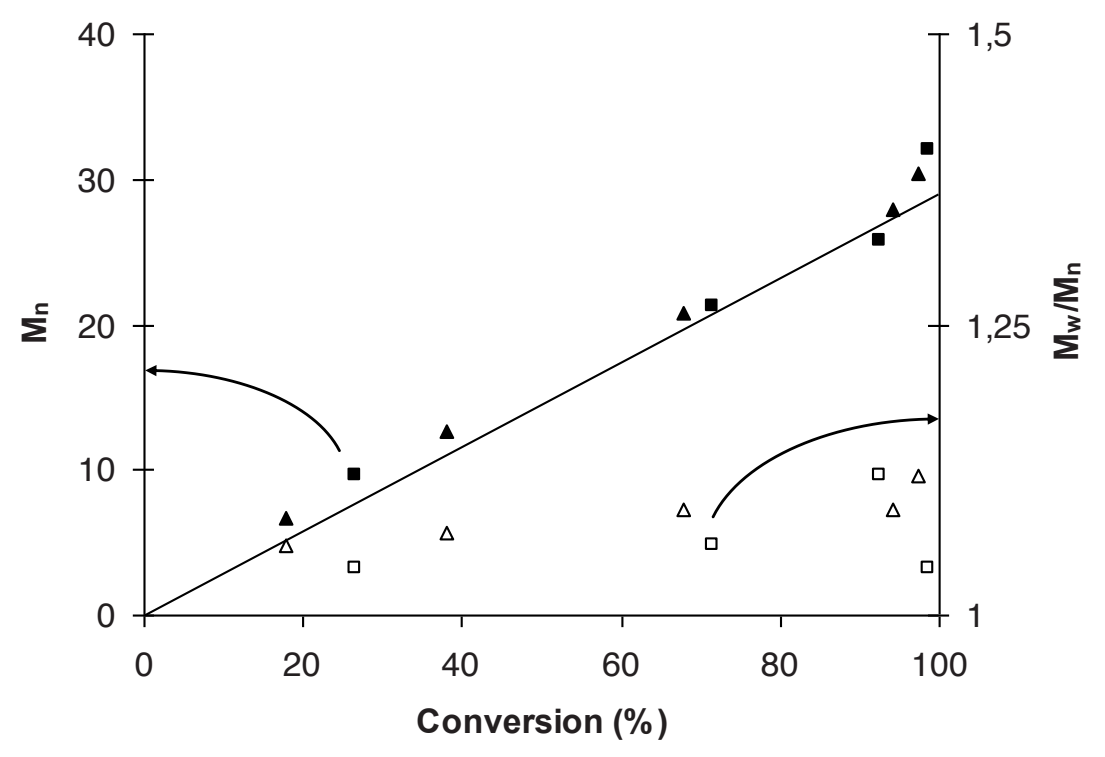

Figure 2. PLLA $M_{n}$ and $M_{w} / M_{n}$ as a function of L-LA conversion using zinc complexes 1 or 3. [M] $]_{0}[\mathrm{HO} i \mathrm{Pr}]:[\mathrm{Zn}]=200: 1 ; 1, \mathrm{CH}_{2} \mathrm{Cl}_{2}, 25^{\circ} \mathrm{C},[\mathrm{M}]_{0} \approx 1.2 \mathrm{M} ;(\mathbf{\Delta}) \mathrm{M}_{\mathrm{n}}$ obtained with catalyst $1 ;(\square) M_{n}$ obtained with catalyst $3 ;(\triangle) \mathrm{M}_{\mathrm{w}} / \mathrm{M}_{\mathrm{n}}$ obtained with catalyst $1 ;(\square)$ $\mathrm{M}_{\mathrm{w}} / \mathrm{M}_{\mathrm{n}}$ obtained with catalyst 3; Solid line: $\mathrm{M}_{\mathrm{n} \text {, theoretical. }}$

Polymerizations of rac-LA in toluene using either $\mathbf{1}$ or $\mathbf{3}$ as a catalyst afforded polymers with a molecular weight in accordance with theoretical values (Table 2, entries 3 and 13). 
However, prolonged reaction times after complete conversion must be avoided, as the polydispersity will increase due to transesterification reactions. Increased temperatures, even at short reacton times, gave higher polydispersities (Table 1, entry 12). GPC data of the polymers prepared in THF as a solvent closely matched the calculated molecular weights, and polydispersities were similar to those of the polymers prepared by solution polymerization in $\mathrm{CH}_{2} \mathrm{Cl}_{2}$ (Table I, entries 4 and 14).

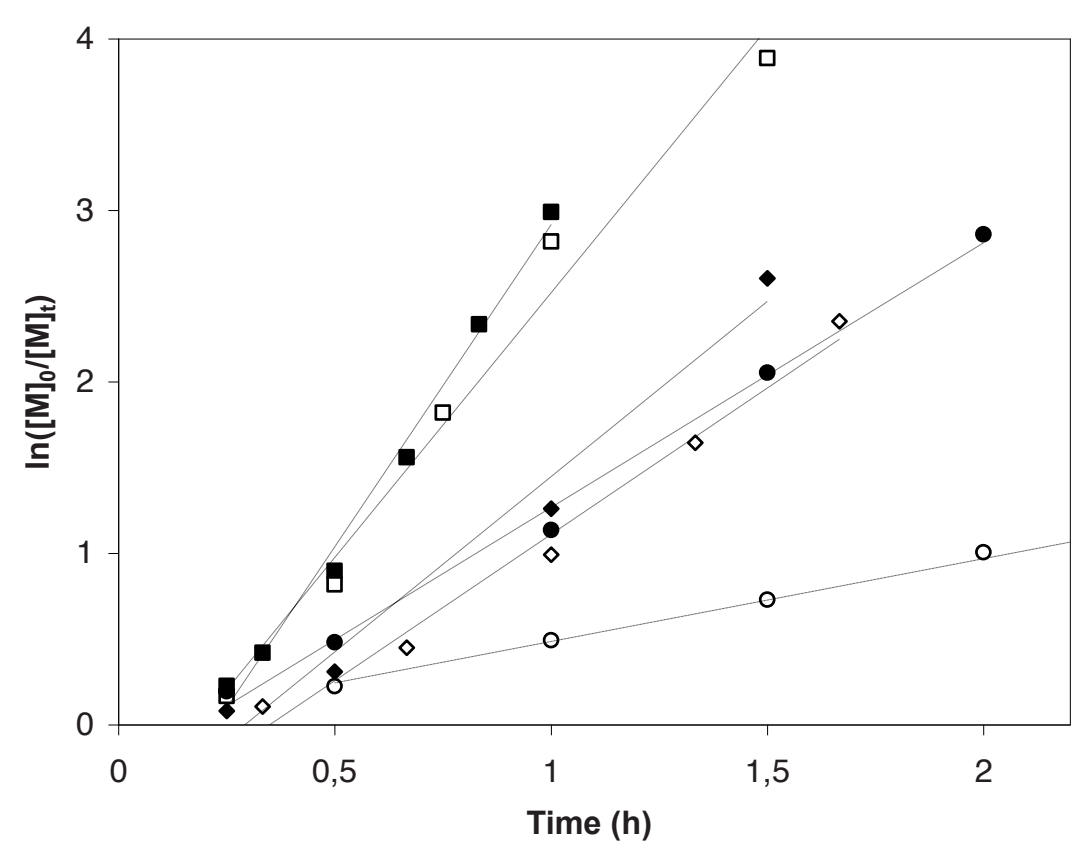

Figure 3. First-order kinetic plots for L-LA and rac-LA polymerizations, performed at 25 ${ }^{\circ} \mathrm{C}$ in $\mathrm{CH}_{2} \mathrm{Cl}_{2}$ with $[\mathrm{M}] \approx 1.2 \mathrm{M}$ and $[\mathrm{M}]:[\mathrm{I}]:[\mathrm{Zn}]=200: 1: 1 ;(\mathbf{m}): \mathbf{1}+\mathrm{L}-\mathrm{LA} ;$ (口) $\mathbf{1}+$ rac$\mathrm{LA}_{i}(\diamond) 2+\mathrm{L}_{-} \mathrm{LA}_{i}(\diamond) 2+\operatorname{rac}-\mathrm{LA}_{i}(\bullet) 3+\mathrm{L}-\mathrm{LA} ;(\circ) 3+$ rac-LA.

\section{Polymerization Kinetics}

Kinetic studies showed that the polymerizations carried out in $\mathrm{CH}_{2} \mathrm{Cl}_{2}$ were first-order in monomer (Figure 3). An induction period was observed in all lactide polymerizations. Prior to initiation, the ethyl group of the catalyst must be exchanged for an isopropoxy group, which is expected to cause the induction time observed. The rate constant of the $L$ LA polymerizations in $\mathrm{CH}_{2} \mathrm{Cl}_{2}$ using catalyst $3\left(\mathrm{k}_{\mathrm{app}}=1.54 \mathrm{~h}^{-1}\right)$ was lower than for $\mathbf{1}\left(\mathrm{k}_{\mathrm{app}}\right.$ 
$\left.=3.76 \mathrm{~h}^{-1}\right)$ and $2\left(\mathrm{k}_{\mathrm{app}}=2.05 \mathrm{~h}^{-1}\right)$. This can be related to an increased bulkiness of the substituent at the 6-position in $\mathbf{3}$ with respect to $\mathbf{1}$ and $\mathbf{2}$, causing sterical hindrance. ${ }^{18,23,31}$ In contrast, as reported recently by Coates et al., an increase in the bulkiness of substituents in the $\beta$-diiminate (BDI) zinc-based systems led to an increase in catalyst activity. ${ }^{33,53}$ In these catalyst systems, the more bulky substituents disfavor association, forcing the catalyst in its monomeric, more active state. Apparently, the additional (dimethylamino)methyl group in $\mathbf{3}$ or methyl group in $\mathbf{2}$ co nol cause such an effect.

The same trend in polymerization rates was observed in the rac-LA polymerizations, applying catalysts $1\left(\mathrm{k}_{\mathrm{app}}=3.09 \mathrm{~h}^{-1}\right), 2\left(\mathrm{k}_{\mathrm{app}}=1.7 \mathrm{I} \mathrm{h}^{-1}\right)$ or $3\left(\mathrm{k}_{\mathrm{app}}=0.48 \mathrm{~b}^{-1}\right)$. However; whereas for $\mathbf{1}$ and $\mathbf{2}$, the polymerization rates for $L$-LA and $r a c$-LA are approximately the same, rac-LA polymerization using $\mathbf{3}$ was more than three times slower than the corresponding $L$-LA polymerization, which may indicate stereoselective behavior of this catalyst.

It is known that catalyst activity and stereoselectivity may be influenced by the solvent used in polymerizations. ${ }^{30.31 .34 .54 .55}$ Consequently, the ROP of rac-LA was also carried out in toluene and THF and compared to results obtained from the polymerizations carried out in $\mathrm{CH}_{2} \mathrm{Cl}_{2}$. Applying catalyst $\mathbf{1}$ in the ROP of rac-LA, polymerization times were similar when applying the solvents THF and foluene, but appeared significantly shorter when performed in $\mathrm{CH}_{2} \mathrm{Cl}_{2}$ (Table 1, entries 2,3 and 4). In contrast, the rates of polymerization of rac-LA polymerizations using $\mathbf{3}$ were in the order toluene $>\mathrm{THF}>\mathrm{CH}_{2} \mathrm{Cl}_{2}$. Most likely, this results from differences in catalyst association behavior in the different solvents. Equilibria between various aggregation states and the presence of Schlenk equilibria should be considered when catalysts like $\mathbf{1}$ and $\mathbf{3}$ are used in solution. ${ }^{49}$ Degrees of association, determined by cryoscopy in benzene, were reported for analogous zinc compounds. The trimethylsilylmethyl analogue of $\mathbf{1}$, $\left[\mathrm{Zn}\left(\mathrm{CH}_{2} \mathrm{SiMe}_{3}\right)\left(\mathrm{OC}_{6} \mathrm{H}_{4} \mathrm{CH}_{2} \mathrm{NMe}_{2}-2\right)\right]$, was shown to exist predominantly as a dimer (degree of association $=1.95$ ) In contrast, for both the trimethylsilylmethyl and the methyl analogue of $\mathbf{3}$, a degree of association of 1.50 was found, indicative of a dimermonomer equilibrium (Scheme 3). ${ }^{56}$ For $\mathbf{1}$ and 3, values of 2.00 and 1.86 were found, respectively, which may point out differences in association behavior of these catalysts in benzene. 

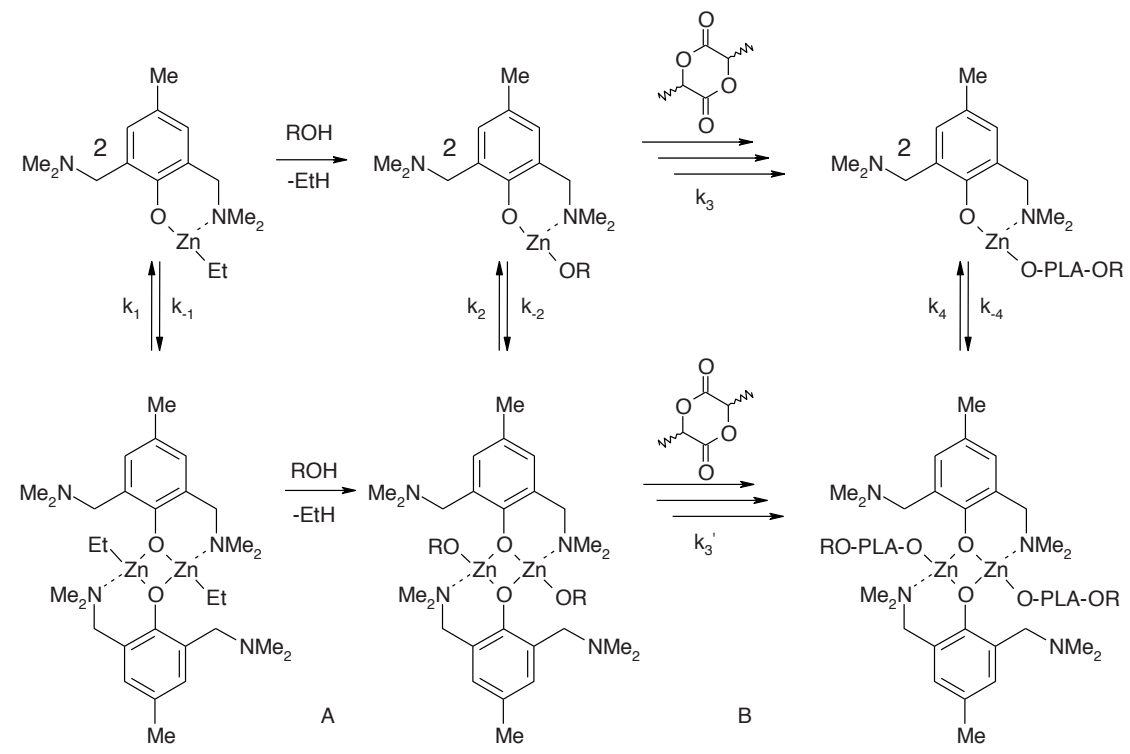

Scheme 3. Various equilibria that may play a role in the ROP of lactide using 3. A: alcoholysis of 3, followed by B: ROP of lactide, either with catalyst monomeric (top) or dimeric (bottom) species.

Though it is not clear whether these associations uphold after alcoholysis and/or insertion of lactide monomer, the order in catalyst in the polymerizations in $\mathrm{CH}_{2} \mathrm{Cl}_{2}$ using 3 suggest that catalyst association and dissociation indeed play a role throughout the reaction. The kinetic law, determined by plotting $\ln k_{\text {app }}\left(=\ln \left\{k_{p}[Z n]^{x}\right\}\right)$ as a function of $\ln [\mathrm{Zn}]$, revealed a linear relationship with a slope of 1.53 , showing a fractional dependency in catalyst (Figure 4). 


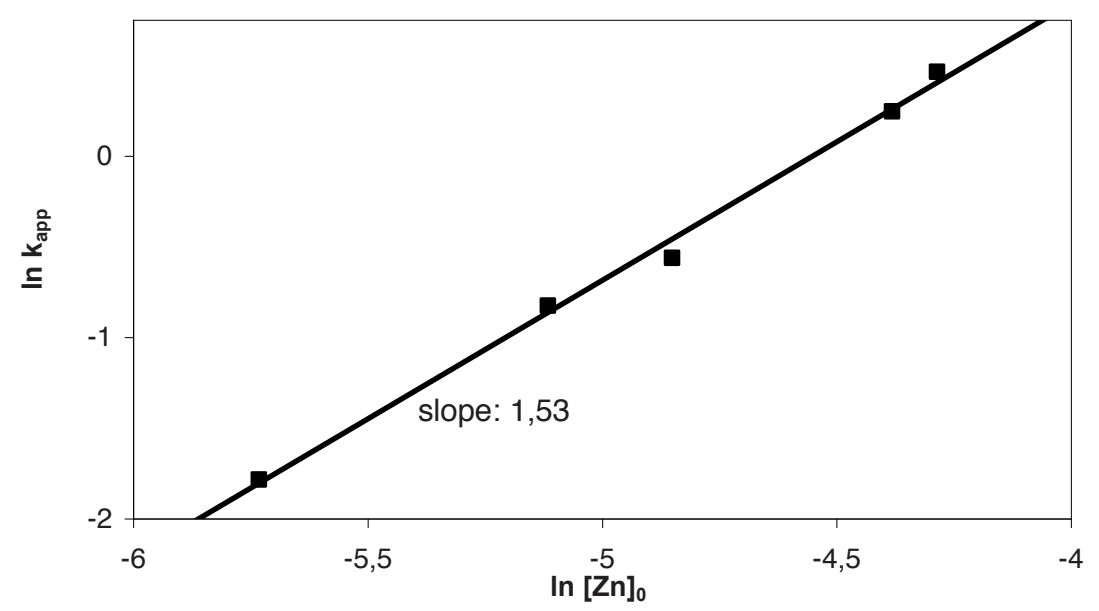

Figure 4. Plot of $\ln \mathrm{k}_{\text {app }}$ versus $\ln [\mathrm{Zn}]$ for the polymerization of rac-LA with 3; $\mathrm{CH}_{2} \mathrm{Cl}_{2}$, $25^{\circ} \mathrm{C},[\mathrm{M}]_{0} \approx 1.2 \mathrm{M}$.

Similar dependencies were observed for other zinc-based catalysts, ${ }^{33,48}$ and are thought to result from aggregation of the active catalytic species in the polymerization medium. THF is known to compete with the lactide monomer in coordination to the metal center, ${ }^{30,54}$ which might result in yet other active species for both $\mathbf{1}$ and $\mathbf{3}$ with respect to those in $\mathrm{CH}_{2} \mathrm{Cl}_{2}$ or toluene. The presence of two (dimethylamino)methyl donor groups in $\mathbf{3}$ versus only one in $\mathbf{1}$ will affect this association/dissociation behavior ${ }_{+}^{30,53,54}$ accounting for the differences in catalyst activity.

\section{Stereoselectivity}

The microstructural architecture of the polymers isolated from the various rac-LA polymerizations was investigated by homonuclear decoupled ${ }^{1} \mathrm{H}-\mathrm{NMR}$. From the integrals of the methyn signals $(\delta=5.3-5.1)$, the probability of isotactic $\left(P_{m}\right)$ and heterotactic $\left(P_{r}\right)$ enchainment were calculated, giving a quantitative measure of stereoselectivity ${ }^{57}$ 
Polymerizations of rac-LA performed in dichloromethane afforded polylactides with an almost fully random incorporation of $D$ - and $L$-lactide sequences when either 1 (Table 1 entry 2: $P_{m}=0.48$ ) or 3 (Table 1 , entry $8: P_{m}=0.52$ ) was used. A minor isotactic enrichment was observed upon using 3 at a polymerization temperature of $0^{\circ} \mathrm{C}$ (entry I0: $\left.P_{m}=0.56\right)$ or a lower $[\mathrm{M}] /[\mathrm{I}]$ ratio of 100 (entry $\left.11: P_{m}=0.56\right)$.

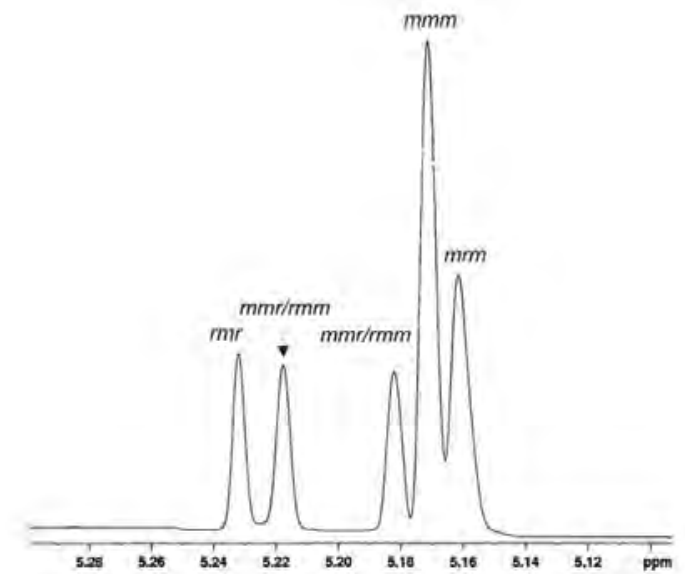

(A)

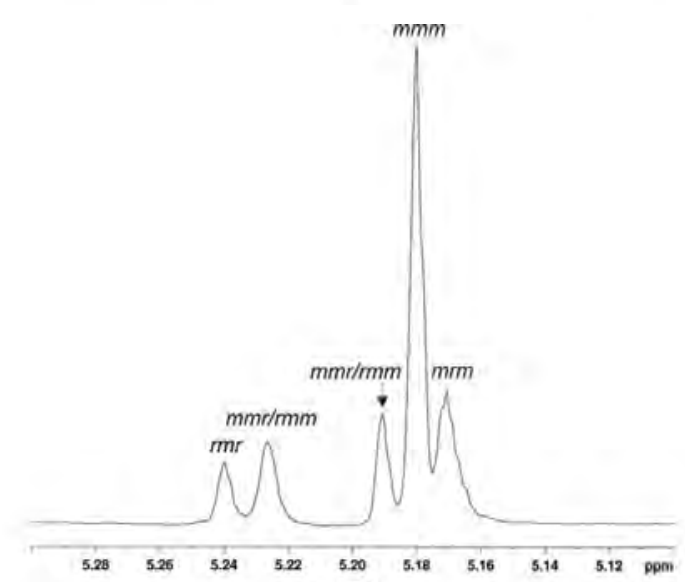

(C)

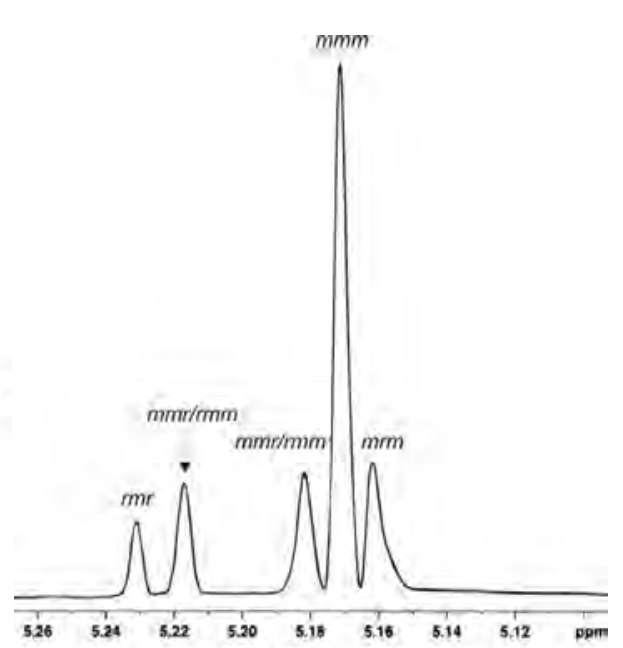

(B)

Figure 5. Homonuclear decoupled ${ }^{1}$ H-NMR spectra of PDLLA polymers synthesized using 3 in dichloromethane (A), toluene (B) and THF (C) at $25^{\circ} \mathrm{C},[\mathrm{M}]:[\mathrm{I}]=200,[\mathrm{M}]_{0} \approx$ $1.2 \mathrm{M}$ 
Most interestingly, whereas 1 displays a small shift towards heterotactic enrichment upon using either toluene (Table 1, entry 3: $P_{r}=1-P_{m}=0.55$ ) or THF (Table 1, entry 4: $P_{r}=$ $1-P_{m}=0.56$ ) as the polymerization media, the stereoselective behavior of 3 notably shifts towards enrichment in isotactic sequences in both toluene (Table 1, entry 12: $P_{m}=$ 0.61 ) and THF (Table 1, entry 14: $P_{m}=0.63$ ). The latter has, to our knowledge, not been achieved with achiral zinc-based catalysts before. Since isotactic enrichments were found upon the use of a polar (THF) as well as a non-polar (toluene) solvent, the stereoselective behavior is not directly related to the solvent polarity or coordination of solvent molecules to the metal center. Most likely, the extra (dimethylamino)methyl group in 3

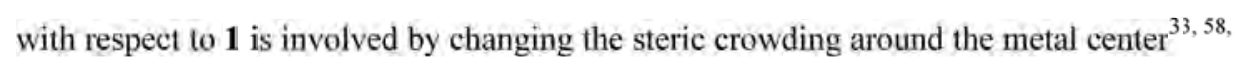
${ }^{59}$ and (he catalyst association behavior ${ }^{30,53,54}$ (as discussed above).

From NMR data of the comounds in solution it is known that at a given time point only one of the two (dimethylamino)methyl groups in $\mathbf{1}$ is coordinated to the metal species, and it is suggested that these groups alternately coordinate by rapid interchange. Any chiral center, possibly formed upon aggregation, is therefore not likely to uphold. $\Lambda \mathrm{s} \mathbf{1}$ itself lacks a chiral center as well, the polymerization is most likely chain-end controlled. A more detailed study of the catalyst association behavior in various solvents is to be performed to gain more insight into its influence on the stereoselective behavior.

\section{Conclusion}

Three novel zinc-based catalysts, based on NO-bidentate and NON-tridentate alkoxides, have been successfully applied in fast and controlled ROP of (racemic) lactides. Reactions have the characteristics of 'living' polymerizations, leading to $\mathrm{M}_{\mathrm{n}}$ values close to the theoretical values and low polydispersities. The polymerizations were first-order in monomer. Catalyst 3 displayed a moderate, solvent-dependent stereoselective behavior, giving enrichment in isotactic sequences when using THF and toluene as the polymerization media, which has not been reported for achiral zinc catalysts up to now. 
Zn Alkoxides for the Controlled ROP of Lactides

\section{Acknowledgements}

The group of prof. Gerard van Koten at the University of Utrecht, and in particular Henk Kleijn, is greatfully acknowledged for supplying and characterizing the catalysts described in this chapter. Rainer Wechselberger is greatfully acknowledged for his help in obtaining the decoupled ${ }^{1} \mathrm{H}-\mathrm{NMR}$ spectra.

\section{References}

1. D. Garlotta, A literature review of poly(lactic acid). J. Polym. Environ., 2001, 9(2), 63-84.

2. R. Auras, B. Harte and S. Selke, An overview of polylactides as packaging materials. Macromol. Biosci., 2004, 4(9), 835-864.

3. A. C. Albertsson and I. K. Varma, Recent developments in ring opening polymerization of lactones for biomedical applications. Biomacromolecules, 2003, 4(6), 1466-1486.

4. U. Edlund and A. C. Albertsson, Degradable polymer microspheres for controlled drug delivery. Adv. Polym. Sci., 2001, 157(-), 67-112.

5. J. C. Middleton and A. J. Tipton, Synthetic biodegradable polymers as orthopedic devices. Biomaterials, 2000, 21(23), 2335-2346.

6. J. C. Wu, T. L. Yu, C. T. Chen and C. C. Lin, Recent developments in main group metal complexes catalyzed/initiated polymerization of lactides and related cyclic esters. Coord. Chem. Rev., 2006, 250(5-6), 602-626.

7. O. Dechy-Cabaret, B. Martin-Vaca and D. Bourissou, Controlled ring-opening polymerization of lactide and glycolide. Chem. Rev., 2004, 104(12), 6147-6176.

8. B. J. O'Keefe, M. A. Hillmyer and W. B. Tolman, Polymerization of lactide and related cyclic esters by discrete metal complexes. J. Chem. Soc.-Dalton Trans., 2001, 2001(15), 2215 - 2224.

9. A. Duda, Stereocontrolled polymerization of chiral heterocyclic monomers. Polimery, 2004, 49(7-8), 469-478.

10. N. Spassky, M. Wisniewski, C. Pluta and A. LeBorgne, Highly stereoelective polymerization of rac-(D,L)-lactide with a chiral Schiff's base/aluminium alkoxide initiator. Macromol. Chem. Phys., 1996, 197(9), 2627-2637.

11. M. Wisniewski, A. LeBorgne and N. Spassky, Synthesis and properties of (D)and (L)-lactide stereocopolymers using the system achiral Schiff's base aluminium methoxide as initiator. Macromol. Chem. Phys., 1997, 198(4), 12271238 .

12. T. M. Ovitt and G. W. Coates, Stereoselective ring-opening polymerization of rac-lactide with a single-site, racemic aluminum alkoxide catalyst: Synthesis of stereoblock poly(lactic acid). J. Polym. Sci., Part A: Polym. Chem., 2000, 38(S1), 4686 - 4692.

13. C. P. Radano, G. L. Baker and M. R. Smith, Stereoselective polymerization of a racemic monomer with a racemic catalyst: Direct preparation of the polylactic 
acid stereocomplex from racemic lactide. J. Am. Chem. Soc., 2000, 122(7), 15521553.

14. N. Nomura, R. Ishii, M. Akakura and K. Aoi, Stereoselective ring-opening polymerization of racemic lactide using aluminum-achiral ligand complexes: Exploration of a chain-end control mechanism. J. Am. Chem. Soc., 2002, 124(21), 5938-5939.

15. Z. Y. Zhong, P. J. Dijkstra and J. Feijen, [(salen)Al]-mediated, controlled and stereoselective ring- opening polymerization of lactide in solution and without solvent: Synthesis of highly isotactic polylactide stereocopolymers from racemic D,L-lactide. Angew. Chem.-Int. Edit., 2002, 41(23), 4510-4513.

16. Z. Y. Zhong, P. J. Dijkstra and J. Feijen, Controlled and stereoselective polymerization of lactide: Kinetics, selectivity, and microstructures. J. Am. Chem. Soc., 2003, 125(37), 11291-11298.

17. J. Belleney, M. Wisniewski and A. Le Borgne, Influence of the nature of the ligand on the microstructure of poly d,1-lactides prepared with organoaluminum initiators. Eur. Polym. J., 2003, 40(3), 523-530.

18. P. Hormnirun, E. L. Marshall, V. C. Gibson, A. J. P. White and D. J. Williams, Remarkable stereocontrol in the polymerization of racemic lactide using aluminum initiators supported by tetradentate aminophenoxide ligands. J. Am. Chem. Soc., 2004, 126(9), 2688-2689.

19. Z. H. Tang, X. S. Chen, X. Pang, Y. K. Yang, X. F. Zhang and X. B. Jing, Stereoselective polymerization of rac-lactide using a monoethylaluminum Schiff base complex. Biomacromolecules, 2004, 5(3), 965-970.

20. Z. H. Tang, X. Pang, J. R. Sun, H. Z. Du and X. S. Chen, Five-coordinated active species in the stereoselective polymerization of rac-lactide using N,N '-(2,2dimethyl-1,3-propylene)bis(3,5-di-tert-butyl-salicylideneimine) aluminum complexes. J. Polym. Sci., Part A: Polym. Chem., 2006, 44(16), 4932-4938.

21. N. Nomura, R. Ishii, Y. Yamamoto and T. Kondo, Stereoselective ring-opening polymerization of a racemic lactide by using achiral salen- and homosalenaluminum complexes. Chem.-Eur. J., 2007, 13(16), 4433-4451.

22. H. Y. Ma, G. Melillo, L. Oliva, T. P. Spaniol, U. Englert and J. Okuda, Aluminium alkyl complexes supported by [OSSO] type bisphenolato ligands: synthesis, characterization and living polymerization of rac-lactide. Dalton Trans., 2005, 2005(4), 721-727.

23. P. Hormnirun, E. L. Marshall, V. C. Gibson, R. I. Pugh and A. J. P. White, Study of ligand substituent effects on the rate and stereoselectivity of lactide polymerization using aluminum salen-type initiators. Proc. Natl. Acad. Sci. U.S. A., 2006, 103(42), 15343-15348.

24. H. Z. Du, X. Pang, H. Y. Yu, X. L. Zhuang, X. S. Chen, D. M. Cui, X. H. Wang and $X$. B. Jing, Polymerization of rac-lactide using schiff base aluminum catalysts: Structure, activity, and stereoselectivity. Macromolecules, 2007, 40(6), 1904-1913.

25. J. Wu, X. Pan, N. Tang and C. C. Lin, Synthesis, characterization of aluminum complexes and the application in ring-opening polymerization of 1-lactide. Eur. Polym. J., 2007, 43(12), 5040-5046. 
26. Z. Tang and V. C. Gibson, rac-Lactide polymerization using aluminum complexes bearing tetradentate phenoxy-amine ligands. Eur. Polym. J., 2007, 43(1), 150-155.

27. X. Pang, D. Du, X. Chen, X. Wang and X. Jing, Enolic Schiff Base Aluminum Complexes and Their Catalytic Stereoselective Polymerization of Racemic Lactide. Chem. Eur. J., 2008, 14(10), 3126-3136.

28. H. Du, A. H. Velders, P. J. Dijkstra, Z. Y. Zhong, X. Chen and J. Feijen, Polymerization of Lactide Using Achiral Bis(pyrrolidene) Schiff Base Aluminum Complexes. Macromolecules, 2009, 42(4), 1058-1066.

29. M. H. Chisholm, N. W. Eilerts, J. C. Huffman, S. S. Iyer, M. Pacold and K. Phomphrai, Molecular design of single-site metal alkoxide catalyst precursors for ring-opening polymerization reactions leading to polyoxygenates. 1. Polylactide formation by achiral and chiral magnesium and zinc alkoxides, $\left(\eta^{3}-\mathrm{L}\right) \mathrm{MOR}$, where $\mathrm{L}=$ trispyrazolyl- and trisindazolylborate ligands. J. Am. Chem. Soc., 2000, 122(48), 11845-11854.

30. M. H. Chisholm, J. Gallucci and K. Phomphrai, Coordination chemistry and reactivity of monomeric alkoxides and amides of magnesium and zinc supported by the diiminato ligand $\mathrm{CH}\left(\mathrm{CMeNC}_{6} \mathrm{H}_{3}-2,6-\mathrm{Pr}_{2}\right)_{2}$. A comparative study. Inorg. Chem., 2002, 41(10), 2785-2794.

31. M. H. Chisholm, J. C. Gallucci and K. Phomphrai, Comparative study of the coordination chemistry and lactide polymerization of alkoxide and amide complexes of zinc and magnesium with a 6-diiminato ligand bearing ether substituents. Inorg. Chem., 2005, 44(22), 8004-8010.

32. M. Cheng, A. B. Attygalle, E. B. Lobkovsky and G. W. Coates, Single-site catalysts for ring-opening polymerization: Synthesis of heterotactic poly(lactic acid) from rac-lactide. J. Am. Chem. Soc., 1999, 121(49), 11583-11584.

33. B. M. Chamberlain, M. Cheng, D. R. Moore, T. M. Ovitt, E. B. Lobkovsky and G. W. Coates, Polymerization of lactide with zinc and magnesium beta-diiminate complexes: Stereocontrol and mechanism. J. Am. Chem. Soc., 2001, 123(14), 3229-3238.

34. H. Y. Chen, H. Y. Tang and C. C. Lin, Ring-opening polymerization of lactides initiated by zinc alkoxides derived from NNO-tridentate ligands. Macromolecules, 2006, 39(11), 3745-3752.

35. T. R. Jensen, C. P. Schaller, M. A. Hillmyer and W. B. Tolman, Zinc Nheterocyclic carbene complexes and their polymerization of D,L-lactide. $J$. Organomet. Chem., 2005, 690(24-25), 5881-5891.

36. A. P. Dove, H. B. Li, R. C. Pratt, B. G. G. Lohmeijer, D. A. Culkin, R. M. Waymouth and J. L. Hedrick, Stereoselective polymerization of rac- and mesolactide catalyzed by sterically encumbered N-heterocyclic carbenes. Chem. Commun., 2006, 2006(27), 2881-2883.

37. M. H. Chisholm, J. C. Gallucci, K. T. Quisenberry and Z. Zhou, Complexities in the Ring-Opening Polymerization of Lactide by Chiral Salen Aluminum Initiators. Inorg. Chem., 2008, 47(7), 2613-2624.

38. H. Y. Chen, B. H. Huang and C. C. Lin, A Highly Efficient Initiator for the RingOpening Polymerization of Lactides and $\varepsilon$-Caprolactone: A Kinetic Study. Macromolecules, 2005, 38(13), 5400-5405. 
39. X. Pang, X. Chen, X. Zhuang and X. Jing, Crown-like macrocycle zinc complex derived from beta-diketone ligand for the polymerization of rac-lactide. J. Polym. Sci., Part A: Polym. Chem., 2007, 46(2), 643-649.

40. C. Alonso-Moreno, A. Garcés, L. F. Sánchez-Barba, M. Fajardo, J. FernándezBaeza, A. Otero, A. Lara-Sánchez, A. Antiñolo, L. Broomfield, M. L. LópezSolera and A. M. Rodríguez, Discrete Heteroscorpionate Lithium and Zinc Alkyl Complexes. Synthesis, Structural Studies, and ROP of Cyclic Esters. Organometallics, 2008, 27(6), 1310-1321.

41. Y. Huang, W. C. Hung, M. Y. Liao, T. E. Tsai, Y. L. Peng and C. C. Lin, Ringopening polymerization of lactides initiated by magnesium and zinc complexes based on NNO-tridentate ketiminate ligands: Activity and stereoselectivity studies. J. Polym. Sci., Part A: Polym. Chem., 2009, 47(9), 2318-2329.

42. R. O. Day, W. H. Batschelet and R. D. Archer, Crystal And Molecular-Structure Of 7-Coordinate Carbonyl(5,7-Dichloro-8-Quinolinolato)(Triphenylphosphine) Chelates Of Tungsten(Ii). Inorg. Chem., 1980, 19(7), 2113-2122.

43. P. A. Van der Schaaf, J. T. B. H. Jastrzebski, M. P. Hogerheide, W. J. J. Smeets, A. L. Spek, J. Boersma and G. Van Koten, Mono-Ortho-Chelated And Bis-OrthoChelated Lithium And Sodium Phenolates - Molecular-Structures Of The 1st Lithium Phenolate With A Stable, Trinuclear Structure And Of A Tetranuclear Sodium Analog, [ $\left.\mathrm{MoC}_{6} \mathrm{H}_{2}\left(\mathrm{CH}_{2} \mathrm{NMe}_{2}\right)_{2}-2,6-\mathrm{Me}-4\right] \mathrm{X}(\mathrm{M}=\mathrm{Li}, \mathrm{X}=3, \mathrm{M}=\mathrm{Na}, \mathrm{X}=$ 4). Inorg. Chem., 1993, 32(19), 4111-4118.

44. J. M. Bruce, B. C. Cutsforth, D. W. Farren, F. G. Hutchinson, F. M. Rabagliati and D. R. Reed, Organozinc compounds. Part III. Further alcoholyses of dimethyl- and diphenyl-zinc. J. Chem. Soc., 1966, 1020-1024.

45. J. Boersma in Comprehensive Organometallic Chemistry; G. Wilkinson, F. G. A. Stone and E. W. Abel; Pergamon, Oxford, 1982, 823-862.

46. E. J. Corey, P. W. Yuen, F. J. Hannon and D. A. Wierda, Polyfunctional, Structurally Defined Catalysts For The Enantioselective Addition Of Dialkylzinc Reagents To Aldehydes. J. Org. Chem., 1990, 55(3), 784-786.

47. B. S. Hammes and C. J. Carrano, Synthesis and characterization of pseudotetrahedral $\mathrm{N} 2 \mathrm{O}$ and $\mathrm{N} 2 \mathrm{~S}$ zinc(II) complexes of two heteroscorpionate ligands: Models for the binding sites of several zinc metalloproteins. Inorg. Chem., 1999, 38(20), 4593-4600.

48. C. K. Williams, L. E. Breyfogle, S. K. Choi, W. Nam, V. G. Young, M. A. Hillmyer and W. B. Tolman, A highly active zinc catalyst for the controlled polymerization of lactide. J. Am. Chem. Soc., 2003, 125(37), 11350-11359.

49. J. T. B. H. Jastrzebski, J. Boersma and G. Van Koten in Patai Series: The Chemistry of Functional Groups, The Chemistry of Organozinc Compounds, Part 1; Z. Rappoport and I. Marek; Wiley, Chichester, 2006, 31-135.

50. H. M. M. Shearer and C. B. Spencer, Tetrametric methylzinc methoxide. Acta Crystallogr., Sect. B: Struct. Sci., 1980, 36(9), 2046-2050.

51. W. A. Herrmann, S. Bogdanovic, J. Behm and M. Denk, Multiple Bonds Between Main-Group Elements And Transition-Metals.110. Methylated Nitridomolybdenum(Vi) Complexes. J. Organomet. Chem., 1992, 430(2), C33C38. 
52. A. D. Bond, D. J. Linton and A. E. H. Wheatley, Methylzinc tert-butoxide tetrahydrofuran solvate. Acta Crystallogr. Sect. E: Struct. Rep. Online, 2001, 57(7), m298-m300.

53. L. R. Rieth, D. R. Moore, E. B. Lobkovsky and G. W. Coates, Single-site $\beta$ diiminate zinc catalysts for the ring-opening polymerization of $\beta$-butyrolactone and $\beta$-valerolactone to poly(3-hydroxyalkanoates). J. Am. Chem. Soc., 2002, 124(51), 15239-15248.

54. M. H. Chisholm and K. Phomphrai, Conformational effects in beta-diiminate ligated magnesium and zinc amides. Solution dynamics and lactide polymerization. Inorg. Chim. Acta, 2003, 350(-), 121-125.

55. C. X. Cai, A. Amgoune, C. W. Lehmann and J. F. Carpentier, Stereoselective ring-opening polymerization of racemic lactide using alkoxy-aminobis(phenolate) group 3 metal complexes. Chem. Commun., 2004, 2004(3), 330331.

56. P. A. Van der Schaaf, E. Wissing, J. Boersma, W. J. J. Smeets, A. L. Spek and G. Van Koten, Organozinc Complexes With Monoanionic Chelating Phenolates Or 2-Pyridylmethanolates - Molecular-Structure Of $\left[\mathrm{Zn}\left(\mathrm{CH}_{2} \mathrm{SiMe}_{3}\right)\left(\mathrm{OCH}_{2}(2-\mathrm{Py})\right)\right]_{4}$. Organometallics, 1993, 12(9), 3624-3629.

57. J. Coudane, C. Ustariz-Peyret, G. Schwach and M. Vert, More about the stereodependence of $\mathrm{DD}$ and LL pair linkages during the ring-opening polymerization of racemic lactide. J. Polym. Sci., Part A: Polym. Chem., 1997, 35(9), 1651-1658.

58. E. L. Marshall, V. C. Gibson and H. S. Rzepa, A computational analysis of the ring-opening polymerization of rac-lactide initiated by single-site betadiketiminate metal complexes: Defining the mechanistic pathway and the origin of stereocontrol. J. Am. Chem. Soc., 2005, 127(16), 6048-6051.

59. M. H. Chisholm, J. C. Gallucci, H. H. Zhen and J. C. Huffman, Three-coordinate zinc amide and phenoxide complexes supported by a bulky Schiff base ligand. Inorg. Chem., 2001, 40(19), 5051-5054. 


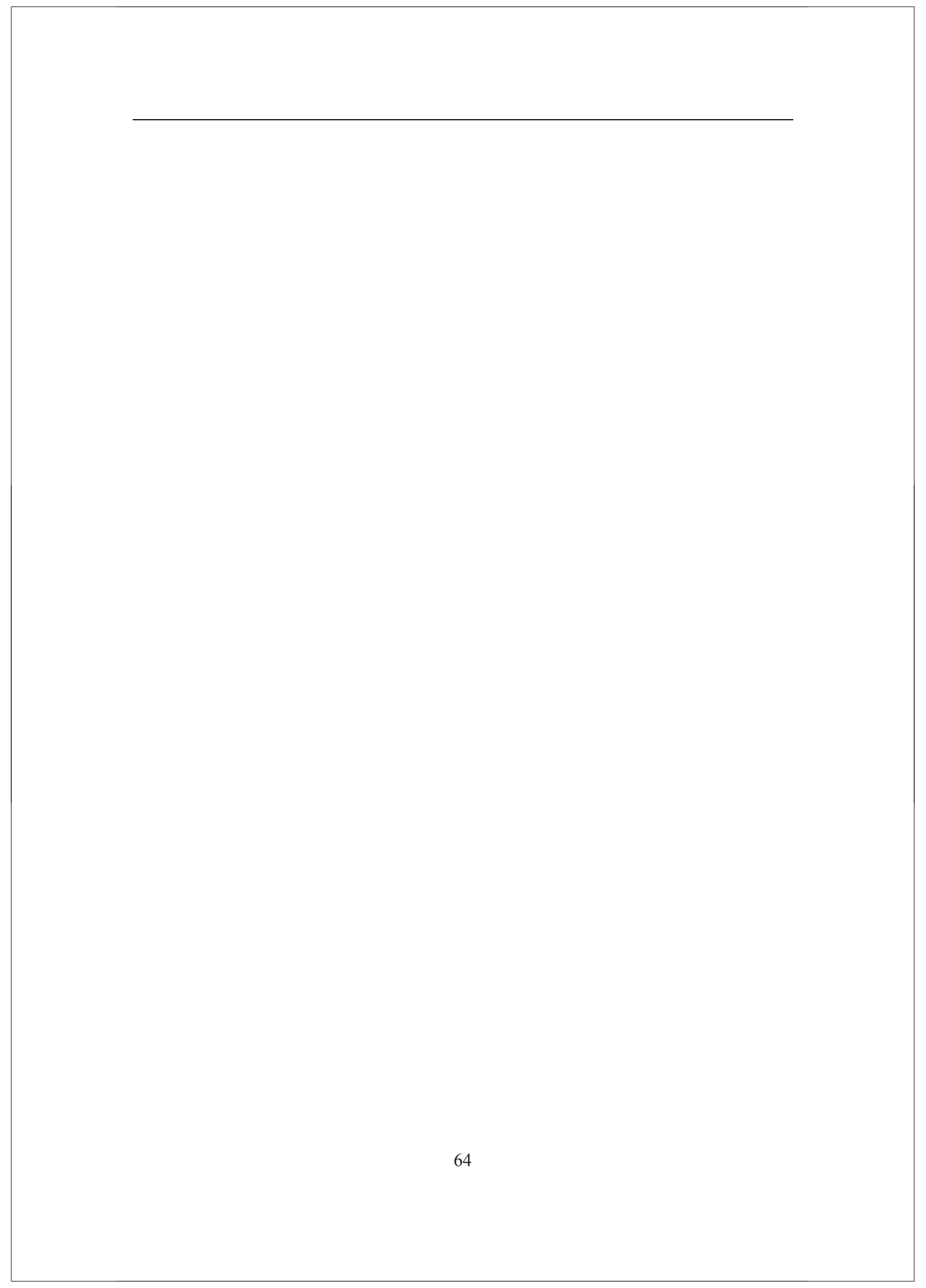




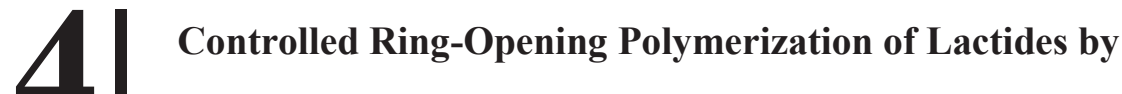 \\ Thiophenolate-Based Zinc Catalysts
}

\begin{abstract}
Three novel zinc-based catalysts of the type $\left[\mathrm{L}_{n} \mathrm{ZnEt}\right]_{\mathrm{n}}$ with $\mathrm{L}_{1}=2$-[1-(pyrrolidin-1yl)ethyl]benzenethiol, $\mathrm{L}_{2}=2$-[1-(dimethylamino)-ethyl]-benzene-thiol and $\mathrm{L}_{3}=2$ [(dimethylamino)methyl]benzenethiol were synthesized and applied in the ring-opening polymerization of (racemic) lactides. Polymerizations afforded poly(lactide)s with $M_{n}$ values close to the theoretical values and low polydispersities in most cases. All polymerizations were first-order in monomer. The polymerizations of racemic lactide were faster than those of the single enantiomers, indicating a preference for heterotactic enrichment. This was confirmed by homonuclear decoupled ${ }^{1} \mathrm{H}-\mathrm{NMR}$ spectra, showing that all catalysts gave polymers with a moderate heterotactic enrichment $\left(P_{r} \approx 0.60\right)$.
\end{abstract}




\section{Introduction}

In the past decades, there has been an increasing attention for (bio)degradable, non-toxic polymers based on renewable resources. with poly(lactic acid) (PLA) as a major example. PLA is conveniently prepared by ring-opening polymerization (ROP) of lactides in solution or the bulk using metal-ligand complexes $s^{1-3}$ and numerous metal alkoxide catalysts have been well-studied in this respect. In general, using more bulky ligands leads to a higher suppression of back-biting and transesterification reactions. The polymerization reactions can be well controlled by these cocrdination catalysts and lead to polymers with narrow molecular weight distributions. The use of coordinating ligands also provides a way to prepare 'single-site' catalysts, allowing the use of multifunctional initiators while avoiding gelation during polymerization.

Coordination catalysts giving stereoselective polymerization of lactides have received much attention in recent years. Non-stereoselective polymerization of racemic lactide (rac-LA) will result in a random enchainment and amorphous PLAs. However, catalysts that discriminate between enantiomeric lactides give polylactides baving domains with increased stereoregularity (Scheme 1). In case of isotactic enrichment. stereocomplexation will lead to semi-crystalline PLAs with altered mechanical properties.

The design and synthesis of new, stereoselective catalysts for the ROP reactions of lactides have received a lot of attention. Though a general set of rules cannot be given, electronic effects and ligand bulkiness are important parameters in catalyst design. Increasing bulkiness of the ligand generally leads to a higher stereoselectivity, but the activity is usually decreased, most likely because of increased shielding of the active metal center. ${ }^{4-6}$ The catalyst activity may also significantly change with the electrondonating or -withdrawing capacity of the ligand, and an increased activity is thought to originate from the ability of the ligand to generate a more electrophilic metal species, ${ }^{6,7}$ A number of metal-ligand combinations ${ }^{1-3}$ were shown to give stereoselective polymerizations of $\mathrm{rac}$-LA, and most notable results have been obtained with single-site catalysts based on aluminum ${ }^{4,6,8-22}$ and zinc. ${ }^{5,}$, 23-33 Both isotactic and heterotactic enrichment (Scheme 1) were reported for the aluminum based catalyst, which generally comprise salen-type ligands. 


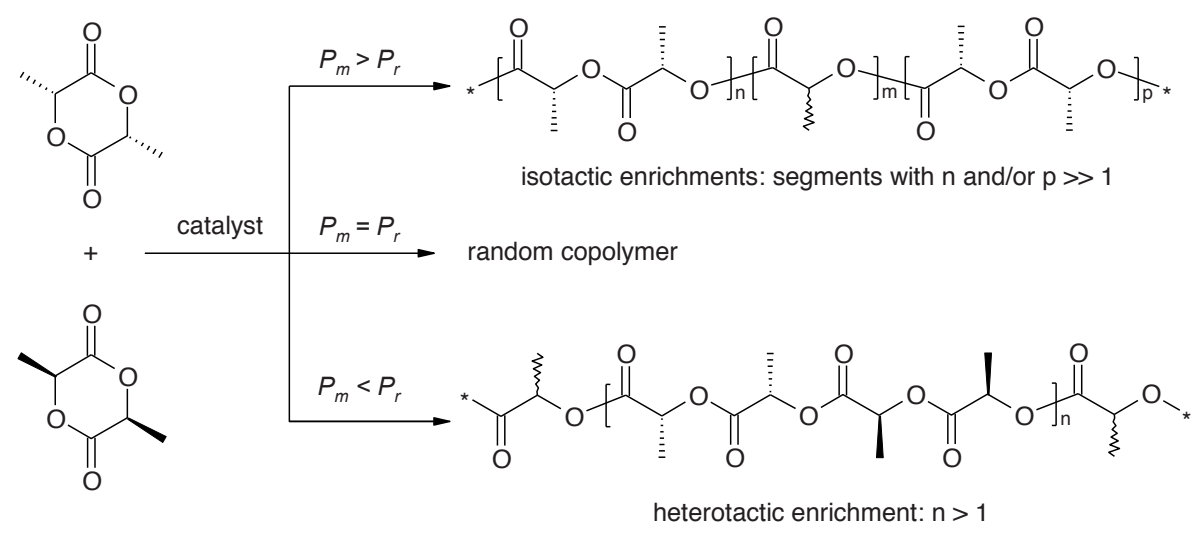

Scheme 1. Various possibilities for the microstructural composition of PLA, made from $r a c$-LA.

Although high levels of enantiomeric enrichment can be obtained, the aluminum based catalysts generally show moderate to low activity. The zinc based catalysts are more advantageous in this respect, giving fast and controlled polymerizations at ambient temperatures. Moreover, the extensive use of PLA in biomedical applications, together with difficulties encountered in complete catalyst removal have led to focusing on lowtoxic metals, ${ }^{1}$ such as iron, calcium ${ }^{34,35}$ and zinc. So far, only heterotactic enrichment has been reported in $r a c$-LA polymerization using $\beta$-diiminate zinc-catalysts, ${ }^{5,26}$ catalysts based on Schiff base ligands ${ }^{7,}{ }^{30}$, NNO-tridentate ketiminate ligands ${ }^{33}$, heteroscorpionate ligands ${ }^{32}$ and $N$-heterocyclic carbenes. ${ }^{27}$ Whereas the use of ligands combining (multiple) nitrogen and/or oxygen donor atoms is frequently encountered in literature, the use of sulfur-containing ligands in ROP-catalysts is rare ${ }^{36-40}$ In analogy with the singlesite phenoxy zinc catalysts, ${ }^{41}$ three zinc catalysts (1-3; Scheme 2), containing thiophenolate ligands, were studied for their catalytic activity in the ROP of lactides and their stereoselective behavior in $\mathrm{rac}$-LA polymerizations. 


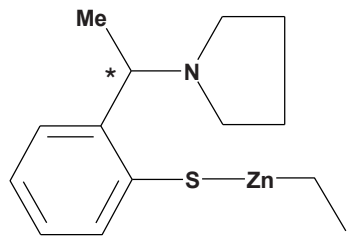

1

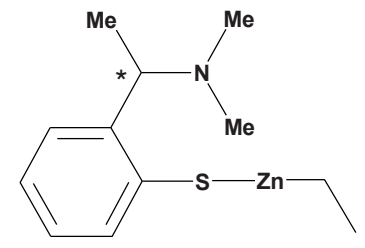

2

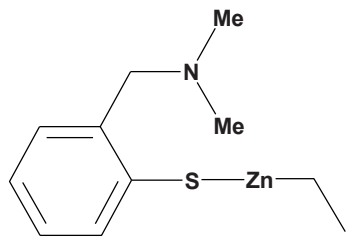

3

Scheme 2. Zinc catalysts 1-3, based on amino-substituted benzenethiols, as used in the polymerizations of $L$-L, $D$-LA and rac-LA with $\mathrm{HO} i \mathrm{Pr}$ as an initiator; $\mathrm{CH}_{2} \mathrm{Cl}_{2}, 25^{\circ} \mathrm{C}$. The asterisks $\left({ }^{*}\right)$ mark chiral centers with an $R$-configuration.

\section{Experimental}

\section{Materials}

L-LA and rac-LA (Purac) were recrystallized from dry toluene. Solvents (Biosolve) were dried by distillation over sodium wire (toluene), calcium hydride (dichloromethane and THF) or sodium sand (pentane and hexane) prior to use. Diethyl ether and methanol were used without further purification. Diethyl zinc, $1 \mathrm{M}$ in hexane, was purchased from Aldrich. The syntheses of 2-(1-pyrrolidinoethyl)thiophenoxy ethylzinc (1), ${ }^{42}$ 2-[1(dimethyl-amino)ethyl]thiophenoxy ethylzinc $(\mathbf{2})^{43,} \quad 44$ and 2-[(dimethylamino)methyl]thiophenoxy ethylzinc $(3)^{43,44}$ have been described elsewhere. The chiral catalysts 1 and $\mathbf{2}$ were almost exclusively of the $R$-configuration (97\%).

Synthesis

Lactide Polymerizations: All experiments were carried out under nitrogen in a glovebox or under argon using Schlenk techniques. In a typical polymerization lactide $(2.0 \mathrm{~g}, 13.9$ mmol), isopropanol (4.2 mg $0.069 \mathrm{mmol}_{\text {, }}$ added as $2 \mathrm{wt} \%$ solution in dichloromethane) and $7.5 \mathrm{ml}$ of dichloromethane were introduced into a dried reaction vessel equipped with a magnetic stirring bar. The vessel was placed in an oil bath thermostated at $25^{\circ} \mathrm{C}$. To the vigorously stirred mixture, a solution of $0.069 \mathrm{mmol}$ catalyst in $2 \mathrm{ml}$ of dichloromethane was added, resulting in $[\mathrm{M}]:[\mathrm{HO} i \mathrm{Pr}]:[\mathrm{Zn}]=200: 1: 1$. At selected time intervals, about 0.8-1.0 ml-aliquots were removed and the conversion was determined using ${ }^{1} \mathrm{H}-\mathrm{NMR}$. AI high conversion, the reaction was terminated by adding glacial acetic acid, followed by removal of the solvent by evaporation. The remaining residues were redissolved in chloroform and polymers were precipitated in cold diethyl ether or cold methanol. The 
polymers were subsequently dried in vacuo. ${ }^{1} \mathrm{H}-\mathrm{NMR}\left(\mathrm{CDCl}_{3}\right)$ : PLLA: $\delta=5.15\left(\mathrm{q}, \mathrm{IH}_{1}\right.$ $\mathrm{CH}\left(\mathrm{CH}_{3}\right)-\mathrm{O}$ ). 5.00 (q, $\left.1 \mathrm{H}, \mathrm{CH}\left(\mathrm{CH}_{3}\right)_{2}\right) 4.35$ (q, $\left.1 \mathrm{H}, \mathrm{CH}\left(\mathrm{CH}_{3}\right)-\mathrm{OH}\right), 1.57(\mathrm{~d}, 3 \mathrm{H}$, $\left.\mathrm{CH}\left(\mathrm{CH}_{3}\right)-\mathrm{O}\right), 1.22$ (dd, 6H, $\left.-\mathrm{CH}-\left(\mathrm{CH}_{3}\right)_{2}\right)$.

\section{Characterization}

NMR: ${ }^{1} \mathrm{H}-\mathrm{NMR}(300 \mathrm{MHz})$ spectra were recorded on a Varian Inova spectrometer using $\mathrm{CDCl}_{3}$ solutions, and were referenced to shifts of residual $\mathrm{CHCl}_{3}(\delta=7.26)$. The homonuclear decoupled ${ }^{1} \mathrm{H}-\mathrm{NMR}$ were recorded on a Bruker Avance $750 \mathrm{MHz}$ spectrometer with triple axis gradient.

GPC: GPC measurements were conducted with a Waters 6000A GPC apparatus equipped with a series of standard Waters Styragel HR columns and a H502 viscometer detector (Viscotek Corp.). Polystyrene standards were used and the molecular weights were determined using universal calibration. Polymers were dissolved in chloroform ( $\sim 5$ $\mathrm{mg} / \mathrm{ml}$ ) and eluted with chloroform at $25^{\circ} \mathrm{C}$ at a flow rate of $1.5 \mathrm{ml} / \mathrm{min}$.

DSC: Thermal analysis was carried out using a Perkin-Elmer DSC-7 Differential Scanning Calorimeter equipped with a PE7700 computer and TAS-7 software. Calibration was performed with pure indium. A polymer sample (ca. $5 \mathrm{mg}$ ) was heated to $250{ }^{\circ} \mathrm{C}$ at $20^{\circ} \mathrm{C} \cdot \min ^{-1}$, cooled to $0^{\circ} \mathrm{C}$ at $20{ }^{\circ} \mathrm{C} \cdot \min ^{-1}$ and reheated to $250{ }^{\circ} \mathrm{C}$ at $20^{\circ} \mathrm{C}$ min ${ }^{1}$. Alternatively, the sample was annealed at $250^{\circ} \mathrm{C}$ for 5 minutes after the first heating run. Melting temperatures $\left(\mathrm{T}_{\mathrm{m}}\right)$ were taken from the peak maxima of the second heating curves. 


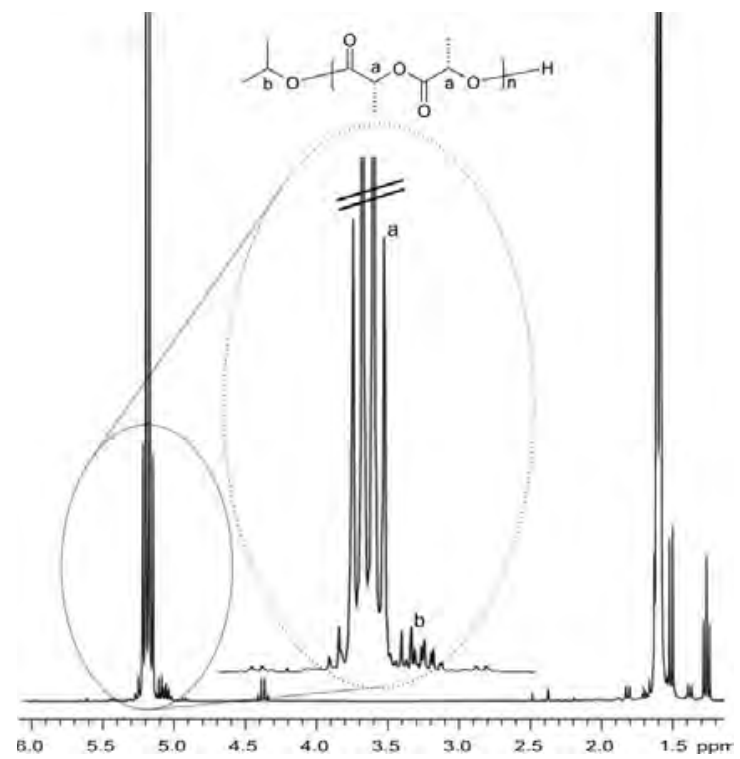

Figure 1A. Characteristic ${ }^{1}$ H-NMR signals of polymers made by ROP of $L$-LA. Solvent: $\mathrm{CDCl}_{3}$

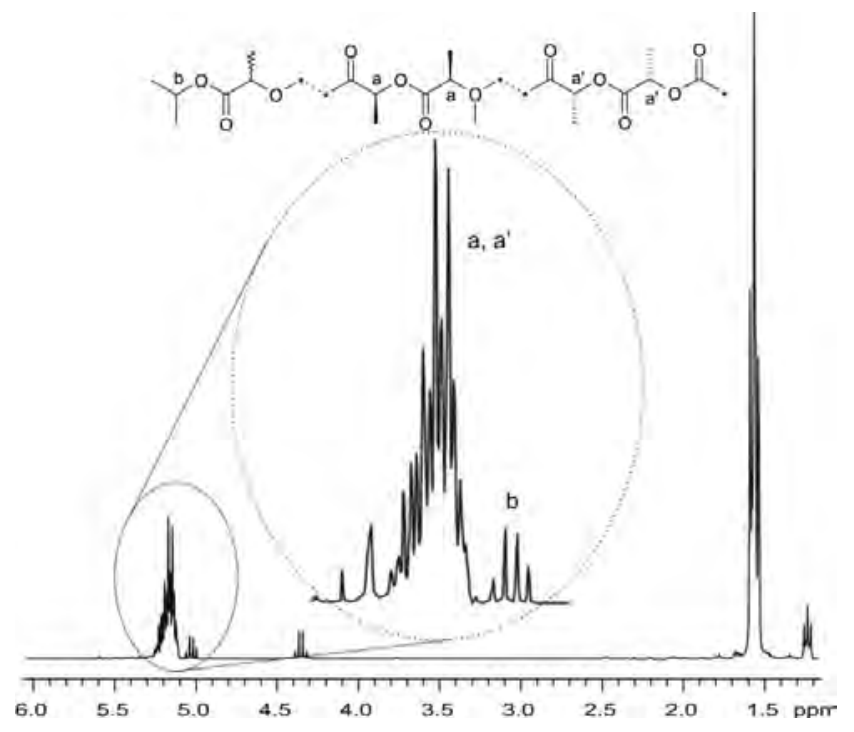

Figure IB. Characteristic ${ }^{1} \mathrm{H}-\mathrm{NMR}$ signals of polymers made by ROP of rac-LA

Solvent: $\mathrm{CDCl}_{3}$ 


\section{Results and Discussion}

\section{Lactide polymerizations}

The solution ring-opening polymerizations of lactide using the catalysts 1-3 were performed in the presence of equimolar amounts of isopropanol with respect to the zinc. Polymerizations were carried out at $25{ }^{\circ} \mathrm{C}$ in dichloromethane. The amounts of solvent and catalyst were chosen sucls that the monomer concentration $[\mathrm{M}] \approx 1.2 \mathrm{M}$, and that the monomer to initiator to catalyst ratio $[\mathrm{M}]:[1]:[\mathrm{Zn}]=200: 1: 1$.

Compared to the previously reporled $\beta$-diiminato zinc complexes, ${ }^{5,25}$ zinc $\mathrm{N}$-heterocyclic carbene complexes ${ }^{27}$ and NNO-tridentate Schiff's base zinc complexes, ${ }^{7}$ the catalysts 1-3 showed moderate activity in the lactide polymerization, and high conversions were obtained in 5-18 h (Table 1) at room temperature.

The enantiomerically pure and racemic polymers show characteristic differences in their ${ }^{1} \mathrm{H}-\mathrm{NMR}$ spectra at $\delta=5.0-5.5 \mathrm{ppm}$ (Figure 1A, B). Conversions were determined from the ratio of the integral values of the methyn peaks of monomer $(\delta=5.00)$ and polymer $(\delta$ $=5.15$ ). These calculations are slightly disturbed by the methyn proton signal of isopropanol, which also appears at $\delta=5.0 \mathrm{ppm}$. ${ }^{1} \mathrm{H}$-NMR end group analysis revealed that all polymer chains were end-capped with an isopropyl ester and a hydroxyl end group. These data show that the actual initiating species in these polymerizations are the zinc isopropoxides, formed upon the in situ alcoholysis of catalysts 1-3 with isopropanol. The polymerizations proceed via a coordination-insertion mechanism.

\section{Polymer Molecular Weights}

The molecular weights and polydispersities of the PLAs prepared using 1-3 as catalysts were determined with GPC. The molecular weight buildup in polymerization of $L$-LA using 1 was linear with conversion (Figure 2), with values closely matching the theoretical values, and all polymers had low polydispersities $(\sim 1.1)$ up to high conversion. Likewise, polymerization of $D$-LA and rac-LA using $\mathbf{1}$, as well as polymerization of $L$-LA, $D$-LA and rac-LA using the catalysts $\mathbf{2}$ and $\mathbf{3}$ resulted in polymers with $\mathrm{M}_{\mathrm{n}}$ values close to the theoretical values (Table 1 ). 


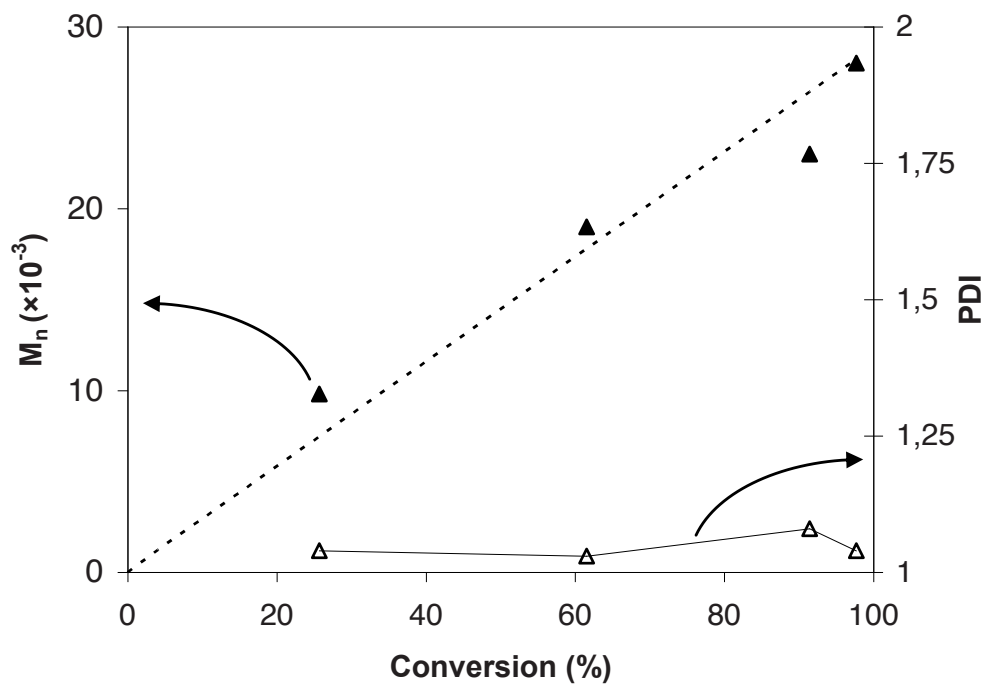

Figure 2. PLLA $M_{n}$ and $M_{w} / M_{n}$ as a function of L-LA conversion using zinc complex 1 . $[\mathrm{M}]_{0}:[\mathrm{HO} i \mathrm{Pr}]:[\mathrm{Zn}]=200: 1: 1, \mathrm{CH}_{2} \mathrm{Cl}_{2} ; 25^{\circ} \mathrm{C} ;[\mathrm{M}]_{0} \approx 1.2 \mathrm{M}$. (厶) $\mathrm{M}_{\mathrm{n}} ;(\triangle) \mathrm{M}_{\mathrm{w}} / \mathrm{M}_{\mathrm{n}}$. Dotted line: $\mathrm{M}_{\mathrm{n}, \text { theoretical }}$.

The polydispersities of these materials were generally low $(<1.1)$. Similar results have been obtained with the $\beta$-diiminate-based zinc catalysts. ${ }^{5,24}$ However, the initiating moiety $\left(-\mathrm{O} i \mathrm{Pr},-\mathrm{OCH}(\mathrm{Me}) \mathrm{CO}_{2} \mathrm{Me}\right.$ or $\left.-\mathrm{O} t \mathrm{Bu}\right)$ had to be incorporated in the complex before polymerization, since in sim hydrolysis or alcoholysis gave significantly broader polydispersities (1.4-1.8). ${ }^{24,26}$ This is attributed to a slow in situ generation of the zinc alkoxide with respect to the propagation reaction. Nevertheless, these $\beta$-diiminate-based catalysts are highly active and complete monomer conversion is generally obtained in minutes. 
Table I. Lactide ROPs using in situ generated zinc isopropoxides from 1-3 and isopropanol; $\mathrm{CH}_{2} \mathrm{Cl}_{2} ; 25^{\circ} \mathrm{C} ;[\mathrm{M}]:[1]:[\mathrm{Zn}]=200: 1: 1 ;[\mathrm{M}] \approx 1.2 \mathrm{M}$.

\begin{tabular}{|c|c|c|c|c|c|c|c|c|}
\hline Entry & Catalyst & Monomer & $\begin{array}{l}\text { Time } \\
\text { (h) }\end{array}$ & $\begin{array}{c}\text { Conversion } \\
(\%)\end{array}$ & $\begin{array}{c}\mathrm{M}_{\mathrm{n} \text { theory }}{ }^{\mathrm{a}} \\
\left(\times 10^{-3}\right)\end{array}$ & $\begin{array}{l}\mathrm{M}_{\mathrm{nGC}}{ }^{\mathrm{b}} \\
\left(\times 10^{-3}\right)\end{array}$ & PDI $^{\mathbf{b}}$ & $P_{r}{ }^{c}$ \\
\hline 1 & 1 & $L$-LA & 6 & 98 & 28.2 & 28.4 & 1.04 & - \\
\hline 2 & 1 & $D$-LA & 7 & 95 & 27.4 & 18.9 & 1.04 & - \\
\hline 3 & 1 & $L$-LA $/ D$-LA & 50 & $\sim 100$ & 28.8 & 30.6 & 1.23 & - \\
\hline 3 & 1 & $r a c-\mathrm{LA}$ & 5 & 97 & 279 & 27.5 & 1.06 & 0.60 \\
\hline 4 & 2 & $L$-LA & 18 & 97 & 279 & 27.5 & 1.10 & - \\
\hline 5 & 2 & $D$-LA & 9 & 84 & 23.4 & 23.1 & 1.11 & - \\
\hline 6 & 2 & $r a c-\mathrm{LA}$ & 9 & 93 & 26.8 & 20.3 & 1.31 & 0.58 \\
\hline 7 & 3 & $L$-LA & 8 & 71 & 20.3 & 19.3 & 1.06 & - \\
\hline 8 & 3 & $D$-LA & 8.5 & 74 & 21.4 & 19.1 & 1.04 & - \\
\hline 9 & 3 & $r a c-\mathrm{LA}$ & 10.5 & 95 & 27.4 & 22.0 & 1.10 & 0.60 \\
\hline \multicolumn{9}{|c|}{$\begin{array}{l}{ }^{\mathrm{a}} \mathrm{M}_{\mathrm{n}} \text { theory }=\mathrm{MW}_{\mathrm{HO} \text { iPr }}+[\mathrm{M}] /[\mathrm{II}]^{*} \mathrm{MW}_{\text {lactic acid }} \times \text { conversion, }{ }^{\mathrm{b}} \text { Average number molecular } \\
\text { weight }\left(\mathrm{M}_{\mathrm{n}}\right) \text { and polydispersity index }(\mathrm{PDI}) \text { as determined by GPC using universal } \\
\text { calibration with polystyrene standards, c Calculated using }\end{array}$} \\
\hline & & $2 \cdot r m r$ & & & & & & \\
\hline
\end{tabular}


Catalyst 1 was used in the synthesis of a block-copolymer, in which $D$-LA was added to a living PLLA polymer after $24 \mathrm{~h}$ of polymerization. In the ${ }^{1} \mathrm{H}-\mathrm{NMR}$ spectrum, the methyn region showed a single quartet $(\delta=5.15)$ instead of the typical multiplet of the rac-LA polymers (Figure 1B). The molecular weight of the copolymer, as obtained with GPC, closely matched the theoretical value. These data suggest the formation of the block copolymer as intended. The polydispersity was slightly higher than for the homopolymers (1.23).

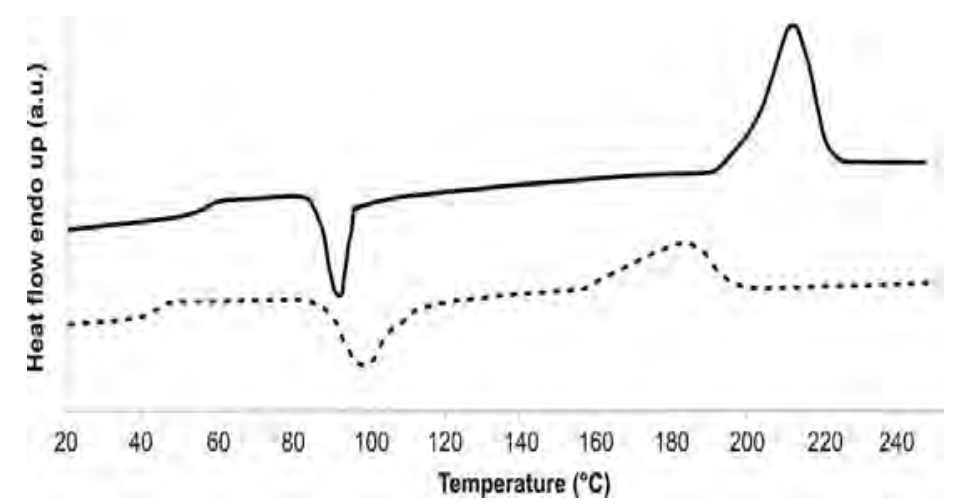

Figure 3. Second heating scans of PLLA-PDLA as synthesized using $\mathbf{1}\left(\mathrm{CH}_{2} \mathrm{Cl}_{2} ; 25^{\circ} \mathrm{C}\right.$; $[\mathrm{M}]:[1]:[\mathrm{Zn}]=200: 1: 1 ;[\mathrm{M}] \approx 1.2 \mathrm{M}$ ). Dotted line: sample annealed for $5 \mathrm{~min}$ at $250{ }^{\circ} \mathrm{C}$ between heating runs. Solid line: sample not annealed between heating runs.

DSC measurements (Figure 3) showed a higher melting point $\left(\mathrm{T}_{\text {m,copolymer }}=215^{\circ} \mathrm{C}, \Delta \mathrm{H}=\right.$ $57.8 \mathrm{~J} / \mathrm{g})$ compared to enantiomerically pure polymers $\left(\mathrm{T}_{\mathrm{m}} \approx 170^{\circ} \mathrm{C}\right)$. This increase is due to the formation of stereocomplexes between the $L$ - and $D$-regions within the blockcopolymer. The homonuclear decoupled ${ }^{1} \mathrm{H}-\mathrm{NMR}$ spectrum of the block copolymer showed only one peak, corresponding to the $\mathrm{mmm}$ tetrad, indicating that a pure diblock copolymer was obtained. It can therefore be concluded that despite long reaction times of 50 hrs, transesterification reactions were hardly taking place when using $\mathbf{1}$.

Taking into account the controlled molecular weight buildup, the low polydispersities and the successful synthesis of block-copolymers, the polymerizations catalyzed by 1-3 can be regarded as "living" polymerizations. 


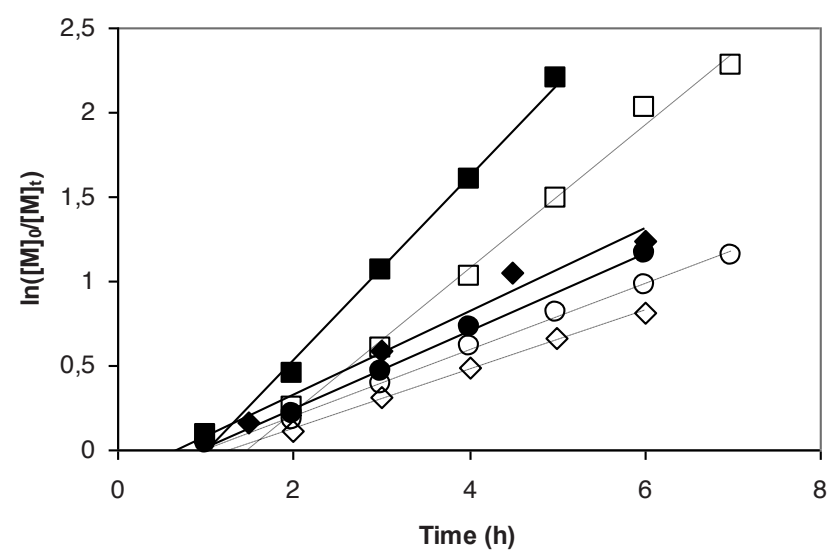

Figure 4A. First-order kinetic plots for $D$-LA and $L$-LA polymerizations, performed at $25^{\circ} \mathrm{C}$ in $\mathrm{CH}_{2} \mathrm{Cl}_{2}$ with $[\mathrm{M}] \approx 1.2$ and $[\mathrm{M}]:[\mathrm{HO} i \mathrm{Pr}]:[\mathrm{Zn}]=200: 1: 1 ;(\mathbf{\square})=\mathbf{1}+D$-LA; $(\square)=$ $\mathbf{1}+L$-LA $;(\bigcirc)=\mathbf{2}+D$-LA $;(\bigcirc)=\mathbf{2}+L$-LA $;(\diamond)=\mathbf{3}+D$-LA; $(\diamond)=\mathbf{3}+L$-LA

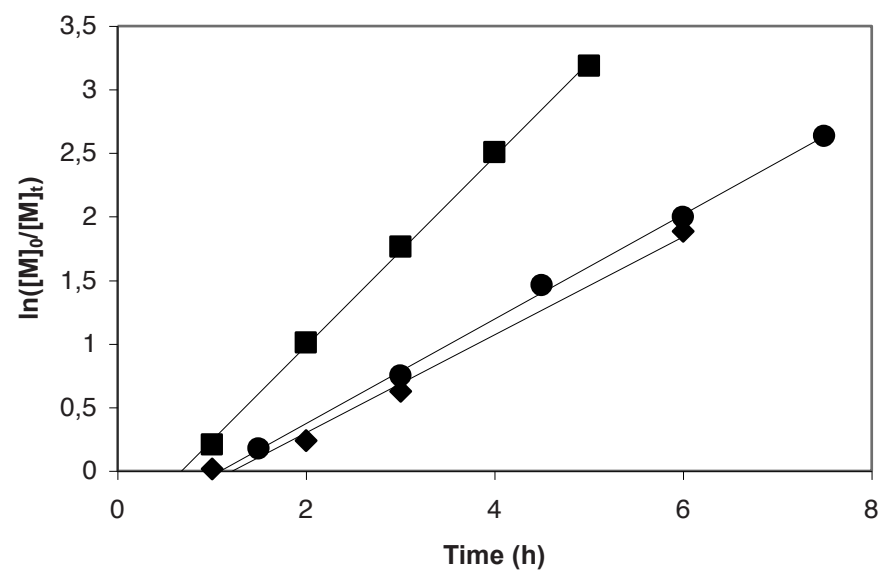

Figure 4B. First-order kinetic plots for rac-LA polymerizations, performed at $25^{\circ} \mathrm{C}$ in $\mathrm{CH}_{2} \mathrm{Cl}_{2}$ with $[\mathrm{M}] \approx 1.2$ and $[\mathrm{M}]:[\mathrm{HO} i \mathrm{Pr}]:[\mathrm{Zn}]=200: 1: 1 ;(\boldsymbol{\square})=\mathbf{1}+\operatorname{rac}-\mathrm{LA}(\mathbf{O})=\mathbf{2}+$ $r a c-\mathrm{LA} ;(\diamond)=\mathbf{3}+r a c-\mathrm{LA}$. 


\section{Polymerization Kinetics}

Kinetic studies showed that polymerizations were first-order in monomer in $L$-LA, $D$-LA and $r a c$-LA polymerizations (Figure 4A and 4B), regardless of the catalyst used. In all polymerizations, an induction period was observed. This phenomenon is likely caused by the time necessary to exchange the ethyl group for the alkoxide, which starts the initiation reaction.

The difference in ligand substitution between $\mathbf{1}$ and catalysts $\mathbf{2}$ and $\mathbf{3}$ had a significant effect on the kinetics of the polymerizations of both the single enantiomers and rac-LA. As described in literature, an increased ligand bulkiness generally renders a decreased catalyst activity, which is ascribed to the increased steric shielding of the active metal center. ${ }^{4-6}$ Within this series of thiophenolate-based catalysts, however, the opposite effect is observed. Though the pyrrolidino group can be regarded as more bulky than the dimethylamino group $(\sim 140 \%)$, the activity of $1\left(\mathrm{k}_{\mathrm{app}}=0.43 \mathrm{~h}^{-1}\right)$ was higher than both 2 $\left(\mathrm{k}_{\text {app }}=0.18 \mathrm{~h}^{-1}\right)$ and $3\left(\mathrm{k}_{\text {app }}=0.20 \mathrm{~h}^{-1}\right)$ in $L$-LA polymerizations. Similar trends were observed for the polymerizations of $D$-LA $\left(\mathbf{1}: \mathrm{k}_{\text {app }}=0.54 \mathrm{~h}^{-1}, 2: \mathrm{k}_{\mathrm{app}}=0.23 \mathrm{~h}^{-1}, \mathbf{3}: \mathrm{k}_{\text {app }}=\right.$ $\left.0.25 \mathrm{~h}^{-1}\right)$ and $\mathrm{rac}$-LA $\left(\mathbf{1}: \mathrm{k}_{\mathrm{app}}=0.75 \mathrm{~h}^{-1}, \mathbf{2}: \mathrm{k}_{\mathrm{app}}=0.41 \mathrm{~h}^{-1}, \mathbf{3}: \mathrm{k}_{\mathrm{app}}=0.38 \mathrm{~h}^{-1}\right)$, indicating that shielding of the active center is not the dominant factor here. Increasing catalyst activities upon increasing bulkiness of the ligand substituents have also been reported recently by Coates et al. for the $\beta$-diiminate (BDI) zinc-based systems, ${ }^{26,45}$ and were explained by the fact that the more bulky substituents disfavored association, forcing the catalyst in its monomeric, more active state. For solutions of the methylzinc analogue of 2 in benzene, degrees of association varying between 2.9 and 3.3 have been reported, indicating an equilibrium between a dimer and a tetramer. ${ }^{42}$ The formation of higher aggregates is supposedly driven by the release in steric strain in the metal-ligand complexes. Assuming that these findings can be extrapolated to the ethylzinc analogues, the differences in the catalyst activities of $\mathbf{1 , 2}$ and $\mathbf{3}$ in $\mathrm{CH}_{2} \mathrm{Cl}_{2}$ may be explained by a possible difference in association behavior. The more bulky group in $\mathbf{1}$ may disfavor the formation of such higher aggregates. In this respect, the catalysts' stability in the presence of alcohols may also play a role. When 3 was reacted with ethanol in stoichiometric amounts, disproportionation into diethoxy zinc and bis[2$\{($ dimethylamino)methyl $\}$ phenylthio]zinc was observed (Scheme 3). 
2<smiles>CC[Se]c1ccccc1CNC</smiles><smiles>CCO[Ga]c1ccccc1CN(C)CCO</smiles>

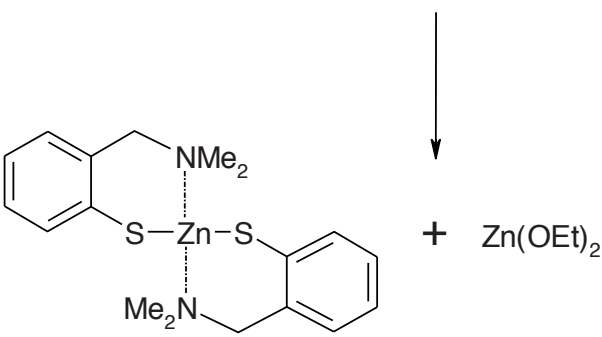

Scheme 3. Disproportionation of thiophenoxy zinc catalyst 3 when mixed with stoechiometric amounts of ethanol.

As described in detail elsewhere, the catalysts $\mathbf{2}$ and $\mathbf{3}$ were in fact prepared by comproportionation reactions of such zinc bis(aminoarenethiolate) complexes with diethyl zinc. This approach, however, failed for 1, and the bis[2-\{1-(pyrrolidin-1yl)ethyl $\}$ phenylthio]zinc could not be isolated. ${ }^{42}$ This was explained by the enhanced Lewis basicity of the amino substituent in $\mathbf{1}$ with respect to those in $\mathbf{2}$ and $\mathbf{3}$, which results in a stronger $\mathrm{Zn}-\mathrm{N}$ interaction and an increased steric congestion at the nitrogen center. Due to this incapability of formation of the bis[2-(1-(pyrrolidin-1yl)ethyl)phenylthio]zinc, 1 may suffer less from disproportionation and emanating change in catalyst activity.

Another possible explanation for the differences in catalyst activities may be found in the electronegativity of the ligands. It has been suggested ${ }^{6,7}$ that upon increasing ligand electronegativity (e.g. by introducing electron-withdrawing ligand substituents such as chlorine), the bond between the metal and alkoxide becomes stronger, which slows down the ring-opening reaction. The higher reactivity of $\mathbf{1}$ compared to $\mathbf{2}$ and $\mathbf{3}$ can be explained by the opposite effect, as the pyrrolidino group is slightly more electrondonating than the dimethylamino group. ${ }^{46}$ The almost equal reaction rate constants of $\mathbf{2}$ and $\mathbf{3}$ pointed out that the additional methyl group on $\mathbf{2}$ with respect to $\mathbf{3}$ does not have a significant influence in this respect. Surprisingly, although the zine aminoarenethiolates 
(1-3) contain an $\mathrm{S}$ donor atom that is less electronegative than the $\mathrm{O}$ donor atom in the analogous zinc phenolate catalyst 2-[(dimethylamino)methyl]-4-methylphenoxy ethylzinc, ${ }^{41}$ their catalytic activity is $\sim 10-20$ times lower. This is in contradiction with the observation that using more electronegative ligands leads to a decrease in catalyst activity ${ }^{6,7}$ It must be emphasized, however, that the degree of association of these phenolate analogues is approximately 2 , rather than 3 as suggested for $\mathbf{2}$ and $\mathbf{3}$, which may account for the higher activity of the phenolate catalysts in the ROP of lactides.

$D$-LA was polymerized faster than $L$-LA with all catalysts, and the ratios of $k_{\text {app }, D-L A}$ $/ \mathrm{k}_{\mathrm{app}, L \text {-LA }}$ are similar (1.26, 1.25 and 1.28 for $\mathbf{1}, \mathbf{2}$ and $\mathbf{3}$, respectively). The faster polymerization of $D$-LA might be explained by the fact that structural rearrangements of the catalysts. necessary to accommodate the $D$-enantioner, were more facile or favorable than for the $L$-enantiomer, thus giving enhanced reactivity ('enantiomorphic site control'), A prerequisite for this stereoselective control, however, is the presence of (a) stereocenter(s) within the catalytic species. Catalysts $\mathbf{1}$ and $\mathbf{2}$ are chiral and have the $R$ configuration. The absence of a stereocenter in $\mathbf{3}$, however, as well as the fact that $k_{\text {app }}$ values for $\mathbf{2}$ and $\mathbf{3}$ are almost equal, imply that the observed difference in $\mathrm{k}_{\text {app }}$ cannot be the result of stereocontrol due to the configuration of a single, monomeric catalyst species. Moreover, if the $D$-enantiomer was indeed ring-opened preferentially, polymerization of the racemic mixture would have taken place at rates in between those observed for $L$-LA and $D$-LA polymerizations. The reaction rates for the rac-LA polymerizations using 1-3, however, were significantly higher than those observed for the polymerizations of both $L$-LA and $D$-LA, therewith making enantiomorphic site control less plausible. The faster polymerizations of rac-LA may be explained by the fact that the catalysts 1-3 favor alternating built-in of $D$-LA and $L$-LA, which is only feasible when using an enantiomeric mixture such as rac-LA (chain-end control).

\section{Stereoselective behavior.}

The microstructural architecture of the polymers isolated from the various rac-LA polymerizations was investigated using homonuclear decoupled ${ }^{1} \mathrm{H}-\mathrm{NMR}$, From the proton spectra integrals in the methyn region $(\delta=5.3-5.1)$, the probability of isotactic $\left(P_{m}\right)$ and heterotactic $\left(P_{r}\right)$ enchainment were calculated, giving a quantitative measure of 
Controlled ROP of Lactides by Thiophenolate-Based Zn Catalysts

stereoselectivity ${ }^{47}$ Upon using catalysts 1-3, a moderate enrichment in heterotactic sequences was found in the resulting polymers (Table 1, entries 3, 6, 12: $P_{r}=0.60 ; 0.58$ and 0.60 for $\mathbf{1}, \mathbf{2}$ and $\mathbf{3}$, respectively). This indicates a mild preference for the addition of a monomer of opposing chirality to the growing chain. This is in accordance with the higher rates of polymerizations of rac-LA compared to those of the single enantiomers. Polymers prepared in toluene using 1-3 as a catalyst also showed a moderate enrichment in heterotactic sequences $\left(P_{r}=0.60,0.60\right.$ and 0.62 for 1,2 and 3 , respectively). Interestingly, polymerization reactions with the analogous zinc phenoxide catalyst (2[(dimethylamino)methyl]-4-methylphenoxy zinc) in $\mathrm{CH}_{2} \mathrm{Cl}_{2}$ or toluene resulted in polymers with hardly any enrichment $\left(P_{r}=0.52\right.$ and 0.54 , respectively) ${ }^{41}$ The electronegativity of the donor atoms thus play a role in stereoselectivity, either through causing different association behavior or directly affecting the electrophilicity of the metal atom.

\section{Conclusion}

Thiophenolate zinc alkoxides formed in situ from the corresponding zinc ethyls are effective catalyst/initiator systems for ROP of lactides, giving 'living' polymerizations that resulted in polymers with $M_{n}$ values close to the theoretical values and low polydispersities. Furthermore, the catalysts gave a slight predominance of heterotactic sequences in the resulting polymers. These initial finding may serve as a basis for new catalyst design for stereoselective synthesis of PL.As.

\section{Acknowledgements}

The group of prof. Gerard van Koten at the University of Utrecht, and in particular Henk Kleijn, is greatfully acknowledged for supplying and characterizing the catalysts described in this chapter. Rainer Wechselberger is greatfully acknowledged for his help in obtaining the decoupled ${ }^{1} \mathrm{H}-\mathrm{NMR}$ spectra. 


\section{References}

1. B. J. O'Keefe, M. A. Hillmyer and W. B. Tolman, Polymerization of lactide and related cyclic esters by discrete metal complexes. J. Chem. Soc.-Dalton Trans., 2001, 2001(15), 2215 - 2224.

2. J. C. Wu, T. L. Yu, C. T. Chen and C. C. Lin, Recent developments in main group metal complexes catalyzed/initiated polymerization of lactides and related cyclic esters. Coord. Chem. Rev., 2006, 250(5-6), 602-626.

3. O. Dechy-Cabaret, B. Martin-Vaca and D. Bourissou, Controlled ring-opening polymerization of lactide and glycolide. Chem. Rev., 2004, 104(12), 6147-6176.

4. P. Hormnirun, E. L. Marshall, V. C. Gibson, A. J. P. White and D. J. Williams, Remarkable stereocontrol in the polymerization of racemic lactide using aluminum initiators supported by tetradentate aminophenoxide ligands. J. Am. Chem. Soc., 2004, 126(9), 2688-2689.

5. M. H. Chisholm, J. C. Gallucci and K. Phomphrai, Comparative study of the coordination chemistry and lactide polymerization of alkoxide and amide complexes of zinc and magnesium with a 6-diiminato ligand bearing ether substituents. Inorg. Chem., 2005, 44(22), 8004-8010.

6. P. Hormnirun, E. L. Marshall, V. C. Gibson, R. I. Pugh and A. J. P. White, Study of ligand substituent effects on the rate and stereoselectivity of lactide polymerization using aluminum salen-type initiators. Proc. Natl. Acad. Sci. U. S. A., 2006, 103(42), 15343-15348.

7. H. Y. Chen, H. Y. Tang and C. C. Lin, Ring-opening polymerization of lactides initiated by zinc alkoxides derived from NNO-tridentate ligands. Macromolecules, 2006, 39(11), 3745-3752.

8. N. Spassky, M. Wisniewski, C. Pluta and A. LeBorgne, Highly stereoelective polymerization of rac-(D,L)-lactide with a chiral Schiff's base/aluminium alkoxide initiator. Macromol. Chem. Phys., 1996, 197(9), 2627-2637.

9. M. Wisniewski, A. LeBorgne and N. Spassky, Synthesis and properties of (D)and (L)-lactide stereocopolymers using the system achiral Schiff's base aluminium methoxide as initiator. Macromol. Chem. Phys., 1997, 198(4), 1227-1238.

10. T. M. Ovitt and G. W. Coates, Stereoselective ring-opening polymerization of rac-lactide with a single-site, racemic aluminum alkoxide catalyst: Synthesis of stereoblock poly(lactic acid). J. Polym. Sci., Part A: Polym. Chem., 2000, 38(S1), $4686-4692$.

11. C. P. Radano, G. L. Baker and M. R. Smith, Stereoselective polymerization of a racemic monomer with a racemic catalyst: Direct preparation of the polylactic acid stereocomplex from racemic lactide. J. Am. Chem. Soc., 2000, 122(7), 15521553 .

12. N. Nomura, R. Ishii, M. Akakura and K. Aoi, Stereoselective ring-opening polymerization of racemic lactide using aluminum-achiral ligand complexes: Exploration of a chain-end control mechanism. J. Am. Chem. Soc., 2002, 124(21), 5938-5939.

13. Z. Y. Zhong, P. J. Dijkstra and J. Feijen, Controlled and stereoselective polymerization of lactide: Kinetics, selectivity, and microstructures. J. Am. Chem. Soc., 2003, 125(37), 11291-11298. 
14. J. Belleney, M. Wisniewski and A. Le Borgne, Influence of the nature of the ligand on the microstructure of poly d,1-lactides prepared with organoaluminum initiators. Eur. Polym. J., 2003, 40(3), 523-530.

15. Z. H. Tang, X. S. Chen, X. Pang, Y. K. Yang, X. F. Zhang and X. B. Jing, Stereoselective polymerization of rac-lactide using a monoethylaluminum Schiff base complex. Biomacromolecules, 2004, 5(3), 965-970.

16. Z. H. Tang, X. Pang, J. R. Sun, H. Z. Du and X. S. Chen, Five-coordinated active species in the stereoselective polymerization of rac-lactide using N,N '-(2,2dimethyl-1,3-propylene)bis(3,5-di-tert-butyl-salicylideneimine) aluminum complexes. J. Polym. Sci., Part A: Polym. Chem., 2006, 44(16), 4932-4938.

17. N. Nomura, R. Ishii, Y. Yamamoto and T. Kondo, Stereoselective ring-opening polymerization of a racemic lactide by using achiral salen- and homosalenaluminum complexes. Chem.-Eur. J., 2007, 13(16), 4433-4451.

18. H. Z. Du, X. Pang, H. Y. Yu, X. L. Zhuang, X. S. Chen, D. M. Cui, X. H. Wang and X. B. Jing, Polymerization of rac-lactide using schiff base aluminum catalysts: Structure, activity, and stereoselectivity. Macromolecules, 2007, 40(6), 1904-1913.

19. J. Wu, X. Pan, N. Tang and C. C. Lin, Synthesis, characterization of aluminum complexes and the application in ring-opening polymerization of 1-lactide. Eur. Polym. J., 2007, 43(12), 5040-5046.

20. Z. Tang and V. C. Gibson, rac-Lactide polymerization using aluminum complexes bearing tetradentate phenoxy-amine ligands. Eur. Polym. J., 2007, 43(1), 150-155.

21. X. Pang, D. Du, X. Chen, X. Wang and X. Jing, Enolic Schiff Base Aluminum Complexes and Their Catalytic Stereoselective Polymerization of Racemic Lactide. Chem. Eur. J., 2008, 14(10), 3126-3136.

22. H. Du, A. H. Velders, P. J. Dijkstra, Z. Y. Zhong, X. Chen and J. Feijen, Polymerization of Lactide Using Achiral Bis(pyrrolidene) Schiff Base Aluminum Complexes. Macromolecules, 2009, 42(4), 1058-1066.

23. M. H. Chisholm, N. W. Eilerts, J. C. Huffman, S. S. Iyer, M. Pacold and K. Phomphrai, Molecular design of single-site metal alkoxide catalyst precursors for ring-opening polymerization reactions leading to polyoxygenates. 1. Polylactide formation by achiral and chiral magnesium and zinc alkoxides, $\left(\eta^{3}-\mathrm{L}\right) \mathrm{MOR}$, where $\mathrm{L}=$ trispyrazolyl- and trisindazolylborate ligands. J. Am. Chem. Soc., 2000, 122(48), 11845-11854.

24. M. H. Chisholm, J. Gallucci and K. Phomphrai, Coordination chemistry and reactivity of monomeric alkoxides and amides of magnesium and zinc supported by the diiminato ligand $\mathrm{CH}\left(\mathrm{CMeNC}_{6} \mathrm{H}_{3}-2,6-{ }^{\mathrm{i}} \mathrm{Pr}_{2}\right)_{2}$. A comparative study. Inorg. Chem., 2002, 41(10), 2785-2794.

25. M. Cheng, A. B. Attygalle, E. B. Lobkovsky and G. W. Coates, Single-site catalysts for ring-opening polymerization: Synthesis of heterotactic poly(lactic acid) from rac-lactide. J. Am. Chem. Soc., 1999, 121(49), 11583-11584.

26. B. M. Chamberlain, M. Cheng, D. R. Moore, T. M. Ovitt, E. B. Lobkovsky and G. W. Coates, Polymerization of lactide with zinc and magnesium beta-diiminate complexes: Stereocontrol and mechanism. J. Am. Chem. Soc., 2001, 123(14), 3229-3238. 
27. T. R. Jensen, C. P. Schaller, M. A. Hillmyer and W. B. Tolman, Zinc Nheterocyclic carbene complexes and their polymerization of D,L-lactide. $J$. Organomet. Chem., 2005, 690(24-25), 5881-5891.

28. H. Y. Chen, B. H. Huang and C. C. Lin, A Highly Efficient Initiator for the RingOpening Polymerization of Lactides and $\varepsilon$-Caprolactone: A Kinetic Study. Macromolecules, 2005, 38(13), 5400-5405.

29. A. P. Dove, H. B. Li, R. C. Pratt, B. G. G. Lohmeijer, D. A. Culkin, R. M. Waymouth and J. L. Hedrick, Stereoselective polymerization of rac- and mesolactide catalyzed by sterically encumbered N-heterocyclic carbenes. Chem. Commun., 2006, 2006(27), 2881-2883.

30. X. Pang, X. Chen, X. Zhuang and X. Jing, Crown-like macrocycle zinc complex derived from beta-diketone ligand for the polymerization of rac-lactide. J. Polym. Sci., Part A: Polym. Chem., 2007, 46(2), 643-649.

31. M. H. Chisholm, J. C. Gallucci, K. T. Quisenberry and Z. Zhou, Complexities in the Ring-Opening Polymerization of Lactide by Chiral Salen Aluminum Initiators. Inorg. Chem., 2008, 47(7), 2613-2624.

32. C. Alonso-Moreno, A. Garcés, L. F. Sánchez-Barba, M. Fajardo, J. FernándezBaeza, A. Otero, A. Lara-Sánchez, A. Antiñolo, L. Broomfield, M. L. LópezSolera and A. M. Rodríguez, Discrete Heteroscorpionate Lithium and Zinc Alkyl Complexes. Synthesis, Structural Studies, and ROP of Cyclic Esters. Organometallics, 2008, 27(6), 1310-1321.

33. Y. Huang, W. C. Hung, M. Y. Liao, T. E. Tsai, Y. L. Peng and C. C. Lin, Ringopening polymerization of lactides initiated by magnesium and zinc complexes based on NNO-tridentate ketiminate ligands: Activity and stereoselectivity studies. J. Polym. Sci., Part A: Polym. Chem., 2009, 47(9), 2318-2329.

34. M. Westerhausen, S. Schneiderbauer, A. N. Kneifel, Y. Söltl, P. Mayer, H. Nöth, Z. Zhong, P. J. Dijkstra and J. Feijen, Organocalcium Compounds with Catalytic Activity for the Ring-Opening Polymerization of Lactones. Eur. J. Inorg. Chem., 2003, 3432-3439.

35. Z. Y. Zhong, S. Schneiderbauer, P. J. Dijkstra, M. Westerhausen and J. Feijen, Single-site calcium initiators for the controlled ring-opening polymerization of lactides and lactones. Polym. Bull., 2003, 51(3), 175-182.

36. H. M. Sun, H. R. Li, C. S. Yao, Y. M. Yao, H. T. Sheng and Q. Shen, Lanthanide thiolate complexes: Novel initiators for ring-opening polymerization of epsiloncaprolactone. Chin. J. Chem., 2005, 23(11), 1541-1544.

37. H. Y. Ma, G. Melillo, L. Oliva, T. P. Spaniol, U. Englert and J. Okuda, Aluminium alkyl complexes supported by [OSSO] type bisphenolato ligands: synthesis, characterization and living polymerization of rac-lactide. Dalton Trans., 2005, 2005(4), 721-727.

38. H. Y. Ma, T. P. Spaniol and J. Okuda, Rare earth metal complexes supported by 1,omega-dithiaalkanediyl-bridged, bis(phenolato) ligands: synthesis, characterization and ring-opening polymerization catalysis of L-lactide. Dalton Trans., 2003, 24), 4770-4780.

39. H. Y. Ma, T. P. Spaniol and J. Okuda, Highly heteroselective ring-opening polymerization of rac-lactide initiated by bis(phenolato)scandium complexes. Angew. Chem.-Int. Edit., 2006, 45(46), 7818-7821. 
40. C. H. Huang, F. C. Wang, B. T. Ko, T. L. Yu and C. C. Lin, Ring-opening polymerization of epsilon-caprolactone and L-lactide using aluminum thiolates as initiator. Macromolecules, 2001, 34(3), 356.

41. M. R. Ten Breteler, Z. Y. Zhong, P. J. Dijkstra and J. Feijen, NO-Bidentate and NON-Tridentate Zinc Alkoxides for the Controlled Ring-Opening Polymerization of Lactides. Chapter 3, this thesis, 2009.

42. E. Rijnberg, N. J. Hovestad, A. W. Kleij, J. Jastrzebski, J. Boersma, M. D. Janssen, A. L. Spek and G. van Koten, Application of S,N-chelating chiral zinc bis(aminoarenethiolates) as new precursor catalysts in the enantioselective addition of dialkylzincs to aldehydes. Organometallics, 1997, 16(13), 2847-2857.

43. E. Rijnberg, J. Jastrzebski, M. D. Janssen, J. Boersma and G. van Koten, Application Of N,S-Chelating Chiral Zinc Bis(Arenethiolate) Complexes As New Precursor Catalysts In The Enantioselective Addition Of Diethylzinc To Aldehydes. Tetrahedron Lett., 1994, 35(35), 6521-6524.

44. D. M. Knotter, H. L. Vanmaanen, D. M. Grove, A. L. Spek and G. van Koten, Synthesis And Properties Of Trimeric Ortho-Chelated (Arenethiolato)Copper(I) Complexes. Inorg. Chem., 1991, 30(17), 3309-3317.

45. L. R. Rieth, D. R. Moore, E. B. Lobkovsky and G. W. Coates, Single-site $\beta$ diiminate zinc catalysts for the ring-opening polymerization of $\beta$-butyrolactone and $\beta$-valerolactone to poly(3-hydroxyalkanoates). J. Am. Chem. Soc., 2002, 124(51), 15239-15248.

46. S. A. Gorman, J. D. Hepworth and D. Mason, The effects of cyclic terminal groups in di- and tri-arylmethane dyes. Part 3. Consequences of unsymmetrical substitution in Malachite Green. J.Chem.Soc., Perkin Trans., 2000, 2000(2), 1889-1895.

47. J. Coudane, C. Ustariz-Peyret, G. Schwach and M. Vert, More about the stereodependence of DD and LL pair linkages during the ring-opening polymerization of racemic lactide. J. Polym. Sci., Part A: Polym. Chem., 1997, 35(9), 1651-1658. 


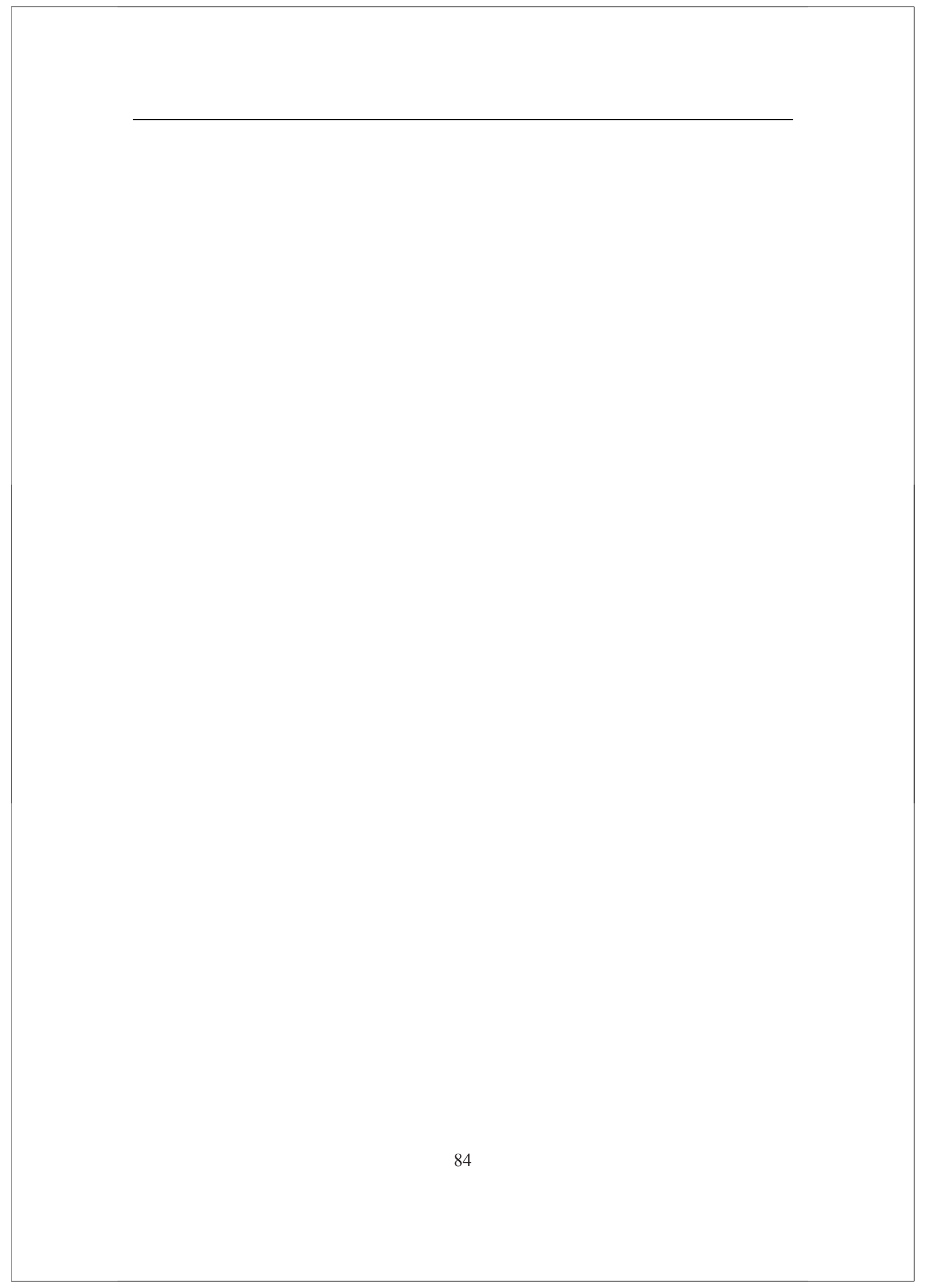




\title{
5 Ring-Opening Polymerization of Substituted $\varepsilon$ - Caprolactones Using a Chiral (Salen) AlOiPr-Complex ${ }^{1}$
}

M. R. ten Breteler, ${ }^{a}$ Z. Zhong, ${ }^{a}$ P.J. Dijkstra, ${ }^{a}$ A.R.A. Palmans, ${ }^{b}$ J.W. Peeters ${ }^{b}$ and J. Feijen. $^{a}$

anstitute for Biomedical Technology, Polymer Chemistry and Biomaterials Group, Faculty of Science and Technology, University of Twente, P.O. Box 217, 7500 AE Enschede, the Netherlands

${ }^{\mathrm{b}}$ Laboratory of Macromolecular and Organic Chemistry, Eindhoven University of Technology, P.O. Box 513, 5600 MB Eindhoven, the Netherlands

\begin{abstract}
The ring-opening polymerization (ROP) of $\varepsilon$-caprolactone ( $\varepsilon$-CL), 4-methyl- $\varepsilon$ caprolactone (4-MeCL) and 6-methyl- $\varepsilon$-caprolactone (6-MeCL) using a single-site chiral initiator, $R, R^{\prime}$-(salen) aluminum isopropoxide $\left(R, R^{\prime}-[1]\right)$, was investigated. Kinetic data for the ROP of the three monomers at $90{ }^{\circ} \mathrm{C}$ in toluene correspond to first-order reactions in monomer and propagation rate constants $\mathrm{k}_{\varepsilon-\mathrm{CL}}>\mathrm{k}_{4-\mathrm{MeCL}}>>\mathrm{k}_{6-\mathrm{MeCL}}$. A notable stereoselectivity with a preference for the $R$-enantiomer was observed in the ROP of 6MeCL using $R, R^{\prime}-[1]$, whereas for 4-MeCL, no stereoselectivity was found.
\end{abstract}

${ }^{11}$ This chapter has been published in Journal of Polymer Science, Part A: Polymer Chemistry, 2007, 45(3), 429-436. 


\section{Introduction}

Aliphatic polyesters, in particular materials based on glycolide, lactide and $\varepsilon$ caprolactone $(\varepsilon-\mathrm{CL})$, have attracted a great deal of interest because of their (bio)degradability and biocompatibility, and the nontoxicity of their degradation products. They are used in various applications, ranging from environmentally friendly packaging materials to sophisticated medical products such as sutures and cell seeding constructs. $^{1,2}$

These polymers are conveniently prepared by the ring-opening polymerization (ROP) of lactones, lactides and glycolides with either an organometallic-based catalyst (nonenzymatic polymerization) or an enzyme, usually a lipase (enzymatic polymerization). Catalysts used in the former type of polymerization are mainly metal carboxylates and metal alkoxides. Initiation is believed to take place by coordination of the monomer (e.g., $\varepsilon-\mathrm{CL})$ at the metal center, followed by ring opening and formation of a new metal alkoxide (Scheme 1). In propagation, this newly formed species will continue the polymerization. The growing chain is liberated upon termination by, for example, acetic acid.

a. iniliation

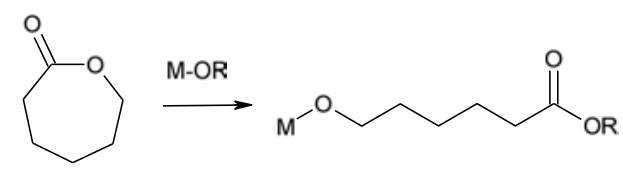

b. propagation

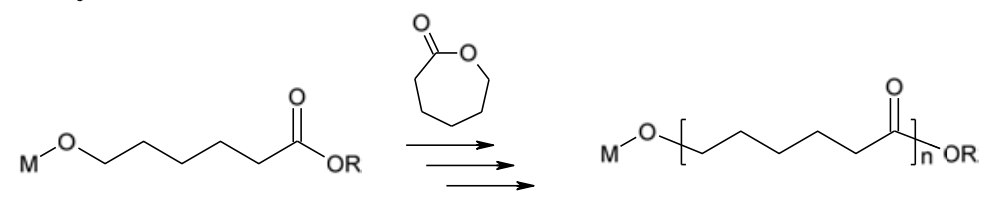

Scheme 1. Mechanism of metal alkoxide-based polymerization of lactones, generalized for $\varepsilon$-caprolactone. $\mathrm{ROH}$ is e.g. $\left(\mathrm{CH}_{3}\right)_{2} \mathrm{CHOH}$.

A widely used catalyst is stannous octoate $\left[\mathrm{Sn}(\mathrm{Oct})_{2}\right]$, which is approved by the Food and Drug Administration, is generally applicable, and gives reasonable control over molecular weight. However, it is also a strong transesterification agent and relatively slow in the ROP of lactides. ${ }^{3,4}$ Improvements have been accomplished with aluminum-, yttrium-, and, more recently calcium alkoxides. ${ }^{3-5}$ In the past few years, chiral catalysts, 
which induce a controlled and stereoselective polymerization of lactides, have also been developed. ${ }^{6-8}$ With an enantioselective catalyst, polylactides with stereoregular domains can be prepared from a racemic mixture of lactide stereoisomers, which will have significantly different mechanical properties than $\operatorname{poly}(D, L$-lactide) with random distributions of $D$ - and $L$-enantiomers along the chains. In this respect, the formation of stereocomplexes between enantiomerically pure $D$ - and $L$-regions is of great interest.

Enzymes such as the lipase Candida antarctica $B$ (known as Novozym 435 when immobilized) are known to display stereoselective behavior in the ROP of various substituted lactones. ${ }^{9-20}$ Enzymes have the advantage of generally working under mild conditions, and the widely applied immobilization of enzymes facilitates the complete removal of the catalyst from the final product. However, with respect to stereoselective polymerizations, the selectivity is fixed by the nature of the enzyme, and usually only one enantiomer is polymerized on a realistic timescale.

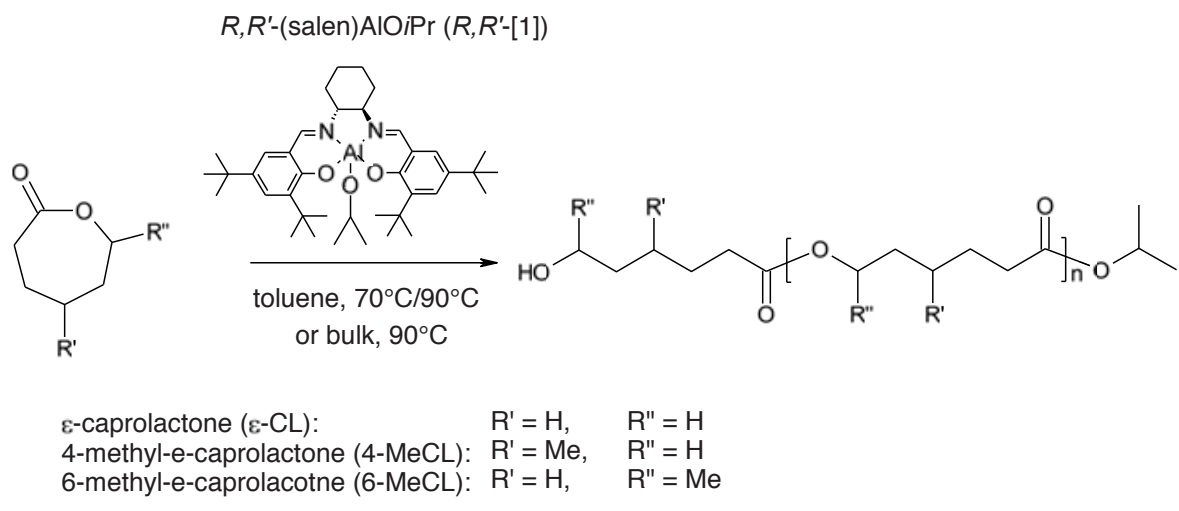

Scheme 2. Polymerization of $\varepsilon-\mathrm{CL}, 4-\mathrm{MeCL}$ and 6-MeCL in toluene using $R, R^{\prime}$-(salen) AlOiPr.

In this work, the use of the chiral catalyst $R, R^{\prime}$-(salen) aluminum isopropoxide $\left(R, R^{\prime}-[1]\right)$ in the ROP of $\varepsilon$-CL and the methyl-substituted $\varepsilon$-CLs, 4-methyl- $\varepsilon$-caprolactone (4$\mathrm{MeCL}$ ) and 6-methyl- $\varepsilon$-caprolactone (6-MeCL; Scheme 2), is described. As $R, R^{\prime}-[1]$ shows stereoselective behavior in the ROP of lactides, ${ }^{7}$ it was hypothesized that the 
substituted lactones would also be polymerized selectively. In contrast with Novozym 435 , any stereoselective behavior of $R, R^{\prime}-[1]$ can be complemented by its $S, S^{\prime}$-analogue, and this broadens the range of synthetic varieties. The polymerization results, particularly with respect to enantioselectivity, were compared with those obtained for the polymerization of the corresponding monomers with Novozym 435.

\section{Experimental}

\section{Materials}

All experiments were carried out under nitrogen in a glovebox or under argon using Schlenk techniques. Toluene and hexane (Biosolve, the Netherlands) were distilled from sodium wire. Dichloromethane (Biosolve) was distilled from $\mathrm{CaH}_{2}$ (Aldrich). Chloroform, diethyl ether, hexane and methanol (Biosolve) were used as received. Aluminum isopropoxide ( $>99.99 \% \mathrm{Al}$; Strem Chemicals) and $R, R^{\prime}$-Jacobsen ligand $\{[1 \mathrm{R}$, 2R]-(-)-1,2-cyclohexanediamino-N,N'-bis[3,5-di-tert-butyl-salicilidene]; 98.0\%; Acros Organics $\}$ were used without further purification. The catalyst $R, R^{\prime}-[1]$ was synthesized according to Zhong et al. ${ }^{7}$

The racemic methyl substituted monomers, 4-MeCL and 6-MeCL, were prepared from 4methylcyclohexanone (Aldrich) and racemic 2-methylcyclohexanone (Aldrich), respectively, by a Baeyer-Villiger oxidation with $m$-chloroperbenzoic acid (Aldrich), as previously described. ${ }^{21}$ The oxidation of 4-methylcyclohexanone afforded 4-MeCL as the single lactone, whereas oxidation of 2-methylcyclohexanone gave 6-MeCL with 2methyl- $\varepsilon$-caprolactone as a byproduct (4-5\%). The monomers $\varepsilon$-CL (Aldrich), 4-MeCL and 6-MeCL were distilled over $\mathrm{CaH}_{2}$ in vacuo and stored over 4- $\AA$ molecular sieves before use.

Synthesis

\section{$R, R^{\prime}$-[1] Catalyzed Polymerizations}

In a typical experiment, $R, R^{\prime}$-[1] $(0.103 \mathrm{~g}, 0.163 \mathrm{mmol}), \varepsilon$-CL $(0.7 \mathrm{~g}, 6.13 \mathrm{mmol})$ and 5.4 $\mathrm{ml}$ of toluene were introduced into a dried reaction vessel equipped with a magnetic stirring bar. The vessel was placed in an oil bath thermostated at $90{ }^{\circ} \mathrm{C}$. At certain time intervals, about $0.2-0.5 \mathrm{ml}$-aliquots were removed and the reaction was terminated by the addition of acetic acid. Most of the solvent was evaporated and the conversion was 
determined using ${ }^{1} \mathrm{H}-\mathrm{NMR}$. The remaining residues were redissolved in chloroform, and polymers were precipitated in cold diethyl ether. After centrifugation, the supernatant was decanted and the polymers were dried in vacuo. To isolate poly(4-methyl- $\varepsilon-$ caprolactone) and poly(6-methyl-e-caprolactone), hexane was used as the non-solvent. After standing overnight, the hexane was removed, leaving the polymers as clear oils.

\section{Characterization}

NMR: ${ }^{1} \mathrm{H}-\mathrm{NMR}(300 \mathrm{MHz})$ spectra were recorded on a Varian Inova spectrometer using $\mathrm{CDCl}_{3}$ solutions and were referenced to shifts of residual $\mathrm{CHCl}_{3}\left(\delta=7.25\right.$ in $\left.{ }^{1} \mathrm{H} \mathrm{NMR}\right)$.

GPC: Gel permeation chromatography (GPC) measurements were conducted with a Waters 6000A GPC apparatus equipped with a series of standard Waters Styragel HR columns and a H502 viscometer detector (Viscotek Corp.). Polystyrene standards were used and the molecular weights were determined using the universal calibration principle. Polymers were dissolved in chloroform $(\sim 10 \mathrm{mg} / \mathrm{ml})$ and eluted with chloroform at $25^{\circ} \mathrm{C}$ at a flow rate of $1.5 \mathrm{ml} / \mathrm{min}$.

MALDI-TOF: Matrix assisted laser desorption ionization time-of-flight (MALDI-TOF) mass spectrometry was performed using a VoyageR-DE-RP MALDI-TOF mass spectrometer (Applied Biosystems/PerSeptive Biosystems, Inc., Framingham, MA) equipped with delayed extraction. A 337-nm UV nitrogen laser producing 3-ns pulses was used, and mass spectra were obtained in the linear mode. Samples were prepared non-quantitatively by mixing a polymer solution in tetrahydrofuran with [2-(4hydroxyphenylazo)benzoic acid] (HABA). Approximately $1 \mu$ l of the solution was transferred onto a gold sample plate, and the solvent was removed by drying on air.

GC: Chiral gas chromatography (GC) was performed with a Shimadzu 6C-17A GC equipped with a FID, employing a Chrompack Chirasil-DEX CB $(\mathrm{DF}=0.12)$ column under isocratic conditions $\left(\mathrm{T}=125^{\circ} \mathrm{C}\right)$. Injection and detection temperatures were set at $300{ }^{\circ} \mathrm{C}$ and $325^{\circ} \mathrm{C}$, respectively. The split ratio was 80 , and the gas velocity was set at 35 cm/s. Retention times: $S$-4-MeCL: $9.6 \mathrm{~min}$ and $R$-4-MeCL: $9.9 \mathrm{~min}$; S-6-MeCL: $6.5 \mathrm{~min}$ and R-6-MeCL: 7.3 min. All samples were measured three times using a Shimadzu AOC20I autosampler. 


\section{Results and Discussion}

\section{Ring-Opening Polymerizations of $\varepsilon-C L$ and Substituted Lactones}

Polymerizations of $\varepsilon$-CL, 4-MeCL and 6-MeCL with $R, R^{\prime}-[1]$ were carried out in dry toluene. In all cases, $\sim 1 \mathrm{M}$ monomeric solutions were prepared, and a 40:1 monomer to catalyst ratio was applied. At $90{ }^{\circ} \mathrm{C}$, all monomers could be polymerized up to high conversion ( $>95 \%$; Table 1, entry 1, 3, 5). A bulk polymerization (entry 6) was performed at $90^{\circ} \mathrm{C}$ with $6-\mathrm{MeCL}$ and $R, R^{\prime}-[1]$ in a $100: 1$ monomer to catalyst ratio. The reaction was stopped at a conversion of $\sim 90 \%$. Reactions were also performed successfully with $\varepsilon$-CL (Table 1 , entry 2 ) and $4-\mathrm{MeCL}$ at $70{ }^{\circ} \mathrm{C}$ (Table 1 , entry 4 ) with conversions greater than $95 \%$. The polymerization of $6-\mathrm{MeCL}$ was virtually absent when performed at $70^{\circ} \mathrm{C}$.

Table 1. Polymerization data for ROP of $\varepsilon-\mathrm{CL}, 4-\mathrm{MeCL}$ and 6-MeCL in toluene, and 6MeCL in bulk using $R, R^{\prime}$-(salen)AlO $i \mathrm{Pr}$

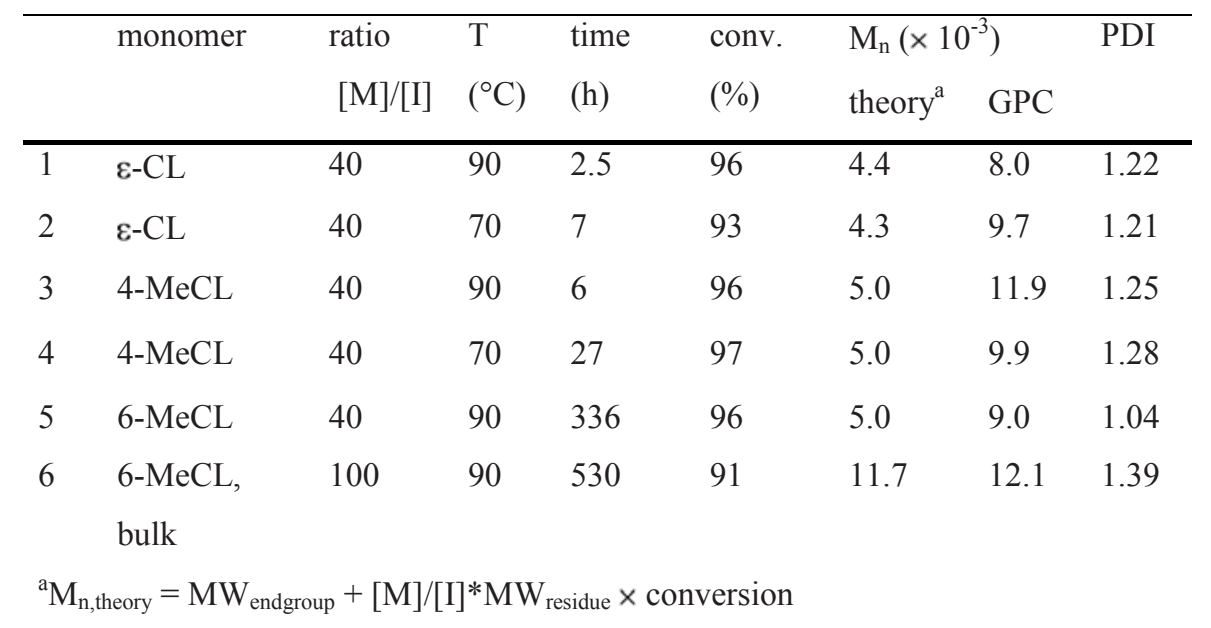

\section{Polymer Molecular Weights}

The number-aveage molecular weights $\left(\mathrm{M}_{\mathrm{n}}\right)$ of the different polymers were calculated from the ${ }^{1} \mathrm{H}$-NMR spectra. A typical spectrum of poly(E-caprolactone), with isopropanol as the initiator, reveals a doublet at $\delta=1.22$ and a triplet at $\delta=3.63$. These signals were assigned to the methyl protons of the isopropoxycarbonyl end group and the methyl 
protons neighboring a hydroxyl end group, respectively. In all cases, the integral ratio was close to the theoretical 3:1 value. For 4-MeCL and 6-MeCL, the peaks of the methyl protons neighboring a hydroxyl end group were found at $\delta=3.70$ and $\delta=3.75$, respectively. Because of the chirality introduced by the methyl substituent, these peaks appear as multiplets rather than triplets. In the case of $6-\mathrm{MeCL}$, the peak of the isopropoxycarbonyl end group was overlapping the peak of the methyl substituent. The $\mathrm{M}_{\mathrm{n}}$ values were therefore calculated by taking the integral ratio of the methyl protons neighboring a carbonyl group at $\delta=4.05$ and the methyl protons neighboring the hydroxyl end group $(\delta=3.63-3.75)$. For 6-MeCL, these values were in good accordance with the initial monomer-to-initiator ratio and with the theoretical values for increasing degrees of conversion, implying quantitative initiation and controlled molecular weight buildup. Indeed, the $\mathrm{M}_{\mathrm{n}}$ values, as determined from ${ }^{1} \mathrm{H}-\mathrm{NMR}$ spectra of the crude polymers, increase linearly with conversion and closely match the theoretical curve (Figure 1A).

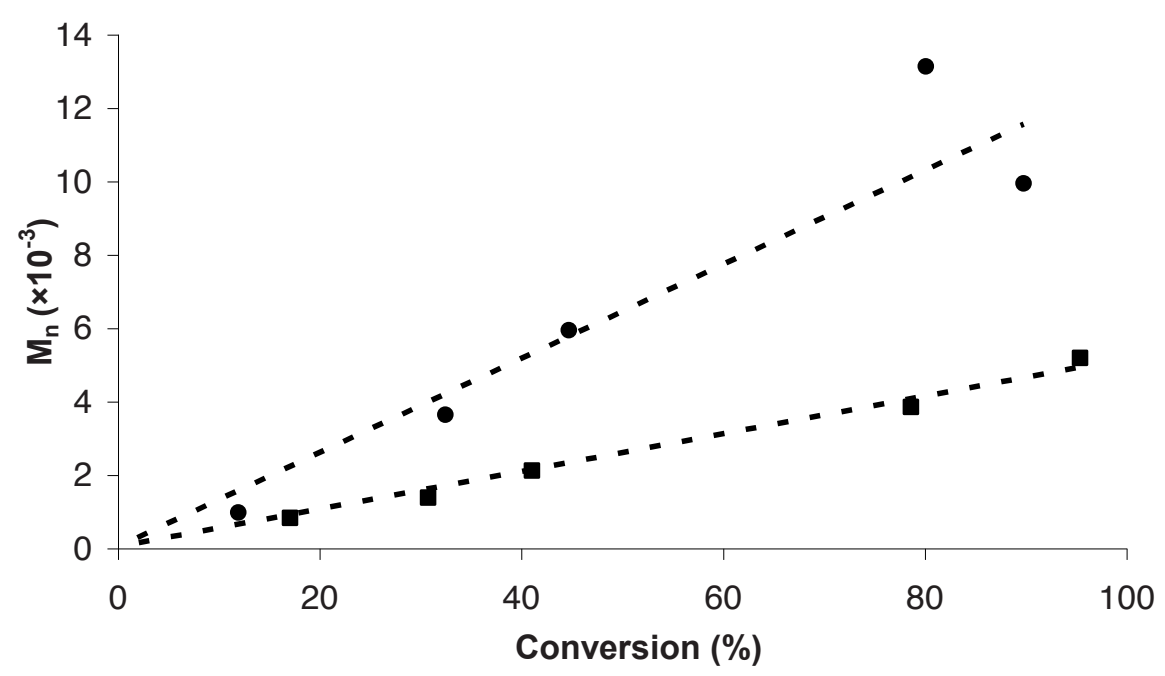

Figure 1A. $\mathrm{M}_{\mathrm{n}}$ (determined by NMR) versus the conversion for polymerization of 6MeCL with $R, R^{\prime}-[1]$ at $90{ }^{\circ} \mathrm{C}$ in toluene $(\bullet,[\mathrm{M}] /[\mathrm{I}]=40)$ and in bulk $(\boldsymbol{\square},[\mathrm{M}] /[\mathrm{I}]=100)$. 


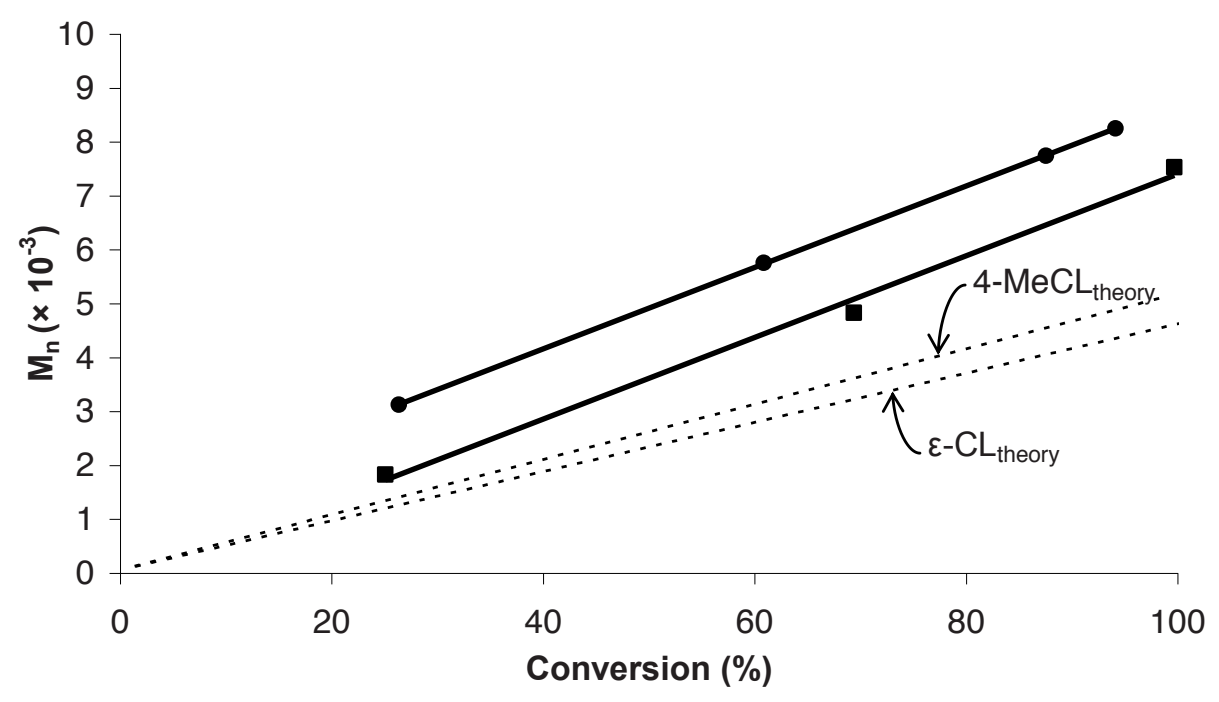

Figure 1B. $\mathrm{M}_{\mathrm{n}}$ (determined by NMR) versus the conversion for polymerization of $\varepsilon-\mathrm{CL}$

$(\bullet,[\mathrm{M}] /[\mathrm{I}]=40)$ and 4-MeCL $(\bullet,[\mathrm{M}] /[\mathrm{I}]=40)$ with $R, R^{\prime}-[1]$ at $90^{\circ} \mathrm{C}$ in toluene. Dotted lines: theoretical curves.

When $\varepsilon$-CL and 4-MeCL were polymerized, increase in the molecular weight was also linear with conversion, but significant deviations from the theoretical molecular weight were found (Figure 1B). A possible explanation is that in these polymerizations, the initiation was relatively slow in comparison with propagation, and the initiation may have not been quantitative. This may partly explain the deviation of GPC data for the isolated polymers from the calculated theoretical molecular weights (Table 1). The polydispersities were relatively low $\left(\mathrm{M}_{\mathrm{w}} / \mathrm{M}_{\mathrm{n}}=1.04-1.25\right)$. In recently published data on the polymerization of $\varepsilon$-CL with analogous salen-type catalysts with methano ${ }^{22}$ or various poly(ethylene glycol) $\mathrm{s}^{23}$ as the initiator, the polydispersities reported were in the same range (1.21-1.65 and 1.14-1.33).

The molecular weights as derived from MALDI-TOF mass spectra (based on the isolated polymers) matched the theoretical values very nicely at $\sim 95 \%$ conversion, and PDI values were low (1.04-1.13). The molecular weight buildup was linear with the 
conversion. However, the deviation from the theoretical values was more significant at lower degrees of conversion, and the molecular weights found were generally too high; this suggests a loss of the smaller oligomers upon polymer isolation. At high conversions, the spectra of $\varepsilon-\mathrm{CL}$ (Figure 2A) and 4-MeCL revealed the presence of cyclic oligomers, attributed to intramolecular transesterifications, ${ }^{24,} 25$ which may have influenced the GPC results.

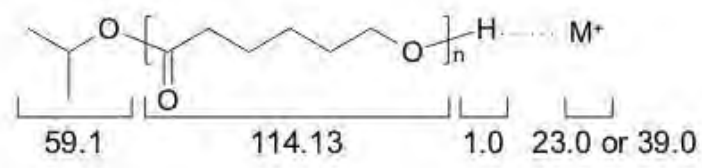

$$
\begin{aligned}
& \text { Ia: } M=\mathrm{Na} \\
& \text { Ib: } M=K
\end{aligned}
$$
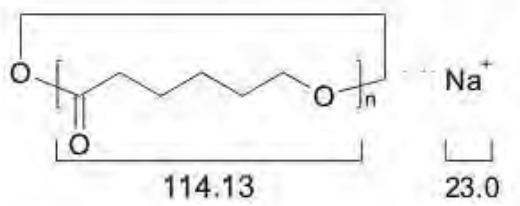

$$
\text { II }
$$

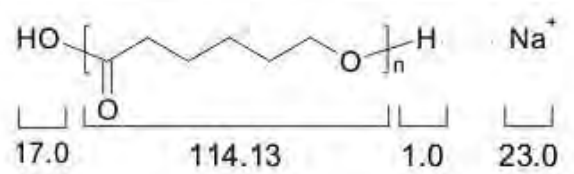

III

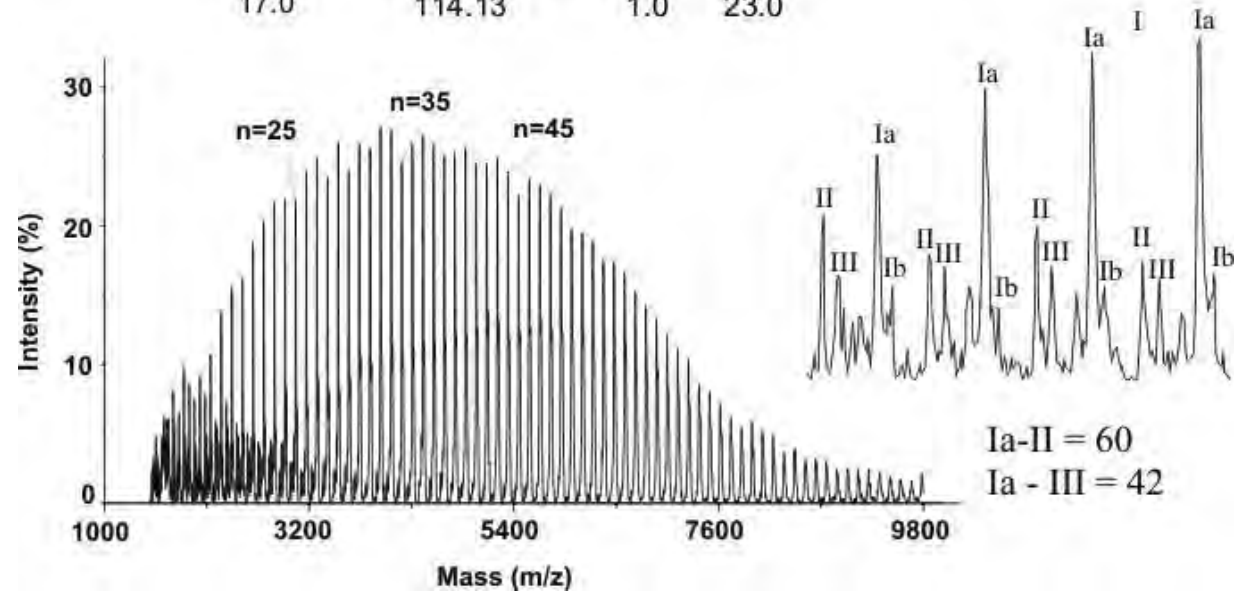

Figure 2A. Mass spectrum of poly( $\varepsilon$-caprolactone) (Table 1, entry 2) as determined with MALDI-TOF MS; matrix HABA; solvent THF. 
In contrast, despite of relatively long reaction times, cyclic oligomers were not found for poly(6-methyl- $\varepsilon$-caprolactone), and this suggests that the methyl group at the $\omega$ position may have a suppressive effect on back-biting (Figure 2B).

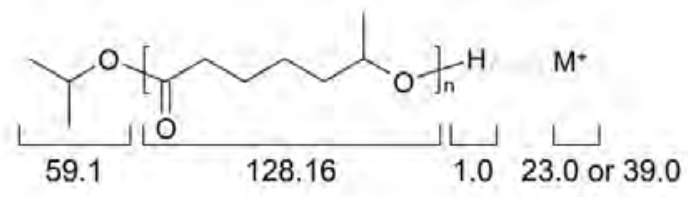

$$
\begin{aligned}
& \text { Ia: } M=N a \\
& \text { Ib: } M=K
\end{aligned}
$$

\section{II: I - M}

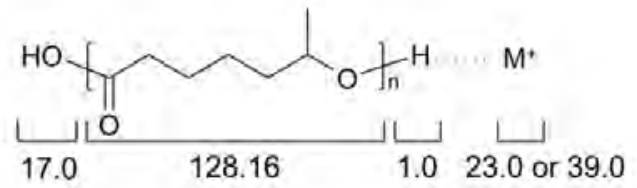

$$
\text { III: } \mathrm{M}=\mathrm{Na}
$$

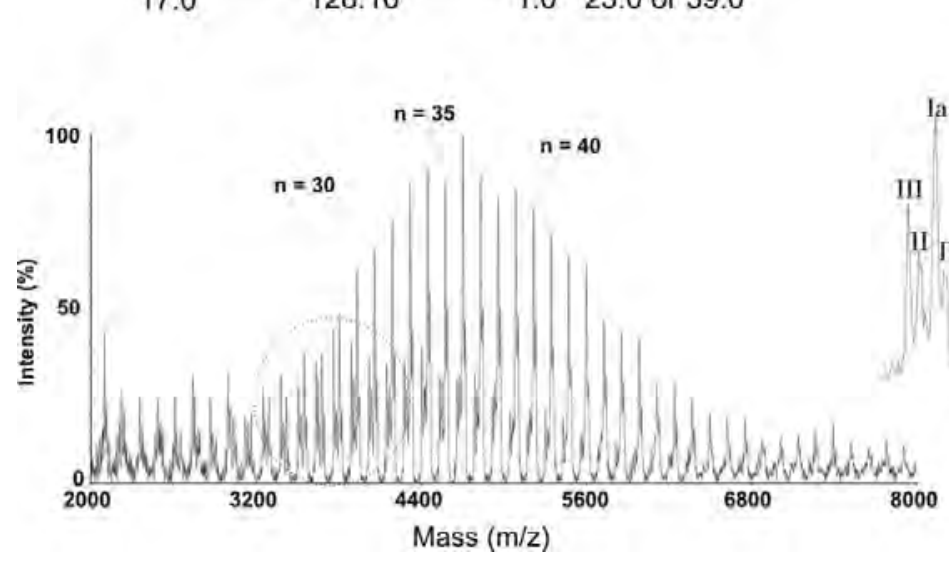

$$
\begin{aligned}
& \mathrm{Ia}-\mathrm{II}=23 \\
& \mathrm{Ia}-\mathrm{III}=42
\end{aligned}
$$

Figure 2B. Mass spectrum of poly(6-methyl-e-caprolactone) (Table 1, entry 5) as determined with MALDI-TOF MS; matrix HABA; solvent THF.

The other minor distribution observed in all MALDI-TOF spectra was ascribed to carboxylic acid-terminated chains, formed upon the fragmentation and loss of the initiating moiety from the PCL blocks. ${ }^{26}$ Both distributions point out the occurrence of side reactions, which most likely disturb the controlled molecular weight buildup. 
MALDI-TOF mass spectrometry data further confirmed the end group identity, as the main peaks corresponded to $(114.1 \times \mathrm{n}+60.1+23)$ for $\varepsilon$-CL and $(128.1 \times \mathrm{n}+60.1+23)$ for 4-MeCL and 6-MeCL (i.e., $M_{\text {residue }} \times$ number of residues $+M_{\text {end group }}+M_{N a}$, where $\mathrm{M}_{\text {residue }}$ is the molecular weight of the residue, $\mathrm{M}_{\text {end group }}$ is the molecular weight of the end group, and $\mathrm{M}_{\mathrm{Na}}$ is the molecular weight of $\mathrm{Na}$; Figure 2). On this basis, the $R, R^{\prime}-[1]-$ catalyzed ROP of $\varepsilon-\mathrm{CL}$ and its methyl-substituted derivatives most likely proceeds according to the coordination insertion mechanism, as described by Zhong et al. for the ROP of lactides. ${ }^{7}$

\section{Polymerization Kinetics}

The kinetic data reveal that all the polymerizations are first-order in the monomer (Figure 3 ), including the bulk polymerization of 6-MeCl (Figure 3B). The ROPs of $\varepsilon$-CL, 4MeCL and 6-MeCL with $R, R^{\prime}-[1]$ show an induction period. Because the ${ }^{27} \mathrm{Al}$ NMR data ${ }^{7}$ for this catalyst are in line with a monomeric five coordinate aluminum center, the observed induction periods are most likely due to rearrangement of the initiator ligands in order to allow the monomer to access the coordination sphere of the metal, ${ }^{27}$ rather than dissociation of catalyst aggregates into active species. ${ }^{28-30}$

At both $90^{\circ} \mathrm{C}$ and $70^{\circ} \mathrm{C}, 4-\mathrm{MeCL}$ is polymerized slower than $\varepsilon$-CL, whereas $6-\mathrm{MeCL}$ is polymerized at an even slower rate. At $90^{\circ} \mathrm{C}$, values for $\mathrm{k}_{\text {app }}$ are $1.64,0.65$ and $0.010 \mathrm{~h}^{-1}$ for $\varepsilon-\mathrm{CL}, 4-\mathrm{MeCL}$ and 6-MeCl, respectively. Applying a lower reaction temperature of $70^{\circ} \mathrm{C}$ slowed down all polymerizations, though more pronounced for $\varepsilon-\mathrm{CL}\left(\mathrm{k}_{\mathrm{app}}=0.27 \mathrm{~h}^{-}\right.$ ${ }^{1}$ ) and 6-MeCL (polymerization virtually absent) than for 4-MeCL $\left(\mathrm{k}_{\mathrm{app}}=0.18 \mathrm{~h}^{-1}\right)$. The significantly slower propagation rate in the ROP of 6-MeCL compared to $\varepsilon-C L$ is likely due to steric hindrance by the methyl substituent. 


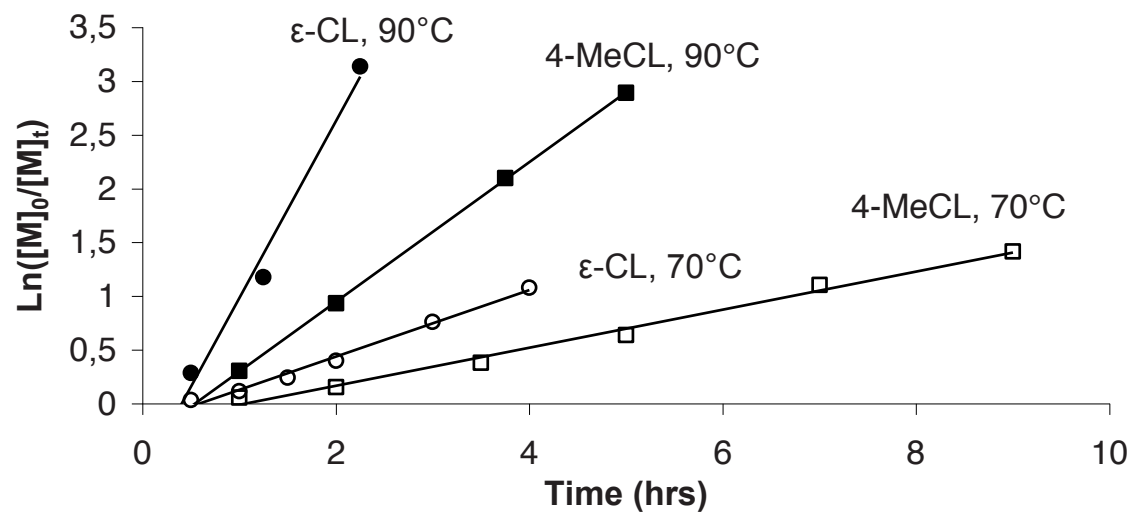

(A)

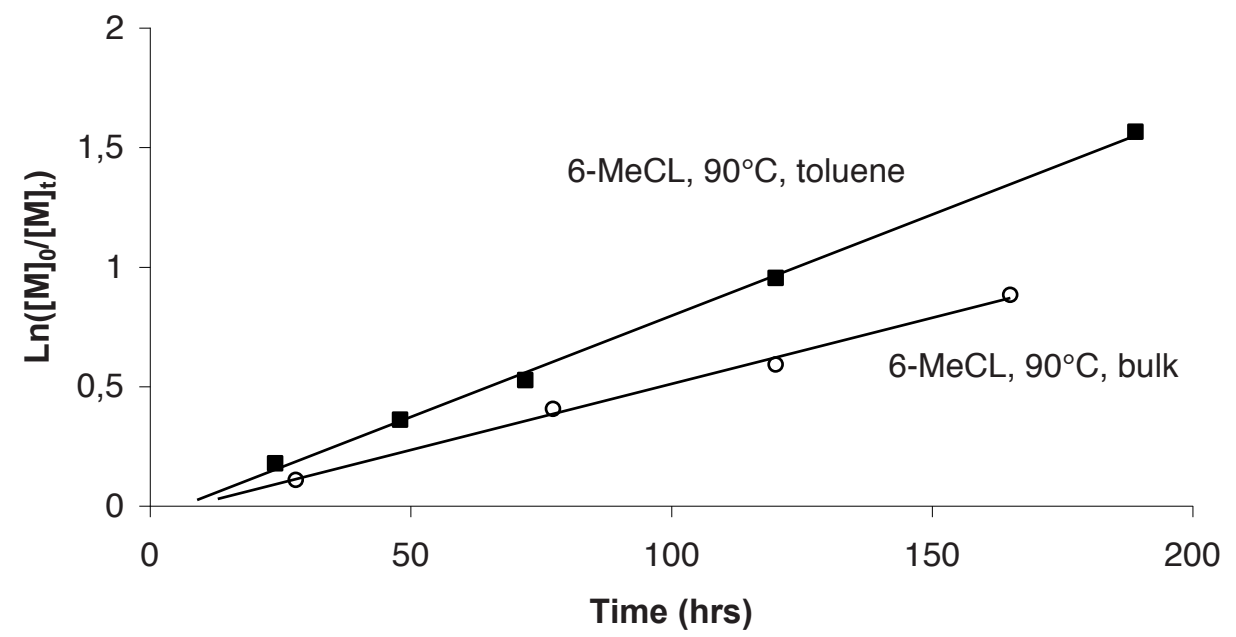

(B)

Figure 3. $\mathrm{Ln}\left([\mathrm{M}]_{0} /[\mathrm{M}]_{\mathrm{t}}\right)$ versus time for polymerizations using $R, R^{\prime}-[1]$ and $(\mathrm{A}) \varepsilon-\mathrm{CL}$ and 4-MeCL in toluene at $70{ }^{\circ} \mathrm{C}$ and $90{ }^{\circ} \mathrm{C},[\mathrm{M}] /[\mathrm{I}]=40$; (B) $6-\mathrm{MeCL}$ in toluene at $90{ }^{\circ} \mathrm{C}$, $[\mathrm{M}] /[\mathrm{I}]=40 ; 6-\mathrm{MeCL}$ in bulk at $90^{\circ} \mathrm{C},[\mathrm{M}] /[\mathrm{I}]=100$. 


\section{Stereoselectivity}

As shown by Zhong et al., ${ }^{7}$ the presence of stereocenters in the catalyst $R, R^{\prime}-[1]$ resulted in stereoselective ROP of racemic lactide. Both $4-\mathrm{MeCL}$ and 6-MeCL, prepared by Baeyer-Villiger oxidation of 4-methylcyclohexanone and racemic 2methylcyclohexanone, respectively, were obtained as racemic mixtures. It was anticipated that $R, R^{\prime}-[1]$ might induce the stereoselective ROP of these racemates. At different time points, the ratio of the unreacted monomer enantiomers was determined with chiral GC, giving the enantiomeric excess (ee) (Figure 4) and the selectivity factor $\mathbf{s}$ (Equation 5.1; $\mathbf{c}$ is the conversion as determined by ${ }^{1} \mathrm{H}-\mathrm{NMR}$ ). ${ }^{31,32}$

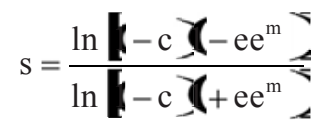

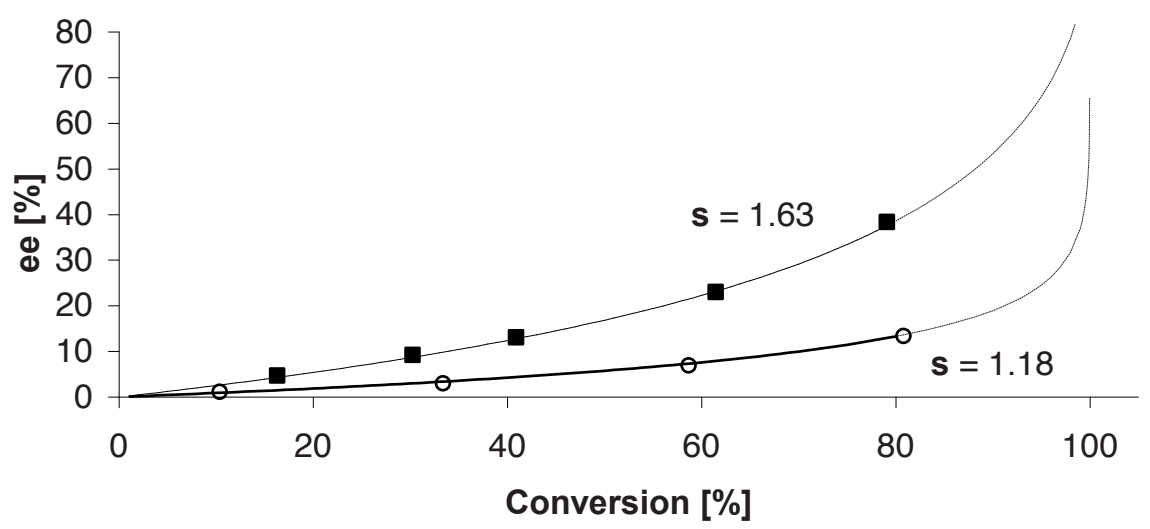

Figure 4. Polymerization of 6-MeCL at $90^{\circ} \mathrm{C}$ using $R, R$ '-[1]: ee versus conversion; [-]: 6-MeCL in toluene, $[\mathrm{M}] /[\mathrm{Al}]=40 ;[\mathrm{O}]$ : 6-MeCL, bulk, $[\mathrm{M}] /[\mathrm{Al}]=100 ;-$ : fits of Equation 5.1 for $\mathbf{s}=1.63$ and 1.18 , respectively.

Most interestingly, the GC data revealed that $R, R^{\prime}-[1]$ had a notable preference for $R-6$ MeCL polymerization. At $40 \%$ conversion, an ee close to 18 was found; at $80 \%$ conversion, the ee was nearly 50. Fitting gives $\mathbf{s}=1.63$. For the bulk polymerization, the catalyst system still showed a preference for $R-6-\mathrm{MeCL}$, although the selectivity 


\section{Chapter 5}

decreased ( $\mathbf{s}=1.18$, Figure 4$)$. This may be explained by diffusion limitations due to the higher viscosity in the bulk reaction mixture. The selectivity effects may also explain the relatively low propagation rate found for $6-\mathrm{MeCL}$, as effective concentrations of catalyst and monomer are lower in a stereoselectively polymerized racemic mixture. No enantiomeric preference was observed for the ROP of 4-MeCL, and this shows that the position of the substituent has a large influence on the catalyst's enantioselectivity.

\section{Non-Enzymatic Versus Enzymatic Polymerization}

The use of enzymes, particularly lipases, as stereoselective catalysts ${ }^{33}$ is a relatively new approach in (bio)polymer synthesis. On the basis of achievements in organic chemistry in the late 1980s, Kobayashi started to explore the use of a hydrolase enzyme for the in vitro synthesis of cellulose. ${ }^{34}$ Since then, several reports on enzymatic polymerizations have been published, including the ROP of lactones. ${ }^{9-12,15-20,35}$ In contrast to the $R$-selectivity displayed by the $R, R^{\prime}$-[1] system, Novozym 435 is known to preferably ring-open the $S$ enantiomers of both 4-MeCL and 6-MeCL. 10, 13, 14, 18 Although the stereoselectivity is higher, and comparable rate constants can be achieved at lower temperatures and lower catalyst concentrations when using Novozym 435 instead of $R, R^{\prime}-[1]$, the polydispersities of the polymers obtained are generally higher than those in nonenzymatic polymerization. This is likely due to the propensity of lipases to catalyze both intra- and interchain transesterification reactions. ${ }^{10,} 36-40$ Moreover, although 6-MeCL is ring-opened, Novozym 435 fails to polymerize this monomer. ${ }^{10}$ It has been reported that the reactivity of $\alpha$ - and $\gamma$-substituted lactone rings in ring-opening is generally higher than that of rings with the substituent attached to the carbon atom neighboring the ester linkage at the oxygen side ( $\omega$-substition). ${ }^{12}$ This behavior is ascribed to the formation of a secondary alcohol upon the ring opening of the latter, of which particularly the $S$-enantiomer hardly propagates as a result of the stereospecific pocket at the active site of the enzyme. ${ }^{41,42}$ Similarly, despite a fast initiation, Novozym 435 is regarded as incapable of polymerizing lactide. ${ }^{43-45}$ 
ROP of Substituted $\varepsilon$-CLs Using a Chiral (Salen) AlOiPr-Complex

\section{Conclusion}

$R, R^{\prime}-[1]$ has been shown to effectively catalyze the ROP of $\varepsilon-\mathrm{CL}, 4-\mathrm{MeCL}$ and 6-MeCL.

The polymerization kinetics as well as the stereoselective behavior in the ROP of 4MeCL and 6-MeCL depend on the position of the substituent, giving relatively fast and nonselective opening for 4-MeCL and relatively slow and selective opening for 6-MeCL. The presence of a substituent slows down propagation in all cases. These results are opposite of those obtained using the enzyme Novozym 435, which gives fast and stereoselective polymerization of 4-MeCL, but no polymerization of 6-MeCL.

The selectivity displayed by $R, R^{\prime}-[1]$ can be a helpful tool in the synthesis of new biomaterials based on lactones and lactides. Comparing $R, R^{\prime}-[1]$ with enzymes like Novozym 435, we find that both types of catalyst have their own advantages when combined with different kinds of monomers. By complementary use, a broad spectrum of polymers can be obtained. Recently, ROP of 6-MeCL was performed using Novozym 435 in combination with a ruthenium catalyst. ${ }^{46}$ As the $S$-enantiomer was selectively ring-opened, but only the $R$-enantiomer favored propagation, the ruthenium catalyst was added to enable racemization of the secondary alcohol from the $S$ - to the $R$-configuration. Likewise, it will be interesting to combine $R, R^{\prime}-[1]$ and Novozym 435 for the synthesis of novel types of biodegradable polymers.

\section{References}

1. Y. Ikada and H. Tsuji, Biodegradable polyesters for medical and ecological applications. Macromol. Rapid Commun., 2000, 21(3), 117-132.

2. A. C. Albertsson and I. K. Varma, Aliphatic polyesters: Synthesis, properties and applications. Advances in Polymer Science, 2002, 157(1-40.

3. K. M. Stridsberg, M. Ryner and A. C. Albertsson, Controlled ring-opening polymerization: Polymers with designed macromolecular architecture. Advances in Polymer Science, 2002, 157(41-65.

4. A. C. Albertsson and I. K. Varma, Recent developments in ring opening polymerization of lactones for biomedical applications. Biomacromolecules, 2003, 4(6), 1466-1486.

5. Z. Y. Zhong, P. J. Dijkstra, C. Birg, M. Westerhausen and J. Feijen, A novel and versatile calcium-based initiator system for the ring-opening polymerization of cyclic esters. Macromolecules, 2001, 34(12), 3863-3868.

6. Z. Y. Zhong, P. J. Dijkstra and J. Feijen, [(salen)Al]-mediated, controlled and stereoselective ring- opening polymerization of lactide in solution and without 
solvent: Synthesis of highly isotactic polylactide stereocopolymers from racemic D,L-lactide. Angew. Chem.-Int. Edit., 2002, 41(23), 4510-4513.

7. Z. Y. Zhong, P. J. Dijkstra and J. Feijen, Controlled and stereoselective polymerization of lactide: Kinetics, selectivity, and microstructures. J. Am. Chem. Soc., 2003, 125(37), 11291-11298.

8. T. M. Ovitt and G. W. Coates, Stereoselective ring-opening polymerization of rac-lactide with a single-site, racemic aluminum alkoxide catalyst: Synthesis of stereoblock poly(lactic acid). J. Polym. Sci. Pol. Chem., 2000, 38(4686-4692.

9. J. W. Peeters, O. van Leeuwen, A. R. A. Palmans and E. W. Meijer, Lipasecatalyzed ring-opening polymerizations of 4-substituted epsilon-caprolactones: Mechanistic considerations. Macromolecules, 2005, 38(13), 5587-5592.

10. J. W. Peeters, A. R. A. Palmans, M. Veld, F. Scheijen, A. Heise and E. W. Meijer, Cascade synthesis of chiral block copolymers combining lipases catalysed ring opening polymerisation and atom transfer radical polymerisation. Biomacromolecules, 2004, 5(5), 1862-1868.

11. A. Duda, A. Kowalski, S. Penczek, H. Uyama and S. Kobayashi, Kinetics of the ring-opening polymerization of 6-, 7-, 9-, 12-, 13-, 16-, and 17-membered lactones. Comparison of chemical and enzymatic polymerizations. Macromolecules, 2002, 35(11), 4266-4270.

12. H. Kikuchi, H. Uyama and S. Kobayashi, Lipase-catalyzed ring-opening polymerization of substituted lactones. Polymer Journal, 2002, 34(11), 835-840.

13. T. F. Al-Azemi, L. Kondaveti and K. S. Bisht, Solventless enantioelective ringopening polymerization of substituted epsilon-caprolactones by enzymatic catalysis. Macromolecules, 2002, 35(9), 3380-3386.

14. L. Kondaveti, T. F. Al-Azemi and K. S. Bisht, Lipase-catalyzed solvent-free kinetic resolution of substituted racemic epsilon-caprolactones. TetrahedronAsymmetry, 2002, 13(2), 129-135.

15. R. A. Gross, B. Kalra and A. Kumar, Polyester and polycarbonate synthesis by in vitro enzyme catalysis. Appl. Microbiol. Biotechnol., 2001, 55(6), 655-660.

16. R. A. Gross, A. Kumar and B. Kalra, Polymer synthesis by in vitro enzyme catalysis. Chem. Rev., 2001, 101(7), 2097-2124.

17. H. Kikuchi, H. Uyama and S. Kobayashi, Lipase-catalyzed enantioselective copolymerization of substituted lactones to optically active polyesters. Macromolecules, 2000, 33(24), 8971-8975.

18. K. Shioji, A. Matsuo, K. Okuma, K. Nakamura and A. Ohno, Lipase-catalyzed kinetic resolution of racemic seven-membered substituted lactones. Tetrahedron Lett., 2000, 41(45), 8799-8802.

19. K. Kullmer, H. Kikuchi, H. Uyama and S. Kobayashi, Lipase-catalyzed ringopening polymerization of alpha-methyl- delta-valerolactone and alpha-methylepsilon-caprolactone. Macromol. Rapid Commun., 1998, 19(2), 127-130.

20. Y. Y. Svirkin, J. Xu, R. A. Gross, D. L. Kaplan and G. Swift, Enzyme-catalyzed stereoelective ring-opening polymerization of alpha-methyl-beta-propiolactone. Macromolecules, 1996, 29(13), 4591-4597.

21. M. Trollsas, M. A. Kelly, H. Claesson, R. Siemens and J. L. Hedrick, Highly branched block copolymers: Design, synthesis, and morphology. Macromolecules, 1999, 32(15), 4917-4924. 
22. J. Yang, Y. H. Yu, Q. B. Li, Y. Li and A. I. Cao, Chemical synthesis of biodegradable aliphatic polyesters and polycarbonates catalyzed by novel versatile aluminum metal complexes bearing salen ligands. J. Polym. Sci. Pol. Chem., 2005, 43(2), 373-384.

23. J. Yang, L. Jia, L. Z. Yin, J. Y. Yu, Z. Shi, Q. Fang and A. M. Cao, A novel approach to biodegradable block copolymers of epsilon-caprolactone and deltavalerolactone catalyzed by new aluminum metal complexes. Macromol. Biosci., 2004, 4(12), 1092-1104.

24. R. F. Storey and J. W. Sherman, Kinetics and mechanism of the stannous octoatecatalyzed bulk polymerization of epsilon-caprolactone. Macromolecules, 2002, 35(5), 1504-1512.

25. G. Montaudo, M. S. Montaudo, C. Puglisi, F. Samperi, N. Spassky, A. LeBorgne and M. Wisniewski, Evidence for ester-exchange reactions and cyclic oligomer formation in the ring-opening polymerization of lactide with aluminum complex initiators. Macromolecules, 1996, 29(20), 6461-6465.

26. R. F. Storey, L. B. Brister and J. W. Sherman, Structural characterization of poly(epsilon-caprolactone) and poly(epsilon-caprolactone-b-isobutylene-bepsilon-caprolactone) block copolymers by MALDI-TOF mass spectrometry. $J$. Macromol. Sci.-Pure Appl. Chem., 2001, 38(2), 107-122.

27. Z. Y. Zhong, S. Schneiderbauer, P. J. Dijkstra, M. Westerhausen and J. Feijen, Single-site calcium initiators for the controlled ring-opening polymerization of lactides and lactones. Polym. Bull., 2003, 51(3), 175-182.

28. A. Duda and S. Penczek, Polymerization of Epsilon-Caprolactone Initiated By Aluminum Isopropoxide Trimer and/or Tetramer. Macromolecules, 1995, 28(18), 5981-5992.

29. P. Dubois, N. Ropson, R. Jerome and P. Teyssie, Macromolecular engineering of polylactones and polylactides.19. Kinetics of ring-opening polymerization of epsilon- caprolactone initiated with functional aluminum alkoxides. Macromolecules, 1996, 29(6), 1965-1975.

30. W. M. Stevels, M. J. K. Ankone, P. J. Dijkstra and J. Feijen, Kinetics and mechanism of epsilon-caprolactone polymerization using yttrium alkoxides as initiators. Macromolecules, 1996, 29(26), 8296-8303.

31. Z. Y. Zhong, P. J. Dijkstra and J. Feijen, Determination of the stereoselectivity factor for an asymmetric enantiomer-differentiating polymerization: A revisit. Macromolecules, 2003, 36(21), 8198-8200.

32. Z. Y. Zhong, P. J. Dijkstra and J. Feijen, Determination of the stereoselectivity factor for an asymmetric enantiomer-differentiating polymerization: A revisit (vol 36, pg 8198, 2003). Macromolecules, 2004, 37(12), 4740-4740.

33. S. Matsumura, Enzyme-catalyzed synthesis and chemical recycling of polyesters. Macromol. Biosci., 2002, 2(3), 105-126.

34. S. Kobayashi, Enzymatic polymerization: A new method of polymer synthesis. $J$. Polym. Sci. Pol. Chem., 1999, 37(16), 3041-3056.

35. L. van der Mee, F. Helmich, R. de Bruijn, J. A. J. M. Vekemans, A. R. A. Palmans and E. W. Meijer, Investigation of Lipase-Catalyzed Ring-Opening Polymerizations of Lactones with Various Ring Sizes: Kinetic Evaluation. Macromolecules, 2006, 39(15), 5021-5027. 
36. Y. Mei, A. Kumar and R. Gross, Kinetics and mechanism of Candida antarctica Lipase B catalyzed solution polymerization of epsilon-caprolactone. Macromolecules, 2003, 36(15), 5530-5536.

37. M. Bankova, A. Kumar, G. Impallomeni, A. Ballistreri and R. A. Gross, Massselective lipase-catalyzed poly(epsilon-caprolactone) transesterification reactions. Macromolecules, 2002, 35(18), 6858-6866.

38. T. Takamoto, P. Kerep, H. Uyama and S. Kobayashi, Lipase-catalyzed transesterification of polyesters to ester copolymers. Macromol. Biosci., 2001, $1(6), 223-227$.

39. A. Kumar and R. A. Gross, Candida antarctica lipase B-catalyzed transesterification: New synthetic routes to copolyesters. J. Am. Chem. Soc., 2000, 122(48), 11767-11770.

40. A. Cordova, T. Iversen, K. Hult and M. Martinelle, Lipase-catalysed formation of macrocycles by ring-opening polymerisation of epsilon-caprolactone. Polymer, 1998, 39(25), 6519-6524.

41. D. Rotticci, F. Haeffner, C. Orrenius, T. Norin and K. Hult, Molecular recognition of sec-alcohol enantiomers by Candida antarctica lipase B. Journal of Molecular Catalysis B-Enzymatic, 1998, 5(1-4), 267-272.

42. C. Orrenius, F. Haeffner, D. Rotticci, N. Ohrner, T. Norin and K. Hult, Chiral recognition of alcohol enantiomers in acyl transfer reactions catalysed by Candida antarctica lipase B. Biocatalysis and Biotransformation, 1998, 16(1), 1.

43. J. Wahlberg, P. V. Persson, T. Olsson, E. Hedenstrom and T. Iversen, Structural characterization of a lipase-catalyzed copolymerization of epsilon-caprolactone and D,L-lactide. Biomacromolecules, 2003, 4(4), 1068-1071.

44. S. Matsumura, K. Mabuchi and K. Toshima, Novel ring-opening polymerization of lactide by lipase. Macromol. Symp., 1998, 130(285-304.

45. S. Matsumura, K. Mabuchi and K. Toshima, Lipase-catalyzed ring-opening polymerization of lactide. Macromol. Rapid Commun., 1997, 18(6), 477-482.

46. B. A. C. van As, J. van Buijtenen, A. Heise, Q. B. Broxterman, G. K. M. Verzij1, A. R. A. Palmans and E. W. Meijer, Chiral oligomers by iterative tandem catalysis. J. Am. Chem. Soc., 2005, 127(28), 9964-9965. 


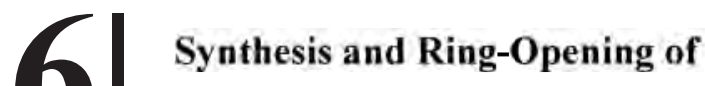 $\gamma$-Boc-Amino- $\varepsilon$-Caprolactone
}

\begin{abstract}
The amine-functionalized 7-membered $\gamma$-Boc-amino- $\varepsilon$-caprolactone $(\gamma$-Boc-NH- $\varepsilon$-CL) was synthesized and the ring opening reaction of this monomer by different catalystinitiator systems was studied. The monomer was prepared in a three-step process, starting from 4-aminocyclohexanol, protecting the amine with a Boc-group, oxidation of the alcohol to the ketone and a Bayer-Villager rearrangement to the lactone in an overall yield of $\sim 50 \%$. The monomer could be ring-opened, both by coordination or pseudoanionic ring-opening using stannous octoate, $\mathrm{Zn}\left[\mathrm{N}\left(\mathrm{SiMe}_{3}\right)_{2}\right]_{2}$ or $\left[\mathrm{Zn}(\mathrm{Et}) \mathrm{OC}_{4} \mathrm{H}_{6} \mathrm{NMe}_{2}-2-\right.$ $\mathrm{Me}-4]$ and by cationic ring-opening using fumaric acid, but polymerization did not occur. Rather than giving the functional amine protected poly( $\varepsilon$-caprolactone) the $\gamma$-Boc-amino$\varepsilon$-caprolactone rearranged into a 5-membered cyclic amide.
\end{abstract}




\section{Introduction}

Aliphatic polyesters, in particular materials prepared from glycolide, lactide and $\varepsilon$ caprolactone, receive a great deal of interest due to their (bio)degradability, biocompatibility and nontoxicity of their degradation products. They find use in various applications, ranging from environmentally friendly packaging materials to medical products such as sutures, drug delivery systems and scaffolds for tissue engineering. ${ }^{1,2}$

These polymers are conveniently prepared by ring-opening (co)polymerization (ROP) of the aforementioned (di)lactones by using an organometallic-based catalyst. The use of an enzyme (usually a lipase) as a catalyst has also been reported for several lactones ${ }^{3-18}$ as well as for lactide ${ }^{19-22}$ (enzymatic polymerization). In the last decade several studies were directed to the polymerizability of lactones containing functional groups on the ring. Ring opening (co)polymerization of these monomers may provide materials with a wide range of properties.

Two main strategies for the synthesis of aliphatic polyesters containing functional side groups can be distinguished, being a) direct incorporation of the (protected form of the) desired functionality into the monomer and $\mathbf{b}$ ) chemical conversion of functional groups in preformed polyesters. The most straightforward way is to synthesize a functionalized cyclic ester monomer rather than performing post-substitution reactions on the functional groups introduced. In recent years, several monomers containing functional groups on the ring were synthesized, and these were mainly based on the seven-membered lactone $\varepsilon$ caprolactone. Specific examples are 2,3,4,5-tetra-O-methyl-1,6-galactonolactone (1), ${ }^{23} 7$ allyl-1-oxacycloheptan-2-one (2), ${ }^{24} \alpha$-benzyl carboxylate- $\varepsilon$-CL (3), ${ }^{25} \alpha$-acetyl- $\varepsilon$-CL (4), ${ }^{26}$ $\alpha$-(1-acryloyloxyethyl)- $\varepsilon$-CL (5), ${ }^{27} 1,4,8$-trioxaspiro[4.6]-9-undecanone $(\mathbf{6})^{28-31}$ (to give ketone or hydroxyl groups when deprotected after ROP), 2-oxepane-1,5-dione (7), ${ }^{32} \gamma$-(2hydroxyethyl)- $\varepsilon$-CL (8), ${ }^{33} \gamma$-benzyloxy- $\varepsilon$-CL (9), ${ }^{34} \gamma$-triethylsilyloxy- $\varepsilon$-CL (10), ${ }^{31,35} \gamma$ (tert-butyldimethylsilyloxy)- $\varepsilon-\mathrm{CL}(\mathbf{1 1})^{36}$ (to give hydroxyl groups when deprotected after ROP), PEG-grafted $\varepsilon$-CL (12), ${ }^{37} \gamma$-acetyloxy- $\varepsilon$-CL (13), ${ }^{38} \gamma$-phenoxy- $\varepsilon$-CL (14), ${ }^{38} \gamma$ acryloyloxy- $\varepsilon$-CL (15), ${ }^{39} \gamma$-(2-bromo-2-methylpropionate)- $\varepsilon$-CL (17), ${ }^{40}$ 7-oxooxepan-4-yl 3-hydroxy-2-(hydroxymethyl)-2-methylpropanoate (18), ${ }^{41} \quad \gamma$-benzyl carboxylate- $\varepsilon$-CL $(\mathbf{1 9})^{34}$ and $\gamma$-tert-butyl carboxylate- $\varepsilon$-CL (20) $)^{34}$ (Figure 1). 
<smiles>C=CCC1CCCCC(=O)OC1OC</smiles>

1<smiles>O=C1CCC(CCO)CCO1</smiles>

8
2<smiles>O=C1CCC(O)CCO1</smiles>

9-18<smiles>O=CC1CCCCOC1=O</smiles>

3-4<smiles>[X]C1CCCC(=O)OC1</smiles>

21-22<smiles>[R]C1CCCCOC1=O</smiles>

23-25<smiles>CCC(=O)OC(C)C1CCCCOC1=O</smiles>

5<smiles>O=C1CCOC(=O)CC1</smiles>

7<smiles>O=C1C=CCCCO1</smiles><smiles>O=C1CC=CCCO1</smiles><smiles>O=C1CCC=CCO1</smiles>

26

27

28

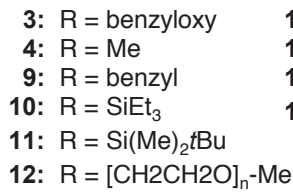

17: $\mathrm{R}=\mathrm{C}(\mathrm{O})-\mathrm{C}(\mathrm{Me})_{2} \mathrm{Br} \quad$ 21: $\mathrm{R}=\mathrm{Br}$

18: $R=C(O)-C(E t O H)_{2} M e$ 22: $R=1$

19: $\mathrm{R}=$ benzyl 23: $\mathrm{R}=\mathrm{Cl}$

20: $R=t B u$

25: $\mathrm{R}=\mathrm{CH}_{2}$ (methylene)

Figure 1. Various functionalized $\varepsilon$-caprolactones.

Two important examples following the second strategy, i.e. substitution reactions on functionalized $\varepsilon$-caprolactones, are starting from $\gamma$-bromo- $\varepsilon$-CL $(\mathbf{2 1})^{42}$ and $\alpha$-chloro- $\varepsilon$-CL $(\mathbf{2 3})^{43-46}$ (Figure 1). Recently, the synthesis of $\gamma$-iodo- $\varepsilon$-CL (22) was reported. ${ }^{47}$ Chloro substituents in poly $(\alpha$-chloro- $\varepsilon-C L)$ have been converted into hydroxyl, carboxyl, epoxide or phenyl ester groups by an atom transfer radical reaction. ${ }^{44}$ Similarly, PEG could be grafted to the polymer backbone. ${ }^{45}$ Alternatively, the chloro groups were converted into azides, both prior to (24) (Figure 1) or after polymerization, and applied in 'click chemistry', involving alkyne cycloaddition. ${ }^{46,48}$ Poly $(\gamma$-bromo- $\varepsilon$-CL) was modified with pyridine to yield the quaternized salt. ${ }^{40,}{ }^{42}$ Polymerization of $\alpha$-methylene- $\varepsilon$-CL (25) renders polymers with unsaturated backbones. Alternatively, the methylene group can be used in radical polymerization, leaving the lactone ring intact for grafting via ROP. ${ }^{49}$ Other unsaturated poly $(\varepsilon-\mathrm{CL}) \mathrm{s}$ were prepared by treating poly $(\gamma$-bromo- $\varepsilon-\mathrm{CL})$ with 1,8 diazabicyclo[5.4.0]-undec-7-ene. ${ }^{40}$ These polymers could be modified to hydroxylated materials. Alternatively, starting from $\alpha$-chloro- $\varepsilon$-CL ${ }^{50}$ or $\gamma$-bromo- $\varepsilon$-CL, ${ }^{40,50,51} \varepsilon$-CL 
monomers with double bonds in the ring (26-28) were prepared (Figure 1). These monomers could be successfully polymerized to polymers with double bonds in the backbone.

Amines are useful functional groups in polymer synthesis and polymer modification. Amines can react with acids and acyl chlorides, anhydrides, aldehydes and acrylates under relatively mild conditions. Amino-substituted propio- and butyrolactones are commercially available. However, to the best of our knowledge, the introduction of amines onto the caprolactone ring and subsequent polymerization has not been reported in literature so far. Described in this chapter are the synthesis of an $\varepsilon$-CL derivative, functionalized with a Boc-protected amine group in its $\gamma$-position, and the ring-opening experiments carried out with this monomer.

\section{Experimental}

\section{Materials}

Trans-4-aminocyclohexanol and sodium bicarbonate were obtained from Merck and used as received. Di-tert-butyl dicarbonate (97\%), pyridinium chlorochromate, mchloroperbenzoic acid (77\%) and sodium thiosulfate were obtained from Aldrich and used as received. Benzyl alcohol (Aldrich) and triethylene glycol monomethyl ether (Aldrich) were dried over molsieves (4-尺̊). Poly(ethylene glycol) and amino-endcapped poly(ethylene glycol) (Fluka) were dried by azeotropic distillation from dry toluene. Stannous octoate and $\mathrm{Zn}\left[\mathrm{N}\left(\mathrm{SiMe}_{3}\right)_{3}\right]_{2}$ were obtained from Aldrich and used as received. The synthesis of $\left[\mathrm{Zn}(\mathrm{Et}) \mathrm{OC}_{4} \mathrm{H}_{6} \mathrm{NMe}_{2}-2-\mathrm{Me}-4\right]$ was previously reported. ${ }^{52}$ Toluene (Biosolve) was dried by distillation over sodium wire. All other solvents (Biosolve) were used as received.

\section{Synthesis}

4-Boc-aminocyclohexanol: The synthesis of 4-Boc-aminocyclohexanol was performed according to the procedure as described by Einhorn et al. ${ }^{53}$ Trans-4-aminocyclohexanol $(10.0 \mathrm{~g}, 0.066 \mathrm{~mol})$ was weighed into a $500 \mathrm{ml}$ flask, and a solution of di-tert-butyl dicarbonate (diBoc, $14.1 \mathrm{~g}, 0.065 \mathrm{~mol}$ ) in $320 \mathrm{ml}$ of methanol was added. To the resulting solution $\mathrm{NaHCO}_{3}(16.45 \mathrm{~g}, 0.196 \mathrm{~mol})$ was added under stirring. The mixture was sonicated at $25-30{ }^{\circ} \mathrm{C}$ for $2 \mathrm{~h}$, and stirred overnight to ensure full conversion. 
Subsequently, the solids were filtered off, and the solvent was removed in vacuo. The remaining solid was dissolved in $\mathrm{CH}_{2} \mathrm{Cl}_{2}$, and the organic phase was washed three times with MilliQ water. The organic phase was dried over $\mathrm{MgSO}_{4}$, filtered and the solvent was removed in vacuo, giving a white powder. Yield: $11.7 \mathrm{~g}(82 \%) .{ }^{1} \mathrm{H}-\mathrm{NMR}\left(\mathrm{CDCl}_{3}\right): \delta=$ $4.40(\mathrm{~s}, 1 \mathrm{H}, \mathrm{NH}-\mathrm{C}=\mathrm{O}), 3.55(\mathrm{~m}, 1 \mathrm{H}, \mathrm{CH}-\mathrm{NH}), 3.38(\mathrm{~s}, 1 \mathrm{H}, \mathrm{CH}-\mathrm{OH}), 1.95\left(4 \mathrm{H}, \mathrm{CH}_{2}\right)$, $1.40\left(\mathrm{~s}, 9 \mathrm{H}, \mathrm{C}\left(\mathrm{CH}_{3}\right)_{3}\right), 1.40-1.30\left(\mathrm{~m}, 2 \mathrm{H}, \mathrm{CH}_{2}\right), 1.20-1.00\left(\mathrm{~m}, 2 \mathrm{H}, \mathrm{CH}_{2}\right) .{ }^{13} \mathrm{C}-\mathrm{NMR}$ $\left(\mathrm{CDCl}_{3}\right): \delta=155.0(\mathrm{C}=\mathrm{O}), 79.0\left(\mathrm{C}\left(\mathrm{CH}_{3}\right)_{3}\right), 69.6(\mathrm{CH}-\mathrm{OH}), 48.7(\mathrm{CH}-\mathrm{NH}), 33.8\left(\mathrm{CH}_{2}-\right.$ $\mathrm{CH}(\mathrm{NH})), 30.9\left(\mathrm{CH}_{3}\right), 28.2\left(\mathrm{CH}_{2}-\mathrm{CH}(\mathrm{OH})\right) . \mathrm{Mp} 172-173{ }^{\circ} \mathrm{C}$.

4-Boc-aminocyclohexanone: Synthesis of 4-Boc-aminocyclohexanone was performed according to a procedure as described by Detrembleur et al. ${ }^{54}$ Pyridinium chlorochromate (7.0 g, $0.032 \mathrm{~mol})$ was added to a solution of 4-Boc-aminocyclohexanol (5.0 g, 0.023 mol) dissolved in $250 \mathrm{ml}$ of $\mathrm{CH}_{2} \mathrm{Cl}_{2}$. Upon stirring, the initially bright orange mixture turned dark brown. The mixture was stirred overnight at room temperature. Solids were filtered off and washed extensively with $\mathrm{CH}_{2} \mathrm{Cl}_{2}$. The combined organic solvent was removed in vacuo, and the remaining product was dissolved in $250 \mathrm{ml}$ of diethyl ether. The yellow-brown solution was filtered to remove precipitates, washed with MilliQ water, dried over $\mathrm{MgSO}_{4}$ and filtered. The solvent was removed in vacuo, giving a white powder. Yield: $3.7 \mathrm{~g}(75 \%) .{ }^{1} \mathrm{H}-\mathrm{NMR}\left(\mathrm{CDCl}_{3}\right): \delta=4.49(\mathrm{~s}, 1 \mathrm{H}, \mathrm{N} H-\mathrm{C}=\mathrm{O}), 3.93(\mathrm{~m}, 1 \mathrm{H}$, $\mathrm{CH}-\mathrm{NH}), 2.40$ (dd, 4H, $\left.\mathrm{CH}_{2}\right), 2.13\left(\mathrm{dd}, 2 \mathrm{H}, \mathrm{CH}_{2}\right), 1.66\left(\mathrm{~m}, 2 \mathrm{H}, \mathrm{CH}_{2}\right), 1.45$ (s, 9H,

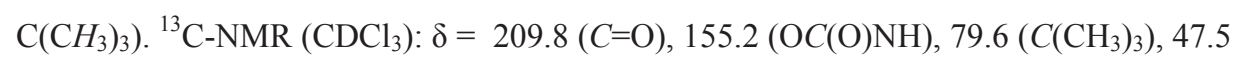
$(\mathrm{CH}-\mathrm{NH}), 38.9\left(\mathrm{CH}_{2}-\mathrm{C}=\mathrm{O}\right), 32.2\left(\mathrm{CH}_{3}\right), 28.3\left(\mathrm{CH}_{2}-\mathrm{CH}(\mathrm{NH})\right) . \mathrm{Mp} 100-101{ }^{\circ} \mathrm{C}$.

$\gamma$-Boc-amino- $\varepsilon$-caprolactone $(\boldsymbol{\gamma}$-Boc-NH- $\varepsilon$-CL): The $\gamma$-Boc-NH- $\varepsilon$-CL was prepared applying the procedure as described by Detrembleur et al. for the synthesis of $\gamma$-bromo- $\varepsilon$ caprolactone. ${ }^{54}$ To a stirred solution of 4-Boc-aminocyclohexanone $(3.5 \mathrm{~g}, 0.016 \mathrm{~mol})$ in $35 \mathrm{ml}$ of $\mathrm{CH}_{2} \mathrm{Cl}_{2}, m$-chloroperbenzoic acid (mCPBA) (5.6 g, $0.025 \mathrm{~mol}$ ) was added. The mixture was stirred overnight, and subsequently stored at $-18{ }^{\circ} \mathrm{C}$ overnight to precipitate the formed $m$-chlorobenzoic acid. The solids were filtered off and the solution was washed three times with saturated solutions of $\mathrm{Na}_{2} \mathrm{~S}_{2} \mathrm{O}_{3}$ and $\mathrm{NaHCO}_{3}$, and finally three times with MilliQ water. The organic phase was dried over $\mathrm{MgSO}_{4}$ and filtered. The solvent was removed in vacuo, giving a white powder. The product was recrystallized twice from warm toluene, in order to remove traces of $m$-chlorobenzoic acid, as well as 
water. Yield: $3.0 \mathrm{~g}(80 \%) .{ }^{1} \mathrm{H}-\mathrm{NMR}\left(\mathrm{CDCl}_{3}\right): \delta=4.60(\mathrm{~s}, 1 \mathrm{H}, \mathrm{N} H-\mathrm{C}=\mathrm{O}), 4.30(\mathrm{~m}, 1 \mathrm{H}$, $\left.\mathrm{CH}_{2}-\mathrm{O}\right), 4.15\left(\mathrm{~m}, 1 \mathrm{H}, \mathrm{CH}_{2}-\mathrm{O}\right), 3.60(\mathrm{~m}, 1 \mathrm{H}, \mathrm{CH}-\mathrm{NH}), 2.60\left(\mathrm{~m}, 2 \mathrm{H}, \mathrm{CH}_{2}-\mathrm{C}=\mathrm{O}\right), 2.20$ (m, $\left.2 \mathrm{H}, \mathrm{CH}_{2}\right), 1.70\left(\mathrm{~m}, 1 \mathrm{H}, \mathrm{CH}_{2}\right), 1.55\left(\mathrm{~m}, 1 \mathrm{H}, \mathrm{C} \mathrm{H}_{2}\right), 1.40\left(\mathrm{~s}, 9 \mathrm{H}, \mathrm{C}\left(\mathrm{CH}_{3}\right)_{3}\right) .{ }^{13} \mathrm{C}-\mathrm{NMR}$

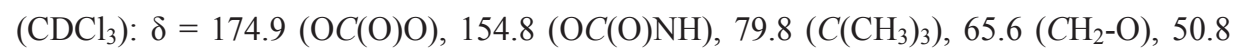
$(C H-N H), 35.7\left(\mathrm{CH}_{2}-\mathrm{CH}_{2}-\mathrm{O}\right), 30.5\left(\mathrm{CH}_{2}-\mathrm{C}=\mathrm{O}\right), 29.1\left(\mathrm{CH}_{2}-\mathrm{CH}_{2}-\mathrm{C}=\mathrm{O}\right), 28.6\left(\mathrm{CH}_{3}\right) . \mathrm{MS}$ (ES): Found: $229,88 . \mathrm{Mp} 165-166^{\circ} \mathrm{C}$.

\section{Ring-Opening Reactions}

'Melt Polymerization' of $\gamma$-Boc-NH- $-\mathrm{CL}$ : Reactions were carried out under an inert $\mathrm{N}_{2}$ atmosphere. In a dry reaction vessel a catalytic amount of stannous octoate was added to $\gamma$-Boc-NH- $\varepsilon$-CL $(229 \mathrm{mg}, 1.00 \mathrm{mmol})$ and the mixture was heated to $165^{\circ} \mathrm{C}$. After $1 \mathrm{~h}$, the mixture was cooled to room temperature, dissolved in $\mathrm{CHCl}_{3}$ and precipitated in diethyl ether. A sticky, brown material was collected upon filtering. Yield: $186 \mathrm{mg}$.

'Melt Copolymerization' of $\gamma$-Boc-NH- $\mathrm{E}-\mathrm{CL}$ and $\varepsilon$-caprolactone: Reactions were carried out under an inert $\mathrm{N}_{2}$ atmosphere. In a dry reaction vessel, $\gamma$-Boc-NH- $\varepsilon$-CL (240 mg, 1.0 mmol) was mixed with $\varepsilon$-CL (1005 mg, $8.8 \mathrm{mmol})$, and benzyl alcohol (11 mg, 0.10 mmol) was added. After stirring, a catalytic amount of stannous octoate was added, and the mixture was heated at $110^{\circ} \mathrm{C}$ for $18 \mathrm{~h}$. The mixture was cooled to room temperature, giving a waxy, pale yellow product which was subsequently dissolved in $2 \mathrm{ml}$ of $\mathrm{CH}_{2} \mathrm{Cl}_{2}$. The solution was added dropwise into $50 \mathrm{ml}$ of diethyl ether, and the resulting mixture was stored at $-18{ }^{\circ} \mathrm{C}$ overnight to give a white precipitate. After filtering the solid was redissolved in $\mathrm{CH}_{2} \mathrm{Cl}_{2}$ and precipitated in diethyl ether. Yield (solid): $814 \mathrm{mg}$. ${ }^{1} \mathrm{H}-\mathrm{NMR}$ (solid: benzyl alcohol initiated PCL): $\delta=7.30$ (s, 5H, aromatic protons), 5.05 (s, 2H, Bz$\mathrm{CH}_{2}-\mathrm{O}$ ), 4.00 (t, 2H, CH$H_{2}-\mathrm{O}-\mathrm{C}=\mathrm{O}$ ), 3.60 (q, 2H, $\left.\mathrm{CH}_{2}-\mathrm{OH}\right), 2.25$ (t, 2H, $\mathrm{CH}_{2}-\mathrm{C}=\mathrm{O}$ ), 1.55 (m, $4 \mathrm{H}, \mathrm{CH}_{2}-\mathrm{CH}_{2}-\mathrm{O}$ and $\left.\mathrm{CH}_{2}-\mathrm{CH}_{2}-\mathrm{C}=\mathrm{O}\right), 1.30\left(\mathrm{~m}, 2 \mathrm{H}, \mathrm{CH}_{2}\right)$. The diethyl ether phases were combined and the solvent was removed in vacuo to give an oily residue. Yield (oil): $132 \mathrm{mg}$. The oily residue was analyzed by ${ }^{1} \mathrm{H}-\mathrm{NMR}$ and MALDI-TOF mass spectrometry, and appeared a mixture of rearranged 4-Boc-NH- $\varepsilon-\mathrm{CL}$ (see 'Solution polymerization'), $\varepsilon$-CL monomer and oligomer.

Pseudo-Anionic 'Solution Polymerization' of $\gamma$-Boc-NH-E-CL: In attempts to polymerize $\gamma$-Boc- NH- $\varepsilon$-CL, a number of different combinations of catalysts, initiators and solvents were explored. In toluene, the monomer was combined with various initiators ( $\mathrm{HO} i \mathrm{Pr}$, 
$\mathrm{BzOH}, \mathrm{mPEG}-\mathrm{OH})$, and stannous octoate as a catalyst under reflux conditions $\left(110^{\circ} \mathrm{C}\right)$. In a typical example, $\gamma$-Boc-NH- $\varepsilon$-CL (500 mg, $2.18 \mathrm{mmol}$ ) was dissolved in $25 \mathrm{ml}$ of dry toluene, and dried azeotropically by removing $15 \mathrm{ml}$ of solvent. Benzyl alcohol (59 mg, 1 $\mathrm{wt} \% \mathrm{BzOH}$ in toluene) was added, giving $[\mathrm{M}]:[\mathrm{I}] \approx 400$. A stannous octoate solution (55 $\mathrm{mg}, 2 \mathrm{wt} \% \mathrm{Sn}(\mathrm{Oct})_{2}$ in toluene) was added under vigorous stirring, and the mixture was refluxed for 50 hours under a $\mathrm{N}_{2}$ atmosphere. After evaporation of the solvent, an oily product remained. ${ }^{1} \mathrm{H}-\mathrm{NMR}\left(\mathrm{CDCl}_{3}\right): \delta=6.00(\mathrm{~s}, 1 \mathrm{H}, \mathrm{OH}), 4.25\left(\mathrm{~m}, 1 \mathrm{H}, \mathrm{CH}_{2}-\mathrm{OH}\right), 4.05$ $\left(\mathrm{m}, 1 \mathrm{H}, \mathrm{CH}_{2}-\mathrm{OH}\right), 3.75(\mathrm{~m}, 1 \mathrm{H}, \mathrm{CH}-\mathrm{N}), 2.30\left(\mathrm{~m}, 3 \mathrm{H}, \mathrm{CH}_{2}-\mathrm{C}=\mathrm{O}\right.$ and $\mathrm{N}-\mathrm{CH}-\mathrm{CH}_{2}-\mathrm{CH}_{2}-$ $\mathrm{C}=\mathrm{O}), 1.80\left(\mathrm{q}, 2 \mathrm{H}, \mathrm{CH}_{2}-\mathrm{CH}_{2}-\mathrm{O}\right), 1.70\left(\mathrm{~m}, 1 \mathrm{H}, \mathrm{N}-\mathrm{CH}-\mathrm{CH}_{2}-\mathrm{CH}_{2}-\mathrm{C}=\mathrm{O}\right), 1.40 \quad(\mathrm{~s}, 9 \mathrm{H}$, $\left.\mathrm{C}\left(\mathrm{CH}_{3}\right)_{3}\right)$.

In dichloromethane, $\gamma$-Boc-NH- $\varepsilon$-CL was combined with $\mathrm{Zn}\left[\mathrm{N}\left(\mathrm{SiMe}_{3}\right)_{2}\right]_{2}$ or dimethylamino)methyl]-4,6-dimethylphenoxy ethylzinc as a catalyst. Experiments were carried out in a glovebox in an inert $\left(\mathrm{N}_{2}\right)$ atmosphere. In a typical example, $\gamma$-Boc-NH- $\varepsilon$ CL (750 mg, $3.27 \mathrm{mmol}$ ) and isopropanol (133 mg, $0.22 \mathrm{mmol}, 10 \mathrm{wt} \% \mathrm{HO} i \mathrm{Pr}$ in $\mathrm{CH}_{2} \mathrm{Cl}_{2}$ ) were dissolved in $20 \mathrm{ml}$ of $\mathrm{CH}_{2} \mathrm{Cl}_{2}$, giving $[\mathrm{M}] /[\mathrm{I}] \approx 15$. Under vigorous stirring, $\mathrm{Zn}\left[\mathrm{N}\left(\mathrm{SiMe}_{3}\right)_{2}\right]_{2}(44 \mathrm{mg}, 0.11 \mathrm{mmol})$ was added, and stirring was continued at room temperature for several days. At certain intervals, small aliquots were taken to determine monomer conversion. The product was the same as described above.

Cationic 'Copolymerization' of $\gamma-B o c-N H-\varepsilon-C L$ and $\varepsilon$-caprolactone: In a dry reaction vessel, $\gamma$-Boc-NH- $\varepsilon$-CL (200 mg, $0.872 \mathrm{mmol}$ ) was mixed with $\varepsilon$-CL (896 mg; 7.84 mmol), and benzyl alcohol (11 mg, $0.0102 \mathrm{mmol}$ ) was added as an initiator. The mixture was heated to $110{ }^{\circ} \mathrm{C}$ under argon atmosphere, and fumaric acid (100 mg, $0.862 \mathrm{mmol}$ ) was added to the mixture. After $20 \mathrm{~h}$ the mixture was cooled to room temperature, upon which it solidified. The solid was dissolved in $2 \mathrm{ml}$ of $\mathrm{CH}_{2} \mathrm{Cl}_{2}$, and the solution was added to $50 \mathrm{ml}$ of $n$-hexane, resulting in a sticky, white material. The product was redissolved in $\mathrm{CH}_{2} \mathrm{Cl}_{2}$ and extracted with water to remove fumaric acid traces. The organic layer was added to $100 \mathrm{ml}$ of diethyl ether, resulting in colorless oil. Washing the oil with pentane gave a waxy solid of oligomeric PCL. Evaporating the pentane phase gave an oily residue consisting of $\varepsilon$-CL monomer and rearranged $\gamma$-Boc-NH- $\varepsilon$-CL.

Cationic 'Solution Polymerization' of $\gamma-B o c-N H-\varepsilon-C L$ : Reactions were carried out under an inert $\left(\mathrm{N}_{2}\right)$ atmosphere. Typically, $\gamma$-Boc-NH- $\varepsilon$-CL (214 mg, $\left.0.93 \mathrm{mmol}\right)$ was dissolved 
in $1.6 \mathrm{ml}$ of toluene in a dry reaction vessel, and triethylene glycol monomethyl ether (72 $\mathrm{mg}$ of a $2 \mathrm{wt} \%$ in toluene, $0,087 \mathrm{mmol}$ ) was added as the initiator. The mixture was heated to $90{ }^{\circ} \mathrm{C}$ under $\mathrm{N}_{2}$ atmosphere, and fumaric acid (11 mg, $0.091 \mathrm{mmol}$ ) was added. At certain time intervals, small aliquots were withdrawn from the reaction mixture for NMR analysis and the solvent was evaporated in vacuo. The product was the same as described above.

\section{Characterization}

NMR: ${ }^{1}$ H-NMR (300 MHz) spectra were recorded on a Varian Inova Spectrometer using $\mathrm{CDCl}_{3}$ solutions, and were referenced to shifts of residual $\mathrm{CHCl}_{3}(\delta 7.26)$.

FT-IR: Fourier Transform Infra-Red spectra were recorded on a Biorad FTS 175 spectrometer using a wide band MCT detector at $4 \mathrm{~cm}^{-1}$ spectral resolution. Samples $(\sim 4$ $\mathrm{mg}$ ) were mixed with $\mathrm{KBr}$ and pressed into pellets. The data were collected between 4000 and $500 \mathrm{~cm}^{-1}$.

ESI-TOF MS: Electrospray ionization time-of-flight (ESI-TOF) mass spectrometry data were recorded on a LCT (Micromass) Electrospray Ionization Time-Of-Flight Mass Spectrometer.

MALDI-TOF MS: Matrix assisted laser desorption ionization time-of-flight (MALDITOF) mass spectrometry was performed using a Voyager-DE-RP MALDI-TOF mass spectrometer (Applied Biosystems/PerSeptive Biosystems, Inc., Framingham, MA) equipped with delayed extraction. A 337-nm UV nitrogen laser producing 3-ns pulses was used, and mass spectra were obtained in the linear mode. Samples were prepared non-quantitatively by mixing the reaction product in tetrahydrofuran with [2-(4hydroxyphenylazo)benzoic acid] (HABA). Approximately $1 \mu$ of the solution was transferred onto a gold sample plate, and the solvent was removed by drying in air.

DSC: Thermal analysis was carried out using a Perkin-Elmer DSC-7 Differential Scanning Calorimeter equipped with a PE7700 computer and TAS-7 software. Calibration was performed with pure indium. Samples (ca. $10 \mathrm{mg}$ ) were heated to $180^{\circ} \mathrm{C}$ at $20{ }^{\circ} \mathrm{C} \cdot \mathrm{min}^{-1}$, cooled to $0^{\circ} \mathrm{C}$ at $20{ }^{\circ} \mathrm{C} \cdot \mathrm{min}^{-1}$ and reheated to $180{ }^{\circ} \mathrm{C}$ at $20{ }^{\circ} \mathrm{C} \cdot \mathrm{min}^{-1}$. Melting temperatures $\left(\mathrm{T}_{\mathrm{m}}\right)$ were taken from the peak maxima of the second heating curves. 


\section{Results and Discussion}

\section{Monomer Synthesis}

Starting from trans-aminocyclohexanol, $\gamma$-Boc-amino- $\varepsilon$-caprolactone $(\gamma$-Boc-NH- $\varepsilon$-CL) was successfully synthesized, following the route depicted in Scheme 1. The amine group of trans-aminocyclohexanol was protected using a stoechiometric amount of diBoc in methanol and $\mathrm{NaHCO}_{3}$ as a base. The protected aminoalcohol was subsequently oxidized, using an excess of pyridinium chlorochromate in dichloromethane.

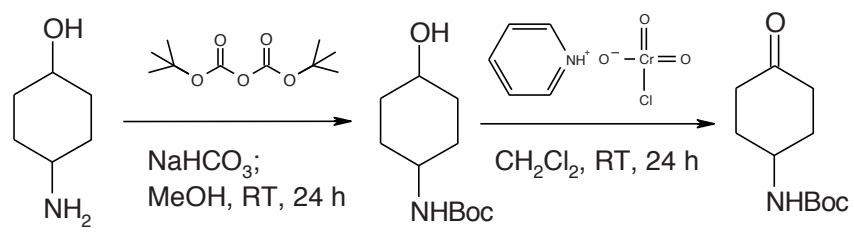<smiles>CC(C)(C)OC(=O)[14C]C(=O)OC(C)(C)C</smiles>

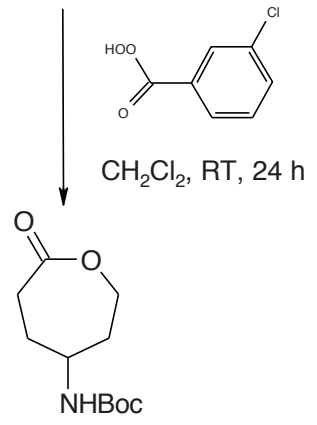

Scheme 1. Synthesis of $\gamma$-Boc-amino- $\varepsilon$-caprolactone ( $\gamma$-Boc-NH- $\varepsilon$-CL).

The resulting 4-Boc-aminocyclohexanone was converted in $\gamma$-Boc-amino- $\varepsilon$-caprolactone by a Baeyer-Villiger rearrangement upon reaction with $m$-chloroperbenzoic acid, giving a white, crystalline powder in $80 \%$ yield. The lactone was purified by crystallization from toluene and had a melting point of $165-166{ }^{\circ} \mathrm{C}$. The ${ }^{1} \mathrm{H}$ - and ${ }^{13} \mathrm{C}-\mathrm{NMR}$ spectra of the $\gamma$ Boc-amino- $\varepsilon$-caprolactone are presented in Figure 1. 

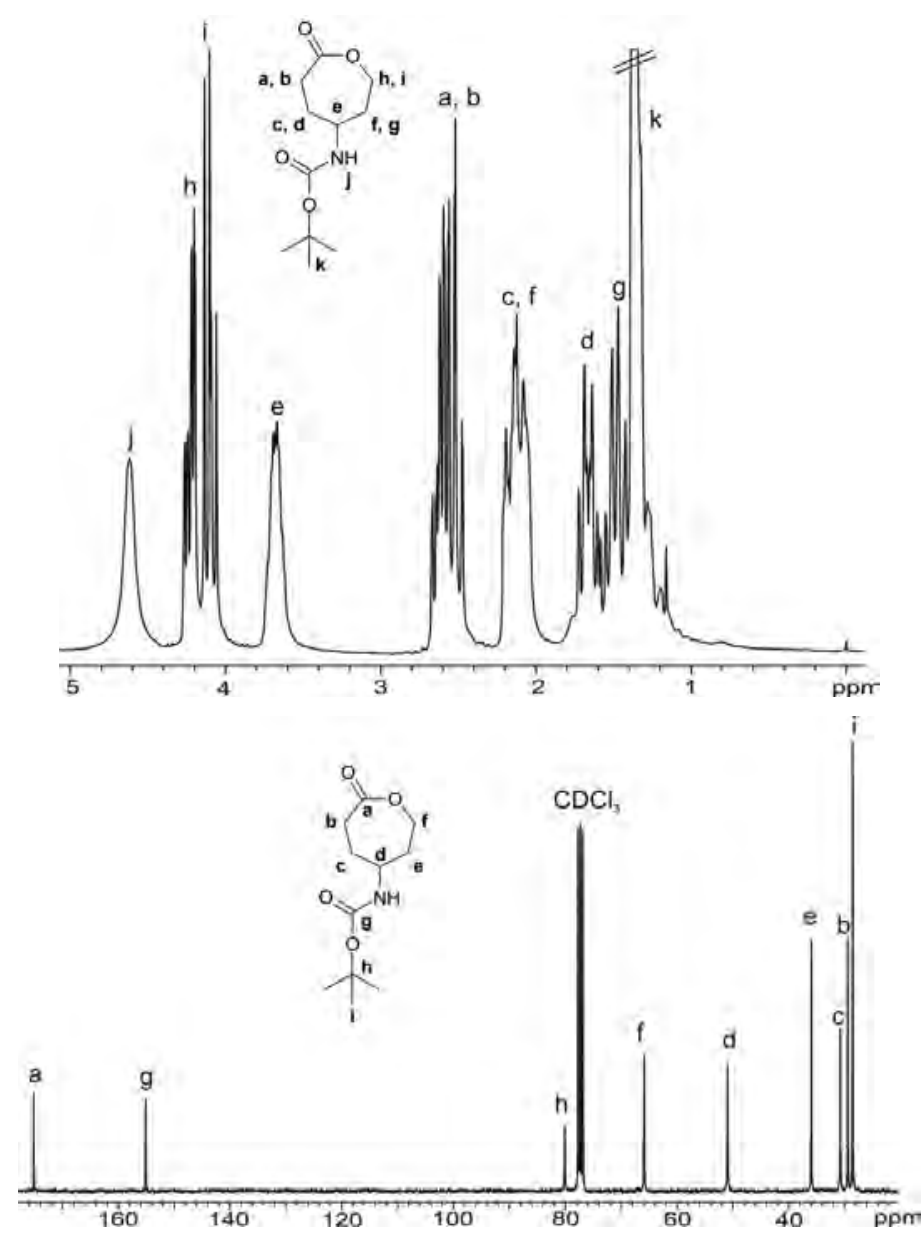

Figure 1. ${ }^{1} \mathrm{H}-\mathrm{NMR}$ (upper) and ${ }^{13} \mathrm{C}$-NMR (lower) spectrum of $\gamma$-Boc-amino- $\varepsilon$ caprolactone. $\left(\mathrm{CDCl}_{3}\right)$.

In the FT-IR spectrum, two distinct stretching vibrations were found at 1700 and 1750 $\mathrm{cm}^{-1}$, corresponding to the carbamate and the ester $\mathrm{C}=\mathrm{O}$ groups, respectively. The characteristic vibrations of the $\mathrm{NH}$ bond were observed at $1530 \mathrm{~cm}^{-1}\left(\mathrm{NH}_{\text {bend }}\right)$ and 3400 $\mathrm{cm}^{-1}\left(\mathrm{NH}_{\text {stretch }}\right)$. The strong signal at $1170 \mathrm{~cm}^{-1}$ was assigned to the $\mathrm{C}-\mathrm{O}$ stretching vibration. In the ESI-TOF MS spectrum, peaks were found at $\mathrm{m} / \mathrm{z}=230$ (4-Boc-NH- $\varepsilon$ $\mathrm{CL}$ ), 174 (parent minus $\left.\cdot \mathrm{C}\left(\mathrm{CH}_{3}\right)_{3}\right), 156$ (parent minus $\left.\cdot \mathrm{OC}\left(\mathrm{CH}_{3}\right)_{3}\right)$, and 130 (parent minus $\left.\cdot \mathrm{C}(\mathrm{O}) \mathrm{C}\left(\mathrm{CH}_{3}\right)_{3}\right)$. 


\section{Ring-opening Reactions}

It is well known that the seven-membered lactone $\varepsilon$-caprolactone and several 2- and 4substituted $\varepsilon$-caprolactones can be ring-opening polymerized to their corresponding (substituted) polyesters. A catalyst commonly applied in these polymerizations is stannous octoate, and an alcohol can be applied to initiate the reaction.

An efficient and common applied synthetic route to polyesters is melt polymerization in the bulk. Conducting the reaction at $170{ }^{\circ} \mathrm{C}$ the $\gamma$-Boc-NH- $\varepsilon-\mathrm{CL}$ in the presence of stannous octoate gave a dark brown product. The ${ }^{1} \mathrm{H}-\mathrm{NMR}$ spectrum was not in accordance with the expected structure of $\operatorname{poly}(\gamma-\mathrm{Boc}-\mathrm{NH}-\varepsilon-\mathrm{CL})$, and no unambiguous product was isolated. Hence, melt homopolymerization was considered not suitable for the preparation of the intended substituted polyester.

Because of the suspected deprotection and decomposition reactions at high temperatures, copolymerization of the 4-Boc-NH- $\varepsilon$-CL and $\varepsilon$-caprolactone $(\varepsilon-\mathrm{CL})$ was considered. The 4-Boc-NH- $\varepsilon$-CL could be dissolved in $\varepsilon$-CL at a temperature of $110^{\circ} \mathrm{C}$. A polymerization was now attempted at $110{ }^{\circ} \mathrm{C}$ using $\mathrm{Sn}(\mathrm{Oct})_{2}$ as a catalyst and benzyl alcohol as an initiator. After an $18 \mathrm{~h}$ reaction time the mixture was cooled to room temperature, affording a waxy product. The reaction mixture could be separated in a white solid material and an oil. ${ }^{1} \mathrm{H}-\mathrm{NMR}$ analysis revealed that the oil contained unreacted $\varepsilon-\mathrm{CL}$ together with a $\gamma$-BocNH- $\varepsilon$-CL-derived product, whereas the solid product contained mainly benzyl alcohol-initiated PCL.

The unsuccessful bulk polymerization reactions prompted us to investigate the homopolymerization of $\gamma$-Boc-NH- $\varepsilon-\mathrm{CL}$ in solution. Polymerization reactions were performed using the catalyst $\mathrm{Sn}(\mathrm{Oct})_{2}$ in toluene under reflux conditions, $\mathrm{Zn}\left[\mathrm{N}\left(\mathrm{SiMe}_{3}\right)_{3}\right]_{2}$ or $\left[\mathrm{Zn}(\mathrm{Et}) \mathrm{OC}_{4} \mathrm{H}_{6} \mathrm{NMe}_{2}-2-\mathrm{Me}-4\right]$ in $\mathrm{CH}_{2} \mathrm{Cl}_{2}$ at room temperature and fumaric acid ${ }^{55}$ in toluene under reflux conditions. Different initiators like 2-propanol and benzyl alcohol were explored. All reactions afforded a similar oily material. ${ }^{1} \mathrm{H}-\mathrm{NMR}$ and ${ }^{13} \mathrm{C}-\mathrm{NMR}$ spectra (Figures 3 and 4) of the product obtained indicated full conversion of the monomer, but lacked initiator signals. MALDI-TOF MS analysis of the reaction product showed that no higher MW products outside the matrix region were present, indicating that polymerization did not take place. 

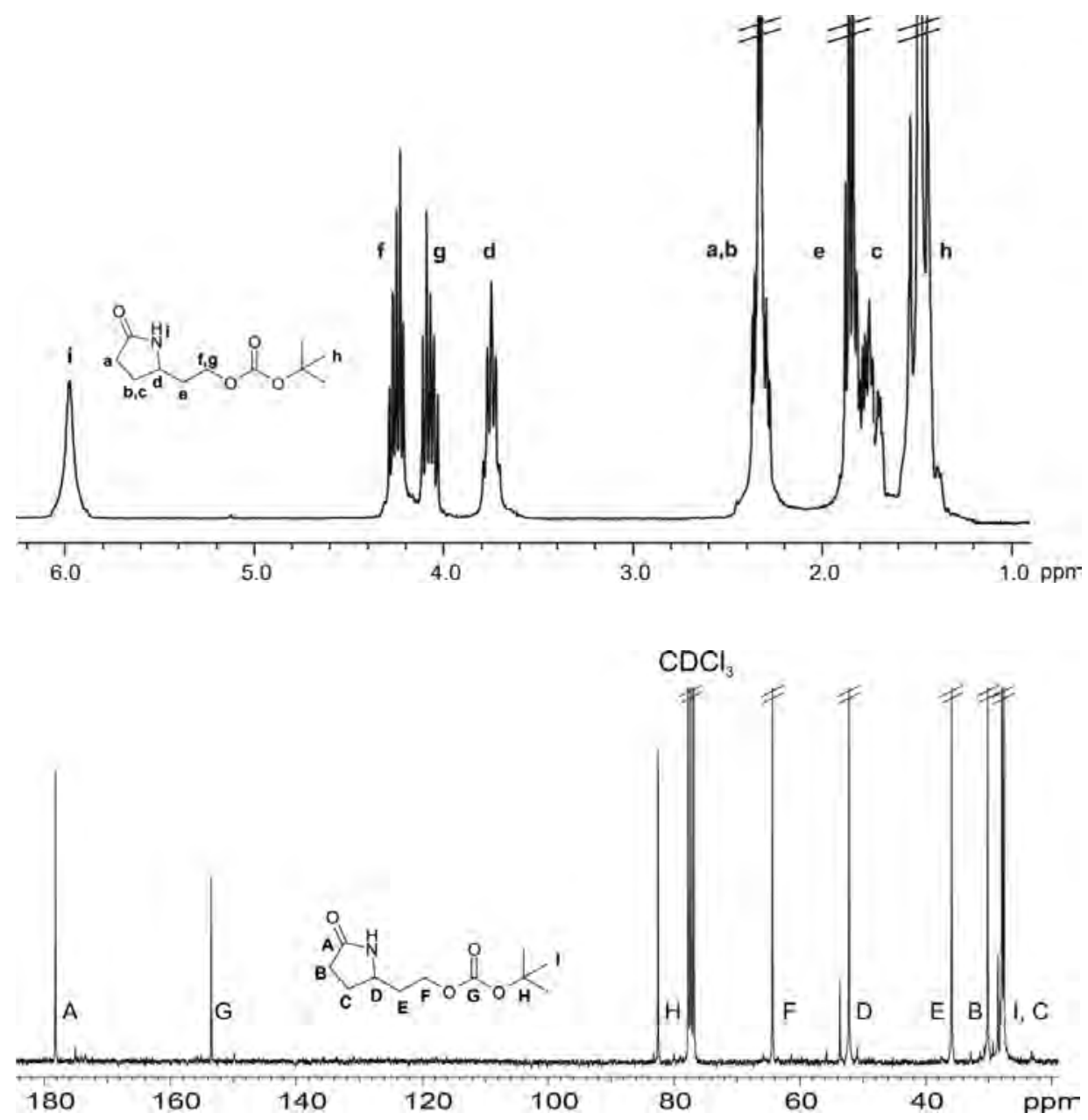

Figure 3. ${ }^{1} \mathrm{H}-\mathrm{NMR}$ (upper) and ${ }^{13} \mathrm{C}-\mathrm{NMR}$ (lower) spectrum of tert-butyl 2-(5oxopyrrolidin-2-yl)ethyl carbonate. Solvent: $\mathrm{CDCl}_{3}$.

\section{Ring-opening Mechanism}

The absence of high molecular weight products in both bulk and solution (co)polymerizations suggests that the ring-opening of $\gamma$-Boc-NH- $\varepsilon$-CL was followed by another reaction rather than propagation. Both ${ }^{1} \mathrm{H}-\mathrm{NMR}$ and ${ }^{13} \mathrm{C}-\mathrm{NMR}$ spectra of the 
reaction product showed no signals of the alcohol that was used as an initiator. Moreover, the disappearance of the signal at $\delta=4.50 \mathrm{ppm}$ of the carbamate proton and the appearance of a signal at $\delta=6.00-7.00 \mathrm{ppm}$ in the ${ }^{1} \mathrm{H}-\mathrm{NMR}$ spectrum was rather unexpected.

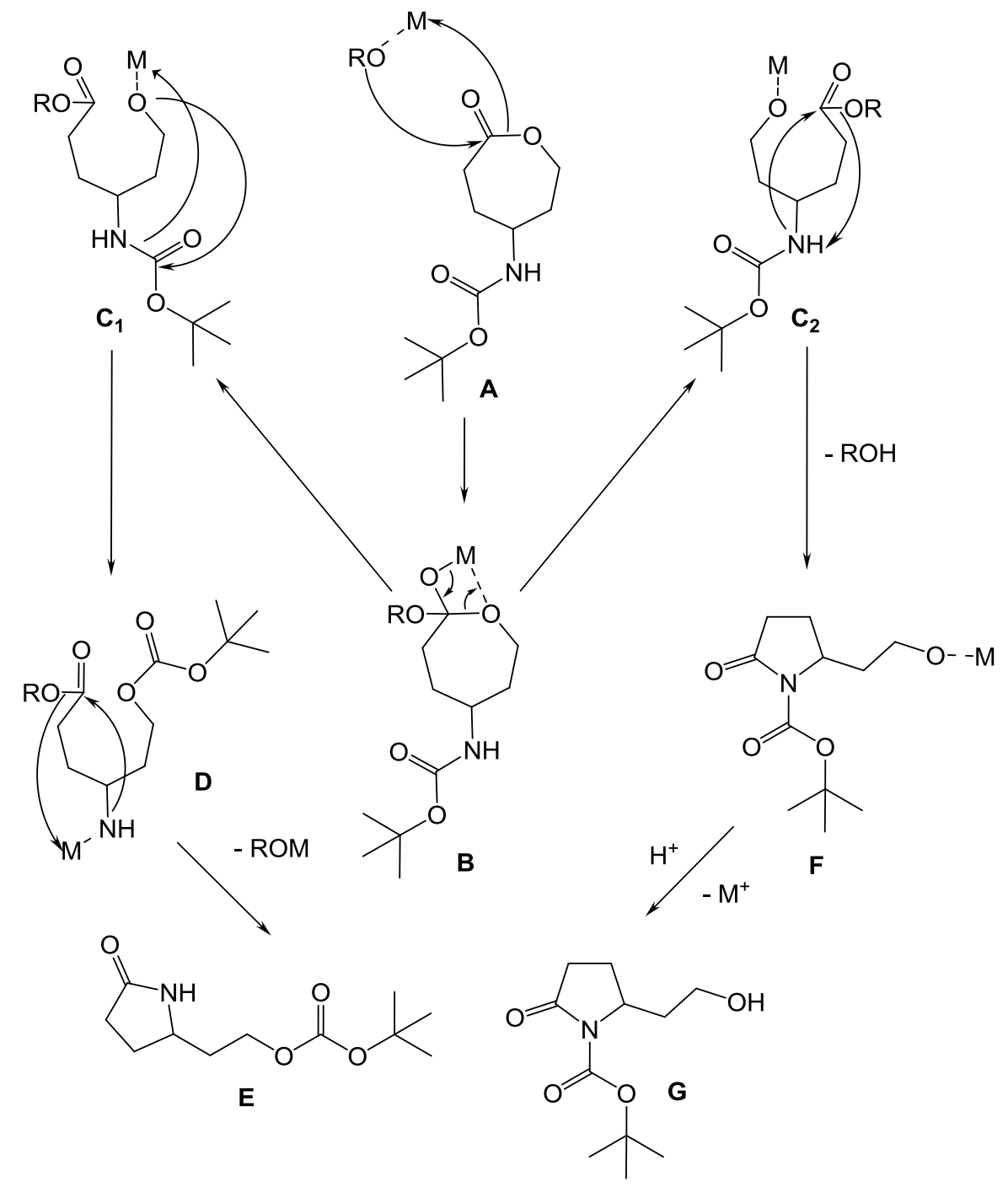

Scheme 2. Mechanism of the rearrangement of $\gamma$-Boc-amino- $\varepsilon$-caprolactone into tertbutyl 2-(5-oxopyrrolidin-2-yl)ethyl carbonate (E) or tert-butyl 2-(2-hydroxyethyl)-5oxopyrrolidine-1-carboxylate (G). 

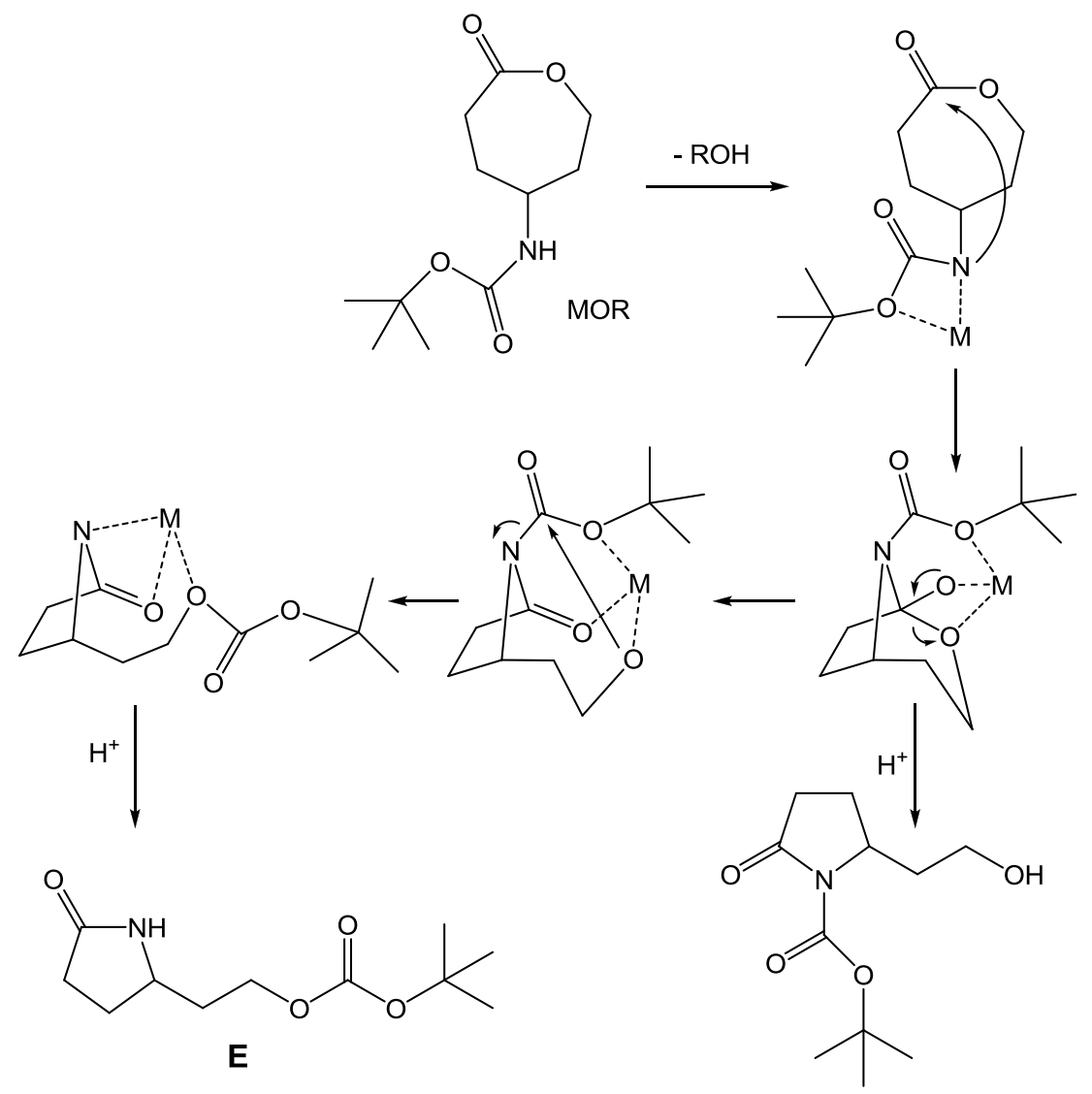

G

Scheme 3. Rearrangement of $\gamma$-BocNH- $\varepsilon$-CL into tert-butyl 2-(5-oxopyrrolidin-2-yl)ethyl carbonate (E) or 2-(2-hydroxyethyl)-5-oxopyrrolidine-1-carboxylate (G) upon deprotonation of the carbamate group.

It has to be noted that the $\gamma$-Boc-NH- $\varepsilon$-CL was thermally stable up to high temperatures in the absence of catalysts. The reaction apparently involves a catalyst and ring opening followed by rearrangement was considered. The interchange of the tert-butyloxy carbonyl group and the metal center after ring opening (forming intermediate D), followed by a nucleophilic attack of the newly formed metal amide on the ester at the 'initiator side' would give the five-membered amide tert-butyl 2-(5-oxopyrrolidin-2- 
yl)ethyl carbonate (Scheme 2, structure E). Recently, attempts to ring open polymerize $\gamma$ acetyloxy- $\varepsilon-C L$, revealed the formation of a similar rearrangement. ${ }^{38}$ Alternatively, the 5membered tert-butyl 2-(2-hydroxyethyl)-5-oxopyrrolidine-1-carboxylate (Scheme 2, structure G) can be formed upon nucleophilic attack by the carbamate nitrogen after activation of the lactone by the metal species. The rearrangement of 4-BocNH- $\varepsilon$-CL into $\mathbf{E}$ or $\mathbf{G}$ may also occur upon deprotonation of the carbamate group by the metal alkoxide, as described by Chisholm et al. for depsipeptides. ${ }^{56}$ Nucleophilic attack by the nitrogen induces the ring-opening (Scheme 3). The chemical shift of the protons $\mathbf{f}$ and $\mathbf{g}$ in the rearranged product $(\delta=4.00-4.35 \mathrm{ppm}$, Figure 3$)$ corresponds more likely to protons next to a carbonate moiety than next to an alcohol group. This means that the product obtained would have structure $\mathbf{E}$ rather then structure $\mathbf{G}$.

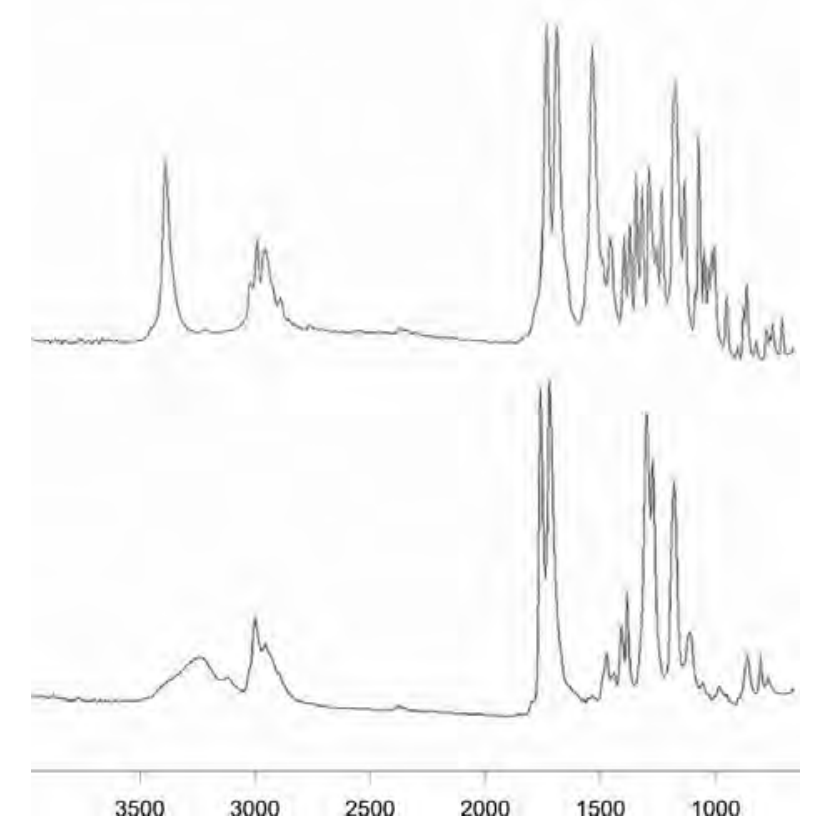

Figure 4. FTIR spectra of $\gamma$-Boc-amino- $\varepsilon$-caprolactone (top) and the rearranged product tert-butyl 2-(5-oxopyrrolidin-2-yl)ethyl carbonate (bottom).

FT-IR analysis of the product revealed the disappearance of the NH stretching band at $\sim 1530 \mathrm{~cm}^{-1}$ of $\gamma$-Boc-NH- $\varepsilon$-CL (Figure 4), which is consistent with the five-membered cyclic amide E. ESI-TOF MS data of the reaction product was consistent with both 


\section{Chapter 6}

structure $\mathbf{E}$ and $\mathbf{G}$, showing peaks at $\mathrm{m} / \mathrm{z}=230$ (parent), 174 (parent minus $\cdot \mathrm{C}\left(\mathrm{CH}_{3}\right)_{3}$ ), 156 (parent minus $\left.\cdot \mathrm{OC}\left(\mathrm{CH}_{3}\right)_{3}\right), 130$ (parent minus $\left.\cdot \mathrm{C}(\mathrm{O}) \mathrm{OC}\left(\mathrm{CH}_{3}\right)_{3}\right), 112(130-\cdot \mathrm{OH})$ and $84\left(130-\cdot\left(\mathrm{CH}_{2}\right)_{2} \mathrm{OH}\right)$.

According to NMR, FT-IR and MS data, a similar product is obtained in both the anionic and cationic approach. The mechanism for 'activated monomer cationic polymerization" (Scheme 4$),{ }^{57}$ does not conflict with the proposed rearrangement and nucleophilic attack of the carbamate nitrogen at the activated carboxyl group may take place. Formation of $\mathbf{G}$ may take place upon activation of the carbamate carbonyl.<smiles>CC(C)(C)OC(=O)NC1CCOC(=O)CC1</smiles>

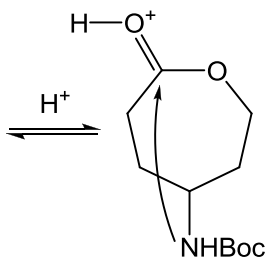

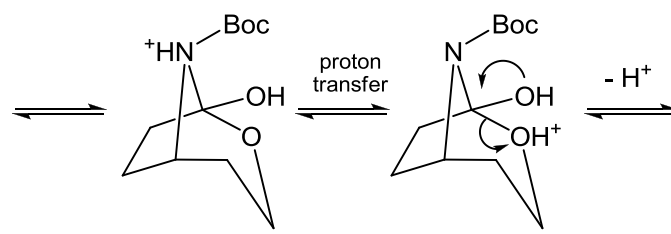<smiles></smiles><smiles>C=[PH+]</smiles><smiles></smiles><smiles>C=C</smiles><smiles>CC(C)(C)OC(O)(O)N1C(=O)[OH+]CC2CCC21</smiles><smiles>CC(C)(C)OC(=O)OCCC1CCC(=O)N1</smiles>

Scheme 4. Monomer activation according to the 'activated monomer cationic polymerization' mechanism. Activation is followed by nucleophilic attack of the carbamate nitrogen at the carbonyl group. 
The above presented mechanisms (Scheme 2-4) point out that the cyclic amide $\mathbf{E}$ can be formed by transferring the tert-butyloxy carbonyl group to the metal alkoxyde after ringopening or in a second step after initial formation of $\mathbf{G}$. Clues to an initial formation of $\mathbf{G}$ can be found in the ${ }^{13} \mathrm{C}$ NMR spectrum of the product (Figure 3). Small signals in the carbonyl region and at e.g. $54 \mathrm{ppm}$ are observed. Especially the latter can be assigned to a C-atom next to an alcohol group.

The presence of the $t$-Boc methyl protons in the NMR spectra of the isolated products pointed out that this group is retained in the newly formed compound. An alternative rearrangement, in which the hydroxyl group of the ring-opened structure $\mathbf{C}$ attacks the carbamate moiety with the formation of a new carbamate ring (Scheme 5: structure $\mathbf{H}$ ) thus appears not to happen.

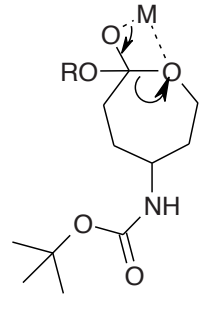

B

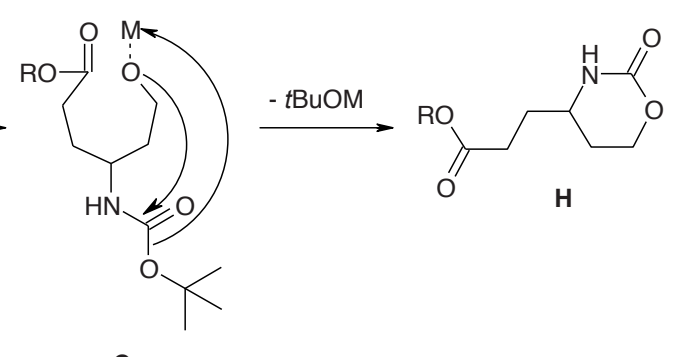

C

Scheme 5. Alternative rearrangement for $\gamma$-Boc-amino- $\varepsilon$-caprolactone, starting from the activated lactone ring $\mathbf{B}$.

In the mechanism proposed in Scheme 2, different metal alcoholates are formed. These alcoholates may initiate a polymerization of $\varepsilon$-caprolactone in copolymerization reactions. In these copolymerization reactions we always observed the formation of some PCL oligomers comprising a small $t$-butyl signal in its NMR spectrum. The rearranged product $\mathbf{G}$ may have served as an initiator, which may explain the relatively low degree of polymerization (with respect to the feed ratio of added initiator and monomer). 


\section{Conclusion}

The amino-functionalized lactone $\gamma$-Boc-amino- $\varepsilon$-caprolactone was successfully synthesized from trans-4-aminocyclohexanol. No polymer is obtained under any of the polymerization conditions explored (including both anionic and cationic ROP) but the lactone rearranges into an oxopyrrolidin-2-yl carbonate. Apparently, the formation of the 5-membered cyclic amide is kinetically favored over polymer chain formation, despite the protective Boc-group on the amine moiety.

\section{References}

1. Y. Ikada and H. Tsuji, Biodegradable polyesters for medical and ecological applications. Macromol. Rapid Commun., 2000, 21(3), 117-132.

2. A. C. Albertsson and I. K. Varma, Aliphatic polyesters: Synthesis, properties and applications. Adv. Polym. Sci., 2002, 157(-), 1-40.

3. T. F. Al-Azemi, L. Kondaveti and K. S. Bisht, Chemoenzymatic Synthesis of Enantioenriched Substituted Polycaprolactones. 2003, 44(2), 597-598.

4. S. Habaue, M. Asai, M. Morita, Y. Okamoto, H. Uyama and S. Kobayashi, Chemospecific ring-opening polymerization of alpha- methylenemacrolides. Polymer, 2003, 44(18), 5195-5200.

5. H. Kikuchi, H. Uyama and S. Kobayashi, Lipase-catalyzed enantioselective copolymerization of substituted lactones to optically active polyesters. Macromolecules, 2000, 33(24), 8971-8975.

6. H. Kikuchi, H. Uyama and S. Kobayashi, Lipase-catalyzed ring-opening polymerization of substituted lactones. Polym. J., 2002, 34(11), 835-840.

7. K. Kullmer, H. Kikuchi, H. Uyama and S. Kobayashi, Lipase-catalyzed ringopening polymerization of alpha-methyl- delta-valerolactone and alpha-methylepsilon-caprolactone. Macromol. Rapid Commun., 1998, 19(2), 127-130.

8. Y. Mei, A. Kumar and R. Gross, Kinetics and mechanism of Candida antarctica Lipase B catalyzed solution polymerization of epsilon-caprolactone. Macromolecules, 2003, 36(15), 5530-5536.

9. A. Kumar and R. A. Gross, Candida antartica lipase B catalyzed polycaprolactone synthesis: Effects of organic media and temperature. Biomacromolecules, 2000, 1(1), 133-138.

10. A. Duda, A. Kowalski, S. Penczek, H. Uyama and S. Kobayashi, Kinetics of the ring-opening polymerization of 6-, 7-, 9-, 12-, 13-, 16-, and 17-membered lactones. Comparison of chemical and enzymatic polymerizations. Macromolecules, 2002, 35(11), 4266-4270.

11. S. Namekawa, H. Uyama and S. Kobayashi, Lipase-catalyzed ring-opening polymerization of lactones in the presence of aliphatic polyesters to ester copolymers. Macromol. Chem. Phys., 2001, 202(6), 801-806.

12. M. Matsumoto, D. Odachi and K. Kondo, Kinetics of ring-opening polymerization of lactones by lipase. Biochem. Eng. J., 1999, 4(1), 73-76. 
13. S. Namekawa, S. Suda, H. Uyama and S. Kobayashi, Lipase-catalyzed ringopening polymerization of lactones to polyesters and its mechanistic aspects. Int. J. Biol. Macromol., 1999, 25(1-3), 145-151.

14. H. Dong, S. G. Cao, Z. Q. Li, S. P. Han, D. L. You and J. C. Shen, Study on the enzymatic polymerization mechanism of lactone and the strategy for improving the degree of polymerization. J. Polym. Sci., Part A: Polym. Chem., 1999, 37(9), 1265-1275.

15. B. Kalra, M. Kunioka, A. Kumar and R. A. Gross, Inhibition of enzymatic ring opening polymerization of caprolactone and pentadecalactone by lactide. Abstr. Pap. Am. Chem. Soc., 2002, 223(-), D7-D7.

16. Y. Y. Svirkin, J. Xu, R. A. Gross, D. L. Kaplan and G. Swift, Enzyme-catalyzed stereoelective ring-opening polymerization of alpha-methyl-beta-propiolactone. Macromolecules, 1996, 29(13), 4591-4597.

17. L. A. Henderson, Y. Y. Svirkin, R. A. Gross, D. L. Kaplan and G. Swift, Enzymecatalyzed polymerizations of epsilon-caprolactone: Effects of initiator on product structure, propagation kinetics, and mechanism. Macromolecules, 1996, 29(24), 7759-7766.

18. R. A. Gross, B. Kalra and A. Kumar, Polyester and polycarbonate synthesis by in vitro enzyme catalysis. Appl. Microbiol. Biotechnol., 2001, 55(6), 655-660.

19. S. Matsumura, K. Mabuchi and K. Toshima, Novel ring-opening polymerization of lactide by lipase. Macromol. Symp., 1998, 130(-), 285-304.

20. S. Matsumura, K. Mabuchi and K. Toshima, Lipase-catalyzed ring-opening polymerization of lactide. Macromol. Rapid Commun., 1997, 18(6), 477-482.

21. K. Numata, R. K. Srivastava, A. Finne-Wistrand, A. C. Albertsson, Y. Doi and H. Abe, Branched poly(lactide) synthesized by enzymatic polymerization: Effects of molecular branches and stereochernistry on enzymatic degradation and alkaline hydrolysis. Biomacromolecules, 2007, 8(10), 3115-3125.

22. K. A. Distel, G. Y. Zhu and P. Wang, Biocatalysis using an organic-soluble enzyme for the preparation of poly(lactic acid) in organic solvents. Bioresour. Technol., 2005, 96(5), 617-623.

23. C. L. R. Zaliz and O. Varela, Facile synthesis of a D-galactono-1,6-lactone derivative, a precursor of a copolyester. Carbohydr. Res., 2006, 341(18), 29732977.

24. D. Mecerreyes, R. D. Miller, J. L. Hedrick, C. Detrembleur and R. Jerome, Ringopening polymerization of 6-hydroxynon-8-enoic acid lactone: Novel biodegradable copolymers containing allyl pendent groups. J. Polym. Sci., Part A: Polym. Chem., 2000, 38(5), 870-875.

25. A. Mahmud, X. B. Xiong and A. Lavasanifar, Novel self-associating poly(ethylene oxide)-block-poly(epsilon-caprolactone) block copolymers with functional side groups on the polyester block for drug delivery. Macromolecules, 2006, 39(26), 9419-9428.

26. B. Parrish and T. Emrick, Aliphatic polyesters with pendant cyclopentene groups: Controlled synthesis and conversion to polyester-graft-PEG copolymers. Macromolecules, 2004, 37(16), 5863-5865. 
27. H. Y. Li, R. Jerome and P. Lecomte, Synthesis of tadpole-shaped copolyesters based on living macrocyclic poly(epsilon-caprolactone). Polymer, 2006, 47(26), 8406-8413.

28. D. Tian, P. Dubois, C. Grandfils and R. Jerome, Ring-opening polymerization of 1,4,8-trioxaspiro[4.6]-9-undecanone: A new route to aliphatic polyesters bearing functional pendent groups. Macromolecules, 1997, 30(3), 406-409.

29. D. Tian, P. Dubois and R. Jerome, Macromolecular engineering of polylactones and polylactides.23. Synthesis and characterization of biodegradable and biocompatible homopolymers and block copolymers based on 1,4,8trioxa[4.6]spiro-9-undecanone. Macromolecules, 1997, 30(7), 1947-1954.

30. D. Tian, P. Dubois and R. Jerome, Macromolecular engineering of polylactones and polylactides.22. Copolymerization of epsilon-caprolactone and 1,4,8trioxaspiro[4.6]-9-undecanone initiated by aluminum isopropoxide. Macromolecules, 1997, 30(9), 2575-2581.

31. F. Stassin, O. Halleux, P. Dubois, C. Detrembleur, P. Lecomte and R. Jerome, Ring opening copolymerization of $\varepsilon$-caprolactone, $\gamma$-(triethylsilyloxy)- $\varepsilon$ caprolactone and $\gamma$-ethylene ketal- $\varepsilon$-caprolactone: a route to hetero-graft copolyesters. Macromol. Symp., 2000, 153(1), 27-39.

32. J. P. Latere, P. Lecomte, P. Dubois and R. Jerome, 2-oxepane-1,5-dione: A precursor of a novel class of versatile semicrystalline biodegradable (Co)polyesters. Macromolecules, 2002, 35(21), 7857-7859.

33. M. J. Liu, N. Vladimirov and J. M. J. Frechet, A new approach to hyperbranched polymers by ring-opening polymerization of an $\mathrm{AB}$ monomer: 4-(2hydroxyethyl)-epsilon-caprolactone. Macromolecules, 1999, 32(20), 6881-6884.

34. M. Trollsas, V. Y. Lee, D. Mecerreyes, P. Lowenhielm, M. Moller, R. D. Miller and J. L. Hedrick, Hydrophilic aliphatic polyesters: Design, synthesis, and ringopening polymerization of functional cyclic esters. Macromolecules, 2000, 33(13), 4619-4627.

35. S. Gautier, V. D'Aloia, O. Halleux, M. Mazza, P. Lecomte and R. Jerome, Amphiphilic copolymers of epsilon-caprolactone and gamma-substituted epsiloncaprolactone. Synthesis and functionalization of poly(D,L-lactide) nanoparticles. J. Biomater. Sci.-Polym. Ed., 2003, 14(1), 63-85.

36. C. G. Pitt, Z. W. Gu, P. Ingram and R. W. Hendren, The Synthesis Of Biodegradable Polymers With Functional Side-Chains. J. Polym. Sci., Part A: Polym. Chem., 1987, 25(4), 955-966.

37. J. Rieger, K. V. Bernaerts, F. E. Du Prez, R. Jerome and C. Jerome, Lactone endcapped poly(ethylene oxide) as a new building block for biomaterials. Macromolecules, 2004, 37(26), 9738-9745.

38. C. Vaida, M. Takwa, M. Martinelle, K. Hult, H. Keul and M. Möller, $\gamma$-Acyloxy$\varepsilon$-Caprolactones: Synthesis, Ring-Opening Polymerization vs. Rearrangement by Means of Chemical and Enzymatic Catalysis. Macromolecular Symposia, 2008, 227(1), 28-38.

39. D. Mecerreyes, J. Humes, R. D. Miller, J. L. Hedrick, C. Detrembleur, P. Lecomte, R. Jerome and J. San Roman, First example of an unsymmetrical difunctional monomer polymerizable by two living/controlled methods. Macromol. Rapid Commun., 2000, 21(11), 779-784. 
40. C. Detrembleur, M. Mazza, X. Lou, O. Halleux, P. Lecomte, D. Mecerreyes, J. L. Hedrick and R. Jerome, New functional aliphatic polyesters by chemical modification of copolymers of epsilon-caprolactone with gamma-(2-bromo-2methylpropionate)-epsilon-caprolactone, gamma-bromo-epsilon- caprolactone, and a mixture of beta- and gamma-ene-epsilon- caprolactone. Macromolecules, 2000, 33(21), 7751-7760.

41. M. Trollsas, P. Lowenhielm, V. Y. Lee, M. Moller, R. D. Miller and J. L. Hedrick, New approach to hyperbranched polyesters: Self-condensing cyclic eater polymerization of bis(hydroxymethyl)-substituted epsilon-caprolactone. Macromolecules, 1999, 32(26), 9062-9066.

42. B. Vroman, M. Mazza, M. R. Fernandez, R. Jerome and V. Preat, Copolymers of epsilon-caprolactone and quaternized epsilon-caprolactone as gene carriers. $J$. Control. Release, 2007, 118(1), 136-144.

43. S. Lenoir, R. Riva, X. Lou, C. Detrembleur, R. Jerome and P. Lecomte, Ringopening polymerization of alpha-chloro-is an element of-caprolactone and chemical modification of poly(alpha-chloro-is an element of-caprolactone) by atom transfer radical processes. Macromolecules, 2004, 37(11), 4055-4061.

44. R. Riva, S. Lenoir, R. Jerome and P. Lecomte, Functionalization of poly(epsiloncaprolactone) by pendant hydroxyl, carboxylic acid and epoxide groups by atom transfer radical addition. Polymer, 2005, 46(19), 8511-8518.

45. R. Riva, J. Rieger, R. Jerome and P. Lecomte, Heterograft copolymers of poly(epsilon-caprolactone) prepared by combination of ATRA "grafting onto" and ATRP "grafting from" processes. J. Polym. Sci., Part A: Polym. Chem., 2006, 44(20), 6015-6024.

46. R. Riva, S. Schmeits, C. Jerome, R. Jerome and P. Lecomte, Combination of ringopening polymerization and "click chemistry": Toward functionalization and grafting of poly(epsilon-caprolactone). Macromolecules, 2007, 40(4), 796-803.

47. S. El Habnouni, V. Darcos and J. Coudane, Synthesis and Ring Opening Polymerization of a New Functional Lactone, $\alpha$-Iodo- $\varepsilon$-caprolactone: A Novel Route to Functionalized Aliphatic Polyesters. Macromol. Rapid Commun., 2008, 30(3), 165 - 169.

48. H. Y. Li, R. Riva, R. Jerome and P. Lecomte, Combination of ring-opening polymerization and "click" chemistry for the synthesis of an amphiphilic tadpoleshaped poly(epsilon-caprolactone) grafted by PEO. Macromolecules, 2007, 40(4), 824-831.

49. S. Sinnwell and H. Ritter, Ring-opening homo- and copolymerization of alphamethylene-epsilon-caprolactone. Macromolecules, 2006, 39(8), 2804-2807.

50. X. D. Lou, C. Detrembleur, P. Lecomte and R. Jerome, Controlled synthesis and chemical modification of unsaturated aliphatic (co)polyesters based on 6,7dihydro-2(3H)-oxepinone. J. Polym. Sci., Part A: Polym. Chem., 2002, 40(14), 2286-2297.

51. X. Lou, C. Detrembleur, P. Lecomte and R. Jerome, Living ring-opening (co)polymerization of 6,7-dihydro-2 $(5 \mathrm{H})$ - oxepinone into unsaturated aliphatic polyesters. Macromolecules, 2001, 34(17), 5806-5811. 
52. M. R. Ten Breteler, Z. Y. Zhong, P. J. Dijkstra and J. Feijen, NO-Bidentate and NON-Tridentate Zinc Alkoxides for the Controlled Ring-Opening Polymerization of Lactides. Chapter 3, this thesis, 2008.

53. J. Einhorn, C. Einhorn and J. L. Luche, A Mild And Efficient Sonochemical TertButoxycarbonylation Of Amines From Their Salts. Synlett, 1991, 1991(1), 37-38.

54. C. Detrembleur, M. Mazza, O. Halleux, P. Lecomte, D. Mecerreyes, J. L. Hedrick and R. Jerome, Ring-opening polymerization of gamma-bromo-epsiloncaprolactone: A novel route to functionalized aliphatic polyesters. Macromolecules, 2000, 33(1), 14-18.

55. F. Sanda, H. Sanada, Y. Shibasaki and T. Endo, Star polymer synthesis from epsilon-caprolactone utilizing polyol/protonic acid initiator. Macromolecules, 2002, 35(3), 680-683.

56. M. H. Chisholm, J. Galucci, C. Krempner and C. Wiggenhorn, Comments on the ring-opening polymerization of morpholine-2,5-dione derivatives by various metal catalysts and characterization of the products formed in the reactions involving $\mathrm{R}_{2} \mathrm{SnX} \mathrm{X}_{2}$, where $\mathrm{X}=\mathrm{OPr}^{\mathrm{i}}$ and $\mathrm{NMe}_{2}$ and $\mathrm{R}=\mathrm{Bu}^{\mathrm{n}}$, $\mathrm{Ph}$ and $p-\mathrm{Me}_{2} \mathrm{NC}_{6} \mathrm{H}_{4}$. Dalton Trans., 2006, 2006(6), 846-851.

57. Y. Shibasaki, H. Sanada, M. Yokoi, F. Sanda and T. Endo, Activated monomer cationic polymerization of lactones and the application to well-defined block copolymer synthesis with seven-membered cyclic carbonate. Macromolecules, 2000, 33(12), 4316-4320. 


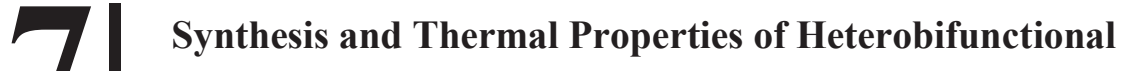 PLA Oligomers and their Stereocomplexes
}

\begin{abstract}
Low molecular weight heterotelechelic polylactides were prepared by the zinc catalyzed ring-opening polymerization of $L$-lactide or $D$-lactide using functional initiators and subsequent reaction with termination reagents. An amine group was introduced using the functional initiator 3-(tert-butoxycarbonylamino)-1-propanol and deprotection after polymerization. Initiation by 2,2 '-dithiodiethanol afforded a polylactide with a central disulfide group that could be reduced to give polylactides with a thiol group. Reaction of the living chain end with succinic anhydride or $N$-(tert-butoxycarbonyl)glycine after the ring-opening polymerization afforded a carboxylic acid and, after deprotection, an amine end group, respectively. Thermal analysis revealed that modification of the hydroxyl terminus lowered the number of lactic acid units within a PLA chain that can effectively participate in crystallization. Both $\mathrm{T}_{\mathrm{m}}$ and $\Delta \mathrm{H}_{\mathrm{m}}$ values for these polymers were lower compared to PLAs of comparable chain lengths with no modification of the hydroxyl end group. In stereocomplexes prepared from equimolar amounts of the heterotelechelic PLLAs and PDLAs, this suppressive effect on $\mathrm{T}_{\mathrm{m}}$ and $\Delta \mathrm{H}_{\mathrm{m}}$ was also observed. Modification of the hydroxyl end resulted in a decrease in stereocomplex $\mathrm{T}_{\mathrm{m}}$ values of $\sim 10-20{ }^{\circ} \mathrm{C}$. The lower limit for the crystallization of stereocomplexes was at a DP of 5 .
\end{abstract}




\section{Introduction}

Synthetic polymers nowadays cover a tremendous range of applications in different areas, varying from construction and household utensils to materials for packaging and medical devices. By combining different polymers in e.g. blends, block, star, and graft copolymers, manipulation of properties can be extended beyond the chemical/physical properties of a single material, and the specific advantages of certain polymers can be combined. In this respect, heterobifuctional polymers are versatile building blocks in the preparation of such materials. These polymers however, are generally not commercially available and have to be synthesized. Functional end groups that are of interest for chemical coupling reactions are vinyl groups, amines, thiols and (activated) carboxylic acids.

Biodegradable polyesters are widely investigated for pharmaceutical and biomedical applications. Most well known examples of biodegradable polymers are poly(glycolide), poly(lactide) and poly( $\varepsilon$-caprolactone). ${ }^{1-16}$ Homopolymers and copolymers of these materials are preferably synthesized by ring-opening polymerization (ROP) in bulk or solution of the monomers glycolide, lactide and $\varepsilon$-caprolactone using metal alkoxides as catalyst/initiator systems. ${ }^{17-20}$ These metal alkoxides are either commercially available or can be generated in situ from the addition of an alcohol to a variety of metal containing compounds. In principal, any alcohol that can be dissolved in the commonly used ROP reaction media like $\mathrm{CH}_{2} \mathrm{Cl}_{2}$, dioxane, THF and toluene, and that would coordinate to the metal center under the given conditions (solvent, temperature) could be used to initiate the reaction. This includes the use of diols ${ }^{21}$, polyols ${ }^{22}$ and alcohols containing other functional groups. The latter enables the modification of the carbonyl chain end of the polymer, and is a straightforward method to prepare heterofunctional PLAs. Protection of these functional groups, however, is generally required, as some may act as initiators in the ROP. ${ }^{23-26}$

Solution ring-opening polymerization of (di)lactones using metal alkoxides in many cases proceeds via a 'living' coordination polymerization mechanism. The metal center remains coordinated to the chain end. This metal alkoxide is highly reactive and as long as monomer is present the polymerization will continue. As no monomer is present 
anymore this nucleophilic living chain end may react with electrophiles to introduce another functional group.

A requisite for the preparation of heterobifunctional polyesters via ring-opening polymerization, either through initiation or end group modification, is the quantitative incorporation or conversion of the ligand in the initiation or electrophile in the termination reaction, respectively. The catalyst and initiator used in the polymerization reaction should be of high purity. Moreover, when bi- or multifunctional initiators are used in combination with metal-ligand precursors, in situ generation of a 'single-site' catalyst-initiator is preferred, as the combination of multifunctional catalyst with multifunctional initiators easily forms networks in solution, which hampers the ROP reaction. The syntheses of linear and branched PLAs comprising e.g carboxylic, ${ }^{27-30}$ amine, $^{23,24,31,32}$ (meth)acrylic, ${ }^{30,33-35}$ halogen $^{36,37}$ or isocyanate ${ }^{38}$ end groups have occasionally been described in literature.

In this study we have focused on the synthesis of heterobifunctional poly(lactide)s of low molecular weights $(\mathrm{DP} \sim 7)$, to be used in the synthesis of block or graft copolymers by coupling reactions. The influence of the end groups of the oligomers on the thermal properties of enantiomeric PLAs and their sterocomplexes was investigated.

\section{Experimental}

\section{Materials}

All experiments were carried out under nitrogen in a glovebox or under argon using Schlenk techniques. Dichloromethane and toluene (Biosolve) were dried by distillation over $\mathrm{CaH}_{2}$ (Aldrich) and sodium wire, respectively. Diethyl ether and methanol (Biosolve) were used as received. Bidistilled water was prepared using a MilliQ apparatus. The monomers $L$-lactide and $D$-lactide (Purac) were recrystallized from dry toluene prior to use. Triethylamine (TEA) (Aldrich) was purified by distillation over $\mathrm{KOH}$. Zinc bis[bis(trimethylsilyl)amide] $\left\{\mathrm{Zn}\left[\mathrm{N}\left(\mathrm{SiMe}_{3}\right)_{2}\right]_{2}\right\}$ (Aldrich) was used as received. 2-[(Dimethylamino)methyl]-4-methylphenoxy ethylzinc $\left\{\left[\mathrm{Zn}(\mathrm{Et}) \mathrm{OC}_{4} \mathrm{H}_{6} \mathrm{NMe}_{2}-\right.\right.$ 2-Me-4]\} was synthesized as described previously. ${ }^{39}$ Succinic anhydride, 3-(tertbutoxycarbonylamino)-1-propanol, dicyclohexyl carbodiimide (DCC) (Aldrich), $N$-(tert- 
butoxycarbonyl)glycine, 4-dimethylamino-pyridine (DMAP) (Fluka) and 2,2'dithiodiethanol (ABCR) were used as received.

\section{Synthesis}

Polymers: The synthetic procedures are described for the preparation of poly( $L$-lactide)s. The procedures for poly $(D$-lactide $)$ s are similar.

Boc-NH-PLA-OH: In a typical experiment, L-lactide (3.0 g, $21.0 \mathrm{mmol})$, 3-(tertbutoxycarbonylamino)-1-propanol (0.52 $\mathrm{g}, 3.0 \mathrm{mmol})$ and $16 \mathrm{ml}$ of dichloromethane were introduced into a dried reaction vessel equipped with a magnetic stirring bar. A solution of $\mathrm{Zn}\left[\mathrm{N}\left(\mathrm{SiMe}_{3}\right)_{2}\right]_{2}(0.059 \mathrm{~g}, 0.15 \mathrm{mmol})$ in $2 \mathrm{ml}$ of dichloromethane was added under vigorous stirring. After $24 \mathrm{~h}$, the reaction was quenched with a few drops of glacial acetic acid. A small aliquot was withdrawn for determination of the $L$-lactide conversion. The solvent was removed in vacuo, giving a white, waxy product, which was redissolved in a small amount of acetone. The polymer was isolated by precipitation in water, collected by filtration and subsequently freeze-dried. $L$-Lactide conversion: $98 \%$. Yield: $2.4 \mathrm{~g}(80 \%) .{ }^{1} \mathrm{H}-\mathrm{NMR}\left(\mathrm{CDCl}_{3}\right): \delta=5.15\left(\mathrm{q}, 1 \mathrm{H}, \mathrm{CH}\left(\mathrm{CH}_{3}\right)-\mathrm{O}\right), 4.70(\mathrm{~b}, 1 \mathrm{H}, \mathrm{N} H), 4.35(\mathrm{q}$, 1H, $\left.\mathrm{CH}\left(\mathrm{CH}_{3}\right)-\mathrm{OH}\right), 4.20$ (t, 2H, $\left.\mathrm{CH}_{2}-\mathrm{O}\right), 3.15$ (q, 2H, $\left.\mathrm{CH}_{2}-\mathrm{NH}\right), 1.85$ (m, 2H, $\left.\mathrm{CH}_{2}\right), 1.55$ (d, 3H, $\left.\mathrm{CH}\left(\mathrm{CH}_{3}\right)-\mathrm{O}\right), 1.40\left(\mathrm{~s}, 9 \mathrm{H},\left(\mathrm{CH}_{3}\right)_{3} \mathrm{C}\right)$.

Boc-NH-PLA-COOH: The synthesis of the polymer Boc-NH-PLA-COOH was carried out analogously to the synthesis of Boc-NH-PLA-OH, with the following modifications. Instead of quenching the reaction with glacial acetic acid, succinic anhydride $(0.35 \mathrm{~g}, 3.5$ mmol), TEA (0.35 g, $3.5 \mathrm{mmol})$ and DMAP (0.42 g, $3.5 \mathrm{mmol})$ were added under vigorous stirring. After $24 \mathrm{~h}$, the organic phase was washed several times with a $0.2 \mathrm{M}$ citric acid solution and water. The organic phase was dried over $\mathrm{MgSO}_{4}$, filtered, and the solvent was removed in vacuo. The remaining product was dissolved in a small amount of acetone. The polymer was isolated by precipitation in water, collected by filtration and subsequently freeze-dried. $L$-Lactide conversion: $98 \%$. Yield: $77 \%$. ${ }^{1} \mathrm{H}-\mathrm{NMR}\left(\mathrm{CDCl}_{3}\right): \delta$ $=5.15\left(\mathrm{q}, 1 \mathrm{H}, \mathrm{CH}\left(\mathrm{CH}_{3}\right)-\mathrm{O}\right), 4.70(\mathrm{bs}, 1 \mathrm{H}, \mathrm{NH}), 4.20\left(\mathrm{t}, 2 \mathrm{H}, \mathrm{CH}_{2}-\mathrm{O}\right), 3.15$ (q, 2H, $\mathrm{CH}_{2}-$ $\mathrm{NH}), 2.70\left(\mathrm{t}, 4 \mathrm{H}, \mathrm{C}(\mathrm{O})-\mathrm{CH}_{2}-\mathrm{CH}_{2}-\mathrm{C}(\mathrm{O})\right) 1.80$ (m, 2H, $\left.\mathrm{CH}_{2}\right), 1.55$ (d, 3H, $\left.\mathrm{CH}\left(\mathrm{CH}_{3}\right)-\mathrm{O}\right)$, $1.40\left(\mathrm{~s}, 9 \mathrm{H},\left(\mathrm{CH}_{3}\right)_{3} \mathrm{C}\right)$.

Boc-NH-PLA-NH-Boc: The synthesis of the polymer Boc-NH-PLA-NH-Boc was carried out analogously to the synthesis of Boc-NH-PLA-OH, with the following modifications. 
Synthesis and Thermal Properties of PLA Oligomers and their Stereocomplexes

Instead of quenching the reaction with glacial acetic acid, $N$-(tert-butoxycarbonyl)glycine (1.3 g, $7.4 \mathrm{mmol})$, DCC (1.5 g, $7.4 \mathrm{mmol})$ and DMAP (0.090 g, $0.74 \mathrm{mmol})$ were added under vigorous stirring. After $24 \mathrm{~h}$, the organic phase was filtered to remove the formed DCU. The filtrate was stored at $-18{ }^{\circ} \mathrm{C}$ overnight to crystallize traces of DCU, and filtered. The polymer was isolated by precipitation in cold methanol, filtration and drying in vacuo. $L$-Lactide conversion: 98\%. Yield: $1.3 \mathrm{~g}(43 \%) .{ }^{1} \mathrm{H}-\mathrm{NMR}\left(\mathrm{CDCl}_{3}\right): \delta=5.15$ (q, 1H, $\left.\mathrm{CH}\left(\mathrm{CH}_{3}\right)-\mathrm{O}\right), 4.70$ (b, 1H, $\left.\mathrm{NH}\right), 4.20$ (t, 2H, $\left.\mathrm{CH}_{2}-\mathrm{O}\right), 4.10-3.90\left(2 \mathrm{H}, \mathrm{C}(\mathrm{O}) \mathrm{CH}_{2}-\mathrm{NH}\right)$, 3.15 (q, 2H, $\left.\mathrm{CH}_{2}-\mathrm{NH}\right), 1.80\left(\mathrm{~m}, 2 \mathrm{H}, \mathrm{CH}_{2}\right), 1.55$ (d, 3H, $\left.\mathrm{CH}\left(\mathrm{CH}_{3}\right)-\mathrm{O}\right), 1.40$ (s, $18 \mathrm{H}$, $\left.\left(\mathrm{CH}_{3}\right)_{3} \mathrm{C}\right)$.

HO-PLA-S-S-PLA-OH: In a typical experiment, L-lactide (3.0 g, $21.0 \mathrm{mmol}), 2,2$ 'dithiodiethanol $(0.23 \mathrm{~g}, 1.5 \mathrm{mmol})$ and $16 \mathrm{ml}$ of dichloromethane were introduced into a dried reaction vessel equipped with a magnetic stirring bar. A solution of 2[(dimethylamino)methyl]-4-methylphenoxy ethylzinc $(0.040 \mathrm{~g}, 0.17 \mathrm{mmol})$ in $2 \mathrm{ml}$ of dichloromethane was added under vigorous stirring. After $24 \mathrm{~h}$, the reaction was quenched with a few drops of glacial acetic acid. A small aliquot was withdrawn for determination of the $L$-lactide conversion. The solvent was removed in vacuo, and the remaining product was dissolved in a small amount of acetone. The polymer was isolated by precipitation in water, filtered, washed with pentane to remove monomer traces and subsequently freeze-dried. $L$-lactide conversion: 98\%. Yield: $2.7 \mathrm{~g}(89 \%)$. ${ }^{1} \mathrm{H}-\mathrm{NMR}$ $\left(\mathrm{CDCl}_{3}\right): \delta=5.15\left(\mathrm{q}, 1 \mathrm{H}, \mathrm{CH}\left(\mathrm{CH}_{3}\right)-\mathrm{O}\right), 4.35\left(\mathrm{~m}, 3 \mathrm{H}, \mathrm{CH}\left(\mathrm{CH}_{3}\right)-\mathrm{OH}\right.$ and $\left.\mathrm{CH}_{2}-\mathrm{O}\right), 2.90$ (t, $\left.2 \mathrm{H}, \mathrm{CH}_{2}-\mathrm{S}\right), 1.55$ (d, 3H, $\left.\mathrm{CH}\left(\mathrm{CH}_{3}\right)-\mathrm{O}\right)$.

HOOC-PLA-S-S-PLA-COOH: The synthesis of the polymer was carried out analogously to the synthesis of HO-PLA-S-S-PLA-OH, with the following modifications. Instead of quenching the reaction with acetic acid, succinic anhydride $(0.69 \mathrm{~g}, 7.0 \mathrm{mmol})$, TEA $(0.30 \mathrm{~g}, 3.0 \mathrm{mmol})$ and DMAP $(0.36 \mathrm{~g}, 3.0 \mathrm{mmol})$ were added under vigorous stirring. After $24 \mathrm{~h}$, the organic phase was washed several times with a $0.2 \mathrm{M}$ citric acid solution and water. The organic phase was dried over $\mathrm{MgSO}_{4}$, filtered, and the solvent was removed in vacuo. The remaining product was dissolved in a small amount of acetone. The polymer was isolated by precipitation in water, collected by filtration and subsequently freeze-dried. L-Lactide conversion: 98\%. Yield: $2.6 \mathrm{~g}$ (85\%). ${ }^{1} \mathrm{H}-\mathrm{NMR}$ 
$\left(\mathrm{CDCl}_{3}\right): \delta=5.15\left(\mathrm{q}, 1 \mathrm{H}, \mathrm{CH}\left(\mathrm{CH}_{3}\right)-\mathrm{O}\right), 4.35\left(\mathrm{~m}, 3 \mathrm{H}, \mathrm{CH}\left(\mathrm{CH}_{3}\right)-\mathrm{OH}\right.$ and $\left.\mathrm{CH}_{2}-\mathrm{O}\right), 2.90$ (t, $\left.2 \mathrm{H}, \mathrm{CH}_{2}-\mathrm{S}\right), 2.70$ (t, 4H, C(O)- $\left.\mathrm{CH}_{2}-\mathrm{CH}_{2}-\mathrm{C}(\mathrm{O})\right) 1.55$ (d, 3H, $\left.\mathrm{CH}\left(\mathrm{CH}_{3}\right)-\mathrm{O}\right)$.

Boc-NH-PLA-S-S-PLA-NH-Boc: The synthesis of the polymer was carried out analogously to the synthesis of HO-PLA-S-S-PLA-OH, with the following modifications. Instead of quenching the reaction with acetic acid, $t$-Boc-glycine $(1.3 \mathrm{~g}, 7.4 \mathrm{mmol})$, DCC (1.6 g, $7.5 \mathrm{mmol})$ and DMAP (0.095 g, $0.78 \mathrm{mmol})$ were added under vigorous stirring. After $24 \mathrm{~h}$, the organic phase was filtered, to remove the formed DCU. The filtrate was stored at $-18{ }^{\circ} \mathrm{C}$ overnight to crystallize traces of DCU, and filtered. The polymer was isolated by precipitation in cold methanol, filtration and drying in vacuo. $L$-Lactide conversion: 98\%. Yield: $1.9 \mathrm{~g}(62 \%) .{ }^{1} \mathrm{H}-\mathrm{NMR}\left(\mathrm{CDCl}_{3}\right): \delta=5.15$ (q, $\left.1 \mathrm{H}, \mathrm{CH}\left(\mathrm{CH}_{3}\right)-\mathrm{O}\right)$, 5.0-4.9 (b, 1H, NH), 4.35 (m, 3H, $\mathrm{CH}\left(\mathrm{CH}_{3}\right)-\mathrm{OH}$ and $\left.\mathrm{CH}_{2}-\mathrm{O}\right), 4.10-3.90\left(2 \mathrm{H}, \mathrm{C}(\mathrm{O}) \mathrm{CH}_{2}-\right.$ $\mathrm{NH}), 2.90$ (t, 2H, - $\left.\mathrm{CH}_{2}-\mathrm{S}-\right), 1.55$ (d, 3H, $\left.\mathrm{CH}\left(\mathrm{CH}_{3}\right)-\mathrm{O}\right), 1.40\left(\mathrm{~s}, 9 \mathrm{H},\left(\mathrm{CH}_{3}\right)_{3} \mathrm{C}\right)$.

Deprotection of the Boc-NH group: In a typical experiment, Boc-NH-PLA-OH (2.0 g, 1.4 mmol) was dissolved in $10 \mathrm{ml}$ of $\mathrm{CH}_{2} \mathrm{Cl}_{2}$. The setup was purged with argon for several minutes, after which gaseous $\mathrm{HCl}$ was gently led through the solution. The mixture was left to stand for $1 \mathrm{~h}$, and after purging with gaseous $\mathrm{N}_{2}$, the solvent was evaporated in vacuo to give $\mathrm{HCl} . \mathrm{H}_{2} \mathrm{~N}-\mathrm{PLA}-\mathrm{OH}$. Yield: $1.7 \mathrm{~g}(89 \%) .{ }^{1} \mathrm{H}-\mathrm{NMR}: \delta=5.15$ (q, $1 \mathrm{H}$, $\left.\mathrm{CH}\left(\mathrm{CH}_{3}\right)-\mathrm{O}\right), 4.20-4.40$ (b, 3H, $\mathrm{CH}\left(\mathrm{CH}_{3}\right)-\mathrm{OH}$ and $\left.\mathrm{CH}_{2}-\mathrm{O}\right), 3.15$ (q, 2H, $\left.\mathrm{CH}_{2}-\mathrm{NH}\right), 2.15$ (m, 2H, $\left.\mathrm{CH}_{2}\right), 1.55$ (d, 3H, $\left.\mathrm{CH}\left(\mathrm{CH}_{3}\right)-\mathrm{O}\right)$.

Reduction of the $S$-S bond: As a typical example, HO-PLA-S-S-PLA-OH (0.5 g, 0.23 mmol) was dissolved in $5 \mathrm{ml}$ of $\mathrm{CH}_{2} \mathrm{Cl}_{2}$. After purging the setup with argon for several minutes, DTT $(0.075 \mathrm{~g}, 0.49 \mathrm{mmol})$ and TEA $(0.023 \mathrm{~g}, 0.23 \mathrm{mmol})$ were added, and the mixture was stirred for 5 days in an air-tight setup. The organic phase was extracted with $0.2 \mathrm{M}$ citric acid and three times with water, dried over $\mathrm{MgSO}_{4}$ and filtered. The solvent was removed in vacuo, giving HS-PLA-OH as a colorless oil. Yield: $0.3 \mathrm{~g}(60 \%) .{ }^{1} \mathrm{H}-$ NMR $\left(\mathrm{CDCl}_{3}\right): \delta=5.15$ (q, $\left.1 \mathrm{H}, \mathrm{CH}\left(\mathrm{CH}_{3}\right)-\mathrm{O}\right), 4.35$ (q, 1H, $\left.\mathrm{CH}\left(\mathrm{CH}_{3}\right)-\mathrm{OH}\right), 4.25$ (t, 2H, $\left.\mathrm{CH}_{2}-\mathrm{O}\right), 2.75$ (q, 2H, $\left.\mathrm{CH}_{2}-\mathrm{S}\right), 1.55\left(\mathrm{~d}, 3 \mathrm{H}, \mathrm{CH}_{3}\right)$. 
Synthesis and Thermal Properties of PLA Oligomers and their Stereocomplexes

\section{Characterization}

NMR: ${ }^{1}$ H-NMR (300 MHz) spectra were recorded on a Varian Inova spectrometer using $\mathrm{CDCl}_{3}$ solutions and were referenced to shifts of residual $\mathrm{CHCl}_{3}(\delta 7.26)$.

MALDI-TOF MS: Matrix assisted laser desorption ionization time-of-flight (MALDITOF) mass spectrometry was performed using a Voyager-DE-RP MALDI-TOF mass spectrometer (Applied Biosystems/PerSeptive Biosystems, Inc., Framingham, MA) equipped with delayed extraction. A 337-nm UV nitrogen laser producing 3-ns pulses was used, and mass spectra were obtained in the linear mode. Samples were prepared non-quantitatively by mixing a polymer solution in tetrahydrofuran with [2-(4hydroxyphenylazo)benzoic acid] (HABA). Approximately $1 \mu$ l of the solution was transferred onto a gold sample plate, and the solvent was removed by drying in air.

DSC: Differential Scanning Calorimetry (DSC) measurements were performed using a DSC7 (Perkin-Elmer). The polymers were first heated from $25{ }^{\circ} \mathrm{C}$ to $160{ }^{\circ} \mathrm{C}$ (or $200{ }^{\circ} \mathrm{C}$ ) at $20^{\circ} \mathrm{C} / \mathrm{min}$, kept at $160{ }^{\circ} \mathrm{C}$ ( or $200^{\circ} \mathrm{C}$ ) for $5 \mathrm{~min}$, cooled to $-20^{\circ} \mathrm{C}$ at $10{ }^{\circ} \mathrm{C} / \mathrm{min}$, kept at $-20{ }^{\circ} \mathrm{C}$ for $5 \mathrm{~min}$ and reheated to $160{ }^{\circ} \mathrm{C}$ (or $200^{\circ} \mathrm{C}$ ) at $10^{\circ} \mathrm{C} / \mathrm{min}$. Melting temperatures were taken from the second heating curve.

\section{Results and Discussion}

\section{Polymer Synthesis}

The solution ring-opening polymerization (ROP) of $L$ - or $D$-lactide (Scheme 1 ) was performed at room temperature in either dichloromethane or toluene. In previous research it was shown that in situ generated catalyst/initiator systems from $\mathrm{Zn}\left[\mathrm{N}\left(\mathrm{SiMe}_{3}\right)_{2}\right]_{2}$ or $\left[\mathrm{Zn}(\mathrm{Et}) \mathrm{OC}_{4} \mathrm{H}_{6} \mathrm{NMe}_{2}-2-\mathrm{Me}-4\right]^{39}$ and an alcohol are highly effective in a controlled ringopening polymerization of lactides. Applying these catalyst/initiator systems afforded PLAs with an ester end group and an alcohol end group upon terminating the reaction with an acid. Using polyfunctional alcohols, star copolymers can be prepared and by using polymers like hydroxyl end-functionalized polymers block copolymers are conveniently synthesized.

The use of alcohols containing a protected functional group was investigated to introduce an end-functional group to the polymer chains. To introduce a functional amino end group to the poly(lactide) chains the amino protected N-tert-butoxycarbonyl-3-amino-1- 
propanol was used as an initiator. Low molecular weight polymers with a degree of polymerization $(\mathrm{DP})$ of 7 were prepared at a $[\mathrm{M}] \approx 1 \mathrm{M}$ and a monomer to initiator to catalyst ratio of $[\mathrm{M}]:[\mathrm{OH}]:[\mathrm{Zn}]=140: 20: 1$.
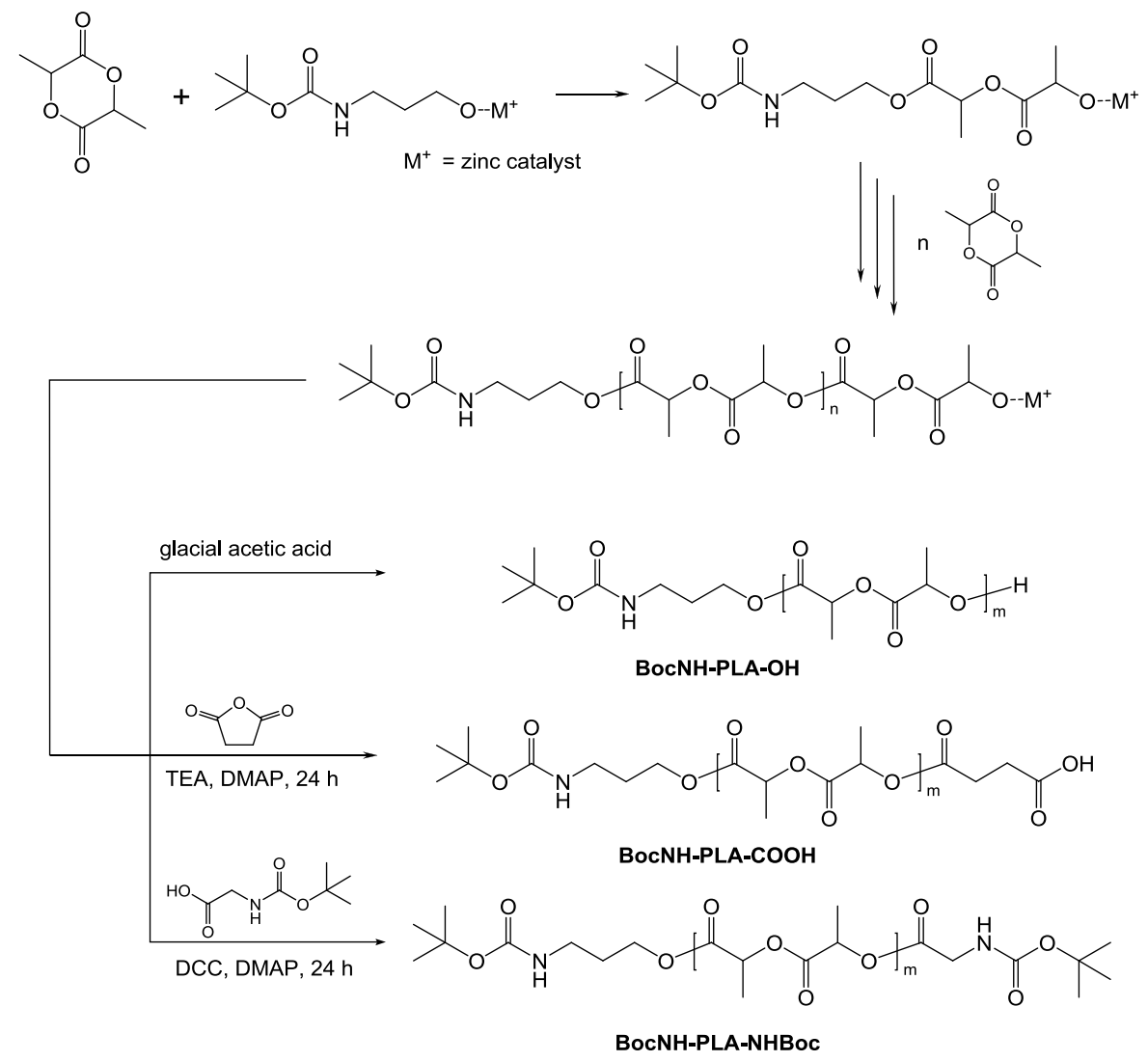

Scheme 1. Ring-opening polymerization of lactide using $\mathrm{Zn}\left[\mathrm{N}\left(\mathrm{SiMe}_{3}\right)_{2}\right]_{2}$ and 3-(tertbutoxycarbonylamino)-1-propanol as an initiator ([M]:[OH]:[Zn] $\approx 140: 20: 1, \mathrm{CH}_{2} \mathrm{Cl}_{2}, 25$ ${ }^{\circ} \mathrm{C},[\mathrm{M}] \approx 1 \mathrm{M}$ ), followed by end group conversion of 'living' PLA chains into a hydroxyl group (upper), a carboxylic acid group (middle) or a protected amine group (lower).

Full conversion (>97\%) in all polymerizations was generally reached within $24 \mathrm{~h}$ as shown by ${ }^{1} \mathrm{H}-\mathrm{NMR}$ analysis of the crude reaction product. Deprotection of the protected 
amine group was best performed by the passage of gaseous $\mathrm{HCl}$ in a polymer dichloromethane solution. For the introduction of a thiol end group the polymerization was initiated with 2,2'-dithiodiethanol and subsequent reduction of the disulfide.

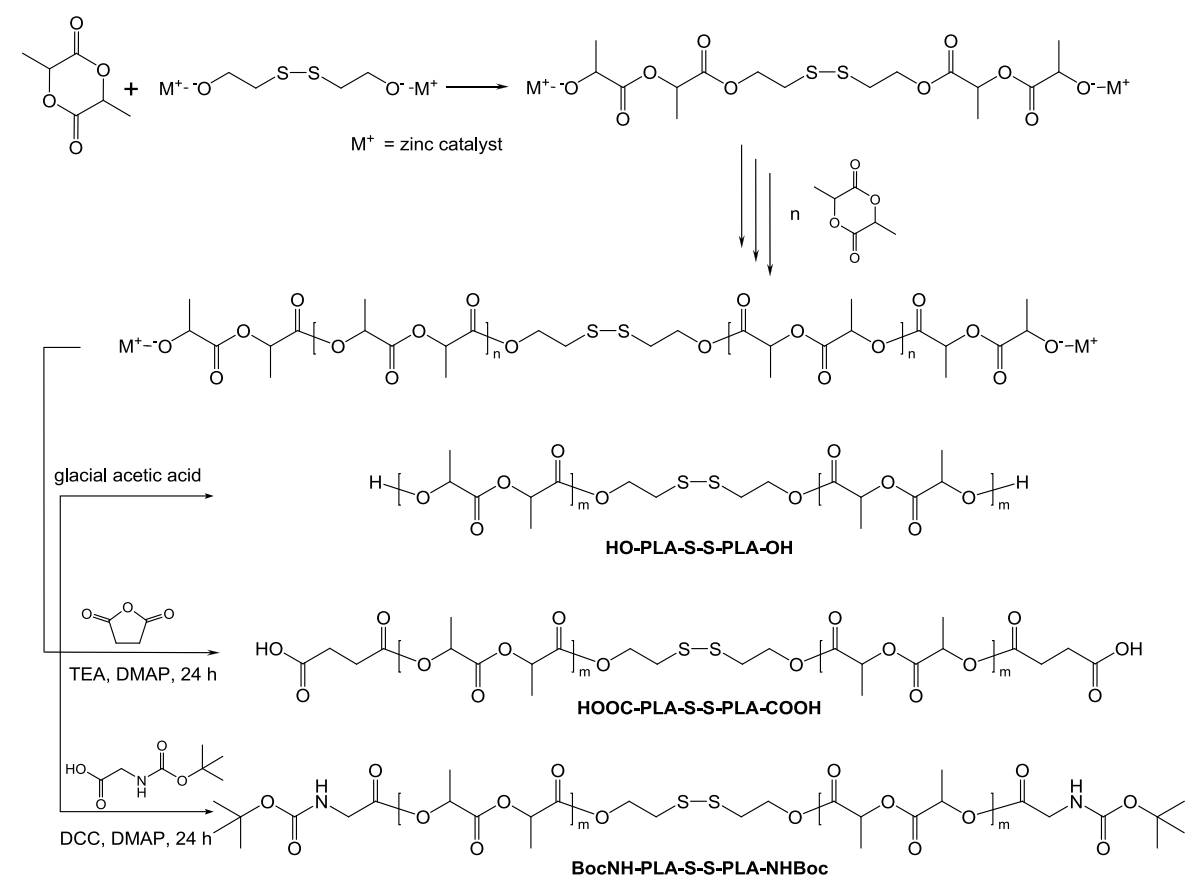

Scheme 2. Ring-opening polymerization of lactide using [ $\left.\mathrm{Zn}(\mathrm{Et}) \mathrm{OC}_{4} \mathrm{H}_{6} \mathrm{NMe}_{2}-2-\mathrm{Me}-4\right]$ and 2,2'-dithiodiethanol as an initiator ([M]:[OH]:[Zn] $\approx 140: 20: 1, \mathrm{CH}_{2} \mathrm{Cl}_{2}, 25^{\circ} \mathrm{C},[\mathrm{M}] \approx$ $1 \mathrm{M})$, followed by end group conversion of 'living' PLA chains into a hydroxyl group (upper), a carboxylic acid group (middle) or a protected amine group (lower).

A number of reducing agents, i.e. dithiothreitol, ${ }^{40,41}$ tri(carboxyethyl)phosphine, ${ }^{42}$ and tributylphosphine, ${ }^{43}$ were explored for the reduction of the disulfide bonds in the polymers synthesized. All reagents appeared efficient and yielded the thiol functionalized poly(lactide)s.

Polymerizations of lactide using the in situ formed zinc catalyst/initiators are taken place via a coordination insertion reaction and are known as 'living' polymerizations. 
Termination of the zinc alkoxides with a proton donor like glacial acetic acid is usually applied and results in polymer chains with hydroxyl end groups (Scheme 1, 2: upper).

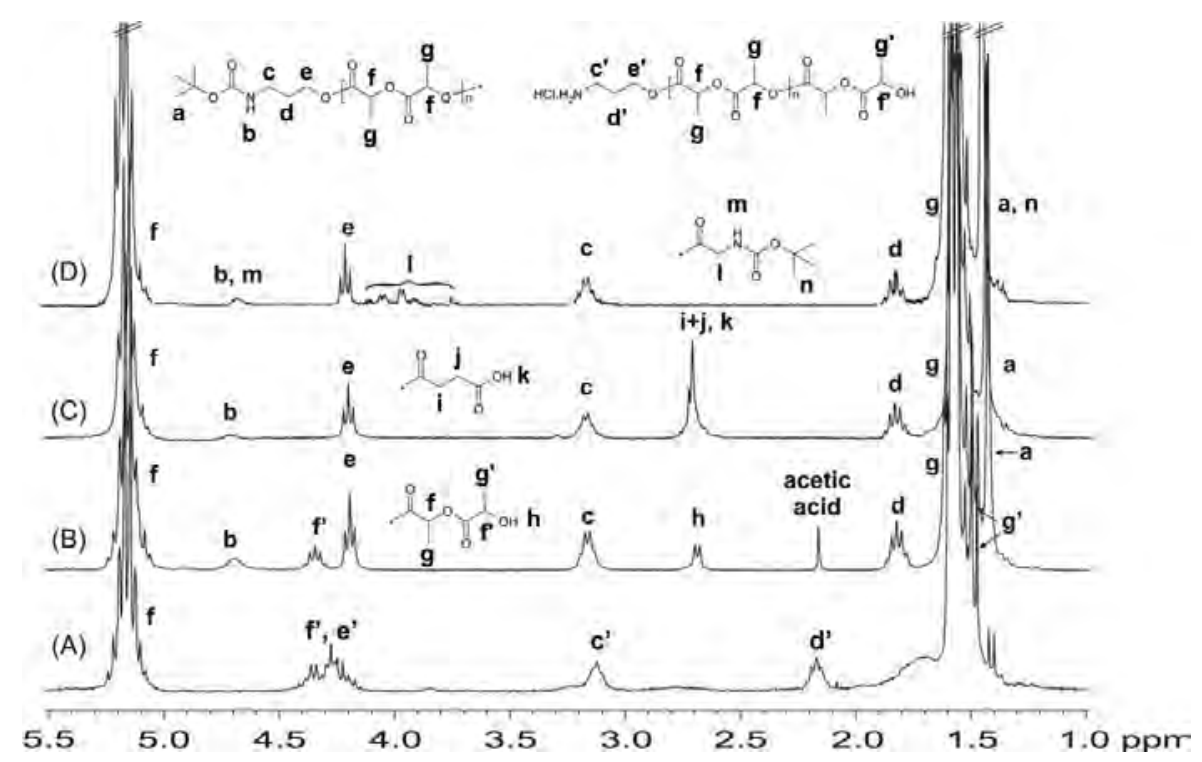

Figure 1. ${ }^{1} \mathrm{H}-\mathrm{NMR}$ spectra of $\mathrm{H}_{2} \mathrm{~N}-\mathrm{PLLA}-\mathrm{OH}(\mathrm{A})$, Boc-NH-PLLA-OH (B), Boc-NHPLLA-COOH (D) and Boc-NH-PLLA-NH-Boc (D). Solvent: $\mathrm{CDCl}_{3}$.

The strongly nucleophilic zinc alkoxides do also allow the introduction of other end groups by reaction with electrophiles or compounds containing an electrophilic site like carbonyls. Two types of reactions were tested to introduce a carboxylic acid end group or an amine end group to the 'living' Boc-NH-PLLA prepolymer. When reacted with succinic anhydride, polymers with a carboxylic acid end group (Scheme 1, 2: middle) were obtained. When the zinc alkoxydes were added to a DCC activated $N$-(tertbutoxycarbonyl)glycine ester (Scheme 1, 2: lower), an $N$-(tert-butoxycarbonyl)amine end group was introduced. The absence of the characteristic methyne proton signal, next to a hydroxyl end group, as present in the ${ }^{1} \mathrm{H}-\mathrm{NMR}$ spectra of hydroxyl terminated-PLAs (f' in Figure 1 or c' in Figure 2) showed that the reaction of the 'living' chain ends, to give either the $\mathrm{CO}\left(\mathrm{CH}_{2}\right)_{2} \mathrm{COOH}$ or $\mathrm{COCH}_{2}-\mathrm{NH}-\mathrm{Boc}$ end groups, was quantitative. These 
results were supported by MALDI-TOF MS data, which revealed that all polymers contained the intended end groups.

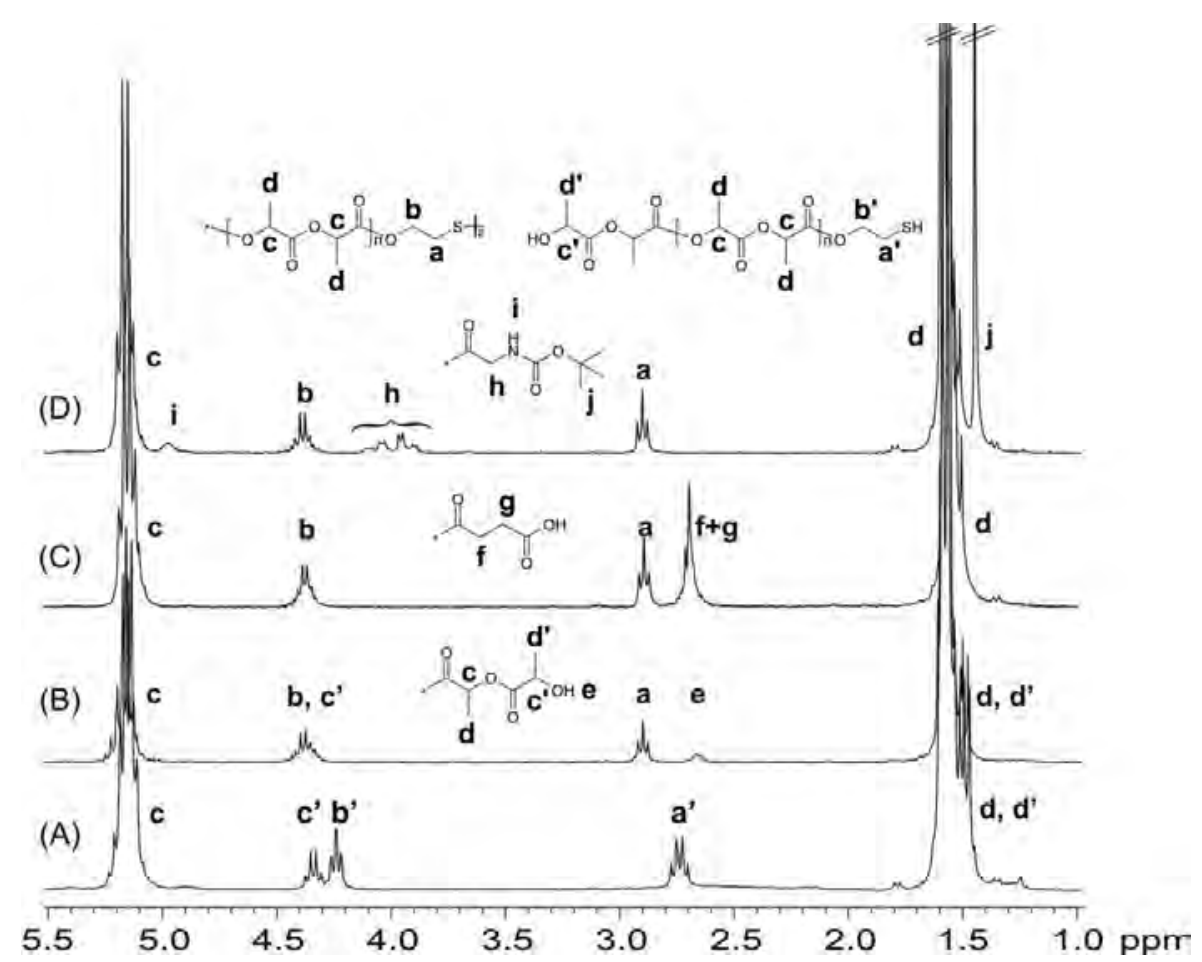

Figure 2. ${ }^{1} \mathrm{H}-\mathrm{NMR}$ spectra of HO-PLLA-SH (A), HO-PLLA-S-S-PLLA-OH (B),

HOOC-PLLA-S-S-PLLA-COOH (C) and Boc-NH-PLLA-S-S-PLLA-NH-Boc (D).

Solvent: $\mathrm{CDCl}_{3}$

In the ${ }^{1} \mathrm{H}-\mathrm{NMR}$ spectra the methylene protons of the initiating moiety $\mathrm{O}-\mathrm{CH}_{2}-\mathrm{CH}_{2}-\mathrm{S}$ at 2.90 and 4.35 ppm are clearly present. Upon reduction of the disulfide bridge by reagents like dithiothreitol, tributyl phosphine and tri(carboxyethyl) phosphine, the $\mathrm{CH}_{2}$-S protons shifted to $2.75 \mathrm{ppm}$, whereas the multiplet at $4.35 \mathrm{ppm}$ (overlapping signals) gives a separated quartet at $4.35 \mathrm{ppm}\left(\mathrm{CH}\left(\mathrm{CH}_{3}\right)-\mathrm{OH}\right)$ and a triplet at $4.25 \mathrm{ppm}\left(\mathrm{HO}-\mathrm{CH}_{2}-\mathrm{CH}_{2}-\mathrm{S}\right)$. The reduction was confirmed by MALDI-TOF MS (data not shown).

\section{Polymer Molecular Weights}


The low molecular weight (MW 500-1000) heterotelechelic PLAs prepared were intended for conjugation to natural polymers (see Chapter 8). Preliminary experiments gave low yields of the synthesized low molecular weight materials. This prompted us to pay special attention to the isolation and purification procedures. Prior to termination with glacial acetic acid or end group conversion with either succinic anhydride or $\mathrm{N}$-(tertbutoxycarbonyl)glycine, a small aliquot of the crude polymerization mixture was analyzed with ${ }^{1} \mathrm{H}-\mathrm{NMR}$. The number of dilactyl units per PLA block was calculated from the integral ratio of the methyl protons $(\delta=1.55)$ and the $t$-butyl protons $(\delta=1.40)$ or the $\mathrm{CH}_{2}-\mathrm{S}$ protons $(\delta=2.90)$. It was found that all DP values were in good agreement with the theoretical values. Isolation of moderate to high molecular weight PLAs is generally performed by precipitation of the polymers in cold diethyl ether. It was found, that for the PLAs prepared with DP values of $\sim 7$, precipitation in diethyl ether leads to fractionation and significant yield loss up to $50 \%$ (Table 1 ).

Table 1. Degrees of polymerization and weight ratio of Boc-NH-PLLA-OH fractions dissolving and precipitating in various non-solvents

\begin{tabular}{|c|c|c|c|c|c|}
\hline \multirow{3}{*}{ Non-solvent } & \multirow{3}{*}{ Weight ratio $^{\mathrm{a}}$} & \multicolumn{4}{|c|}{$\mathrm{DP}^{\mathrm{b}, \mathrm{c}}$} \\
\hline & & \multicolumn{2}{|c|}{ in non-solvent } & \multicolumn{2}{|c|}{ in precipitate } \\
\hline & & ${ }^{1} \mathrm{H}-\mathrm{NMR}$ & MALDI & ${ }^{1} \mathrm{H}-\mathrm{NMR}$ & MALDI \\
\hline Water & 0.00 & -- & -- & 7.7 & 7.6 \\
\hline Pentane & 0.02 & $2-3$ & -- & 8.1 & 8.0 \\
\hline Hexane & 0.13 & $2-3$ & -- & 8.1 & 7.9 \\
\hline Diisopropyl ether & 0.40 & 3.8 & 4.1 & 9.7 & 9.5 \\
\hline Methanol & 1.08 & 4.4 & 3.6 & 11.7 & 11.2 \\
\hline Diethyl ether & 0.92 & 5.7 & 4.6 & 13.2 & 12.1 \\
\hline
\end{tabular}


Analysis of the diethyl ether phase showed that oligomers with a DP $\approx 2-6$ did not precipitate. To avoid this fractionation the polymers preferably were precipitated in water or pentane. However, the removal of dicyclohexyl urea in the preparation of Boc-NHPLLA-NH-Boc (Scheme 1) required the use of methanol as a non-solvent. Consequently, the DP value of the material was much higher due to fractionation (Table 2, entry 3 ). The isolation of Boc-NH-PLLA-S-S-PLLA-NH-Boc (Table 2, entry 6) gave fewer problems due to its higher molecular weight.

The ring-opening polymerization of lactide monomers afforded polymers with a $\mathrm{MW}_{\text {polymer }}=\mathrm{MW}_{\text {initiator }}+n \times \mathrm{MW}_{\text {lactide }}$ and the difference between peaks in the MALDITOF MS spectrum were expected at $\mathrm{m} / \mathrm{z}=144$. However, the spectra of the polymers initiated with 3-(tert-butoxycarbonylamino)-1-propanol (Table 2, entries 1-3) contained peaks that corresponded to molecular masses of polymers containing an odd number of lactic acid repeating units (marked with * in Figure 3).

Table 2. Degrees of polymerization (DP) and number-average molecular weights $\left(M_{n}\right)$ of poly(lactic acid)s synthesized.

\begin{tabular}{|c|c|c|c|c|c|c|}
\hline \multirow[t]{2}{*}{ Entry } & \multirow[t]{2}{*}{ Initiator } & \multirow[t]{2}{*}{ End group } & \multicolumn{2}{|c|}{$\mathrm{DP}^{\mathrm{a}}(\mathrm{n})$} & \multicolumn{2}{|c|}{$\mathrm{M}_{\mathrm{n}}\left(\times 10^{-3}\right)$} \\
\hline & & & ${ }^{1} \mathrm{H}-\mathrm{NMR}$ & MALDI & ${ }^{1} \mathrm{H}-\mathrm{NMR}$ & MALDI \\
\hline 1 & \multirow[t]{3}{*}{ Boc-NH-propanol ${ }^{b, c}$} & $\overline{\mathrm{OH}}$ & 7.5 & 7.5 & 1.3 & 1.3 \\
\hline 2 & & $\mathrm{COOH}$ & 7.0 & 6.7 & 1.3 & 1.2 \\
\hline 3 & & NH-Boc & 16.9 & 15.1 & 2.8 & 2.5 \\
\hline 4 & \multirow[t]{3}{*}{ 2,2'-dithiodiethanol ${ }^{\mathrm{d}}$} & $\mathrm{OH}$ & $7.3^{\mathrm{e}}$ & $7.6^{\mathrm{e}}$ & 2.3 & 2.3 \\
\hline 5 & & $\mathrm{COOH}$ & $7.4^{\mathrm{e}}$ & $8.3^{\mathrm{e}}$ & 2.5 & 2.7 \\
\hline 6 & & NH-Boc & $8.9^{\mathrm{e}}$ & $8.1^{\mathrm{e}}$ & 3.0 & 2.8 \\
\hline \multicolumn{7}{|c|}{ a calculated from ${ }^{1} \mathrm{H}-\mathrm{NMR}$ data, ${ }^{\mathrm{b}}$ 3-(tert-butoxycarbonylamino)-1-propanol, } \\
\hline \multicolumn{7}{|c|}{${ }^{\mathrm{c}}$ catalyst; $\mathrm{Zn}\left[\mathrm{N}\left(\mathrm{SiMe}_{3}\right)_{2}\right]_{2},{ }^{\mathrm{d}}$ catalyst; $\left[\mathrm{Zn}(\mathrm{Et}) \mathrm{OC}_{4} \mathrm{H}_{6} \mathrm{NMe}_{2}-2-\mathrm{Me}-4\right],{ }^{\mathrm{e}} \mathrm{DP}$ value of a } \\
\hline
\end{tabular}



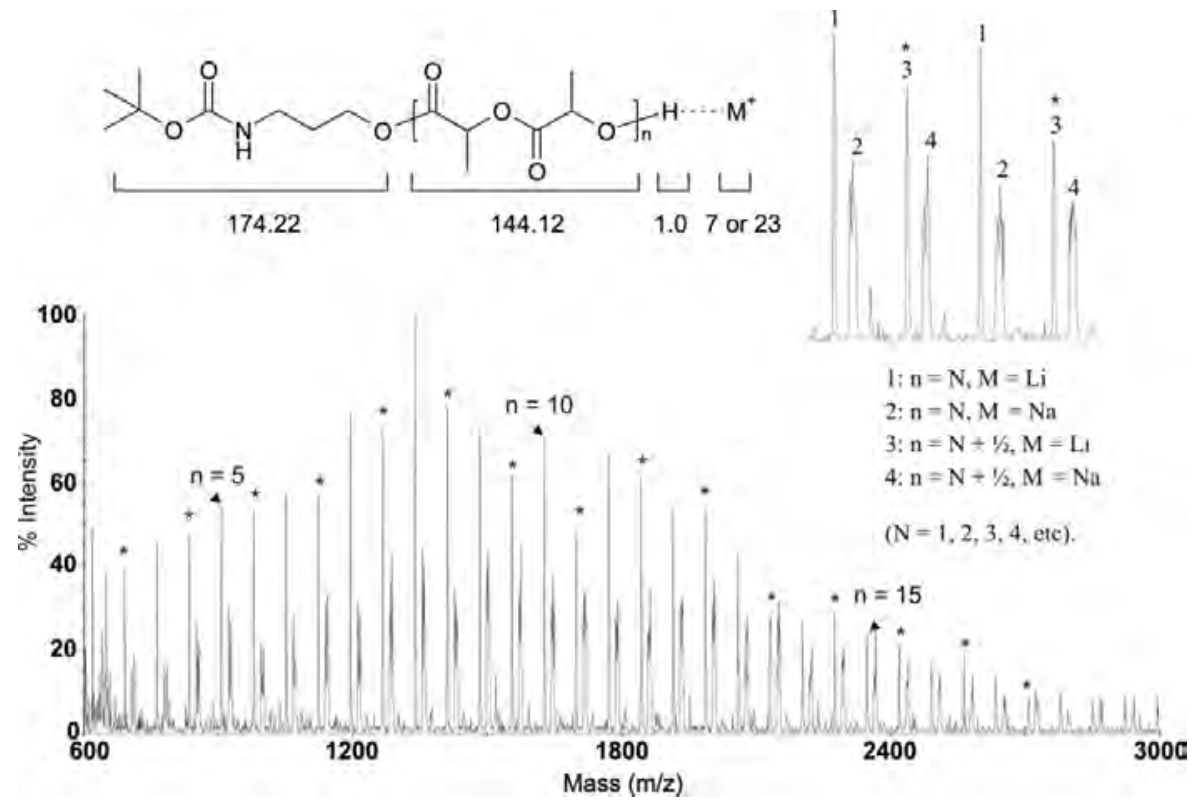

Figure 3. Mass spectrum of Boc-NH-PLLA-OH (Table 2, entry 1) as determined with MALDI-TOF MS; matrix HABA; solvent THF.

These peaks result from inter-molecular ester-exchange reactions, ${ }^{44}$ which apparently play a significant role when using $\mathrm{Zn}\left[\mathrm{N}\left(\mathrm{SiMe}_{3}\right)_{2}\right]_{2}$ as a catalyst under the given conditions. The MALDI-TOF MS spectra of the polymers initiated with 2,2'dithiodiethanol, using $\left[\mathrm{Zn}(\mathrm{Et}) \mathrm{OC}_{4} \mathrm{H}_{6} \mathrm{NMe}_{2}-2-\mathrm{Me}-4\right]$ as a catalyst, also showed these $(n+$ $1 / 2$ ) peaks (marked with * in Figure 4A), but their intensity was much lower. 


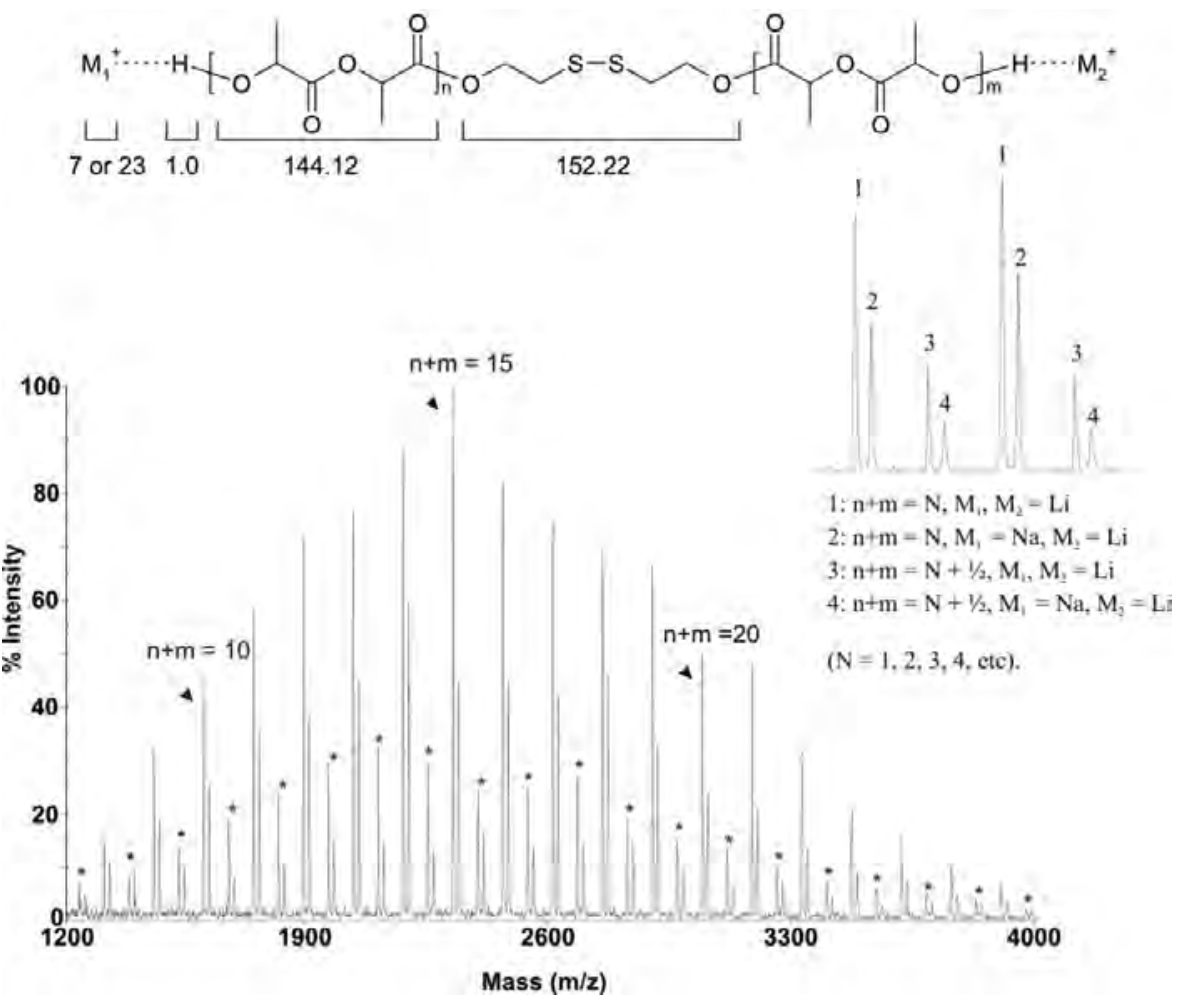

Figure 4A. Mass spectrum of HO-PLLA-S-S-PLLA-OH (Table 2, entry 4) as determined with MALDI-TOF MS; matrix HABA; solvent THF.

These results show that transesterification reactions are taken place during the polymerization in the presence of the zinc catalysts. The polymer prepared using 3-(tertbutoxycarbonylamino)-1-propanol and $\left[\mathrm{Zn}(\mathrm{Et}) \mathrm{OC}_{4} \mathrm{H}_{6} \mathrm{NMe}_{2}-2-\mathrm{Me}-4\right]$ as the initiator and catalyst, respectively, showed an even lower degree of transesterification, possibly due to the much more sterically hindered metal ion. 


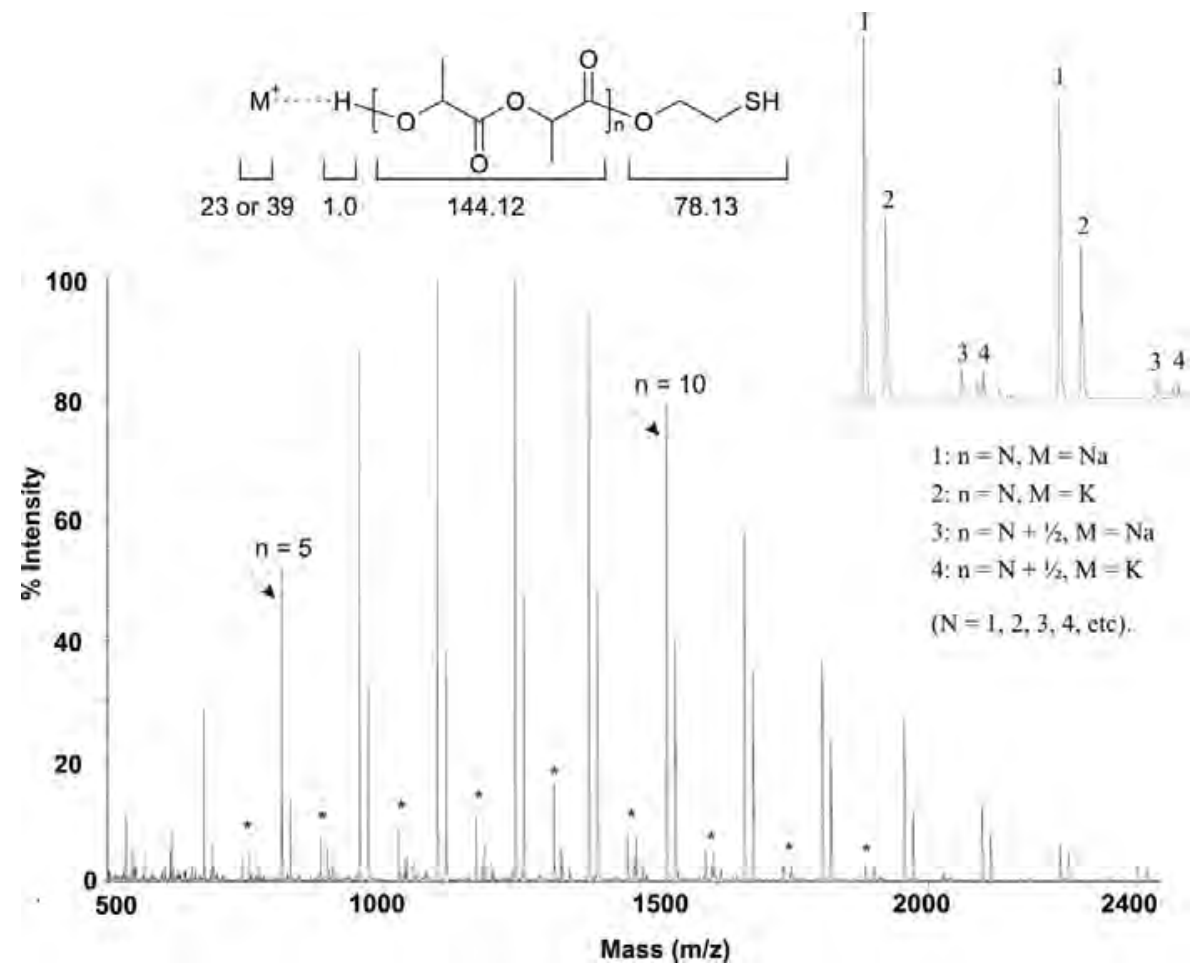

Figure 4B. Mass spectrum of HO-PLLA-SH as determined with MALDI-TOF MS; matrix HABA; solvent THF.

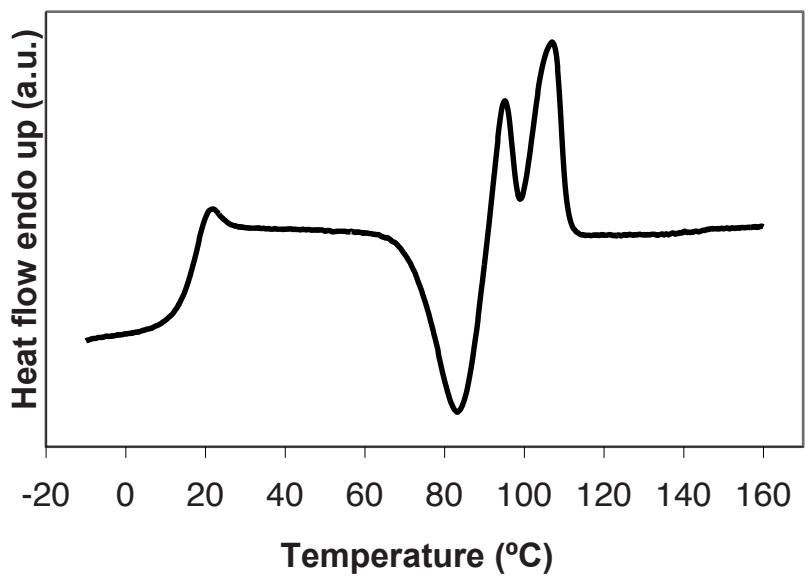

Figure 5. Second heating scan of Boc-NH-PLLA-OH, MW 1250. 


\section{Thermal Properties and Sterecomplex Formation}

The thermal properties of the heterotelechelic PLAs were determined by DSC analysis. As expected, $\mathrm{T}_{\mathrm{m}}$ values linearly increase with increasing DP values (Table 3). ${ }^{45}$ The corresponding $\Delta \mathrm{H}$ values (Table 3 ) also increase, indicating better crystallization at higher DP values. Polymers isolated by precipitation in water (Table 3, entries 1 and 5) and pentane (entries 2 and 6), still contain a relatively large amount of non-crystallizing, low MW oligomers, explaining the rather low $\Delta \mathrm{H}_{\mathrm{m}}$ values. All polymers generally displayed a double melting peak and a cold crystallization peak (Figure 5).

Table 3. Melting temperatures and enthalpies of low molecular weight PLA's, endcapped with hydroxyl groups.

\begin{tabular}{ccrrr} 
Entry & Polymer & $\mathbf{D P}^{\mathbf{a}}$ & $\mathbf{T}_{\mathbf{m}}\left({ }^{\circ} \mathbf{C}\right)$ & $\Delta \mathbf{H}(\mathbf{J} / \mathbf{g})$ \\
\hline 1 & Boc-NH-PLLA-OH & 7.5 & 107 & 9.5 \\
2 & & 8.3 & 109 & 9.9 \\
3 & 11.4 & 114 & 15.1 \\
4 & 12.3 & 116 & 41.9 \\
5 & Boc-NH-PDLA-OH & 7.7 & 108 & 6.5 \\
7 & 8.1 & 109 & 11.8 \\
8 & & 9.8 & 113 & 32.9 \\
9 & HCl-H 2 N-PLLA-OH & 13.2 & 117 & 44.8 \\
10 & Boc-NH-PLLA-COOH & 7.2 & 117 & 4.8 \\
11 & HCl-H ${ }_{2}$ N-PLLA-COOH & 7.7 & 58 & 1.1 \\
12 & HO-PLLA-S-S-PLLA-OH & 7.3 & 121 & 8.6 \\
13 & HO-PDLA-S-S-PDLA-OH & 6.6 & 109 & 16.4 \\
14 & HO-PLLA-SH & 7.3 & 103 & 18.6 \\
15 & HOOC-PLLA-S-S-PLLA-COOH & 7.4 & 45 & 1.6 \\
16 & HOOC-PLLA-SH & 6.5 & 107 & 16.4 \\
${ }^{2}$ calculated from ${ }^{1}$ H-NMR data & & & \\
\hline & & & &
\end{tabular}


This cold crystallization has been observed for PLAs in many cases and was attributed to the low perfection of crystallization upon relative fast cooling in a small cavity (such as a DSC cup) as well as rearrangements in the amorphous state. ${ }^{46}$ The two melting peaks are most likely due to melting, recrystallization and crystal perfection processes. ${ }^{47}$ In the DSC spectra, a $\mathrm{T}_{\mathrm{g}}$ is observed around $\sim 20^{\circ} \mathrm{C}$. These low values result from the large contribution of end groups in low molecular weight PLA's, and have been reported before. $^{45,48}$

Using 2.2\%-dithioldiethanol as an initiator, the $\mathrm{T}_{\mathrm{m}}$ and $\Delta \mathrm{H}_{\mathrm{m}}$ values of the resulting PLA polymers are similar to the Boc-NH-PLA-OH analogues with comparable DP. This indicates that the initiating moiety cannot participate in the crystallization and thus the PLA segments behave as separate blocks. The actual $T_{m}$ and $\Delta H_{m}$ values (Table 3, entries 12 and 13) were slightly higher than those of the corresponding PLA polymers, initiated with 3-(tert-butoxycarbonylamino)-1-propanol (Table 3, entries 1 and 5). The bulky Bocgroup in the latter may have a larger suppressing effect on the crystallization process than the disulfide moiety. Indeed, the polymer obtained upon removing the Boc-group by $\mathrm{HCl}$ treatment to give a 3-aminopropyl ester end group showed an increase of $\sim 10^{\circ} \mathrm{C}$ of the $\mathrm{T}_{\mathrm{m}}$ value (Table 3, entry 9) whereas reducing the disulfide resulted in melting point reduction rather than an increase (Table 3 , entry 14).

The crystals of enantiomerically pure PLA pack in a $10_{3}$ helix and a lower crystallization limit of -11 repeating lactyl units (i.e. DP $=5.5$ ) has been reported for monodisperse PLA oligomers ${ }^{45}$ This effect on the crystallization may be more pronounced when using polydisperse samples and/or bulkier initiators, and the limit might be increased. Crystallization of Boc-NH-PL $\Lambda$-OH with a DP $\approx 7$ resulted in $\mathrm{T}_{\mathrm{m}}$ values that were in good accordance with the reported values for monodisperse PLA blocks in literature, ${ }^{45}$ indicating that the actual limit for crystallization is not highly dependent on modification of PLLAs at the carboxyl terminus.

Interestingly, whereas melting transitions above $100{ }^{\circ} \mathrm{C}$ were observed for the hydroxylterminated PLA's (DP $\geq 7$ ), these transitions were hardly visible and appeared at lower temperatures when the $\mathrm{OH}$ terminus was converted with succinic anhydride in a carboxyl end group (Table 3, entry 10). Modification of the hydroxyl chain end (as in Boc-NHPLA-COOH) will most likely prohibit one or more lactic acid units at this end of the 
Synthesis and Thermal Properties of PLA Oligomers and their Stereocomplexes

chain to participate in crystallization, therewith increasing the minimum number of repeating units at which crystallization can take place. These findings were supported by the poor crystallization of the HOOC-PL $\Lambda$-S-S-PLA-COOH polymers $(\mathrm{DP} \approx 7$ ) (Table 3. entry 15). It appeared that removing the Boc-group of Boc-NH-PLA-COOH to give $\mathrm{HCl} . \mathrm{NH}_{2}-\mathrm{PL} \wedge-\mathrm{COOH}$ led to a significant increase in melting transitions and crystallization enthalpy, likely explained by the fact that more lactic acid units could participate in crystal formation (Table 3, entry 11). This effect is even more prominent upon the reduction of the disulfide bond in HOOC-PL $\Lambda$-S-S-PL $\Lambda$-COOH (Table 3, entry 16) and supports the idea that hampering of the crystallization occurs at both ends of a modified PLA chain.

As the DP values of the Boc-NH-PLA-NH-Boc polymers were significantly higher (DP $\approx$ 17), the 'crystallization limit effect" was not encountered for these materials, and a clear melting transition was observed in the DSC thermogram. Still, the suppressive effect of end group modification on the thermal properties could be observed. As an example, Boc-NH-PLLA-NH-Boc with DP $=16.9$ gave a $\mathrm{T}_{\mathrm{m}}$ of only $106{ }^{\circ} \mathrm{C}$, whereas higher $\mathrm{T}_{\mathrm{m}}$ yalues $\left(107-116^{\circ} \mathrm{C}\right)$ were found for Boc-NH-PLA-OH polymers with lower DP values of 7-12 (Table 3).

It is well known that mixtures of enantiomeric PLAs give stereocomplexes, ${ }^{49}$ with melting points considerably exceeding those of the single enantiomers of comparable block length. Thermal analysis of 1:1 w/w mixtures of the PLLA and PDLA polymers were performed to determine the influence of end group modification on stereocomplexation. As expected, the melting temperatures significantly increased, pointing out the formation of stereocomplexes (Table 4). The double melting transition and cold crystallization, as described for the single enantiomers, were also observed for the stereocomplexes. Due to a significant difference in conformational packing of the chains in the PLA 'single enantiomer crystals' ( $\alpha$-type $10_{3}$-helical structures) and the 'stereoblock crystals' ( $\beta$-type $3{ }_{1}$-helical structures $)^{50}$, the lower limit of the DP for crystallization of PLA stereocomplexes is lower than for the single enantiomers, and has been reported to be 3.5. ${ }^{45}$ This effect was also observed for the Boc-NH-PLA-OH polymers. The lower limit for crystallization of a stereocomplexed Boc-NH-PLA-OH 
was at a $\mathrm{DP} \sim 5.5\left(\mathrm{~T}_{\mathrm{m}} 135^{\circ} \mathrm{C}\right)$, compared to a $\mathrm{DP}$ of 7 for the single enantiomer (vide infra).

Table 4. Melting temperatures and melting enthalpies of mixtures of (heterotelechelic) PLLAs and PDLAs in 1:1 weight ratios.

\begin{tabular}{|c|c|c|c|c|c|}
\hline \multirow[t]{2}{*}{ Entry } & \multirow[t]{2}{*}{ Polymer } & \multicolumn{2}{|c|}{$\mathbf{D P}^{\mathbf{a}}$} & \multirow{2}{*}{$\begin{array}{c}\mathbf{T}_{\mathbf{m}} \\
\left({ }^{\circ} \mathbf{C}\right)\end{array}$} & \multirow{2}{*}{$\begin{array}{l}\Delta \mathbf{H}_{\mathrm{m}} \\
(\mathrm{J} / \mathrm{g})\end{array}$} \\
\hline & & $L$ & $D$ & & \\
\hline 1 & Boc-NH-PLA-OH & 7.5 & 7.7 & 168 & 10.7 \\
\hline 2 & & 8.0 & 8.1 & 157 & 26.0 \\
\hline 3 & & 7.9 & 8.1 & 167 & 30.3 \\
\hline 4 & & 10.8 & 9.7 & 172 & 37.8 \\
\hline 5 & & 12.0 & 11.7 & 179 & 21.4 \\
\hline 6 & & 12.3 & 13.2 & 175 & 37.5 \\
\hline 7 & Boc-NH-PLA-COOH & 7.7 & 7.2 & 142 & 20.7 \\
\hline 8 & Boc-NH-PLA-NHBoc & 16.9 & 17.4 & 154 & 37.1 \\
\hline 9 & HO-PLA-S-S-PLA-OH & 7.3 & 6.7 & 156 & 10.3 \\
\hline 10 & HOOC-PLA-S-S-PLA-COOH & 7.5 & 9.0 & 159 & 29.5 \\
\hline 11 & Boc-NH-PLA-S-S-PLA-NH-Boc & 8.9 & 9.9 & 171 & 29.7 \\
\hline
\end{tabular}

Whereas only minor crystallization was observed for the single enantiomers of the polymers Boc-NH-PLA-COOH and HOOC-PLA-S-S-PLA-COOH, enantiomeric mixtures of these polymers showed clear melting transitions at significantly higher temperatures (Table 4, entries 7 and 11). Apparently, also in these cases the limit for crystallization is lower in stereocomplexes. However, the suggested hampering of crystallization, caused by modification of both PLA chain ends was also observed in their stereocomplexes (Table 4, entries 7-10). $\mathrm{T}_{\mathrm{m}}$ values of the stereocomplexes were always significantly lower than those of Boc-NH-PLA-OH stereocomplexes containing polymers of comparable or even lower average chain lengths. 


\section{Synthesis and Thermal Properties of PLA Oligomers and their Stereocomplexes}

\section{Conclusion}

Various end group modified, low-molecular weight PLAs were prepared in a 'one-pot' synthesis using functional initiators and terminating reagents. Purification of polymers with low DPs can lead to significant fractionation and this could only be avoided by using highly polar or non-polar non-solvents during purification. Thermal analysis showed that modification of the PLA chains on both ends lowers the effective number of lactic acid units that can participate in crystallization, both for single enantiomers as for stereocomplexes of PLLAs and PDLAs.

\section{References}

1. K. S. Anseth, A. T. Metters, S. J. Bryant, P. J. Martens, J. H. Elisseeff and C. N. Bowman, In situ forming degradable networks and their application in tissue engineering and drug delivery. J. Control. Release, 2002, 78(1-3), 199-209.

2. S. J. Bryant and K. S. Anseth, Hydrogel properties influence ECM production by chondrocytes photoencapsulated in poly(ethylene glycol) hydrogels. J. Biomed. Mater. Res., 2002, 59(1), 63-72.

3. S. J. Bryant and K. S. Anseth, Controlling the spatial distribution of ECM components in degradable PEG hydrogels for tissue engineering cartilage. $J$. Biomed. Mater. Res. Part A, 2003, 64A(1), 70-79.

4. K. A. Davis, J. A. Burdick and K. S. Anseth, Photoinitiated crosslinked degradable copolymer networks for tissue engineering applications. Biomaterials, 2003, 24(14), 2485-2495.

5. Y. M. Ju, K. D. Ahn, J. M. Kim, J. A. Hubbell and D. K. Han, Physical properties and biodegradation of lactide-based poly(ethylene glycol) polymer networks for tissue engineering. Polym. Bull., 2003, 50(1-2), 107-114.

6. D. K. Han and J. A. Hubbell, Synthesis of polymer network scaffolds from Llactide and poly(ethylene glycol) and their interaction with cells. Macromolecules, 1997, 30(20), 6077-6083.

7. B. Jeong, Y. K. Choi, Y. H. Bae, G. Zentner and S. W. Kim, New biodegradable polymers for injectable drug delivery systems. J. Control. Release, 1999, 62(1-2), 109-114.

8. B. Jeong, S. W. Kim and Y. H. Bae, Thermosensitive sol-gel reversible hydrogels. Adv. Drug Deliv. Rev., 2002, 54(1), 37-51.

9. T. Kissel, Y. X. Li and F. Unger, ABA-triblock copolymers from biodegradable polyester A-blocks and hydrophilic poly(ethylene oxide) B-blocks as a candidate for in situ forming hydrogel delivery systems for proteins. Adv. Drug Deliv. Rev., 2002, 54(1), 99-134.

10. T. Mukose, T. Fujiwara, J. Nakano, I. Taniguchi, M. Miyamoto, Y. Kimura, I. Teraoka and C. W. Lee, Hydrogel formation between enantiomeric B-A-B-type block copolymers of polylactides (PLLA or PDLA: A) and polyoxyethylene 
(PEG: B); PEG-PLLA-PEG and PEG-PDLA-PEG. Macromol. Biosci., 2004, 4(3), 361-367.

11. S. J. Jong, de, S. C. De Smedt, J. Demeester, C. F. van Nostrum, J. J. Kettenesvan den Bosch and W. E. Hennink, Biodegradable hydrogels based on stereocomplex formation between lactic acid oligomers grafted to dextran. $J$. Control. Release, 2001, 72(1-3), 47-56.

12. T. Fujiwara, T. Mukose, T. Yamaoka, H. Yamane, S. Sakurai and Y. Kimura, Novel thermo-responsive formation of a hydrogel by stereo- complexation between PLLA-PEG-PLLA and PDLA-PEG-PDLA block copolymers. Macromol. Biosci., 2001, 1(5), 204-208.

13. D. W. Grijpma and J. Feijen, Hydrogels by stereo-complexation of water-soluble PLLA-PEO-PLLA and PDLA-PEO-PDLA triblock-copolymers. J. Control. Release, 2001, 72(1-3), 247-249.

14. S. M. Li and M.Vert, Synthesis, Characterization, and Stereocomplex-Induced Gelation of Block Copolymers Prepared by Ring-Opening Polymerization of L(D)-Lactide in the Presence of Poly(ethylene glycol). Macromolecules, 2003, 36(21), 8008-8014.

15. D. W. Lim, S. H. Choi and T. G. Park, A new class of biodegradable hydrogels stereocomplexed by enantiomeric oligo(lactide) side chains of poly(HEMA-gOLA)s. Macromol. Rapid Commun., 2000, 21(8), 464-471.

16. D. W. Lim and T. G. Park, Stereocomplex formation between enantiomeric PLAPEG-PLA triblock copolymers: Characterization and use as protein- delivery microparticulate carriers. J. Appl. Polym. Sci., 2000, 75(13), 1615-1623.

17. D. Garlotta, A literature review of poly(lactic acid). J. Polym. Environ., 2001, 9(2), 63-84.

18. K. M. Stridsberg, M. Ryner and A. C. Albertsson, Controlled ring-opening polymerization: Polymers with designed macromolecular architecture. $A d v$. Polym. Sci., 2002, 157(-), 41-65.

19. A. C. Albertsson and I. K. Varma, Recent developments in ring opening polymerization of lactones for biomedical applications. Biomacromolecules, 2003, 4(6), 1466-1486.

20. A. C. Albertsson and I. K. Varma, Aliphatic polyesters: Synthesis, properties and applications. Adv. Polym. Sci., 2002, 157(-), 1-40.

21. H. R. Kricheldorf, H. Hachmann-Thiessen and G. Schwarz, Telechelic and starshaped poly(L-lactide)s by means of bismuth(III) acetate as initiator. Biomacromolecules, 2004, 5(2), 492-496.

22. C. K. Williams, Synthesis of functionalized biodegradable polyesters. Chem. Soc. Rev., 2007, 36(10), 1573-1580.

23. T. Ouchi, T. Uchida, H. Arimura and Y. Ohya, Synthesis of poly(L-lactide) endcapped with lactose residue. Biomacromolecules, 2003, 4(3), 477-480.

24. M. Gotsche, H. Keul and H. Hocker, Amino-Termined Poly(L-Lactide)s As Initiators For the Polymerization of N-Carboxyanhydrides - Synthesis of Poly(LLactide)-Block-Poly(Alpha-Amino Acid)s. Macromol. Chem. Phys., 1995, 196(12), 3891-3903. 
25. S. Caillol, S. Lecommandoux, A. F. Mingotaud, M. Schappacher, A. Soum, N. Bryson and R. Meyrueix, Synthesis and self-assembly properties of peptide Polylactide block copolymers. Macromolecules, 2003, 36(4), 1118-1124.

26. M. Sobczak, E. Oledzka and W. L. Kolodziejski, NOTE: Polymerization of cyclic esters using aminoacid initiators. J. Macromol. Sci. Pure Appl. Chem., 2008, 45(10), 872-877.

27. O. Jeon, S. H. Lee, S. H. Kim, Y. M. Lee and Y. H. Kim, Synthesis and characterization of poly(L-lactide)-poly(epsilon-caprolactone) multiblock copolymers. Macromolecules, 2003, 36(15), 5585-5592.

28. H. Korhonen, A. O. Helminen and J. V. Seppala, Synthesis of poly (esteranhydrides) based on different polyester precursors. Macromol. Chem. Phys., 2004, 205(7), 937-945.

29. X. Y. Qiu, L. Chen, J. L. Hu, J. R. Sun, Z. K. Hong, A. X. Liu, X. S. Chen and X. B. Jing, Surface-modified hydroxyapatite linked by L-lactic acid oligomer in the absence of catalyst. J. Polym. Sci., Part A: Polym. Chem., 2005, 43(21), $5177-$ 5185 .

30. E. Vidovic, D. Klee and H. Hocker, Synthesis and characterization of poly(vinyl alcohol)-graft-[poly(D,L-lactide)/poly(D,L-lactide-co-glycolide)] hydrogels. $J$. Polym. Sci., Part A: Polym. Chem., 2007, 45(19), 4536-4544.

31. T. Ouchi, T. Minari and Y. Ohya, Synthesis of poly (L-lactide)-grafted pullulan through coupling reaction between amino end-capped poly(L-lactide) and carboxymethyl pullulan and its aggregation behavior in water. J. Polym. Sci., Part A: Polym. Chem., 2004, 42(21), 5482-5487.

32. J. Sun, X. S. Chen, T. C. Lu, S. Liu, H. Y. Tian, Z. P. Guo and X. B. Jing, Formation of reversible shell cross-linked micelles from the biodegradable amphiphilic diblock copolymer poly(L-cysteine)-block-poly(L-lactide). Langmuir, 2008, 24(18), 10099-10106.

33. G. Coullerez, C. Lowe, P. Pechy, H. H. Kausch and J. Hilborn, Synthesis of acrylate functional telechelic poly(lactic acid) oligomer by transesterification. $J$. Mater. Sci.-Mater. Med., 2000, 11(8), 505-510.

34. Y. L. Zhang and C. C. Chu, Biodegradable dextran-polylactide hydrogel network and its controlled release of albumin. J. Biomed. Mater. Res., 2001, 54(1), 1-11.

35. J. A. Burdick, L. M. Philpott and K. S. Anseth, Synthesis and Characterization of Tetrafunctional Lactic Acid Oligomers: A Potential In Situ Forming Degradable Orthopaedic Biomaterial. J. Polym. Sci., Part A: Polym. Chem., 2001, 39(5), 683692.

36. J. M. Messman, A. D. Scheuer and R. F. Storey, Synthesis and characterization of A-B-A triblock copolymers derived from chloro-telechelic poly(L-lactide): combining ring-opening polymerization (ROP) and atom transfer radical polymerization (ATRP). Polymer, 2005, 46(11), 3628-3638.

37. Y. L. Zhao, X. T. Shuai, C. F. Chen and F. Xi, Synthesis of star block copolymers from dendrimer initiators by combining ring-opening polymerization and atom transfer radical polymerization. Macromolecules, 2004, 37(24), 8854-8862.

38. H. Van den Berghe, J. Coudane and M. Vert, Isocyanate-terminated lactic acid oligomers as a new means to conjugate functional drugs or polymers with 
bioresorbable hydrophobic segments. J. Bioact. Compat. Polym., 2007, 22(6), 637-650.

39. M. R. Ten Breteler, Z. Y. Zhong, P. J. Dijkstra and J. Feijen, NO-Bidentate and NON-Tridentate Zinc Alkoxides for the Controlled Ring-Opening Polymerization of Lactides. Chapter 3, this thesis, 2010.

40. X. Z. Shu, Y. C. Liu, Y. Luo, M. C. Roberts and G. D. Prestwich, Disulfide crosslinked hyaluronan hydrogels. Biomacromolecules, 2002, 3(6), 1304-1311.

41. N. Kang and J. C. Leroux, Triblock and star-block copolymers of N-(2hydroxypropyl)methacrylamide or N-vinyl-2-pyrrolidone and D,L-lactide: synthesis and self-assembling properties in water. Polymer, 2004, 45(26), 89678980.

42. J. A. Burns, J. C. Butler, J. Moran and G. M. Whitesides, Selective Reduction Of Disulfides By Tris(2-Carboxyethyl)Phosphine. J. Org. Chem., 1991, 56(8), 26482650.

43. N. V. Tsarevsky and K. Matyjaszewski, Combining atom transfer radical polymerization and disulfide/thiol redox chemistry: A route to well-defined (bio)degradable polymeric materials. Macromolecules, 2005, 38(8), 3087-3092.

44. G. Montaudo, M. S. Montaudo, C. Puglisi, F. Samperi, N. Spassky, A. LeBorgne and M. Wisniewski, Evidence for ester-exchange reactions and cyclic oligomer formation in the ring-opening polymerization of lactide with aluminum complex initiators. Macromolecules, 1996, 29(20), 6461-6465.

45. S. J. Jong, de, W. N. E. van Dijk-Wolthuis, J. J. Kettenes-van den Bosch, P. J. W. Schuyl and W. E. Hennink, Monodisperse enantiomeric lactic acid oligomers: Preparation, characterization, and stereocomplex formation. Macromolecules, 1998, 31(19), 6397-6402.

46. X. Hu, H. S. Xu and Z. M. Li, Morphology and properties of poly(L-lactide) (PLLA) filled with hollow glass beads. Macromol. Mater. Eng., 2007, 292(5), 646-654.

47. M. L. Di Lorenzo, Calorimetric analysis of the multiple melting behavior of poly(L-lactic acid). J. Appl. Polym. Sci., 2006, 100(4), 3145-3151.

48. K. Jamshidi, S.-H. Hyon and Y. Ikada, Thermal characterization of polylactides. Polymer, 1988, 29(12), 2229-2234.

49. H. Tsuji, Poly(lactide) stereocomplexes: Formation, structure, properties, degradation, and applications. Macromol. Biosci., 2005, 5(7), 569-597.

50. D. Brizzolara, H. J. Cantow, K. Diederichs, E. Keller and A. J. Domb, Mechanism of the stereocomplex formation between enantiomeric poly(lactide)s. Macromolecules, 1996, 29(1), 191-197. 


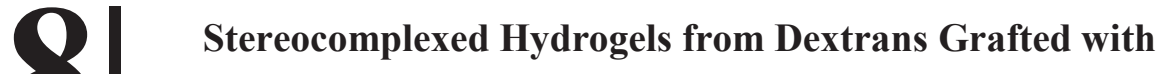

\section{PLA Amines}

\begin{abstract}
Dextran was successfully grafted with short, amine-functionalized polylactide (PLA) segments ( $\mathrm{DP}=4-8)$. Amine end group functionalized PLAs were covalently coupled via carbamate bonds using $p$-nitrophenyl carbonate-activated dextran or secondary amine bonds using oxidized dextran. Whereas the dextran-graft-PLA (Dex-g-PLA) copolymers did not show gelation at different temperatures and concentrations, racemic mixtures of enantiomeric Dex-g-PLAs and ${ }^{o x}$ Dex- $g$-PLAs afforded hydrogels through stereocomplexation. Rheological measurements revealed the gels to have low storage moduli (200-500 Pa). The gelation resulting from physical crosslinking by stereocomplexation was fully reversible by a change in temperature. When placed in PBS buffer ( $\mathrm{pH} 7.4$ ) at $37^{\circ} \mathrm{C}$, the degree of grafting of the copolymers was not changed over a period of fourteen days. Degradation by PLA mass loss was only caused by random scission of ester bonds in the grafts.
\end{abstract}




\section{Introduction}

The presence of stereoregular domains in polymers may significantly affect the mechanical and physical properties ${ }^{1,2}$ of materials. Whereas in polymers atactic domains are amorphous, stereoregular isotactic or syndiotactic domains are able to crystallize, provided that the domains have a sufficient length. A stereocomplex is defined as a stereoselective interaction between complementary stereoregular segments, forming a composite with altered physical properties in comparison to the separate segments. ${ }^{3}$ Stereocomplexation, a term introduced in the $1960 \mathrm{~s}$, is not strictly limited to enantiomeric segments, but has also been reported for combinations of iso- and syndiotactic segments ${ }^{4}$ and combinations of enantiomeric polymers and biomacromolecules such as peptides. ${ }^{3,5-9}$ In most cases however, stereocomplexation refers to the interaction between isotactic segments of opposite chirality, which has been $\operatorname{reported}^{3,5}$ for poly( $\gamma$-benzylglutamate), poly( $\alpha$-methyl- $\alpha$-ethyl- $\beta$-propiolactone), poly(tert-butylethylene oxide), poly(tertbutylethylene sulfide and poly(2,3-dimethyl tartaric acid), and most notably for poly(lactide)s (PLA). In this respect, stereocomplexation implies co-crystallization of PLLA and PDLA segments upon mixing. For monodisperse PLA enantiomers, a minimum segment length of eleven lactic acid units is required for crystallization. Upon mixing enantiomeric PLAs, however, this limit is lowered to seven lactic acid units. ${ }^{10}$ This is explained by a significant difference in the conformational packing of the folding chains in the PLA 'single enantiomer crystals' ( $\alpha$-type $10_{3}$-helical structures) and the more dense 'stereocomplex crystals' ( $\beta$-type 3 -helical structures). ${ }^{11}$ Consequently, stereocomplex melting points considerably exceed those of crystals comprising single enantiomers of comparable segment length, which may be as much as $50{ }^{\circ} \mathrm{C}$ for high MW PLLA/PDLA blends. ${ }^{2,11,12}$

Recently, stereocomplexation between enantiomeric PLA segments was applied as a method to prepare physically crosslinked hydrogels. ${ }^{13-18}$ Hydrogels are polymeric networks, composed of hydrophilic polymer segments and therefore able to absorb and retain large amounts of water. Due to their high water content, hydrogels are attractive for biomedical applications, such as delivery of biologically active compounds ${ }^{19-22}$ and, in particular, tissue engineering. Hydrogels mimic soft tissue in their mechanical properties, generally do not invoke inflammatory responses of surrounding tissue, and are 
compatible with biological entities such as cells and proteins. ${ }^{23-25}$ Over the years, many types of hydrogels have been developed. ${ }^{26}$ Highly interesting are the hydrogels that respond to physical changes (e.g. temperature) ${ }^{27}$ and so-called 'smart gels' containing biological active moieties or in which bioactive molecules such as growth factors or antibodies are incorporated. ${ }^{28}$

In gels based on stereocomplexation between enantiomeric PLA segments, the stereocomplex crystals serve as reversible, physical crosslinks. These types of gels are generally composed of a hydrophilic polymer and relatively short, non-crystallizable PLLA or PDLA oligomers. Stereocomplexation induces gelation upon mixing. Because gelation can not occur in single enantiomer aqueous solutions, components such as cells or proteins can be mixed in one of the two solutions. Provided that gelation times are relatively short, the 'mixing-induced' crystallization enables in situ gelation. A big advantage is that these injectable gels minimize the use of invasive surgery and can fill irregular shaped defects.

Various chemical methods can be used to combine PLA segments and hydrophilic polymers. The hydrophylic polymer may contain hydroxyl groups and thus serve as an initiating moiety in the ROP of lactide. This strategy is frequently applied for PEGs containing hydroxyl end groups, ${ }^{14,}$ 29-31 but has also been reported for partially protected polysaccharides such as amylase, ${ }^{32}$ pullulan, ${ }^{33}$ chitosan $^{34}$ and dextran. ${ }^{35}$ Alternatively, the PLA segments may be synthesized separately, and subsequently coupled to the hydrophilic backbone. ${ }^{36}, 37$ In a third approach, the PLA segments contain a polymerizable end group (e.g. an acrylate group), ${ }^{38}$ and the backbone is formed upon subsequent copolymerization.

De Jong et al. have reported on the formation of dextran hydrogels, based on stereocomplexation of PLLA and PDLA segments, grafted to the hydrophilic dextran backbone. The strength of the network was shown to be related to the PLA segment lengths. The previously mentioned lower crystallization limit of seven lactic acid units ${ }^{10}$ was shown to be raised to approximately eleven units in these graft copolymers. The latter was explained by crystallization limitation, caused by the attachment of the crystallizing segments to a relatively large, non-crystallizing backbone. Increasing the average length of the PLA segments (DP), the number of segments per anhydroglucose 
rings and the solid content of the gels resulted in stronger hydrogels. Degradation times could be varied at $\mathrm{pH} 7$ from 1 day $(70 \%$ water content, DP $=9, \mathrm{DS}=3)$ to 3.5 days ( $70 \%$ water content, $\mathrm{DP}=12, \mathrm{DS}=6)$. At $\mathrm{pH} 4$, the gels remained stable for more than 1 month. ${ }^{39}$

For in vivo tissue engineering applications of hydrogels, a more prolonged stability at $\mathrm{pH}$ $=7.4$ is generally required. The labile ester or carbonate bond at the interface of the hydrophilic dextran and hydrophobic PLA segments is most prone to hydrolysis, and 'degrafting' rather than random PLA scissioning is causing dextran-PLA copolymers to disintegrate in aqueous systems. ${ }^{40}$ It was hypothesized that replacing these hydrolytically unstable linkages by linkages that are less prone to hydrolysis would lead to gels that retain their initial shape and strength for a prolonged period of time. In this work, the synthesis of dextran-PLA copolymers in which the PLA grafts are linked via carbamate or amine bonds and the formation of stereocomplexed hydrogels thereof are described.

\section{Experimental}

\section{Materials}

Dextran $\left(\mathrm{M}_{\mathrm{r}}=15,000-25,000\right)$ (Fluka) was dried by azeotropic destillation from toluene. $L$-lactide and $D$-lactide (Purac) were recrystallized from dry toluene. Lithium chloride (LiCl) (Fluka) was dried at $100{ }^{\circ} \mathrm{C}$ prior to use. Toluene (Biosolve) was dried over sodium wire, followed by distillation. Dimethylformamide (DMF, Biosolve) was dried on molsieves (4 $\AA$ ) and distilled prior to use. $\mathrm{CH}_{2} \mathrm{Cl}_{2}$ (Biosolve) was dried by distillation from calcium hydride $\left(\mathrm{CaH}_{2}\right)$. Dried DMSO (99.7+\%, extra water $<50 \mathrm{ppm}$, Acros), $p$ nitrophenyl chloroformate (Aldrich), pyridine (Aldrich), 3-tert-butyl N-(3hydroxypropyl)carbamate (3-Boc-amino-1-propanol, Aldrich), stannous octoate (Aldrich) and DMAP (Fluka) were used as received. Amino-functionalized poly(lactic acid)s (PLA-NH ${ }_{2}$ ) were prepared according a procedure described in Chapter 7. 


\section{Stereocomplexed Hydrogels from Dextran Grafted with PLA Amines}

\section{Synthesis}

p-Nitrophenyl carbonate-activated dextran: All reactions were performed under a $\mathrm{N}_{2}$ atmosphere. Dextran activation with $p$-nitrophenyl chloroformate was performed according to the procedure as described by Ramirez et al. ${ }^{41}$ Typically, dextran $(25.2 \mathrm{~g}$, $154 \mathrm{mmol}$ anhydroglucosidic rings, AHG) was dried by azeotropic distillation from toluene and subsequently dried in vacuo. The dried dextran was dissolved in dry DMF (900 ml) containing $2 \mathrm{w} / \mathrm{v} \%$ of $\mathrm{LiCl}$ at $90{ }^{\circ} \mathrm{C}$. The reaction mixture was cooled to $0{ }^{\circ} \mathrm{C}$ using an ice bath. Pyridine $(6.6 \mathrm{ml}, 82 \mathrm{mmol}$, molar ratio pyridine: $\mathrm{AHG}=0.56)$ was added to the dextran solution, followed by $p$-nitrophenyl chloroformate (36.5 g, 182 mmol, molar ratio $p$-nitrophenyl chloroformate: $\mathrm{AHG}=1.2)$. The reaction mixture was stirred for $2 \mathrm{~h}$ at $0{ }^{\circ} \mathrm{C}$, after which the major part of the DMF was removed by vacuum distillation. The activated dextran was isolated by precipitation in cold ethanol (twice), washed with diethyl ether and dried in vacuo over $\mathrm{P}_{2} \mathrm{O}_{5}$. Degree of activation (DA) $\left({ }^{1} \mathrm{H}-\right.$ NMR): 11. Yield: 26.0 g, 93 \%. ${ }^{1} \mathrm{H}-\mathrm{NMR}\left(\mathrm{DMSO}_{\mathrm{d}}\right.$ ): $\delta=8.30$ (d, 2H, ArH), 7.50 (d, 2H, $\operatorname{ArH}), 5.25-5.80$ (b, 1H, CH-O-C(O)-O-Ar), 5.00-5.25 (b, 1H, OH), 4.75-4.95 (b, 1H, $\mathrm{OH}), 4.50-4.75$ (s, 1H, O-CH-O), 4.20-4.50 (b, 1H, OH), 3.65-4.00 (s, 1H, O-CH-CH 2 ), 3.55-3.65 (s, $\left.1 \mathrm{H}, \mathrm{CH}_{2}\right), 3.30-3.55$ (b, 2H, $\mathrm{CH}_{2}$ and $\mathrm{CH}(\mathrm{OH})$ ), 3.00-3.30 (b, 2H, $\mathrm{CH}(\mathrm{OH})$ ).

Oxidized dextran: In a typical procedure, dextran (10.0 g, $61.7 \mathrm{mmol} \mathrm{AHG})$, dissolved in MilliQ water $(250 \mathrm{ml})$ was treated with sodium periodate $(1.32 \mathrm{~g}, 6.17 \mathrm{mmol})$. The oxidation reaction was carried out in the dark at $25^{\circ} \mathrm{C}$ for $24 \mathrm{~h}$. The reaction was stopped by adding an equimolar amount of ethylene glycol with respect to periodate. The solution was dialyzed by ultrafiltration, using a membrane MW cutoff of 1,000 and MilliQ water (at least 10 times the reaction volume), and the product was subsequently freeze-dried. Yield: $9.14 \mathrm{~g}(91 \%) .{ }^{1} \mathrm{H}-\mathrm{NMR}(300 \mathrm{MHz})\left(\mathrm{D}_{2} \mathrm{O}\right): \delta=5.05-5.85(\mathrm{~m}, \mathrm{CH}(\mathrm{OH})), 5.00(\mathrm{~d}$, 1H, O-CH-O), 3.95-4.00 (m, 1H, $\left.\mathrm{CH}_{2}-\mathrm{CH}-\mathrm{O}\right), 3.90-3.95$ (m, $\left.1 \mathrm{H}, \mathrm{CH}_{2}-\mathrm{O}\right), 3.65-3.75$ (m, $2 \mathrm{H}, \mathrm{CH}_{2}-\mathrm{O}$ and $\left.\mathrm{CH}(\mathrm{OH})\right), 3.45-3.52(\mathrm{~m}, 2 \mathrm{H}, \mathrm{CH}(\mathrm{OH}))$.

Poly(lactic acid)-grafted dextran (Dex-g-PLA): In a typical procedure, activated dextran (3.0 g, $18.5 \mathrm{mmol}$ AHG) with a degree of activation (DA) of 12 (2.0 mmol pnitrophenyl carbonate groups) was dissolved in $23.8 \mathrm{ml}$ of DMSO under vigorous stirring. PLA-NH 2 (3.25 g, DP = 4, $5.0 \mathrm{mmol} \mathrm{NH}_{2}$ groups) and TEA (0.50 g, $\left.5.0 \mathrm{mmol}\right)$ were separately dissolved in $23.8 \mathrm{ml}$ of DMSO and added to the dextran solution. The 
resulting bright yellow mixture was stirred for $24 \mathrm{~h}$ at room temperature. The product (Dex-g-PLA) was isolated by precipitation in cold ethanol, washed with acetonitrile to remove unreacted PLA and subsequently washed with diethyl ether and dried in vacuo over $\mathrm{P}_{2} \mathrm{O}_{5}$. Degree of grafting (DG) ( $\left.{ }^{1} \mathrm{H}-\mathrm{NMR}\right)$ : 4.4. Yield: $2.8 \mathrm{~g}, 89 \%$. ${ }^{1} \mathrm{H}-\mathrm{NMR}$ (DMSO-d $\mathrm{d}_{6}$ ): $\delta=5.25-5.45$ (b, 1H, CH-OC(O)NH-), 5.20 (q, 1H, $\left.\mathrm{CH}\left(\mathrm{CH}_{3}\right)-\mathrm{O}\right), 4.75-5.05$ (b, 2H, OH), 4.60-4.75 (s, 1H, O-CH-O), 4.30-4.60 (b, OH), 4.20 (q, 1H, $\left.\mathrm{CH}\left(\mathrm{CH}_{3}\right)-\mathrm{OH}\right)$, 3.95-3.05 (mb, dextran glucosidic protons), $2.80\left(\mathrm{~b}, 2 \mathrm{H}, \mathrm{C}(\mathrm{O}) \mathrm{NH}-\mathrm{CH} \mathrm{H}_{2}\right), 1.70(\mathrm{~b}, 2 \mathrm{H}$, $\left.\mathrm{CH}_{2}\right), 1.45$ (d, 3H, $\left.\mathrm{CH}\left(\mathrm{CH}_{3}\right)\right), 1.25$ (d, 3H, $\left.\mathrm{CH}\left(\mathrm{CH}_{3}\right)-\mathrm{OH}\right)$.

Poly(lactic acid)-grafted oxidized dextran $\left({ }^{0 x}\right.$ Dex-g-PLA): In a typical experiment, oxidized dextran (2.0 g, DO $=6.1,1.50 \mathrm{mmol}$ aldehyde groups) was dissolved in $15 \mathrm{ml}$ of DMSO, and a solution of PLA-NH $\mathrm{NH}_{2}\left(1.72 \mathrm{~g}, \mathrm{DP}=7,1.59 \mathrm{mmol} \mathrm{NH}_{2}\right.$ groups $)$ in $5 \mathrm{ml}$ of DMSO was added under stirring. After $1 \mathrm{~h}$, a solution of $50 \mathrm{mg}$ of $\mathrm{NaCNBH}_{3}$ in $5 \mathrm{ml}$ of DMSO was added, and the mixture was stirred for $24 \mathrm{~h}$. Another portion of $30 \mathrm{mg}$ of $\mathrm{NaCNBH}_{3}$ in $3 \mathrm{ml}$ of DMSO was added, and the mixture was stirred for $4 \mathrm{~h}$, after which the solids were isolated by precipitation in $500 \mathrm{ml}$ of cold ethanol $\left(-18{ }^{\circ} \mathrm{C}\right)$. The solids were filtered, washed with ethanol, acetonitrile (to remove uncoupled PLA) and dried in vacuo over $\mathrm{P}_{2} \mathrm{O}_{5}$. Yield: $2.34 \mathrm{~g}(63 \%)$. DG $\left({ }^{1} \mathrm{H}-\mathrm{NMR}\right): 5.4 .{ }^{1} \mathrm{H}-\mathrm{NMR}\left(\mathrm{DMSO}-\mathrm{d}_{6}\right): \delta=$ $5.10\left(\mathrm{q}, 1 \mathrm{H}, \mathrm{CH}\left(\mathrm{CH}_{3}\right)\right), 4.80(\mathrm{ds}, 1 \mathrm{H}, \mathrm{O}-\mathrm{CH}(\mathrm{R})-\mathrm{O}$, dextran), 4.70 (s, 1H, dextran glucosidic proton), 4.50 (s, $1 \mathrm{H}$, dextran glucosidic proton), 3.65-3.75 (ds, $2 \mathrm{H}, \mathrm{CH}_{2}-\mathrm{O}$ and O- $\mathrm{CH}_{2}-\mathrm{CH}(\mathrm{R})-\mathrm{O}$, dextran), $3.50(\mathrm{~m}, 1 \mathrm{H}, \mathrm{CH}(\mathrm{OH})$, dextran), 3.20 (s, $1 \mathrm{H}, \mathrm{CH}(\mathrm{OH})$, dextran), 1.50 (d, 3H, $\left.\mathrm{CH}\left(\mathrm{CH}_{3}\right)-\mathrm{O}\right), 1.25$ (d, 3H, $\left.\mathrm{CH}\left(\mathrm{CH}_{3}\right)-\mathrm{OH}\right)$.

\section{Characterization}

NMR: ${ }^{1} \mathrm{H}-\mathrm{NMR}(300 \mathrm{MHz})$ spectra were recorded on a Varian Inova Spectrometer using $\mathrm{CDCl}_{3}, \mathrm{D}_{2} \mathrm{O}$ or DMSO-d $\mathrm{d}_{6}$ solutions and were referenced to shifts of residual $\mathrm{CHCl}_{3}(\delta$ 7.25), $\mathrm{H}_{2} \mathrm{O}(\delta 4.79)$ or DMSO $(\delta 2.50)$, respectively. ${ }^{1} \mathrm{H}-\mathrm{NMR}(600 \mathrm{MHz})$ spectra were recorded on a Bruker Avance II using $\mathrm{D}_{2} \mathrm{O}$ solutions and were referenced to shifts of $\mathrm{H}_{2} \mathrm{O}$ (4.79).

UV-VIS: UV-VIS spectra were recorded on a Cary 300 Bio UV-visible spectrophotometer (Varian). The critical association concentration (CAC) of the dextran$g$-PLA copolymers in water was determined by the dye solubilization method at $25{ }^{\circ} \mathrm{C}$. To $1.0 \mathrm{ml}$ of the aqueous polymer solutions with concentrations ranging from 0.1 to 
Stereocomplexed Hydrogels from Dextran Grafted with PLA Amines

$0.0001 \mathrm{w} / \mathrm{v} \%, 10 \mu \mathrm{l}$ of a $0.5 \mathrm{mM}$ 1,6-diphenyl-1,3,5-hexatriene (DPH) solution in methanol was added. The resulting mixtures were stored in the dark and equilibrated over night. UV-VIS absorption spectra of the solutions were recorded in the 300 to $500 \mathrm{~nm}$ range. The difference in absorption at $372 \mathrm{~nm}$ relative to $400 \mathrm{~nm}$ was plotted against the polymer concentration $(\log \mathrm{wt} \%)$ and the intercept of the extrapolated straight lines was defined as the CAC of the copolymer.

Degree of oxidation: The degree of oxidation (DO) was determined from ${ }^{1} \mathrm{H}$ NMR spectral data of the product obtained from the reaction of aldehydes with tert-butyl carbazate and subsequent reduction with sodium cyanoborohydride. Typically, at an estimated DO of 10\%, a 10-fold excess of tert-butyl carbazate (172 mg, $1.30 \mathrm{mmol})$ was added to a stirred solution of $96 \mathrm{mg}$ dextran in $2.0 \mathrm{ml}$ of MilliQ water. After $1.5 \mathrm{~h}, 33 \mathrm{mg}$ of a sodium cyanoborohydride solution in $1 \mathrm{ml}$ of MilliQ water was added, and the mixture was stirred for another $24 \mathrm{~h}$. The mixture was precipitated in ethanol, filtered, washed with diethyl ether and dried in vacuo. ${ }^{1} \mathrm{H}-\mathrm{NMR}\left(\mathrm{D}_{2} \mathrm{O}, 300 \mathrm{MHz}\right): \delta=5.00(1 \mathrm{H}$, O-CH(O)-CH(OH)), 3.90-4.10 (m, 2H, $\mathrm{CH}_{2}-\mathrm{O}$ and $\left.\mathrm{CH}\left(\mathrm{CH}_{2}\right)-\mathrm{O}\right), 3.70-3.90$ (m, 2H, $\mathrm{CH}_{2}$ $\mathrm{O}$ and $\left.\mathrm{CH}\left(\mathrm{CH}_{2}\right)-\mathrm{CH}(\mathrm{OH})-\mathrm{CH}(\mathrm{OH})\right)$, 3.50-3.70 (m, 2H, $\mathrm{CH}\left(\mathrm{CH}_{2}\right)-\mathrm{CH}(\mathrm{OH})$ and $\mathrm{O}-$ $\mathrm{CH}(\mathrm{O})-\mathrm{CH}(\mathrm{OH})), 1.50\left(\mathrm{~s}, 9 \mathrm{H}, \mathrm{C}\left(\mathrm{CH}_{3}\right)\right)$.

\section{Aqueous solution properties}

Degradation of Dex-PLAs: The degradation/dissolution of Dex-PLAs was determined by incubating $20 \mathrm{mg}$ copolymer samples in $1.0 \mathrm{ml}$ of PBS buffer (pH 7.4). The samples were placed in a water bath, thermostatted at $37^{\circ} \mathrm{C}$, and were shaken continuously. At 4 , 7 and 14 days, samples were removed from the water bath and freeze-dried. The remaining solids were extracted twice with acetonitrile to remove PLA fragments, and the residue was dried in vacuo. DP PLA values and degrees of grafting were determined with ${ }^{1} \mathrm{H}-\mathrm{NMR}$ (DMSO-d 6 ).

Vial tilting method: The phase behavior of mixed aqueous polymer solutions of PLLA and PDLA grafted dextrans (both Dex-g-PLA and ${ }^{\text {ox }}$ Dex-g-PLA) was investigated using the vial tilting method. The copolymers were dissolved in $500 \mu \mathrm{l}$ MilliQ water (10-30 $\mathrm{wt} \%$ ) in tightly capped $5 \mathrm{ml}$ vials by continuous shaking for $24 \mathrm{~h}$. The resulting solutions of the PLLA and PDLA grafted dextrans were mixed at room temperature by vortexing. In case of gelation the gels were placed in a water bath, and the temperature was 
increased step-wise with $2{ }^{\circ} \mathrm{C}$. The samples were left at the measuring temperature for 10 min to equilibrate. When the sample showed no flow when tilted to a $90{ }^{\circ} \mathrm{C}$ angle for 1 min, it was regarded as a gel.

Swelling/Dissolution: Swelling/dissolution tests were performed by placing $500 \mu \mathrm{l}$ of a saline buffer ( $\mathrm{pH}$ 7.4) on top of the gels, prepared as described above, and placing the tubes in a water bath, thermostatted at $37^{\circ} \mathrm{C}$.

Rheology: Rheology experiments were performed on an Anton Paar Physica MCR Rheometer using a flat plate geometry $(25 \mathrm{~mm}, 0.2 \mathrm{~mm}$ gap) in oscillating mode. Aqueous polymer solutions (20 wt $\%$ ) of Dex-g-PLA and ${ }^{\mathrm{ox}}$ Dex-g-PLA were prepared as described above for the vial tilting method. Mixed polymer solutions Dex-g-PLLA and Dex-g-PDLA or ${ }^{\text {ox }}$ Dex-g-PLLA and ${ }^{\text {ox }}$ Dex-g-PDLA were applied on the rheometer. To prevent evaporation of water, a solvent trap was placed over the geometry. Gelation of the mixture was followed by measuring the storage modulus ( $\left.\mathrm{G}^{\prime}\right)$ and loss modulus (G”) at $20{ }^{\circ} \mathrm{C}$ for $18 \mathrm{~h}$. A frequency $\omega$ of $1 \mathrm{~Hz}$ and a strain $\gamma$ of $1 \%$ were applied to minimize the influence of deformation on the formation of the hydrogels. Following the time sweep, a constant force (equal to the force needed for $1 \%$ deformation at the end of the time sweep) was applied for $60 \mathrm{~s}$ while measuring the strain. Subsequently, the temperature was raised to $80{ }^{\circ} \mathrm{C}$ at $2{ }^{\circ} \mathrm{C} \min ^{-1}$ while measuring $\mathrm{G}^{\prime}$ and $\mathrm{G}$ ” $(\omega=1 \mathrm{~Hz}, \gamma=$ $1 \%$ ). After applying the force to obtain $1 \%$ deformation at $80{ }^{\circ} \mathrm{C}$ for $60 \mathrm{~s}$, the system was cooled again to $20^{\circ} \mathrm{C}$ at $2{ }^{\circ} \mathrm{C} \mathrm{min}^{-1}$ while measuring $\mathrm{G}^{\prime}$ and $\mathrm{G}$ ".

\section{Result and Discussion}

\section{Synthesis}

Activated dextran: The activation of dextran hydroxyl groups by conversion into $p$ nitrophenyl carbonate moieties ( $p$-NPC) was successfully carried out by reaction with $p$ nitrophenyl chloroformate in $\mathrm{DMF} / \mathrm{LiCl}$ at $0{ }^{\circ} \mathrm{C}$, using pyridine as a catalyst. The amount of $p$-NPC groups introduced was determined with ${ }^{1} \mathrm{H}-\mathrm{NMR}$, from the signals of the aromatic protons emerging at $\delta=8.30$ and $7.50 \mathrm{ppm}$ and the protons in the region $\delta=$ $5.40-4.50 \mathrm{ppm}$ of the $\mathrm{OH}$ groups and anomeric protons (Figure 1). 


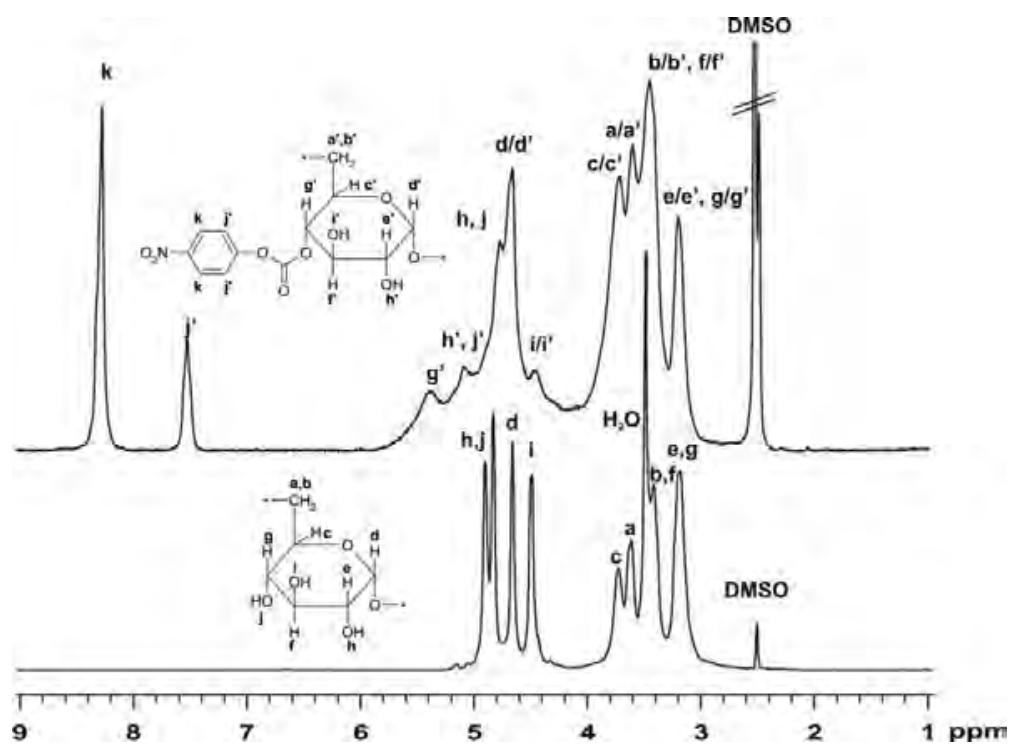

Figure 1. ${ }^{1} \mathrm{H}-\mathrm{NMR}$ spectra of dextran (lower) and $p$-nitrophenyl carbonate-activated dextran (upper). Solvent: DMSO-d $\mathrm{d}_{6}$.

The degree of activation (DA) was defined as the number of activated hydroxyl groups per hundred dextran rings. At a 1.2 molar excess of $p$-nitrophenyl chloroformate to dextran hydroxyl groups, a maximum degree of activation of DA $=12$ could be reached. The activation reaction is thus not very efficient and only $\sim 10 \%$ of the $p$-nitrophenyl chloroformate is effectively used, which is in accordance with literature. ${ }^{42-45}$

Oxidized dextran: Partial oxidation of the anhydroglucosidic (AHG) rings of dextran was carried out by treating aqueous dextran solutions with sodium periodate. The degree of oxidation (DO) can be increased by increasing the molar ratio of periodate ions to the AHG rings. 


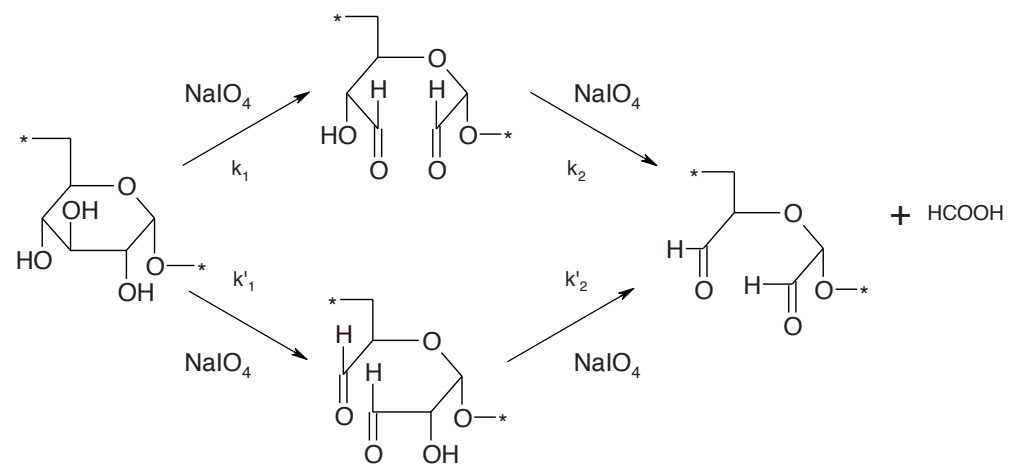

Scheme 1. Single and double oxidations of dextran with sodium periodate.

As described in literature oxidized dextran rings ('single oxidation') are sensitive to further oxidation ('double oxidation') (Scheme 1). ${ }^{46}$ This is more eminent upon using higher amounts of periodate, and results in a lower DO than intended. ${ }^{47}$

Because from ${ }^{1} \mathrm{H}-\mathrm{NMR}$ spectra no estimation of the DO could be made, analysis was done by reaction of the aldehyde groups with $t$-butyl carbazate and subsequent reduction of the imine bonds formed with sodium cyanoborohydride. Assuming that all aldehyde groups react with tert-butyl carbazate, the DO was calculated from the intensities of the tert-butyl $(\delta=1.50)$ and anomeric protons' $(\delta=5.00)$ signals in the ${ }^{1} \mathrm{H}-\mathrm{NMR}$ spectra.

A molar ratio of dextran to periodate of 10:1 (an intended DO of 10\%) afforded a DO of $7 \%$ based on the $t$-butyl carbazate assay. This means that even for low ratios of periodate to anhydroglucosidic rings and relatively short oxidation times, the amount of double oxidized rings may be as high as $30 \%$, which is in accordance with literature data. ${ }^{46}$

\section{Dex-g-PLA}

In previous research it was shown that low molecular-weight amino-functionalized PLAs could be synthesized by solution ring-opening polymerization of $L$ - or $D$-lactide in toluene, using stannous octoate as a catalyst and 3-Boc-amino-1-propanol as an initiator (Chapter 7). The Boc-group was successfully removed by reaction of the polymer in solution with $\mathrm{HCl}$ gas. The DP values of the amine functionalized poly(lactide)s were in good accordance with the theoretical values based on the monomer to initiator ratio (Table 1). 
Table 1: Theoretical and found DP values of tert-butoxycarbonyl-protected amine end group functionalized PLLAs and PDLAs.

\begin{tabular}{cccc|cccc} 
Entry & Polymer & $\mathrm{DP}_{\text {theoretical }}$ & $\mathrm{DP}_{\mathrm{NMR}}$ & Entry & Polymer & $\mathrm{DP}_{\text {theoretical }}$ & $\mathrm{DP}_{\mathrm{NMR}}$ \\
\hline 1 & PLLA-4 & 4 & 4.0 & 5 & PDLA-4 & 4 & 4.0 \\
2 & PLLA-5 & 5 & 5.3 & 6 & PDLA-5 & 5 & 4.8 \\
3 & PLLA-6 & 6 & 5.9 & 7 & PDLA-6 & 6 & 6.1 \\
4 & PLLA-7 & 7 & 6.8 & 8 & PDLA-7 & 7 & 7.0
\end{tabular}

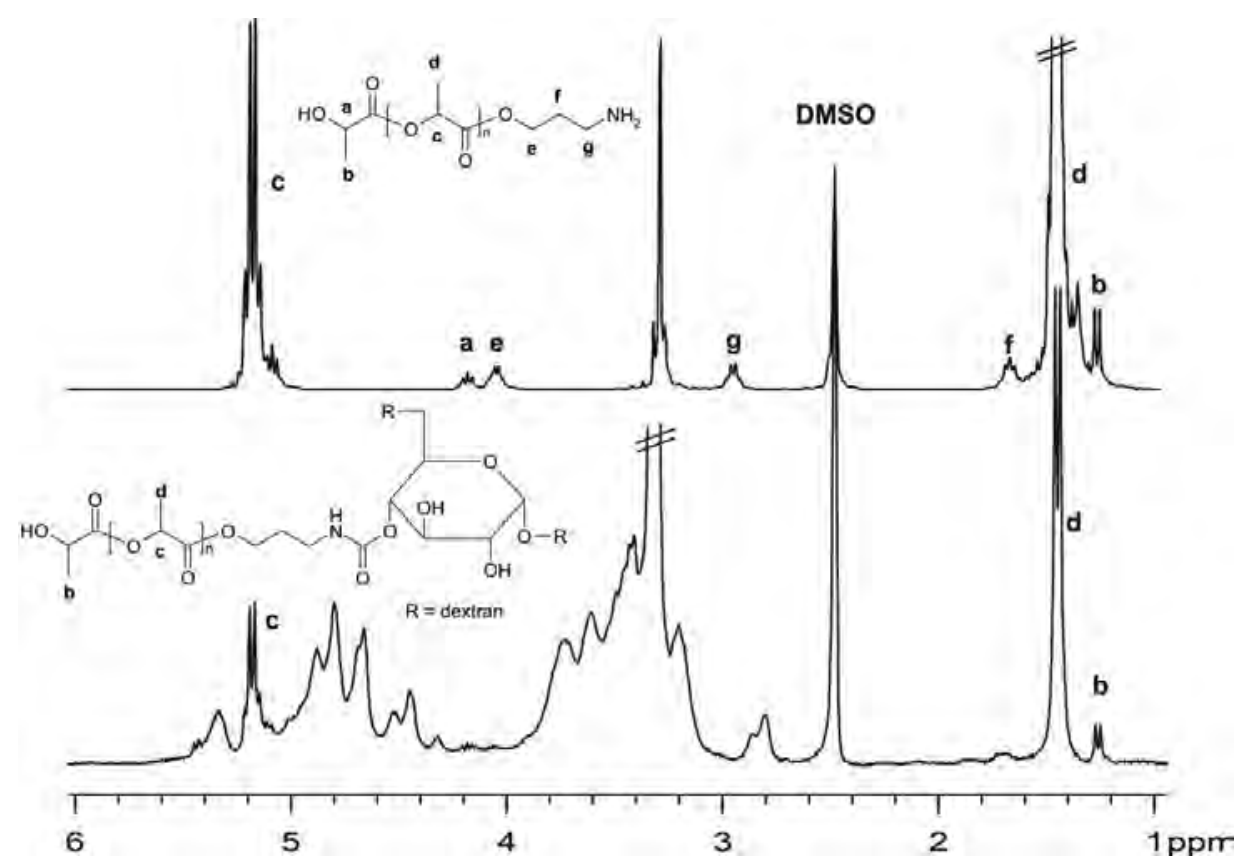

Figure 2. ${ }^{1} \mathrm{H}-\mathrm{NMR}$ spectra of amino-functionalized poly(lactic acid) (upper) and Dex-g-PLA (lower). Solvent: DMSO-d ${ }_{6}$. 
Dex- $g$-PLA conjugates were prepared by the reaction of PLA- $\mathrm{NH}_{2}$ with the p-NPCactivated dextran. The degree of grafting (DG) of dextran, defined as the number of coupled PLA oligomers per 100 AHG, was calculated from the integrals in the region $\delta=$ $4.30-5.50 \mathrm{ppm}$ in the ${ }^{1} \mathrm{H}-\mathrm{NMR}$ spectra of the conjugates (Figure 2). The absence of the aromatic protons in the ${ }^{1} \mathrm{H}-\mathrm{NMR}$ spectra of the isolated copolymers showed that remaining $p$-NPC-activated dextran rings are hydrolyzed during the workup procedure. In almost all conjugation reactions performed the grafting efficiency was approximately $\sim 40 \%$ (Table 2 ).

Table 2. Coupling of PLLA-NH $\mathrm{NH}_{2}$ to $p$-nitrophenyl carbonate-activated dextran with a DA of 12. Degree of grafting (DG), hydrophobic fraction (F $\left.F_{P L A}\right)$ and grafting efficiency.

\begin{tabular}{cccccc} 
Entry & Polymer & {$\left[\mathrm{NH}_{2}\right]:[p-\mathrm{NPC}]$} & $\mathrm{DG}^{\mathrm{a}}$ & $\begin{array}{c}\mathrm{F}_{\mathrm{PLA}} \\
(\mathrm{wt} \%)\end{array}$ & $\begin{array}{c}\text { Grafting efficiency } \\
(\%)\end{array}$ \\
\hline 1 & PLLA-8 & 2.1 & 5.8 & 19 & 49 \\
2 & & 2.1 & 4.4 & 17 & 37 \\
3 & & 2.4 & 4.4 & 15 & 37 \\
4 & PLLA-10 & 2.0 & 4.5 & 19 & 38 \\
5 & & 2.0 & 4.5 & 19 & 38 \\
6 & & 2.5 & 4.5 & 18 & 38 \\
7 & PLLA-12 & 1.5 & 3.8 & 17 & 31 \\
8 & & 1.8 & 4.9 & 23 & 41 \\
9 & & 2.0 & 7.9 & 35 & 66 \\
10 & PLLA-14 & 1.6 & 4.8 & 23 & 40 \\
11 & & 1.8 & 4.1 & 22 & 34 \\
12 & & 2.0 & 5.4 & 29 & 45 \\
a approximated error: $7 \%$ & & & &
\end{tabular}

Applying different reaction times showed that most of the grafting is taking place in the early stages of the reaction $(<2 \mathrm{~h})$, and prolonging the reaction to $24 \mathrm{~h}$ led to an increase in the DG of $\sim 15 \%$. Increasing the reaction temperature to $50{ }^{\circ} \mathrm{C}$ did not result in higher 


\section{Stereocomplexed Hydrogels from Dextran Grafted with PLA Amines}

grafting efficiencies, which was possibly due to an increased deactivation at this temperature. The use of triethylamine (TEA) and small quantities of water still present appeared most important in the grafting reaction. Despite carrying out reactions at anhydrous conditions, the hydrolysis could not completely be suppressed, as was determined in a control experiment without reagents. The base is necessary to liberate the amine group of the PLA-amine $\mathrm{HCl}$-salt but also promotes hydrolysis of the 4nitrophenyl carbonate groups in the presence of water. Upon using the free PLA-amine without the addition of a base, grafting efficiencies of only $5-15 \%$ were obtained. The acidic nature of aqueous solutions of $p$-NPC-activated dextrans $(\mathrm{pH}=3-4)$ may explain the low DG values observed.

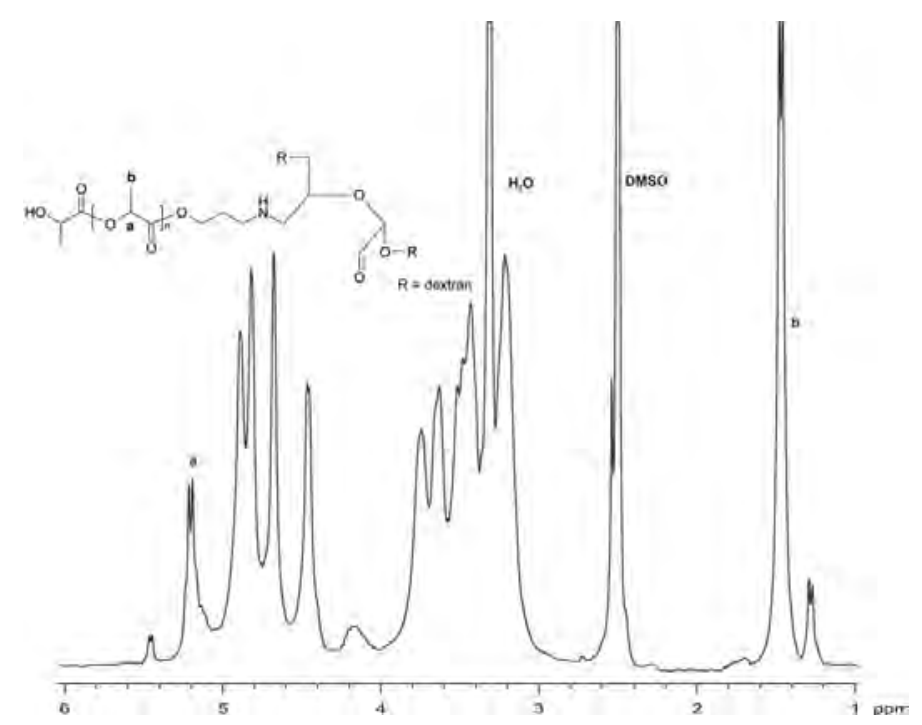

Figure 3. ${ }^{1} \mathrm{H}-\mathrm{NMR}$ spectrum of poly(lactic acid)-grafted periodate-oxidized dextran. Solvent: DMSO-d $\mathrm{d}_{6}$ 
${ }^{o x}$ Dex-g-PLA

The coupling of PLA- $\mathrm{NH}_{2}$ to oxidized dextran was carried out successfully by reductive amination in dry DMSO. The degree of grafting (DG) was calculated from the ${ }^{1} \mathrm{H}-\mathrm{NMR}$ spectra (Figure 3) using the methyl signals of the polylactides at $\delta=1.50$ and $1.30 \mathrm{ppm}$ and the anomeric protons at $\delta=4.70 \mathrm{ppm}$ of the dextran. The 12-14 reactive aldehyde groups per 100 AHG rings present in the oxidized dextran were expected to give, at a $100 \%$ grafting efficiency, i.e. 12-14 grafts per 100 AHG rings. The relatively low values of 4-6 grafts per 100 AHG rings found (Table 3) may be explained by the fact that once a single PLA graft has been attached to the dextran ring, steric hindrance may effectively prohibit the addition of a second graft to the other aldehyde group of the same dextran ring. The DG and F $F_{P L A}$ values are comparable to those obtained for the Dex-g-PLA copolymers.

Table 3. Coupling of PLLA- $\mathrm{NH}_{2}$ to oxidized dextran with a DO of 6.8. Degree of grafting (DG), hydrophobic fraction ( $\left.\mathrm{F}_{\mathrm{PLA}}\right)$ and grafting efficiency.

\begin{tabular}{|c|c|c|c|c|c|}
\hline Entry & Graft & DP & $\mathrm{DG}^{\mathrm{a}}$ & $\begin{array}{l}\mathrm{F}_{\mathrm{PLA}} \\
(\mathrm{wt} \%)\end{array}$ & $\begin{array}{c}\text { Grafting efficiency } \\
(\%)\end{array}$ \\
\hline 1 & PLLA & 4 & 5.9 & 18 & 49 \\
\hline 2 & & 5 & 5.3 & 19 & 44 \\
\hline 3 & & 6 & 3.7 & 17 & 31 \\
\hline 4 & & 7 & 4.1 & 21 & 34 \\
\hline 5 & PDLA & 4 & 5.9 & 18 & 49 \\
\hline 6 & & 5 & 5.1 & 19 & 43 \\
\hline 7 & & 6 & 3.6 & 17 & 30 \\
\hline 8 & & 7 & 4.4 & 22 & 37 \\
\hline
\end{tabular}




\section{Stereocomplexed Hydrogels from Dextran Grafted with PLA Amines}

\section{Aqueous solution properties}

\section{Solubility}

In literature it has been reported that Dex-g-PLA copolymers with PLA grafts (DP = 2-6) covalently coupled via ester bonds and hydrophobic weight fractions ( $F_{\text {PLA }}$ ) of 20-37\% were soluble in water up to high concentrations. ${ }^{35,36,40}$ The Dex-g-PLA copolymers prepared in this study with grafts of DP $=4$ or 5 and $\mathrm{F}_{\mathrm{PLA}}$ of $16-20 \%$ were readily soluble in water up to $30 \mathrm{wt} \%$. The copolymers with grafts of DP $=6$ or 7 only gave clear solutions up to $20 \mathrm{wt} \%$ and afforded suspensions at higher concentrations. Up to $20 \mathrm{wt} \%$ the ${ }^{\text {ox }}$ Dex-g-PLA copolymers gave homogeneous mixtures, but retained a pale white color, despite of prolonged mixing or gentle heating.

These data show that the DP of the PLA chains and the value of F PLA play an important role in the solubility of the copolymer. The limited solubility may be explained by the incapability of forming a hydrophilic dextran 'shield' around the hydrophobic grafts once these are above a certain length. The hydrophobic 'core' gets too crowded (Figure 4), and the grafts are exposed to the water.

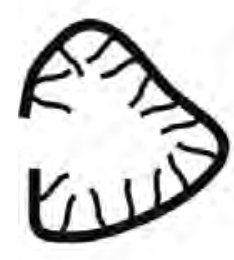

A

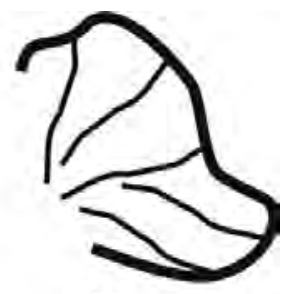

B

Figure 4. Schematic representation of a PLA-grafted dextran backbone in an aqueous environment; short grafts can be shielded (A), whereas longer grafts cannot (B).

Compared to Dex-g-PLA copolymers in which the PLA oligomers are grafted via ester or carbonate linkages, the solubility of the Dex-g-PLA and ${ }^{o x}$ Dex- $g$-PLA copolymers conjugated via carbamate or amine linkages, at comparable DP, DG and FPLA values, thus appears to be somewhat lower. Despite the low degree of grafting and graft lengths, the 
change in the chemical structure may change intra- and intermolecular hydrogen bonding and thereby the solubility of these materials.

\section{Critical association concentration}

The critical association concentration (CAC) (Table 4) of the Dex-g-PLA copolymers in water was measured by UV-VIS using the hydrophobic dye 1,6-diphenyl-1,3,5hexatriene (DPH). The CAC values are within the same range except for Dex-g-PLA with a DP $=4$, and are not significantly influenced by either block length or hydrophobic content. The ${ }^{\text {ox }}$ Dex-g-PLA copolymers have lower CAC values than the Dex-g-PLA analogues, which is in line with their relatively poor solubilization and may be due to inter- and intramolecular hemiacetal formation in oxidized dextrans. ${ }^{46,48}$

Table 4. Critical association concentrations at $25^{\circ} \mathrm{C}$ of Dex-g-PLLA and ${ }^{\mathrm{ox}} \mathrm{Dex}-g$-PLLA copolymers in water.

\begin{tabular}{lcccc} 
Polymer & DP $_{\text {graft }}$ & DG & F $_{\text {PLA }}$ & $\begin{array}{c}\text { CAC } \\
(\mathrm{w} / \mathrm{v} \%)\end{array}$ \\
\hline Dex-g-PLA & 4 & 5.7 & 17 & 0.038 \\
& 5 & 4.7 & 18 & 0.019 \\
& 6 & 3.7 & 16 & 0.022 \\
${ }^{\text {ox Dex-g-PLA }}$ & 7 & 4.7 & 22 & 0.019 \\
& 4 & 6.2 & 20 & 0.017 \\
& 5 & 5.0 & 20 & 0.010 \\
& 6 & 4.4 & 20 & 0.010 \\
& 7 & 5.4 & 27 & 0.012
\end{tabular}

\section{Gelation}

Gelation of Dex-g-PLLA or ${ }^{0 x}$ Dex-g-PLLA solutions does not take place even at high concentrations. However, mixing of equal amounts of the Dex-g-PLLA and Dex-g-PDLA conjugates solutions afforded hydrogels via stereocomplex formation. The gelation through stereocomplexation was investigated by mixing 10,20 or $30 \mathrm{wt} \%$ solutions of the water-soluble Dex-g-PLLAs and Dex-g-PDLAs (Table 5). At concentrations of $10 \mathrm{wt} \%$ no gels were formed, whereas for the $20 \mathrm{wt} \%$ samples gelation took more than $16 \mathrm{~h}$. The 
$30 \mathrm{wt} \%$ samples formed stereocomplexed gels in $\sim 45 \mathrm{~min}$. A similar trend was observed for the ${ }^{\text {ox }}$ Dex-g-PLA copolymers, but with prolonged gelation times (2.5-3 h). It has previously been described that the lower limit for stereocomplex formation of monodisperse PLA oligomers is 7 lactyl repeating units. ${ }^{36}$ This lower limit increases to a value of $\sim 11$ lactyl units when the PLA oligomer is grafted to a polymer or when bulky end groups are introduced (also see Chapter 7).

Table 5. Dependence of concentration on the stereocomplex induced gelation of DexPLLA and Dex-PDLA solutions containing various wt $\%$ of copolymers (vial tilting method).

\begin{tabular}{ccccc} 
& & \multicolumn{3}{c}{ Wt \% copolymer in solution } \\
\cline { 3 - 5 } Copolymer & & 10 & 20 & 30 \\
\hline Dex-g-PLA & 4 & no gel & gel & gel \\
& 5 & no gel & gel & gel \\
${ }^{\text {ox }}$ Dex-g-PLA & 7 & no gel & gel & n.d. ${ }^{\text {a }}$ \\
& 4 & no gel & gel & n.d. ${ }^{\text {a }}$ \\
& 5 & no gel & no gel & gel \\
& 6 & no gel & gel & n.d. ${ }^{\text {a }}$ \\
& 7 & no gel & gel & n.d. ${ }^{\text {a }}$ \\
& 7 & no gel & gel & n.d. ${ }^{\text {a }}$
\end{tabular}

${ }^{\mathrm{a}}$ Copolymers not properly dissolving

As shown previously stereocomplexed dex-PLA gels (conjugation via ester or carbonate units) with an average DP of $4.5, \mathrm{DS} \geq 3$ and solid weight contents $>20 \%$ afforded hydrogels with storage moduli of $>1000 \mathrm{~Pa}^{36}$ At a similar concentration of $20 \mathrm{wt} \%$ most copolymers described in this chapter did form hydrogels despite the use of polydisperse PLA oligomers in the synthesis of the Dex-g-PLA copolymers. All gels formed, however, were rather fragile, and could not be removed from the test tubes without loss of structural integrity.

The thermostability of a series of $20 \mathrm{wt} \%$ gels of Dex-g-PLAs in PBS buffer was determined with the vial tilting method. The temperatures at which the gels started to 
flow are presented in Table 6. The gel/sol transition temperature increased with increasing PLA block length for the Dex-g-PLA copolymers. The mixture based on the conjugate with DP 7 was deviating from the observed trend, most likely explained by the reduced solubility of the copolymers used. The gel/sol transitions of the ${ }^{\text {ox }}$ Dex- $g$-PLA copolymers appeared more difficult to determine and the values given are only an indication.

Table 6. Gel/sol transition temperatures of $20 \mathrm{wt} \%$ gels of dex-PLLA and dex-PDLA mixtures in 1:1 wt/wt ratios in PBS. DG values of the Dex- $g$-PLAs and ${ }^{\text {ox }}$ Dex- $g$-PLA polymers were 4-5.

\begin{tabular}{ccc} 
Polymer & DP & $\mathbf{T}_{\text {gel } / \text { sol }}\left({ }^{\circ} \mathbf{C}\right)$ \\
\hline Dex-g-PLA & 4 & 30 \\
& 5 & 42 \\
& 6 & 54 \\
${ }^{\text {ox }}$ Dex-g-PLA & 7 & 34 \\
& 5 & 60 \\
& 6 & 60 \\
& 7 & 60
\end{tabular}

\section{Rheology}

The gelation behavior of racemic mixtures of Dex-g-PLLA and Dex-g-PDLA was also studied by determining the storage modulus ( $\left.\mathrm{G}^{\prime}\right)$ and loss modulus ( $\left.\mathrm{G}^{\prime \prime}\right)$ as a function of time using oscillatory rheology experiments. For both Dex-g-PLA and ${ }^{\text {ox }}$ Dex-g-PLA, equal amounts of Dex-PLLA and Dex-PDLA solutions were mixed by vortexing, and the resulting mixture was placed between the plates of the rheometer. The mixtures were subjected to a $1 \mathrm{~Hz}$ oscillation at $1 \%$ strain. Measurements pointed out that no stereocomplexed gels were formed from Dex- $g$-PLA with PLA chains of DP $=4$ as both G' and G" values are $<10 \mathrm{~Pa}$. The gelation observed in the vial tilting tests therefore most likely was due to the formation of loose aggregates, rather than crosslinked networks. 


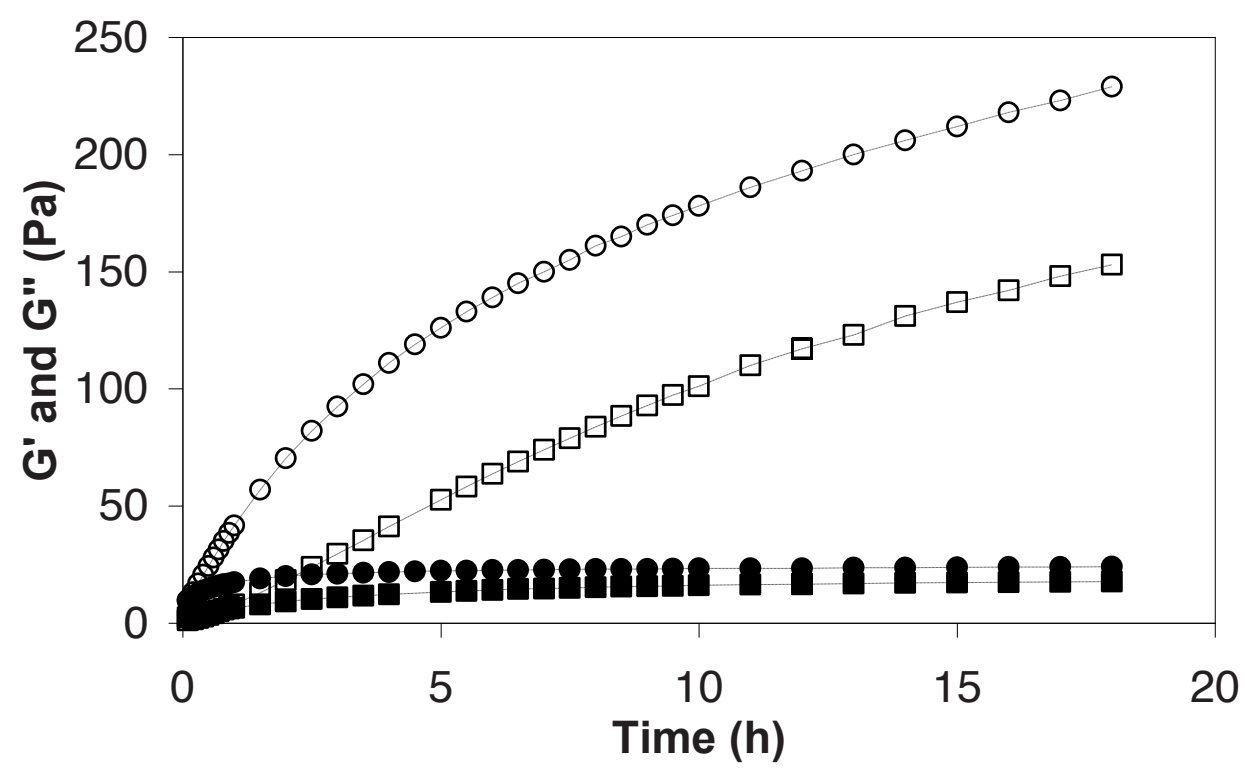

Figure 5. The storage (G'; open markers) and loss (G”; filled markers) moduli of $20 \mathrm{wt} \%$ aqueous mixtures of Dex- $g$-PLLA and Dex- $g$-PDLA, measured at $20^{\circ} \mathrm{C}$.

$(\bigcirc, \bullet) \mathrm{DP}_{\text {graft }}=6 ;(\square, \boldsymbol{\square}) \mathrm{DP}_{\text {graft }}=7$.

For the Dex-g-PLA copolymers with PLAs of DP $=6$ and 7, rheology data pointed out that gel formation occurred after 8 and 45 min, respectively. In contrast, for the ${ }^{o x}$ Dex- $g$ PLA samples gel formation occurred within minutes. After $18 \mathrm{~h}$, the Dex- $g$-PLA gels had not yet reached a plateau value, and a $\mathrm{G}^{\prime}$ of $230 \mathrm{~Pa}(\mathrm{DP}=6)$ and $150 \mathrm{~Pa}(\mathrm{DP}=7)$ were found (Figure 5). For the ${ }^{\mathrm{ox}}$ Dex-g-PLA copolymers, plateau values for G' of 497 (DP = 5), $377(\mathrm{DP}=6)$ and $287 \mathrm{~Pa}(\mathrm{DP}=7)$ were found after 10-12 h (Figure 6). These low values point out that only slightly crosslinked gels are formed. This may explain the large deviation in 'gelation times' derived from the vial tilting test and rheology measurements, and the former may not be suitable for establishing actual gelation times. The G' values are similar to Dex-PLAs in which the PLA oligomers were grafted via ester or carbonate bonds $\left(\mathrm{DP}=4.5, \mathrm{DS}=3\right.$, weight fraction Dex-PLA $=20 \%$; G' $=230 \mathrm{~Pa}$ after $18 \mathrm{~h}$ ). ${ }^{36}$ Although longer PLA segments were expected to facilitate stereocomplex formation, 
storage moduli of the gels seemed to decrease with increasing PLA graft lengths. This is most likely explained by the poorer water solubility of the copolymers upon increasing the PLA chain length. Rather than establishment of intermolecular stereocomplexes, intramolecular hydrophobic associations are likely to be present in these conjugates, which are only slowly converted in intermolecular crosslinks.

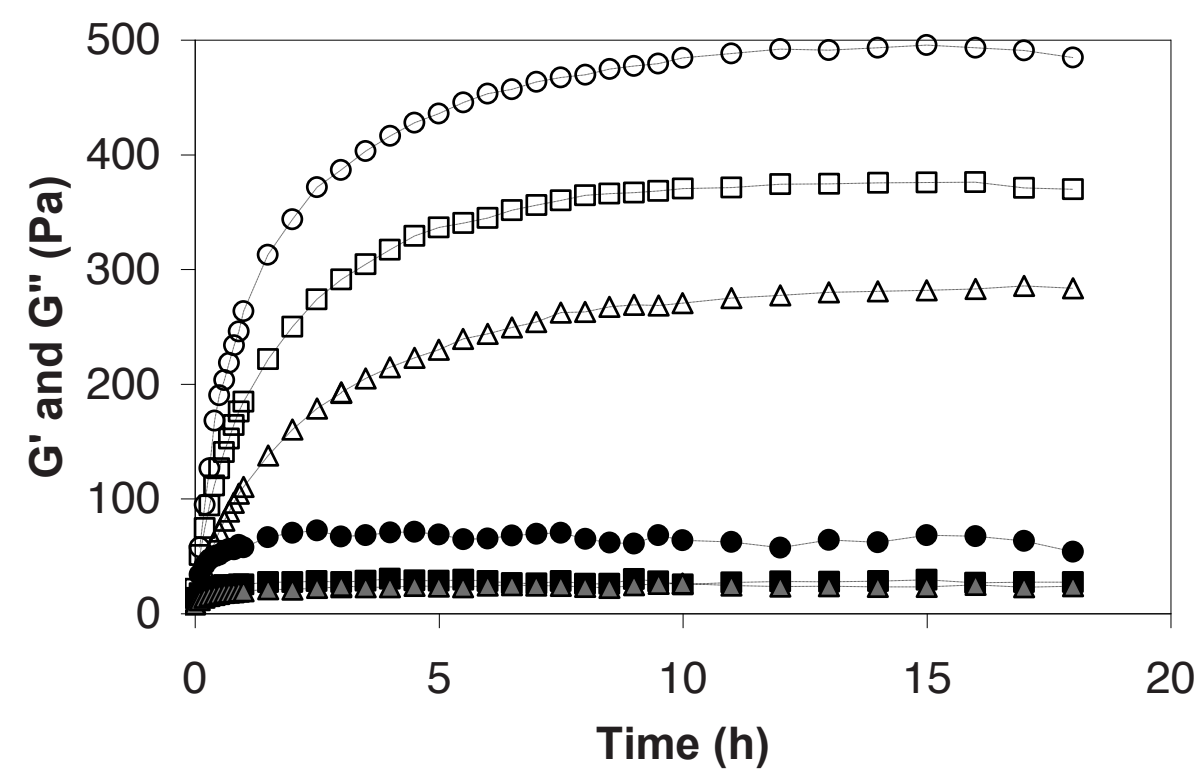

Figure 6. The storage (G'; open markers) and loss (G”; filled markers) moduli of $20 \mathrm{wt} \%$ aqueous mixtures of ${ }^{\mathrm{ox}}$ Dex-g-PLLA and ${ }^{\mathrm{ox}}$ Dex-g-PDLA, measured at $20{ }^{\circ} \mathrm{C}$. $(\mathrm{O}, \bullet)$ $\mathrm{DP}_{\text {graft }}=5 ;(\square, \boldsymbol{\square}) \mathrm{DP}_{\text {graft }}=6 ;(\Delta, \mathbf{\Delta}) \mathrm{DP}_{\text {graft }}=7$.

When performing a temperature sweep from $20{ }^{\circ} \mathrm{C}$ to $80^{\circ} \mathrm{C}$, the gels lost their structural integrity and the $G^{\prime}$ values dropped to almost zero. It was determined that these gel/sol transitions were reversible, though reestablishment of the gel state was rather slow, and was only observed after leaving the mixtures for prolonged times. The recovery of the moduli demonstrates the physical nature of the crosslinks in the gels. 


\section{Stereocomplexed Hydrogels from Dextran Grafted with PLA Amines}

\section{Degradation}

Grafting of oligomeric PLAs to dextran via carbamate or secondary amine bonds provides hydrolytically stable linkages. Degradation of the copolymers will then only proceed through hydrolysis of ester bonds within the PLA grafts. For corresponding copolymers in which the PLA segments are attached to the dextran backbone via ester or carbonate linkages, preferential hydrolysis of the ester linkage at the dextran backbone is the main driving force for the hydrolytic degradation of these materials. ${ }^{40}$ Likely, this hydrolysis is facilitated intramolecularly by neighbouring dextran hydroxyl groups. ${ }^{39}$ The degradation of the Dex-g-PLA and ${ }^{\text {ox }}$ Dex-g-PLA copolymers with DP 4 and 7 of the PLA chains, dissolved in PBS buffer $(\mathrm{pH}=7.4)$ at $37{ }^{\circ} \mathrm{C}$ was followed in time. The change in DP of the PLA grafts was analyzed by ${ }^{1} \mathrm{H}-\mathrm{NMR}$ and revealed a decrease in DP values of $\sim 30 \%$ for the Dex-g-PLA copolymers and $\sim 60 \%$ for the ${ }^{\text {ox }}$ Dex- $g$-PLA copolymers within 14 days. Importantly, structural analysis by ${ }^{1} \mathrm{H}-\mathrm{NMR}$ showed that the degree of grafting did not change over time, indicating that random hydrolysis of the ester bonds within the PLA grafts is taking place rather than cleavage of the dextran-PLA linkage. ${ }^{49,} 50$ This was supported by a lower mass loss over time for the Dex-g-PLA materials comprising carbamate linkages (20-30\% mass loss in 14 days) or secondary amine linkage (55\% mass loss in 14 days) in comparison with Dex-g-PLA materials comprising ester or carbonate linkages ( $80 \%$ mass loss in 5 days). ${ }^{39}$

\section{Conclusions}

The grafting of amine end group-functionalized PLA oligomers onto dextran was successfully carried out by reaction with 4-nitrophenyl-activated or partially oxidized dextran via reductive amination. Because of the hydrolytic stability of the introduced carbamate linkages in the Dex- $g$-PLA or secondary amine linkages in the oxidized Dex$g$-PLA copolymers these materials only degrade through hydrolytic degradation of ester bonds in the PLA grafts, resulting in a slow mass loss over time. Mixing of aqueous solutions of Dex-PLLA and Dex-PDLA or ${ }^{0 x}$ Dex- $g$-PLLA and ${ }^{0 x}$ Dex- $g$-PDLA resulted in gel formation through stereocomplexation. The plateau value of the storage moduli was only reached after several hours in case of ${ }^{{ }^{0 x}}$ Dex-g-PLA and even days for the Dex- $g$ - 
PLA, indicating that intramolecular hydrophobic interactions in enantiomeric Dex-PLA aqueous solutions do hamper fast intermolecular stereocomplex formation. The phenomenon appeared to be higher at increasing PLA block lengths. The hydrophobic intramolecular associations are also reflected in the relatively poor aqueous solubility of the copolymers.

\section{References}

1. H. Shirahama, A. Ichimaru, C. Tsutsumi, Y. Nakayama and H. Yasuda, Characteristics of the biodegradability and physical properties of stereocomplexes between poly(D-lactide) and poly(D-lactide) copolymers. J. Polym. Sci., Part A: Polym. Chem., 2005, 43(2), 438-454.

2. M. Kakuta, M. Hirata and Y. Kimura, Stereoblock Polylactides as HighPerformance Bio-Based Polymers. Polymer Reviews, 2009, 49(2), 107-140.

3. J. Slager and A. J. Domb, Biopolymer stereocomplexes. Adv. Drug Deliv. Rev., 2003, 55(4), 549-583.

4. T. Kitayama, N. Fujimoto, Y. Terawaki and K. Hatada, Stereocomplex formation between isotactic PMMA and syndiotactic polymethacrylates in bulk and in solution. Polym. Bull., 1989, 23(3), 279-286.

5. J. Slager, M. Gladnikoff and A. J. Domb, Stereocomplexes, based on biodegradable polymers and bioactive macromolecules. Macromol. Symp., 2001, $175(105-115$.

6. J. Slager and A. J. Domb, Stereocomplexes based on poly(lactic acid) and insulin: formulation and release studies. Biomaterials, 2002, 23(22), 4389-4396.

7. J. Slager, Y. Cohen, R. Khalfin, Y. Talmon and A. J. Domb, Peptides form stereoselective complexes with chiral polymers. Macromolecules, 2003, 36(9), 2999-3000.

8. J. Slager and A. J. Domb, Heterostereocomplexes prepared from D-poly(lactide) and leuprolide. I. Characterization. Biomacromolecules, 2003, 4(5), 1308-1315.

9. R. Slivniak and A. J. Domb, Stereocomplexes of enantiomeric lactic acid and sebacic acid ester-anhydride triblock copolymers. Biomacromolecules, 2002, 3(4), 754-760.

10. S. J. Jong, de, W. N. E. van Dijk-Wolthuis, J. J. Kettenes-van den Bosch, P. J. W. Schuyl and W. E. Hennink, Monodisperse enantiomeric lactic acid oligomers: Preparation, characterization, and stereocomplex formation. Macromolecules, 1998, 31(19), 6397-6402.

11. D. Brizzolara, H. J. Cantow, K. Diederichs, E. Keller and A. J. Domb, Mechanism of the stereocomplex formation between enantiomeric poly(lactide)s. Macromolecules, 1996, 29(1), 191-197.

12. H. Tsuji, Poly(lactide) stereocomplexes: Formation, structure, properties, degradation, and applications. Macromol. Biosci., 2005, 5(7), 569-597.

13. C. Hiemstra, Z. Y. Zhong, P. J. Dijkstra and J. Feijen, Stereocomplex Mediated Gelation of PEG-(PLA) ${ }_{2}$ and PEG-(PLA) 8 Block Copolymers. Macromolecular Symposia, 2005, 224(1), 119-132. 
14. C. Hiemstra, Z. Y. Zhong, X. Jiang, W. E. Hennink, P. J. Dijkstra and J. Feijen, PEG-PLLA and PEG-PDLA multiblock copolymers: Synthesis and in situ hydrogel formation by stereocomplexation. J. Controlled Release, 2006, 116(2), e17-e19.

15. C. Hiemstra, Z. Y. Zhong, L. Li, P. J. Dijkstra and J. Feijen, In-Situ Formation of Biodegradable Hydrogels by Stereocomplexation of PEG-(PLLA $)_{8}$ and PEG-(PDLA) 8 Star Block Copolymers. Biomacromolecules, 2006, 7(10), 27902795.

16. Y. J. Jun, K. M. Park, Y. K. Joung and K. D. Park, In situ Gel Forming Stereocomplex Composed of Four-Arm PEG-PDLA and PEG-PLLA Block Copolymers. Macromol. Res., 2008, 16(8), 704-710.

17. S. R. Van Tomme, G. Storm and W. E. Hennink, In situ gelling hydrogels for pharmaceutical and biomedical applications. Int. J. Pharm., 2008, 355(1-2), 1-18.

18. H. Y. Chung, Y. Lee and T. G. Park, Thermo-sensitive and biodegradable hydrogels based on stereocomplexed Pluronic multi-block copolymers for controlled protein delivery. J. Controlled Release, 2008, 127(1), 22-30.

19. N. A. Peppas, J. Z. Hilt, A. Khademhosseini and R. Langer, Hydrogels in biology and medicine: From molecular principles to bionanotechnology. Adv. Mater., 2006, 18(11), 1345-1360.

20. M. Malmsten, Soft drug delivery systems. Soft Matter, 2006, 2(9), 760-769.

21. S. R. Van Tomme and W. E. Hennink, Biodegradable dextran hydrogels for protein delivery applications. Expert Rev. Med. Dev., 2007, 4(2), 147-164.

22. J. D. Kretlow, L. Klouda and A. G. Mikos, Injectable matrices and scaffolds for drug delivery in tissue engineering. Adv. Drug Delivery Rev., 2007, 59(4-5), 263273.

23. K. Y. Lee and D. J. Mooney, Hydrogels for tissue engineering. Chem. Rev., 2001, 101(7), 1869-1879.

24. A. S. Hoffman in Advanced Drug Delivery Reviews; Elsevier Science B.V., 2002, 3-12.

25. J. L. Drury and D. J. Mooney, Hydrogels for tissue engineering: scaffold design variables and applications. Biomaterials, 2003, 24(24), 4337-4351.

26. W. E. Hennink and C. F. van Nostrum, Novel crosslinking methods to design hydrogels. Adv. Drug Deliv. Rev., 2002, 54(1), 13-36.

27. L. Klouda and A. G. Mikos, Thermoresponsive hydrogels in biomedical applications. Eur. J. Pharm. Biopharm., 2008, 68(1), 34-45.

28. R. V. Ulijn, N. Bibi, V. Jayawarna, P. D. Thornton, S. J. Todd, R. J. Mart, A. M. Smith and J. E. Gough, Bioresponsive hydrogels. Mater. Today, 2007, 10(4), 4048 .

29. D. W. Lim and T. G. Park, Stereocomplex formation between enantiomeric PLAPEG-PLA triblock copolymers: Characterization and use as protein- delivery microparticulate carriers. J. Appl. Polym. Sci., 2000, 75(13), 1615-1623.

30. T. Fujiwara, T. Mukose, T. Yamaoka, H. Yamane, S. Sakurai and Y. Kimura, Novel thermo-responsive formation of a hydrogel by stereo- complexation between PLLA-PEG-PLLA and PDLA-PEG-PDLA block copolymers. Macromol. Biosci., 2001, 1(5), 204-208. 
31. T. Mukose, T. Fujiwara, J. Nakano, I. Taniguchi, M. Miyamoto, Y. Kimura, I. Teraoka and C. W. Lee, Hydrogel formation between enantiomeric B-A-B-type block copolymers of polylactides (PLLA or PDLA: A) and polyoxyethylene (PEG: B); PEG-PLLA-PEG and PEG-PDLA-PEG. Macromol. Biosci., 2004, 4(3), 361-367.

32. Y. Ohya, S. Maruhashi and T. Ouchi, Preparation of poly(lactic acid)-grafted amylose through the trimethylsilyl protection method and its biodegradation. Macromol. Chem. Phys., 1998, 199(9), 2017-2022.

33. Y. Ohya, S. Maruhashi and T. Ouchi, Graft polymerization of L-lactide on pullulan through the trimethylsilyl protection method and degradation of the graft copolymers. Macromolecules, 1998, 31(14), 4662-4665.

34. Y. Liu, F. Tian and K. A. Hu, Synthesis and characterization of a brush-like copolymer of polylactide grafted onto chitosan. Carbohydr. Res., 2004, 339(4), 845-851.

35. C. Nouvel, C. Frochot, V. Sadtler, P. Dubois, E. Dellacherie and J. L. Six, Polylactide-grafted dextrans: Synthesis and properties at interfaces and in solution. Macromolecules, 2004, 37(13), 4981-4988.

36. S. J. Jong, de, S. C. De Smedt, J. Demeester, C. F. van Nostrum, J. J. Kettenesvan den Bosch and W. E. Hennink, Biodegradable hydrogels based on stereocomplex formation between lactic acid oligomers grafted to dextran. $J$. Control. Release, 2001, 72(1-3), 47-56.

37. K. Nagahama, Y. Mori, Y. Ohya and T. Ouchi, Biodegradable Nanogel Formation of Polylactide-Grafted Dextran Copolymer in Dilute Aqueous Solution and Enhancement of Its Stability by Stereocomplexation. 2007, 8(2135-2141.

38. D. W. Lim, S. H. Choi and T. G. Park, A new class of biodegradable hydrogels stereocomplexed by enantiomeric oligo(lactide) side chains of poly(HEMA-gOLA)s. Macromol. Rapid Commun., 2000, 21(8), 464-471.

39. S. J. de Jong, B. van Eerdenbrugh, C. F. van Nostrum, J. J. Kettenes-van de Bosch and W. E. Hennink, Physically crosslinked dextran hydrogels by stereocomplex formation of lactic acid oligomers: degradation and protein release behavior. $J$. Control. Release, 2001, 71(3), 261-275.

40. P. N. Thanki, E. Dellacherie and J. L. Six, Prevailing mechanisms of the hydrolytic degradation of oligo(D,L-lactide)-grafted dextrans. Eur. Polym. J., 2005, 41(7), 1546-1553.

41. J. C. Ramirez, M. Sanchezchaves and F. Arranz, Dextran Functionalized by 4Nitrophenyl Carbonate Groups - Aminolysis Reactions. Angew. Makromol. Chem., 1995, 225(123-130.

42. D. Callant, F. Vandoorne and E. Schacht, A New Approach To Dextran Derivatives With Pendent Aldehyde Groups. React. Polym., 1988, 8(2), 129-136.

43. V. Coessens, E. Schacht and D. Domurado, Synthesis of polyglutamine and dextran conjugates of streptomycin with an acid-sensitive drug-carrier linkage. $J$. Control. Release, 1996, 38(2-3), 141-150.

44. A. De Marre, H. Soyez, D. Permentier and E. Schacht, 4-Nitrophenyl Chloroformate Activation Of Poly-Alpha,Beta-[N-(2-Hydroxyethyl)-D,LAspartamide] And Poly-Alpha,Beta-[N-(2,3-Dihydroxypropyl)-D,LAspartmaide]. Polymer, 1995, 36(21), 4031-4037. 
45. W. Kamimura, T. Ooya and N. Yui, Self-complex formation of nicotinamidemodified dextran with carboxymethyl dextran using their degradation products. $J$. Biomater. Sci., Polym. Ed., 2000, 11(7), 747-765.

46. M. F. Ishak and T. J. Painter, Kinetic Evidence for Hemiacetal Formation During the Oxidation of Dextran in Aqueous Periodate. 1978, 64(189-197.

47. S. N. Drobchenko, S. Isaeva-Ivanova, A. R. Kleiner and E. V. Eneyskaya, Aldoenol transition in periodate-oxidized dextrans. Carbohydr. Res., 1996, 280(1), 171-176.

48. E. V. Novikova, E. V. Tishchenko, A. A. Iozep and B. V. Passet, Influence of Synthesis and Isolation Conditions on Properties of Dextran Polyaldehyde. 2002, 75(6), 985-988.

49. C. F. van Nostrum, T. F. J. Veldhuis, G. W. Bos and W. E. Hennink, Hydrolytic degradation of oligo(lactic acid): a kinetic and mechanistic study. Polymer, 2004, 45(20), 6779-6787.

50. S. J. de Jong, E. R. Arias, D. T. S. Rijkers, C. F. van Nostrum, J. J. Kettenes-van den Bosch and W. E. Hennink, New insights into the hydrolytic degradation of poly(lactic acid): participation of the alcohol terminus. Polymer, 2001, 42(7), 2795-2802. 


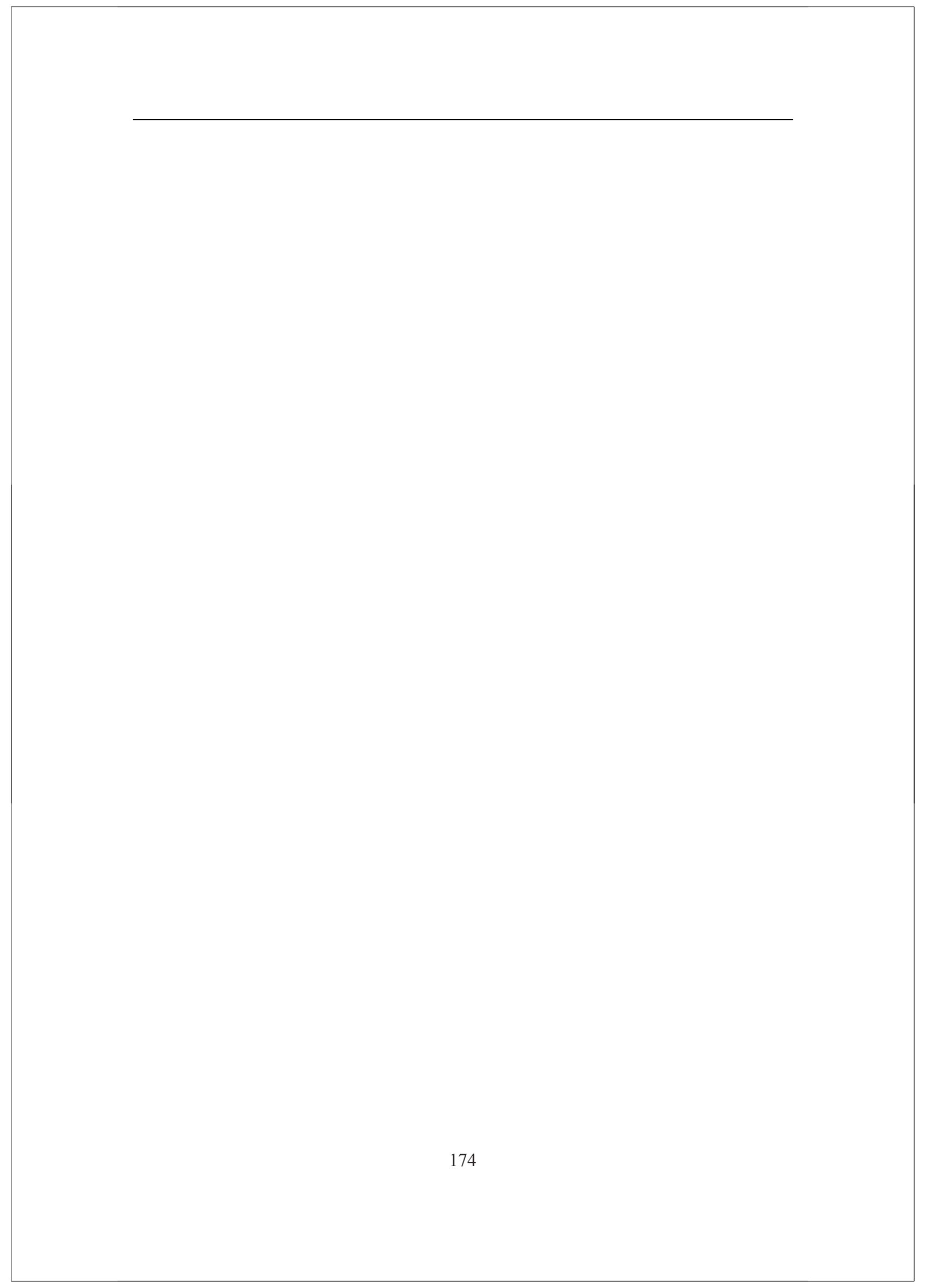




\section{Summary}

Over centuries, mankind has tried to improve the quality of life and find solutions to overcome body limitations caused by disease, injury or old age. In the development of treatments and solutions, biomaterial science has become more and more important, and from research in this field a large variety of so-called 'biomaterials' has emerged. Most importantly, as these materials are applied in vivo, they should be biocompatible. Biocompatibility is defined as the ability of a biomaterial to perform with an appropriate host response on a specific application and is generally related to materials that do not cause e.g. inflammatory or toxicological responses.

Biodegradable materials are a special class of biomaterials, which received a lot of attention during the past decades. These materials, due to natural processes occurring within the body, ultimately are completely removed from the body. A well-known example is the application of synthetic degradable sutures. Many of these materials are based on aliphatic polyesters, in particular poly(lactic acid) (PLA) and poly( $\varepsilon$ caprolactone) (PCL).

PLA and PCL are conveniently prepared by ring-opening polymerization (ROP) of the corresponding cyclic monomers, i.e. lactide and $\varepsilon$-caprolactone $(\varepsilon-\mathrm{CL})$. Ideally, these polymerizations are 'controlled' or 'living', which implies good control over molecular weight, low polydispersities and in principal 'infinite' chain growth as long as monomer is provided and no terminating agent has been added. In the case of chiral monomers (such as lactides or substituted lactones), stereoselectivity of the ROP catalyst has become an important topic. In stereoselective polymerizations, the resulting polymers are enriched in stereoregular sequences, which in turn significantly affect the material properties.

The aims of the research described in this thesis and summarized in Chapter $\mathbf{1}$ have been to study (1) potential biocompatible catalyst systems that can induce stereoselective polymerization of lactides and substituted caprolactones and (2) to apply these systems in the preparation of new polyesters bearing functional groups. Finally, such functional polyesters were studied in the preparation of molecular assemblies by stereocomplexation, for application in tissue engineering. 
In Chapter 2, the current status of catalysts applied in the stereoselective of chiral lactones is discussed. Although the actual mechanism of stereocontrolled ring opening polymerization is still relatively poorly understood, a number of parameters influencing a catalyst's stereoselectivity have been identified over the years. In general, a more active shielding of the reactive metal center by bulky ligands results in increased selectivity, but lowers a catalyst's activity. The selectivity is improved by lowering reaction temperatures, and in certain systems, the selectivity depends on the polymerization medium. Yet, no general set of rules for catalyst design can be given, and predictions for newly designed catalysts with respect to their stereoselective behavior are difficult. In Chapter 3 the synthesis of three novel phenolate-ligated zinc-based catalysts of the type $\left[\mathrm{L}_{\mathrm{n}} \mathrm{ZnEt}\right]_{2}$ and their application in the ring-opening polymerization of (racemic) lactides is described. Polymerizations were fast and controlled, giving $M_{n}$ values close to the theoretical values and low polydispersities. The potential tridentate catalyst 2,6bis[(dimethylamino)methyl]-4-methylphenoxy ethylzinc showed a remarkable shift in selectivity upon changing the polymerization medium. In $\mathrm{CH}_{2} \mathrm{Cl}_{2}$, atactic polymers were obtained, whereas the use of toluene or THF gave moderate enrichments in isotactic sequences in the resulting polymers, which has not been previously reported for Zn-based catalysts. In Chapter 4, the synthesis of three thiophenolate-ligated zinc-based catalysts of the type $\left[\mathrm{L}_{\mathrm{n}} \mathrm{ZnEt}\right]_{\mathrm{n}}$ and their applicaton in the ROP of (racemic) lactides is presented. The polymerizations were 'living', with good control over molecular weight and low polydispersities. The polymerizations of racemic lactide were faster than those of the single enantiomers, indicating a preference for heterotactic enrichment as confirmed by homonuclear decoupled ${ }^{1} \mathrm{H}-\mathrm{NMR}$ spectra $\left(P_{r} \approx 0.60\right)$.

The ROP of $\varepsilon$-caprolactone ( $\varepsilon$-CL), 4-methyl- $\varepsilon$-caprolactone (4-MeCL) and 6-methyl- $\varepsilon$ caprolactone (6-MeCL) using the single-site initiator, $R, R^{\prime}$-(salen) aluminum isopropoxide, is presented in Chapter 5. Kinetic data for the ROP of the three monomers at $90{ }^{\circ} \mathrm{C}$ in toluene revealed a first-order reaction in monomer and propagation rate constants $\mathrm{k}_{\varepsilon-\mathrm{CL}}>\mathrm{k}_{4-\mathrm{MeCL}}>>\mathrm{k}_{6-\mathrm{MeCL}}$. The catalyst, which had previously been shown to preferably polymerize $S, S$-lactide over $R, R$-lactide, showed a notable stereoselectivity with a preference for the $R$-enantiomer in the ROP of 6-MeCL. In contrast, no stereoselectivity was found upon polymerizing 4-MeCL. In Chapter 6 we describe the 
synthesis of the amine-functionalized 7-membered $\gamma$-Boc-amino- $\varepsilon$-caprolactone $(\gamma$-Boc$\mathrm{NH}-\varepsilon-\mathrm{CL}$ ) and the ring-opening reaction of this monomer by different catalyst-initiator systems. Although the monomer could be ring-opened both anionically and cationically, polymerization did not occur. Rather than giving the functional amine-protected poly $(\varepsilon-$ caprolactone), the $\gamma$-Boc-amino- $\varepsilon$-caprolactone rearranged into an oxopyrrolidine carboxylate. In Chapter 7, we describe the synthesis of several heterotelechelic polylactides using functional initiators in the ring opening polymerization of $L$-lactide or $D$-lactide, Amine, thio and carboxylic acid groups were introduced. Thermal analysis revealed that the PLA crystallization is hampered by modification of the chain ends. $\mathrm{T}_{\mathrm{m}}$ and $\Delta \mathrm{H}_{\mathrm{m}}$ values for the polymers that were modified on both chain ends were lower compared to PLAs of comparable chain lengths with no modification of the hydroxyl end group. In stereocomplexes prepared from equimolar amounts of the heterotelechelic PLLAs and PDLAs, this suppressive effect on $\mathrm{T}_{\mathrm{m}}$ and $\Delta \mathrm{H}_{\mathrm{m}}$ was also observed. Modification of the hydroxyl end resulted in a decrease in stereocomplex $\mathrm{T}_{\mathrm{m}}$ values of $\sim 10-20{ }^{\circ} \mathrm{C}$. The lower limit for the crystallization of stereocomplexes was at a DP of 5 .

In Chapter 8, the synthesis of dextran-g-PLA copolymers and the formation of hydrogels thereof are described. In order to improve the hydrolytic stability of these hydrogels, PLA segments were grafted onto the dextran backbone using the hydrolytically stable carbamate and secondary amine linkage. This was successfully achieved by reacting amino-functionalized PLAs of various chain lengths with $p$-nitrophenyl carbonateactivated dextran or periodatively oxidized dextran. Although the hydrolytic stability of the copolymers was indeed improved, their relatively poor water solubility resulted in rather weak hydrogels (200-500 Pa), which quickly lost their structural integrity when placed in an aqueous environment. Such materials are not applicable as load bearing materials but may be well used as vehicles for the release of biologically active agents in tissue engineering constructs. 


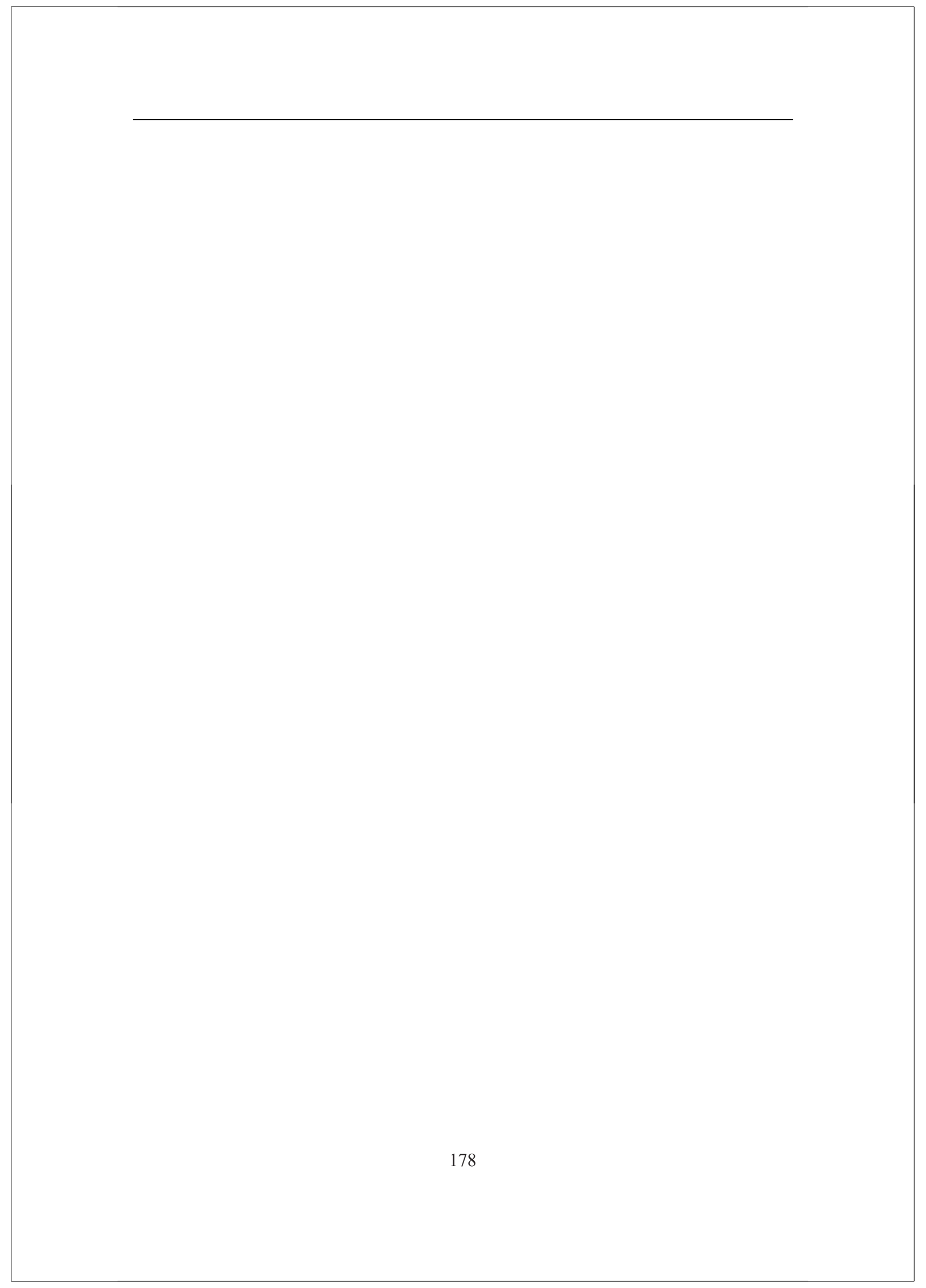




\section{Samenvatting}

Door de eeuwen heen heeft de mensheid geprobeerd de kwaliteit van het leven te verbeteren en oplossingen te vinden om lichamelijke beperkingen, veroorzaakt door ziekte, ongevallen of ouderdom te verhelpen. In de ontwikkeling van behandelingen en oplossingen is biomateriaaltechnologie steeds belangrijker geworden, en uit onderzoek in deze tak van wetenschap is een grote verscheidenheid aan zogeheten 'biomaterialen' voortgekomen. Aangezien deze materialen in het lichaam worden toegepast, is het belangrijk dat ze biocompatibel zijn. Onder biocompatibel wordt verstaan dat het organisme waarin het biomateriaal wordt aangewend reageert op een wijze die strookt met de beoogde toepassing van het materiaal, en dit betekent in de regel dat het materiaal geen immunologische of toxicologische reacties mag uitlokken.

Biodegradeerbare materialen vormen een speciale groep van biomaterialen, welke de laatste decennia veel aandacht heeft gekregen. Dankzij de natuurlijke afbraakprocesen in het lichaam kan een dergelijk materiaal weer geheel uit het lichaam verdwijnen. Een bekend voorbeeld is de toepassing van synthetische, afbreekbare hechtdraden.Veel van deze materialen zijn gebaseerd op polyesters, in het bijzonder polymelkzuur (PLA) en poly( $\varepsilon$-caprolacton) (PCL).

Een zeer gepaste methode voor de bereiding van PLA en PCL is ringopeningspolymerisatie (ROP), uitgaande van de corresponderende cyclische monomeren, d.i. lactide en $\varepsilon$-caprolacton $(\varepsilon-C L)$. In het ideale geval zijn deze polymerisaties 'gecontroleerd' en 'levend', wat impliceert dat de molecuulmassa goed onder controle gehouden kan worden, waarden voor de polydispersiteit laag zijn en de groei van de polymeerketen in principe 'oneindig' door kan gaan, zolang er monomeer voorhanden is en geen ketenstopper (terminating agent) wordt toegevoegd. Wanneer de monomeren chiraal zijn, is het interessant om te kijken naar stereoselectieve ROP. Polymeren die zijn gemaakt door middel van een stereoselectieve polymerisatie, zijn verrijkt met gebieden met een bepaalde, regelmatige structuur (zogenaamde stereoregular sequences). Deze regelmatigheden beïnvloeden op hun beurt de eigenschappen van het materiaal. 


\section{Samenvatting}

De onderzoeksdoelen in dit proefschrift, zoals samengevat in Hoofdstuk 1, waren het bestuderen van 1) potentieel biocompatibele katalysatorsystemen die een stereoselectieve polymerisatie van lactides en gesubstitueerde lactonen kunnen bewerkstelligen en 2) het toepassen van deze systemen in het vervaardigen van nieuwe polyesters met functionele groepen. Deze functionele polyesters zijn uiteindelijk gebruikt in zogenaamde molecular assemblies (zichzelf vormende moleculaire bouwwerken) op basis van stereocomplexatie, met tissue engineering (weefselkweek) als beoogde toepassing.

Hoofdstuk 2 beschrijft de huidige stand van zaken met betrekking tot katalysatoren welke worden toegepast in stereoselectieve polymerisatie van chirale lactonen. Hoewel het precieze mechanisme achter stereoselectieve ringopening nog steeds relatief weinig helder is, is door de jaren heen van verschillende parameters aangetoond dat zij van invloed zijn. In het algemeen geldt dat een betere afscherming van het reactieve metaaldeeltje door omvangrijke liganden leidt tot een verhoogde selectiviteit, maar een lagere katalysatoractiviteit. De selectiviteit kan worden verhoogd door lagere polymerisatietemperaturen, en in sommige gevallen blijkt de selectiviteit af te hangen van het medium waarin de polymerisatie wordt uitgevoerd. Toch bestaat er nog altijd geen algemene set van regels, en het voorspellen van de stereoselectiviteit van nieuw ontworpen katalysatorsystemen is moeilijk. In Hoofdstuk 3 wordt de synthese van drie nieuwe zinkkatalysatoren met fenolaatliganden van het type $\left[\mathrm{L}_{\mathrm{n}} \mathrm{ZnEt}\right]_{2}$ alsook de toepassing ervan in de ROP van (racemische) lactides beschreven. De polymerisaties waren snel en gecontroleerd, met $\mathrm{M}_{\mathrm{n}}$-waardes die goed overeenkomen met de theoretisch voorspelde waarden en met lage waarden voor de polydispersiteit. De potentiële tridentaat ('drietand') 2,6-bis[(dimethylamino)methyl]-4-methylfenoxyethylzink liet een opvallende verschuiving in selectiviteit zien bij verandering van het oplosmiddel, gebruikt in de polymerisatie. Bij gebruik van $\mathrm{CH}_{2} \mathrm{Cl}_{2}$ waren de polymeren atactisch (vertonen geen regelmatig patroon), terwijl bij gebruik van THF en tolueen de polymeren enige verrijking in zogenaamde isotactische gebieden lieten zien - iets dat tot nu toe niet is beschreven voor katalysatoren op basis van zink. Hoofdstuk $\mathbf{4}$ beschrijft de synthese van drie nieuwe zinkkatalysatoren met thiofenolaatliganden van het type $\left[\mathrm{L}_{\mathrm{n}} \mathrm{ZnEt}\right]_{\mathrm{n}}$, en de toepassing ervan in de ROP van (racemische) lactides. De polymerisaties waren 'levend', met gecontroleerde molecuulmassa's en lage waarden voor de polydispersiteit. De 
polymerisaties van racemisch lactide waren sneller dan die van de afzonderlijke enantiomeren, wat een voorkeur voor zogenaamde heterotactische verrijking impliceert. Deze verrijking is inderdaad aangetoond met ontkoppelde ${ }^{1} \mathrm{H}$-NMR spectra $\left(P_{r} \approx 0,60\right)$.

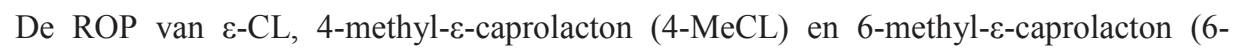
MeCL) met behulp van de single site katalysator $R, R^{\prime}$-(salen) aluminium isopropoxide is beschreven in Hoofdstuk 5. De kinetiekgegevens voor de ROP van deze drie monomeren bij $90{ }^{\circ} \mathrm{C}$ in tolueen laten zien dat de reacties van een $1^{\text {ste }}$ orde in monomeer zijn, en de propagatiesnelheidsconstanten verhouden zich als $\mathrm{k}_{\varepsilon-\mathrm{CL}}>\mathrm{k}_{4-\mathrm{MeCL}}>>\mathrm{k}_{6-\mathrm{MeCL}}$. De katalysator, waarvan al eerder was aangetoond dat deze een voorkeur voor de polymerisatie van $S, S$ lactide had, liet een duidelijke stereoselectiviteit zien (met een voorkeur voor de $R$ enantiomeer) in de ROP van 6-MeCL. Het monomeer 4-MeCL werd echter niet stereoselectief gepolymeriseerd. In Hoofdstuk 6 wordt de synthese van het aminegefunctionaliseerd monomeer $\gamma$-Boc-amino- $\varepsilon$-caprolacton en de ringopening hiervan beschreven. Alhoewel de ring van het monomeer zowel via anionische als kationische weg geopend kon worden, trad geen polymerisatie op. In plaats van te worden gepolymeriseerd tot het amine-gefunctionaliseerde polymeer, vond in het monomeer een omlegging plaats tot een oxopyrrolidino-carboxylaat. Hoofdstuk 7 beschrijft de synthese van verschillende heterotelechelische PLAs via de ROP van lactides, gebruik makend van functionele initiatoren. Amine-, thiol- en carboxylgroepen konden op deze manier worden geïntroduceerd. Thermische analyse van de gevormde polymeren toonde aan dat kristallisatie van de PLA-segmenten gehinderd wordt door het modificeren van de ketenuiteinden. De smeltpunten en smeltenthalpiën van de polymeren waarvan de keten aan beide zijden gemodificeerd was, waren lager dan de waarden voor polymeren van vergelijkbare ketenlengte, maar zonder modificatie van de hydroxy-eindgroep. Dit verlagende effect was ook te zien in de smeltpunten van de stereocomplexen van deze polymeren, en leidde tot een verlaging van $\sim 10-20{ }^{\circ} \mathrm{C}$. Een minimale ketenlengte van 5,5 lactide-eenheden is vereist om te kunnen kristalliseren. In Hoofdstuk 8 wordt de synthese van dextran-graft-PLA copolymeren en de hieruit gevormde hydrogelen beschreven. Om de stabiliteit jegens afbraak door water te verhogen, zijn de PLAsegmenten met zogenaamde carbamaat- en secundaire amine-bindingen aan de dextranen gekoppeld. Dit is bereikt door gebruik te maken van $p$-nitrofenylcarbonaat- 


\section{Samenvatting}

geactiveerde dextranen en dextranen geoxideerd door perjodaat. Alhoewel de hydrolitische stabiliteit inderdaad verbeterd is, leidde de relatief matige oplosbaarheid van de copolymeren tot vrij zwakke hydrogelen (200-500 Pa), die in een waterige omgeving spoedig hun structuur verloren. Deze materialen zijn niet geschikt in situaties waarin zij aan sterke krachten onderworpen worden, maar kunnen misschien wel gebruikt worden als transportdeeltjes voor de afgifte van biologisch actieve componenten in tissue engineering. 


\section{Curriculum Vitae}

Mark Randolf ten Breteler werd geboren op 15 september 1979 te Haaksbergen. In 1997 behaalde hij het VWO-diploma aan Het Assink Lyceum te Haaksbergen. In datzelfde jaar begon hij aan de opleiding Chemische Technologie aan de Universiteit Twente te Enschede. Na de zogenaamde bachelor-periode werd gekozen voor Biomedische Materiaaltechnologie als hoofdrichting. Zijn stage in 2002 bracht hij door bij Bayer te Leverkusen, alwaar hij werkte aan autolakken, in een onderzoek met als titel 'Synthesis, Characterisation and Application of a New Michael Acitve Polymer - A Copolymer of MMA, BA and a Functional Monomer Capable of Crosslinking Through Michael Additon'. Hierna volgde een afstuderen onder begeleiding van dr.ing. P.A.M. Lips bij de vakgroep Polymeerchemie en Biomaterialen (PBM) aan de Universiteit Twente van prof. dr. J. Feijen. De afstudeeropdracht, die werd afgerond in juni 2003, droeg de titel 'Segmented and Alternating Poly(ester amide)s - Structure-Property Relationships Investigated'. De studie werd voortgezet met de aanvaarding van een AIO-schap bij dezelfde vakgroep, onder begeleiding van prof. dr. J. Feijen, dr. P.J. Dijkstra alsook prof. dr. Z.Y. Zhong, en resulteerde in dit proefschrift, getiteld 'Stereoselective Polymerization of Lactones. Properties of Stereocomplexed PLA Building Blocks.' In 2007 behaalde hij zijn master in Science Education, en staat sindsdien voor de klas op Het Assink Lyceum te Haaksbergen voor de vakken Scheikunde en Algemene Natuurwetenschappen. Hij trouwde in 2009 met Kim Kroezen. 


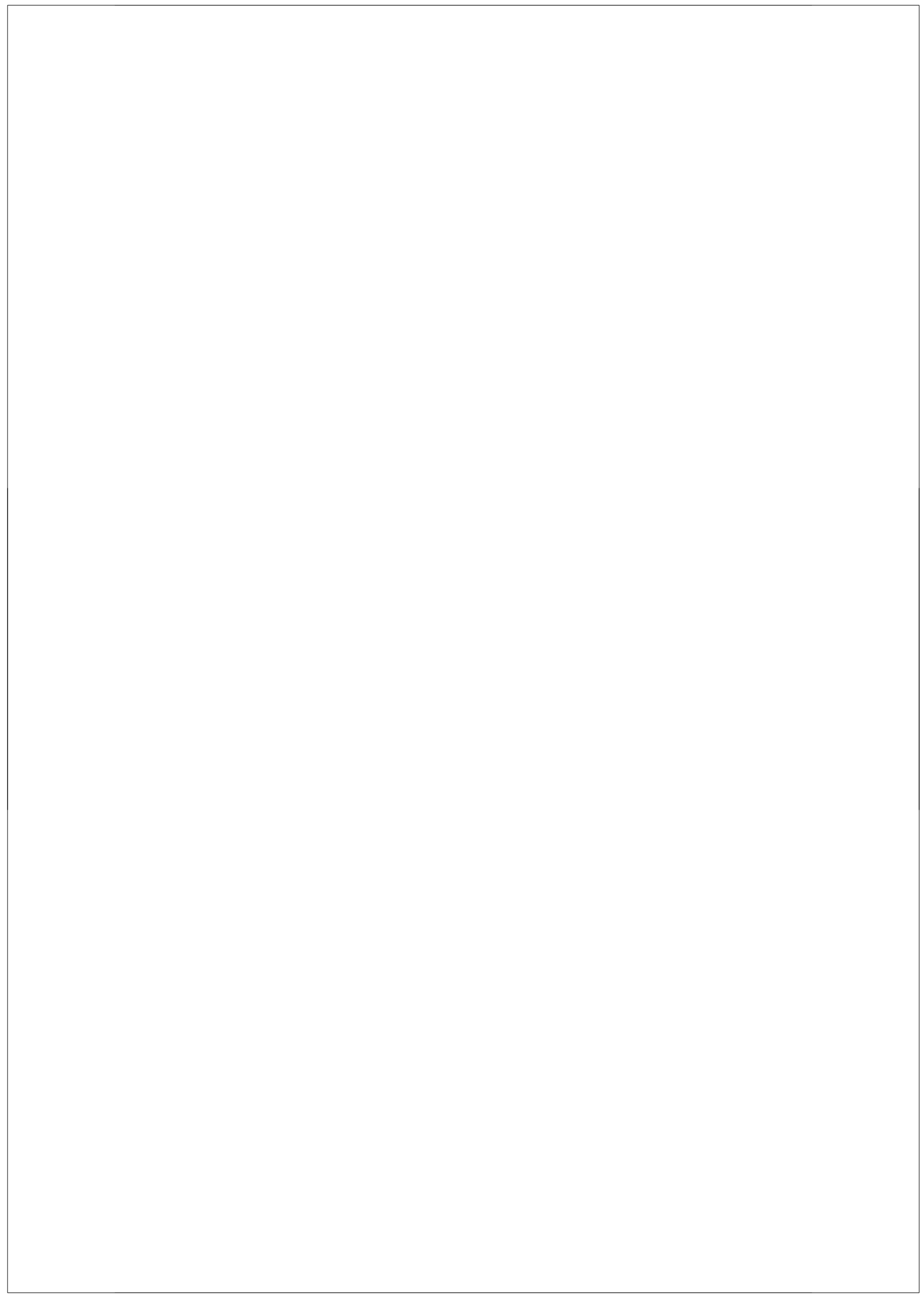

